\title{
Innovations in a fuzzy domain : healthy cities and (health) policy development in the Netherlands and the United Kingdom
}

Citation for published version (APA):

Goumans, M. J. B. M. (1998). Innovations in a fuzzy domain : healthy cities and (health) policy development in the Netherlands and the United Kingdom. [Doctoral Thesis, Maastricht University]. Universiteit Maastricht. https://doi.org/10.26481/dis.19980123mg

Document status and date:

Published: 01/01/1998

DOI:

10.26481/dis.19980123mg

Document Version:

Publisher's PDF, also known as Version of record

Please check the document version of this publication:

- A submitted manuscript is the version of the article upon submission and before peer-review. There can be important differences between the submitted version and the official published version of record. People interested in the research are advised to contact the author for the final version of the publication, or visit the DOI to the publisher's website.

- The final author version and the galley proof are versions of the publication after peer review.

- The final published version features the final layout of the paper including the volume, issue and page numbers.

Link to publication

\footnotetext{
General rights rights.

- You may freely distribute the URL identifying the publication in the public portal. please follow below link for the End User Agreement:

www.umlib.nl/taverne-license

Take down policy

If you believe that this document breaches copyright please contact us at:

repository@maastrichtuniversity.nl

providing details and we will investigate your claim.
}

Copyright and moral rights for the publications made accessible in the public portal are retained by the authors and/or other copyright owners and it is a condition of accessing publications that users recognise and abide by the legal requirements associated with these

- Users may download and print one copy of any publication from the public portal for the purpose of private study or research.

- You may not further distribute the material or use it for any profit-making activity or commercial gain

If the publication is distributed under the terms of Article $25 \mathrm{fa}$ of the Dutch Copyright Act, indicated by the "Taverne" license above, 
Innovations in a Fuzzy Domain

Healthy Cities and (Health) Policy Development in the Netherlands and the United Kingdom

\section{Proefschrift}

ter verkriiging van de graad van doctor

aan de Universiteit Maastricht, op gezag van de Rector Magnificus,

Prof. dr. A.C. Nieuwenhuijzen Kruseman, volgens het besluit van het College van Dekanen, in het openbaar te verdedigen op

vrijdag 23 januari 1998 om 14.00 uur

door

Marleen J.B.M. Goumans

Geboren te Geysteren 19 december 1967 


\section{Promotor:}

Prof. dr. J.A.M. Maarse

Co-promotor:

Dr. E.J.J. de Leeuw

\section{Beoordelingscommissie:}

Prof. dr. G.J. Kok (voorzitter)

Prof. dr. A.F.A. Korsten

Dr. I. Mur-Veeman

Prof. dr. M. O'Neill (Université Laval, Quebec, Canada)

Prof. dr. J. Springett (Liverpool John Moores University, United Kingdom)

\section{Colofon:}

Gover design and lay-out: Nora Oosting English editing: Matt Commers

Printed: Unigraphic, Mastricht

The study presented in this thesis was conducted at the Maastricht Health Research Institute for Prevention and Care (HEALTH), which participates in the Netherlands School of Primary Care Research (CaRe), acknowledged in 1995 by the Royal Dutch. Acaderny of Science (KNAW). 


\section{Part 1 Setting the scene and introducing the research}

1 HEALTHY CITIES AND HEALTH POLICY IN AN URBAN SETTING

1.1 Introduction 11

1.2 The WHO Healthy Cities Project 12

$\begin{array}{ll}\text { 1.2.1 The start and development of the Project } & 12\end{array}$

1.2.2 What is a Healthy City? 14

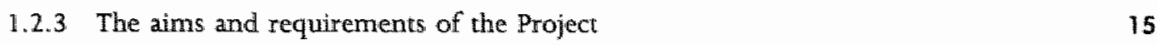

1.2.4 The structure of the Project $\quad 17$

$\begin{array}{lll}1.3 \text { City health plans } & 18\end{array}$

1 .4 Healthy Cities in the Netherlands and the United Kingdom 19

1.5 The backgrounds to the ideas and content of the Healthy Cities Project 24

1.5.1 A positive health concept $\quad 24$

1.5.2 Health for All 26

1.5.3 Health promotion and the Ottawa Charter 27

1.5.4 European Charter on Environument and Health 29

1.6 Explanations for a focus on health promotion in cities 30

1.6.1 Strategy: Investments in health and a setting approach 30

1.6.2 History: Public health in cities $\quad 32$

1.7 Development of a local health policy

1.7.1 Health policy approaches $\quad 34$

1.7.2 Characteristics of health policy

1.8 Research questions 36

1.9 How to read this book 37

2 RESEARCH FRAMEWORK 39

2.1 Introduction 39

2.2 Healthy Cities (policy) research $\quad 39$

2.3 The Healthy Cities (policy) assumptions 42

2.3.1 Assumptions about the local government and public health 43

2.3.2 Assumptions about community participation and intersectoral collaboration in policy-making

2.3.3 Assumptions about clangeability 4.5

2.4 Policy approach $\quad 45$

2.5 The method 48

2.6 International comparison 49

2.7 Research population, sources of evidence, and data analysis 51

2.8 Generalization $\quad 55$ 


\section{Part II Showing the evidence}

3 RHETORICAL STRENGTH AND SCIENTIFIC EVIDENCE

Experience with the key-concepts of Heolthy Cities

3.1 Introduction

3.2 Healthy Cities key-concepts

$\begin{array}{ll}3.3 \text { Community involvement } & 60\end{array}$

$\begin{array}{lr}3.3 .1 \text { What is community involvement? } & 60\end{array}$

3.3.2 When community inwolvement? 61

3.3.3 How community inwolvement?

3.4 Intersectoral collaboration $\quad 65$

3.4.1 What is intersectoral collaboration? 65

3.4.2 When intersectoral collaboration? 65

3.4.3 How intersectoral collaboration? 66

$\begin{array}{ll}3.5 \text { Political commitment } & 68\end{array}$

3.5.1 What is political commitment? 68

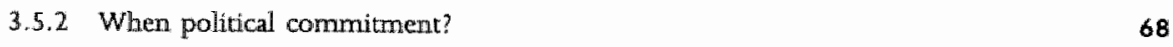

$\begin{array}{ll}3.5 .3 \text { How political commitment? } & 69\end{array}$

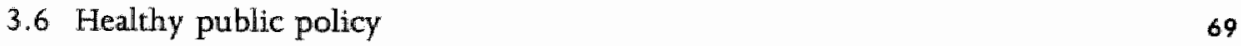

3.6.1 What is bealthy public policy?

$\begin{array}{ll}\text { 3.6.2 When healthy public policy? } & 70\end{array}$

$\begin{array}{ll}3.6 .3 \text { How healthy public policy? } & 71\end{array}$

$\begin{array}{lll}3.7 & \text { Conclusion } & 73\end{array}$

4 WHY ACT? $\quad 75$

Gatting health on the political agenda

$\begin{array}{ll}4.1 \text { Introduction } & 75\end{array}$

$\begin{array}{ll}\text { 4.2. What is agenda building? } & 76\end{array}$

$\begin{array}{ll}4.3 \text { Two theories on agenda building } & 77\end{array}$

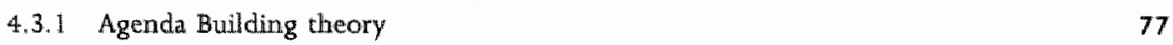

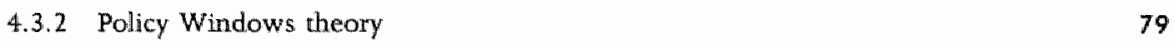

4.3.3 Comparing the two theories on agenda change 84

4.4 Why join Healthy Cities?

4.5 Political support $\quad 91$

$\begin{array}{ll}\text { 4.5.1 The wisualization of political support } & 91\end{array}$

4.5.2 The establishment of political support 94

4.6 Political agenda status for Healthy Cities 96

4.7 An explanation of the political agenda status of Healthy Cities 100

4.7.1 The polival agenda stacus explained by the Agenda Building theory 100

4.7.2 The political agenda status explained by the Policy Windows theory 102

4.7.3 The political agenda stans explained by issue characteristics 107

$\begin{array}{ll}4.8 \text { Conclusion } & 109\end{array}$

5 THE FUZZY DOMAIN $\quad 113$

A reconstruction of the Healthy Cities domain based on activities, structures, and actors

5.1 Introduction $\quad 113$

5.2 Domain construction 115

$\begin{array}{ll}5.2 .1 \text { What is a domain? } & 115\end{array}$

$\begin{array}{ll}5.2 .2 \text { Discovering the Healthy Cicies domain } & 117\end{array}$

$\begin{array}{ll}5.3 \text { The activities } & 118\end{array}$ 
5.4 The structures 125

5.4.1 New, existing, integrated, and separate structures $\quad 125$

5.4.2 Barriers that hinder integration 131

5.5 The actors 132

5.5.1 Categories of participants

5.5 .2 Core and peripheral 136

$\begin{array}{lll}5.5 .3 \text { Roles } & 139\end{array}$

5.6 A. Healthy City standard domain 141

5.6.1 Comparing the domains 141

5.6.2 A standard domain 142

5.7 Conclusion $\quad 143$

6 PATHWAYS OF DEVELOPMENT 147

How successfuliy are concepts put into practice?

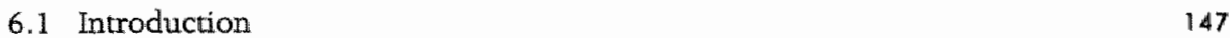

$\begin{array}{ll}6.2 \text { Evaluation } & 148\end{array}$

6.2.1 Process evaluation 148

6.2.2 Healthy Cities evaluation 150

6.3 The evaluation of Healthy Cities processes $\quad 154$

6.3.1 Social processes: comnuunity inwolvement 154

6.3.2 Organizational processes: intersectoral collaboration $\quad 159$

6.3.3 Political processes: political commitment 166

6.4 The additional benefit of Healthy Cities 169

6.5 How successfully are key-concepts put into practice?

$\begin{array}{lll}6.5 .1 & \text { Community inxolvement } & 171\end{array}$

6.5.2 Intersectora] collaboration 173

6.5.3 Political commitment 176

$\begin{array}{ll}6.6 \text { Conclusion } & 178\end{array}$

Part III Drawing the conclusions

7 THE MEANING OF HEALTHY CITIES FOR POLICY DEVELOPMENT

Conclusioms

7.1 Introduction

7.2 Type and level of policy development 182

7.3 Policy models and their pathways of development 186

7.4 Innovation 188

7.5. Long lasting effects 189

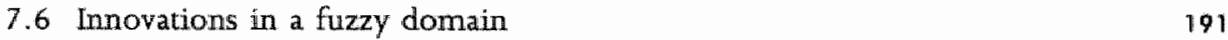

$\begin{array}{ll}\text { SUMMARY } & 194\end{array}$

SUMMARY IN DUTCH $\quad 201$

NOTES $\quad 206$

LIST OF REFERENCES $\quad 213$

APPENDICES: $\quad 226$

appendix 1 Local Public Administration $\quad 226$

appendix 2 Item list for interviews $\quad 236$

appendix 3 Healthy Cities domains $\quad 240$

$\begin{array}{lr}\text { THE AUTHOR } & 255\end{array}$ 


\section{List of abbreviations}

\begin{tabular}{|c|c|}
\hline ARBO & Aubeidisornstandigheden dienst [Working circumstances service, MG] \\
\hline $\mathrm{CAD}$ & Consultatie buro woor Alcohol on Drugs [Consultation Dwsk for Alcohol ond Drugs, MG] \\
\hline $\mathrm{CCT}$ & Compulsory Competitive Tendering \\
\hline $\mathrm{CHC}$ & Community Heattis Couneil \\
\hline COM & $\begin{array}{l}\text { Centrum voor Gezondheidszorg en Macischoppelijke Dienstverlening [Centre for Health Core and } \\
\text { Community Support, MG] }\end{array}$ \\
\hline EFILWC & European Foundotion for the Improvement of Living and Working Canditions \\
\hline EURONET & European Network of national Healthy Citie networks \\
\hline FAO & Fonds Achterstand Bestrifjing [Fund for the Reduction of Disodvantages, MG] \\
\hline FHSA & Farilly and Health Service Autharity \\
\hline GGD & Gemeentelitke of Gemeenschappeltike Gezondheidsdienst [Local Public Health service, MG] \\
\hline GNP & Gross National Product \\
\hline HA & Health Autharity \\
\hline HALT & Criminal prevention project/buro \\
\hline HCPO & Healithy Citles Project Office \\
\hline $\mathrm{HCT}$ & Healithy Cities Team \\
\hline HFA2000 & Health For dill by the year 2000 \\
\hline HPR & Health Promotion \\
\hline $\mathrm{JCC}$ & Joint Consuitalive Committee \\
\hline JCPT & Jaint Care Planning Team \\
\hline JPHT & Joint Public Health Team \\
\hline LA & Local Authority \\
\hline LAHN & Local Authority Health Network \\
\hline NHS & National Health Service \\
\hline MCAP & Multi City Action Plan \\
\hline $\mathrm{N} N \mathrm{HS}$ & National Health Service \\
\hline$N H G Z$ & $\begin{array}{l}\text { Nationad Instituut woor Gezondheidsbevordering en Ziektepreventie [Nationall Institule for Health } \\
\text { Promotion and Disease Prevention, MG] }\end{array}$ \\
\hline NIZW & Nederlands Instituut woor Zorg on Welzijn | Netherlands Institute for Care and Welfare, MG] \\
\hline OECD & Organization of Economic Cooperation and Development \\
\hline PRT & Performance Review Team \\
\hline REGUS & $\begin{array}{l}\text { Rotterdams Epidemialogisch Buurtkenmerken System [Rotterdam Epidemiological Neighbourhood } \\
\text { Intormation System, MG] }\end{array}$ \\
\hline RAOG & $\begin{array}{l}\text { Regional Institute for Ambulatory Mental Health Care [Regionaal Instifuut voor Ambulante Geestelitke } \\
\text { Gezondheidstorg. MG] }\end{array}$ \\
\hline RIO & Rottlerdams Instituit woor bewoneirs Ondersteuning [Rotterdam Institute for residents' Support, MG] \\
\hline ROTEB & Reiniging, Ontsmetting, Tronsport en Badrififswerken [Cleansing and Public transport department, MG] \\
\hline SEGV & Sociaal Economische Gezondheidswerschillen [Social Ecanomic Health Inequalities, MG] \\
\hline SUPER & $\begin{array}{l}\text { Project to promate a batter" nutritional behaviour, through inwolvement of, amongst athers, } \\
\text { SUPERmarkets }\end{array}$ \\
\hline UK & United Kingdom \\
\hline UKHFA Nowwork & United Kingdom Health for All Netwark \\
\hline UN & Unifed Nations \\
\hline UNCHS & United Nattions Conference on Human Settlements \\
\hline VNG & Vervniging van Nederlandse: Gemeenten [Netheriands Association of Municipalities, MG] \\
\hline WCPV & Wet Collectitive Preventie Volksgezondheid [low on Collective Prevention, MG] \\
\hline WNO & We Vaorzieningen Gezondheidszorg llow on Health Care Facilities, MGI \\
\hline
\end{tabular}


WHO World Health Organization

WHO CC RHC World Health Organization Collaborating Centre for Research on Healthy Cities

WHO/EURO European Regional Office of the World Health Organization

\section{List of Figures}

Figure 1.1 Social ecological health madel.

Figure 1.2 The Ottawa Charter for Health Promotion, 28

Figure 1.3 A difference between healith policy, intersectoral policy, and public health policy. 35

Figure 2.1 A tramework for research as it opplies to the Healthy Cities projects and movement. 40

Figure 2.2 Basic reasaning regarding thealth policy dewelopment behind the WhO Healthy Cities Project. 43

Figure 3.1 Correlates between (environmental) determinants and health states:

Figure 4.] The Policy Windows theory.

Figure 5.1 Healthy City domain (general) based on activities. 123

Figure 5.20 Healthy City domain based on activities: (the Netherlands case studies). 240

Figure 5.2b Healthy City domain based on activities (the United Kingdom cast studies). 242

Figure 5.2c Healthy City domain bosed on activities (the Netherlands and United Kingdom). 244

Figure 5.3 Heathy City domain bosed on actors [1).

Figure 5.4a Healthy City domain bosed on actors (I) [the Netherlands case studies). 245

Figure 5.4b Healthy City domain based on actors (1) (the United Kingdom case studies) 247

Figure 5.4c Healthy City damain bosed on actors (l) (the Netherlands and United Kingdam). 249

Figure 5.5 Healthy City domain based on actors (II).

Figure 5.60 Healthy City domain based on actors [II] (the Netherlands case studies'). 250

Figure 5.6b Healthy City domain based on actors (II) (the United Kingdom case studies). 252

Figure 5.6c Healthy City domain based on actors [et] the Netherlande and United Kingdom]. 254

$\begin{array}{lll}\text { Figure } 6.1 & \text { Evaluation approaches. } & 149\end{array}$

$\begin{array}{lll}\text { Figure 7.1 Pollicy development patterns for Healthy Cities. } & 187\end{array}$ 


\section{List of Tables}

Table 1.1 Cities porticipating in the WHO/EURO Healthy Cities Project.

Table: 1.2 Characteristics of a Healthy City.

Tabla 1.3 Requirements for WHO Project cities: 16

Table 1.4 Health definitions.

Table 1.5 A comparison of thealth indicators between the United Kingdom and the Netherlands. 234

Tabile 1.6 A comporison of omployment rates between the Unifed Kingdom and the Nethertands on social economic indicators.

Table 1.7 A comparison of unemployment rattes between the United Kingdom and the Netherlands.

Table 1,8 A comporison of household composition between the United Kingdom and the Nethertands

Table 2 il Policy approcehes:

Toble 3.1 Healthy Cittes key-concepts.

Table 3.2 Core elements of three appraches to organizing community involwement in health.

table 3.3 Collaboration forms at a scale from informal and shortaterm fat the left sidel, to formatl and long-term fat the right sidel.

Table 4.1 Reosons for participation in Healthy Cities.

Table 4.2 Political support for Healithy Cities.

Table 4.3 No political support for Healthy Cities.

Table 4.4 Elements that influence the political agendo status of Healthy Cities.

Tabel 4.5 Issues that are perceived as health (relatted) problems at local level flacting in the problem stream

Table 4.6 Important detterminants of the political agenda stotus of Healthy Cities.

Table 5.10 lllustratiwe examples of Healthy Cities activities: starting from a graup perspective, addressing: within these groups certoin issues and, if possible, taking place within certain settings.

Table 5. 1 b Illustrative examples of Healthy Cities activities: starting from a setting perspective and addressing within this setting centain issues. Certain groups may be addressed.

Table 5. lc Illustrative excmples of Heathy Cities cctivities: starting from on issue perspective, aimed at specific groups, and, if possible, taking place within specilic seitings.

Table 5.2 The Healthy Cilty organization in the case studies.

Table 5.3 Members of a Heolthy City steering committee.

Table 5.4 Different meanings of a Healthy City porticipant in relation to the amount of formeli authority and decision making power they posses.

Table 5.5 Care people who are pushing the Healthy Cities bandwagon.

Table 6.I Healthy Cities and community involwement.

Toble 6.2 The contributions of Healthy Citties to intersectional collabaration.

Táblie 6.3 Healthy Cities and political cammitment.

Toble 6.4 Healthy Cities successes.

Table 6.5 Camparison between community involvement in theory and Healthy Citties practice.

Table 4.6 Comparison between intersectoral collobaration in theory and Healthy Cities practice.

Table 6.7 Comparison between political commitment in theary and Healthy Cities proctice. 176

Table 6.8 Major problems that Heolthy Cities has to overcome.

Table 7.1 Healthy Cities policy models and their descriptors. 


\section{A new experience}

Doing a Phd has been a very meaningful and exciting period of my life. This experience, working with all these people with different backgrounds involved in Healthy Cities and local health policy development has been a wonderful opportunity. If I could choose I would do it again. Doing the research and analysis was highly appreciated by me. Writing it up was a different story. Because at that stage I was confronted with the fact that one tends to write for an as diverse public as one has researched. In the end I came to the conclusion that the research provides for scientific researchers new insights and explanations of relations between theory and health policy practice. For practitioners it provides new glasses to look in a different way at their daily work; to step a bit back and reflect on business as usual.

I did my research in a very supportive environment. I appreciated very much the discussions and soup with my colleague Phd researchers from the University of Maastricht. I also want to express my thanks to my promoter Hans Maarse. It took some time before we had a common understanding on 'where this research was all about'. And Hans I have to admit that I admired you very much because of your capability of distracting from my" stories and never-ending new ideas a compact and structured list of the key-points that were at stake. Then of course my co-promoter Evelyne de Leeuw. Evelyne, what can I say, you are an amazing person. So energetic, busy and so involved in the subject of Healthy Cities. I owe you very, very much. Thanks for giving me years ago this chance of proving that health policy and administration students indeed deliver important contributions which move health promotion policy further.

Thanks to Angel Waaijen for re-educating me in the english language. I also appreciate very much the time and energy that Matt Commers has put in the english editing of this book. Thank you Karin and Regina for helping me with the 'annoying parts' of my research. Nora Oosting has been very helpful and patient, for which I thank her, in the lay-out, cover design and printing part.

Thanks also to the people in the cities of Sheffield, Glasgow, Liverpool, Rotterdam, Almelo, Newcastle, Winchester, Tilburg, Eindhoven and Groningen. They have been so kind to provide me with much information and with their assistance in gaining insight in their local health policy practices. Also thanks to the people involved in the WHO Healthy Cities Project and the WHO Healthy Cities Project team in Copenhagen for making me a member of this movement.

Then there are all these many other people who have been there and still are there to support me in various ways and many places. I mention a few. My colleagues of the department of Health Ethics and Philosophy at the University of Mastricht and my colleagues at the Association of Dutch Municipalities in the Hague. Of them I want to mention Agnes Meershoek who has been my roommate at the university for some five years. Agnes. thanks for being a friend, for your time and your understanding of things that I did not need to tell and for the 'what do you think about...' answers. Thank you Katja, Paulien, Mariellle, Karina, Ilene, Chantal, Loes, Nicolle, Philip, Eugenie, Astrid and Paul for your friendship and your support on this road. Thanks mam and dad for your faith in me and that you sometimes quite frankly admitted that parts did not make sense to you. Then I knew that again "I was thinking too difficult". 
Now I have written down the story and I am a bit afraid for the things which are going to happen. Just as we are a bit afraid of ourselves, as Stef Bos (1992)* puts it:

"time has come to go

time has come to choose

time has come to let go what you have got

then you have nothing to loose

because the world is a circle Marleen

we can go onywhere Marleen

the world is a circle

and we are not afraid

the world is fourthy-thousand kilometres straight."

So, there I go; off to my new experience.

all the best,

Marleen

(Maastricht, november 1997)

" From: Stef Bos (1992). Tussen de liefde en de legte. Hilversum: CNR records. 


\title{
Chapter Healthy Cities \\ 7 and health policy \\ in an urban setting
}

\author{
Why can't we be a healthy city? \\ A city where, \\ as the sun rises \\ your morning face on the pillow \\ through strands of darkbrown hair. \\ the river lying back open to the day, \\ the lace curtains of terrace houses \\ sing like schoolchildren. \\ This city \\ is your mother \\ and your lover. \\ She is your first thought, \\ and your last. \\ She is your future \\ and your past. \\ Adrian Henry - City 2000
}

\section{$\overline{1.1 \quad \text { Introduction }}$}

About 50 percent of the human population lives in urban contexts, even though urbanization has not been occurring as rapidly as anticipated by some theorists (United Nations Conference on Human Settlements (UNCHS) 1996; World Health Organization (WHO), 1996). It is therefore not surprising that, in Europe as elsewhere, many urban issues seem to be prominently represented on the political agendas of the Nineties. Examples of contemporary urban issues are economic development, environment, transport, city planning, and liveability. These issues are receiving increasing attention in local, national, and international programmes, policy, politics, and research (see for exarnples Mega, 1996) ${ }^{2}$.

Why not address health in an urban context? Why not address the question of whether a city maintains a healthy living ecology for its inhabitants? Health has most commonly been associated with individuals and their lifestyles. Over the years, however, evidence has accumulated that individual health status is not determined merely by biological heritage and access to health care. As will be shown in this chapter, research has provided evidence that social, working, and living environments have a significant influence on an individual's health. These environments are formed and transformed by activities and policies of government, organizations, and groups in and outside the city. 
A consideration of the city as a an organism in and of itself, whose health must be promoted, is not a new idea. For example, in 1875 the passing of the Public Health Act in the United Kingdon was celebrated by a description of a utopian city by Sir Benjamin WardRíchardson (see for example WHO European Office (EURO) Healthy Cities Project Office (HCPO), 1988a p. 12-14). The idea, however, has recently been given new impetus by the World Health Organization, an impetus embodied by the founding of the Healthy Cities Project eleven years ago, in 1986. WHO/EURO regarded the concept of a Healthy City as an innovative and promising one with which to promote health in urban environments. They believed then, and still believe today, that such a concept would inspire people to develop a vision and idea in regards to health, and at least to imagine a place such as WardRichardson described. WHO did not talk much about the time-frame, nor did they put great effort into assessing the practical implications of their ideas (WHO/EURO/HCPO, 1988a). According to them, the meaning of a Healthy City could only be explained demonstratively, in effect, by working on it. And as every person and culture imagines a Healthy City differently, it was acknowledged that Healthy Cities effort would take different forms in different localities. The idea was to regard a Healthy Cities approach as a framework for linking different ideas, strategies, and policies. In other words, Healthy Cuties could be used to bring a focus on health to a wide variety of public policy initiatives. Healthy Cities could be used to create what Nancy Milio has described as "healthy public policy." A Healthy Cities policy would promote the health of the ciry, and thereby promote health and reduce health inequity among individuals living and working there.

Now that the WHO Healthy Cities Project has been functioning for more than ten years, interest has emerged in finding out whether or not Healthy Cities has indeed been used to create policy and/or to change previously existing policy and activities. How have ideas and concepts championed and promoted by the Healthy Cities Project actually been put into practice?

This thesis attempts to play a role in satisfying the curiosity regarding the outcomes of Healthy Cities efforts in Europe by detailing and analysing the results of a qualitative inquiry into the development of (health) policy in cities involved in the WHO Healthy Cities Project and/or a comparable initiative with very similar ideological foundations. The research has been conducted in ten cities in the Netherlands and the United Kingdom.

This chapter provides the background to the inquiry ${ }^{2}$. First, the Healthy Cities Project will be explained in terms of its stated ideas, requirements, purposes, and policy approach. Also included in the first section is a short description of how Healthy Cities ideas were taken up in the Netherlands and the United Kingdom. Then, some attention will be paid to the origins of the WHO Healthy Cities Project and we will explain what is meant by health policy development in this research. Finally, the research questions will be presented, and an outline of the other chapters in this book will be ciescribed.

\subsection{The WHO Healthy Cities Project}

\subsubsection{The start and development of the Project}

In 1984, a conference was organized in Toronto, Canada, called "Beyond Health Care", to review the achievements of the now famous Lalonde report (see section 1.4). During this particular conference, the role of the city in relation to the so-called "New Public Health" was discussed. It was not a surprise that this discussion took place in Toronto, because the city was aiming to become the healthiest city in North America by the year 2000 
WHO Healthy Cifies Project Cities Phase II 1993-1997:

$\begin{array}{llll}\text { Amadora } & \text { Eindhoven } & \text { Liege } & \text { Rotterdam } \\ \text { Athens } & \text { Frankfurt } & \text { Liwerpool } & \text { Sandnes: } \\ \text { Belfast } & \text { Geneva } & \text { Lodz } & \text { Sumperk } \\ \text { Bialystok } & \text { Glasgow } & \text { Maribor } & \text { Torun } \\ \text { Bologna } & \text { Gothenburg } & \text { Mechelen } & \text { Turku } \\ \text { Brna } & \text { Györ } & \text { Nancy } & \text { Mienna } \\ \text { Camden } & \text { Horsens } & \text { Padua } & \\ \text { Copenhagen } & \text { Jerusalem } & \text { Pécs } & \text { Honorary } \\ \text { Dresden } & \text { Kaunasi } & \text { Poznan } & \text { member: } \\ \text { Dublin } & \text { Kosice } & \text { Rennes } & \text { Tononto }\end{array}$

(Hancock, 1990a; Pederson, O'Neill \& Rootman, 1994). A diverse, critical mass of people -among them health and other professionals, scientists, and politicians- artended the conference. It was at that conference that the possibility of taking cities and communities as settings for health initiatives first gained serious momentum, and in particular the idea of a European Programme on Healthy Cities was first voiced. Although the idea as such was not new, it did receive significant new input, and was adjusted to the standards and problems of the 1980 s at the same time.

Ilona Kickbusch, at that time the Regional Officer for Health Education at the Furopean Office of the World Health Organization in Copenhagen, was present at the Toronto meeting. She became quite convinced of the importance of the ideas presented. A WHO/EURO planning group subsequently further explored the idea of considering the urban environment as a primary setting for health promotion.

It was imagined that cities could be the focus for the implementation of Health for All 2000 strategy (HFA2000) and the Health Promotion Programme (WHO/EURO/HCPO, 1988a; Ashton, 1992). The plaming group, and in particular the Regional Officer, recog nized the great potential and political relevance of creating a project on this theme. "The city offered a social and cultural entity, with an identifiable space and physical environment, and with a political body that can make political choices." (Kickbusch, 1989b p. 78)

The concept was presented at a first Healthy Cities symposium in Lisbon. Portugal, in April of 1986. During this meeting, visions on health, health promotion, and health measurement in a city were explored (Ashton, Grey \& Barnard, 1986). WHO subsequently designated the first eleven. Healthy Cities Project cities by the end of 1986. In 1987, the second symposium took place in Düsseldorf. Federal Republic of Germany, and after that symposium, another 14 cities were designated in 1988. By the end of 1992, a total of 35 European cities were participating in the WHO/EURO Healthy Cities Project.

In 1992, WHO/EURO director Asvall decided to prolong the Healthy Cities Project for another five years (1993-1998) ${ }^{3}$. New cities could apply for participation and old Project cities were given the opportunity to continue. However, a ceiling was set at a maximum of 45 cities. Today, in 1997, the WHO/EURO Project consists of 36 project cities located in 23 countries. The majority of the cities joining the Project during the first five years continued their relationship with the WHO as so called second phase Project cities. New cities have come mainly from Central and Eastern Europe. 
In the first phase of the Project (1987-1992), cities were supposed to work according to the annual themes of the five year action framework (see WHO/EURO/HCPO, 1988b). Emphasis was particularly put on bullding supportive structures, setting processes into motion, providing information, and giving visibility to the Project"s ideas through events such as demonstration projects. The second five year phase of the Project is meant to be action-oriented (Tsouros, 1995). It should mature on the basis of what has been achieved so far, with "old cities' mentoring and prowing assistance to 'new cities'. Strategic planning, building intersectoral alliances, and development and implementation of a city health policy are now key aspects of the Project.

Since the start of the WHO/EURO Project in 1986, the idea of taking the health of a city as a starting point for action has gained roots world-wide in a variety of forms. This globalisation is reflected, for instance, in the fact that Healthy Cities was the theme of World Health Day in 1996. The expansion of Healthy Cities and its approach has been stimulated by WHO headquarters and other WHO regional offices; gemerally, attention has been focused on how the Healthy Cities Project adidresses aspects of potential direct relevance to other WHO programmes. Also, the undertaking of individual city initiatives as well as personal initiatives has also contributed to the reach and influence of the Healthy Cities concept. What can be concluded is that, since its start, Healthy Cities has expanded substantially over the years, and its influence can now be seen in efforts world-wide. We have briefly considered the origin and current status of Healthy Cities. But it remains to be seen what exactly is implied by the phrase, "a Healthy City".

\subsubsection{What is a Healthy City?}

A city can be visualized as a geographic structure in which to live and work. A city can also be regarded as an administrative entity, or as a social and community structure. Duhl, a city planner and psychiatrist described the city as an organism that has inputs and outputs (Duhl, 1963). Different systems interact with each other to keep the urban organism in balance. This is to our opinion the meaning of city within the WHO Healthy Cities Project. According to WHO, the health of a city depends on:

- how well the city functions as a physical and social environment;

- to what extent and how wel] the city provides the community resources that people need, not just for health in the conventional sense, but to develop to their maximum potential;

- the degree to which the city makes it possible for people to mutually support each other in growing, developing and performing all the functions of life.

(WHO/EURO/HCPO $1988 \mathrm{a}$, p. 10).

A definition of a Healthy City has been given by Hancock and Duhl: "A healthy city is ane that is continually creating and improving those physical and sacial environments and expanding those community resources which enable people to mutually support each other in performing all the functions of life and in developing to their moximum potential." (WHO/EURO/HCPO, 1988a p. 24) Thus, a Healthy City is not a city with a certain health status. Instead it is a city that is committed to the goal of health for its citizens and is willing to work continuously toward that goal. Beyond simply working for health with existing structures, however, it is a city that continually improves the municipal structures and processes available for the promotion of health. The most important characteristics of a Healthy City, according to the WHO/EURO, are expressed in table 1.2. What a Healthy City exactly means in a specific urban context depends on the vision and ideas of its inhabitants. Kickbusch agrees with such a vision by mentioning that project "diversity was a key idea from the start of the WHO Healthy Cities Project." (Kickbusch, $1989 \mathrm{~b}$ p. 82$)^{4}$ 
1 A clean, safe physical environment of high quality (including housing quality):

2 An ecosystem that is stable now and sustainable in the long term;

3 A strang, mutuolly supportive and non-exploitive community;

4 A high degree of participation and control by the public over the decisions affecting their lives, health and wellbeing;

5 The meeting of brasic needs (for food, water shelter, income, sofety and work) for all the cily"s people;

6 Access to a wide variety of experiences and resources, with the chance for a wide variety af contact, interaction and communication;

7 A diverse, vital and innovative cily economy;

8 The encouragement of connectedness with the past, with the cultural and biological heritage of citydwellers and with other groups and individuals;

9 A form that is compatible with and enhances the preceding tharacteristics:

10 An optimum level of appropriate public health and sick core services accesible to all; and

11 High health status (high levels of positive health and low levels of disease).

Source: Tsouros, A. (ed.)(11991). A project becomes a Movement. Copenhngem: FADL.

Unfortunately, in terms of research, this diversity in operationalization of Healthy Cities complicates the research efforts that have been undertaken to set up baseline indicators for measuring changes in the health of a city and to develop city profiles (Webster \& Price. 1996). Webster and Price hesitate to provide health indicators that allow for inter-city comparison. Not only the availability and collection of data differ from city to city, but emerge from radically different city environments.

It is worth noting that only rather substantially-sized cities have been allowed to apply for participation in the WHO Healthy Cities Project, and thus the rhetoric and research in connection with the Project has traditionally focused on "cities". The simple use of the word "city," however, may implicitly delegitimize ocher types of communities in terms of their capacity to carry out Healthy Cities initiatives as described by the WHO Project. Although in this thesis the word "city" will be used, however, the messages are meant to be of relevance to any municipality, whatever its size.

\subsubsection{The aims and requirements of the Project}

In order to avoid confusion, it is necessary to make a distinction between the official WHO Healthy Ciries Project and ather related or similar efforts. The WHO Heallhy Cities Project has been spearheaded by the European Regional Office of the World Healch Organization (WHO/EURO) and sets specific requirements for continued designation as a Healthy City (see for example table 1.2). Other initiatives have come to be known as Healthy City projects and initiatives because they employ a Healthy Cities or Health for All style. Local interpretations and conceptualizations of a Healthy Cities style vary. In general, such initiatives embody similar principles and ideas to those made explicit by and for the WHO Project cities; additionally, non-official healthy cities projects are joined together by various national, provincial, and regional networks. Examples of these efforts are healthy communities, healthy towns, healthy municipalities or local Health for All initiatives. A further distinction also needs to be made between individual health promotion projects under the Healthy Cities banner within individual cities and WHO/EURO's Project, always referred to with a capital " $\mathrm{P}$ ". In this thesis we will from now on use Healthy Cities to 
- To boblish an intersectoral policy steering committe with links to the politicol decision moking systiem:

- To appoint a palitically responsible person.

- To have a visible project office to which the public has access.

- To appoint a coordinator and have full time staff and a runming budget.

- To develop a Heallth for All policy and prepare a city health plan that addresses equity. environmentital, social, and health issues within 2 years affer entering the second phase for old project cities and within 4 years for new cities.

- Cities should secure resources to implement the policy.

- To establish a mechanism for accountability and develop strong links with the city council.

- To take active stieps in the implementation of the European Tobacco Action Plan and the European Alcohol Action Plan and other WHO/Euro strategic action priority areas.

- To stablish mechanisms for public participation, to stimulate debate and involve the media in the process of advocating health.

- To create a health profile of the city.

- To address the needs of the most vutnerable and disadvanitaged social groups.

- The politically responsible perswan and the profect coordinator should participate in busimess meetings of the project.

- The city should repart to WHO on their progress and activities at a regular basis. Therefore one must link up with an electronic mail system.

- It is essential tho participate im one or more Multi City Action Plans (a collaborative strategy between cities on o specifice topic).

- To explore worys of resourcing the development of the WHO network.

- To cooperate with other local and nationall networks and imitiatives, such as schools of public health, urban development, medical associations.

- To establish active working links with other project cities, to exchange information and experiences and to foster debate.

- Cities that took part in the first phase of the project (1987.1992) should advise and support the new project cities (mentors).

- Project cities should support the dewelopment of national networks of Healthy Cifies in their perspective countries.

Soure: WHO/EURO/HCPO (1993), Setting standards for WHO Project chies: the requirements and the designation process for WHO Projict citiess. WHO Healthy Cities Project Phase ll 11993-7997\%. Copenhagen: WHOJEURO.

imply the Healthy Cities movement, including the WHO Project and all other initiatives that are somehow conrected with it worldwide.

The Healthy Cities Project is based on developments that took place both within the WHO and the health sector in general. Its major aims are (see Tsouros, 1991):

- to bring together a network of European cities to assist in and support the implementation of local HFA efforts;

- to move health higher on the political agenda;

- to put health on the public agenda and integrate the goal of health into the local economy, culture, and city life:

- to develop city health policies;

- to foster the development of supportive physical and social enwironments; 
- to create action in the interest of health;

- to build international, nationall, and local alliances for urban development;

- to facilitate the development of networks and communication links;

- to exchange knowledge and expertise.

As challenges for the project Draper et al. (1993) mention:

- to modify local public policies and programmes such that they contribute in greater measure to health;

- to adjust working styles in the city according to the WHO Health for All strategy and health promotion programme;

- to develop projects which can facilitate and promote awareness of the role that health plays in the city.

Project cities are not only supposed to subscribe to the above mentioned aims and challenges, but must also meet requirements (see table 1.3). Only a few of them, such as the creation of a city health plan, of health policy, or of a health profile, or to work on certain WHO/EURO programmes, actually concern the project's content. The majority of these requirements relate only to the structure and organisation of the Project (see also WHO/EURO/HCPO, 1988a; WHO/EURO/HCPO, 1988b; WHO/EURO/HCPO, 1988c).

In this inquiry the WHO definition of a Healthy City and its accompanying require ments and aims will be taken as a starting point. From that starting point the research aims to detect the perceived relevance and contribution of the Project to local health policy development.

\subsubsection{The structure of the Project}

The Healthy Cities Project was defined as an international project, implying as such, that it would have a fixed term of existence. The mandate behind the project's creation was to develop structures in and among cities which would make it possible for the WHO eventually to merely facilitate and support cities as they worked on realizing their vision of a Healthy City.

In order to support and communicate with each other, the cities organized themselves into networks. These networks are used to channel knowledge and expertise for local action on health to among relevant organizations. A network structure is also expected to ensure access to politicians and decision-makers at specific levels (see also WHO, 1991). As will be illustrated later, partnerships and the involvement of key-decision-makers and politicians is essential for the success of the Project and of local health policy development. "The international WHO Healthy Cities Project network is composed of Project cities and the WHO/EURO Healthy Cities Project Office (HCPO). This coordinating centre at the WHO/EURO manages the Project and provides participating cities with information and support. Publications and conferences are the most important instruments the Project has for dissemination of information and advice to participating cities" these means have been especially favoured because only limited financial commitment is involved. Apart from the international WHO Project cities network, national Healthy Cities networks and linguistic networks exist which support the interchange of information among participating cities (see also Price \& Tsouros, 1996; Tsouros, 1991; Goumans, 1993). Furthermore, cities are comnected through Multi-City-Action-Plans (MCAP's) and City Twinning.

National networks. National networks can best be regarded as organizational structures which facilitate information exchange and provide tools to their participants, and other interested cities, organizations and individuals, for working toward the improvement of the health of a city (WHO/EURO/HCPO, 1994a). In 1997, 26 national networks were operational in Europe. 
WHO Healthy City Project cities are encouraged to stimulate the development of a national Healthy Cities network in their respective countries. In addition to Project cities thenselves, howewer, the $W H O$, national umbrella organizations, research institutes, and individuals have been very active in the stimulation of national network development (WHO/EURO/HCPO, 1994a). The specific participation criteria for these networks differ from one country to another. Most criteria are based on WHO's Project requirements and most aims or other criteria derived from the HFA2000 strategy. In Europe these national networks are part of, or work together with, EURONET. EURONET is an international non-governmental European Association of National Healthy Cities Networks (WHO/ EURO/HCPO, 1994a), In order to become an official member of EURONET, a network needs to have formal structure. Financial and in-kind support for national networks comes from their national government, though the content and intent of such support may vary by country. Examples of support are financial contributions, office space, or political support. The basic aim of these networks is to influence health pollicy development. Members use their network membership as a legitimization of and support for their innovative local health activities. Specific network activities are organized to inspire and to stimulate members to continue with health promotion and health policy development in their own localities. Section 1.4 will discuss two of these national networks, the Dutch and British networks, and their member cities.

Linguistic networks. Apart from networks that are bound by geographical boundaries, there are also operating linguistic networks. Examples of these networks are the Francophone, the Spanish, the Portuguese, and Arabic speaking Healthy Cities networks.

Multi City Action Plans. Multi City Action Plans (MCAP) is a collaborative strategy between WHO Project cities. They work together on a specific issue, such as AIDS, Sports and Active Living, and Elderly people. These MCAPs are linked with WHO/EURO through linkages with the WHO/EURO/HCPO and the support they receive from WHO (technical) units.

City Twinning. City Twinning was originally initiated by WHO/EURO to assist cities in Central and Eastern Europe in restructuring their health system and tackling environmental hazards by relating them to Western European cities. Within the context of the Healthy Cities Project, City Twinning means that cities which have long been involved in the Project offer assistance to new cities by sharing their own experience and through help in the development of derronstration projects.

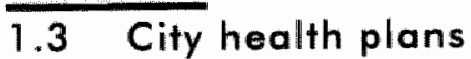

More explicitly than in the first phase of the Project, the aspect of policy development was mentioned by the WHO/EURO/HCPO as a key issue for the second five year phase. One way in which the WHO/EURO/HCPO tries to stimulate cities to work on health policy development is through the development of a city health plan. "The main focus for activities in this phase is on formulating and implementing HFA-oriented city policies, developing city health profiles and comprehensive city health plans that set explicit targets and address issues such as equity and sustainable development, and establishing mechomisms to promote accountability for health." (Tsouros, 1995 p. 139)

A city health plan is defined by WHO/EURO/HCPO (1994c;1995a) as a plan that describes the broad policies and strategic objectives for improving health in a city within a given time frame. The implications and details of this plan are expected to be elaborated in so-called operational plans. Key-issues in the health policy plan are the development of intersectoral collaboration and recognition of the responsibilities that each public policy 
sector has with regards to health. It is obvious that the development of such a plan requires the participation of many stakeholders. WHO contributes the local Healthy Cities Project Offices an important role in involving these stakeholders and starting this development process. Presumably the city council has the political responsibility for assuring that such a plan will be developed. The City Council must have signed a formall letter expressing its commitment to the Project and its requirements. It is, however, questionable whether the city council actually takes such a leading role within Healthy Cities initiatives. This question will be explored in Chapter Four.

WHO mentions (WHO/EURO/HCPO, 1994c p. 4) that a city health plan should not be regarded as an end in itself. It should be seen as a process leading to policy development, a process which provides change and breaks down existing political, social, and organizational barriers. However, cities may and do at times consider the city health plan as the city's health policy. Unfortunately, this means that the development of thorough and real policy is neglected, and the process therefore does not lead to a written policy paper. Such a stunted policy approach will be further explored in Chapter Two. It seems odd that this requirement, the development of a city health plan, is meant to be of equal importance to all Project cities. The only difference is that recently designated cities, those who started to participate in 1993 have been given two years more than their predecessors, namely four years instead of two, to present a city health plan (see table 1.3).

From a WHO questionnaire sent out in 1994 (WHO/EURO/HCPO, 1995a), it appears that most Project cities ( 25 out of 28 responses) were involved in the development of a city health plan. In the cities where a start had recently been made with a plan, expectations were quite optimistic. It was generally expected in such cities that one to one and a half years were need for implementation of the plan. In cities where they were about to consult the general public about the first ideas, or in those in which the plan was about to be implemented, people had already been working on the issue for two years or more (two out of three). From this questionnaire it also appeared that in all, old and new, cities an important barrier to development of such a plan turned out to be a lack of political and organizational support (WHO/EURO/HCPO, 1995a).

So far the ideas and background to the WHO/EURO Healthy Cities. Project have been discussed. The next section will focus on how these ideas have matured in the Netherlands and United Kingdom.

\subsection{Healthy Cities in the Netherlands and the United Kingdom}

The discussion and conclusions in this thesis are based upon information collected in ten cities involved in Healthy Cities, located both in the Netherlands and the United Kingdon. Healthy Cities involvement in each of these two countries will be separately discussed below. Furthermore, a very brief introduction to the initiation and development of Healthy Cities in each of the ten case studies will be given. Background information on the case studies which is not specifically related to Healthy Cities is included in appendix one, such as administrative structure, city and country characteristics, and the role of local government in public health affairs.

Netherlands. The Netherlands national network of Healthy Cities [Netwerk Gezonde Steden, MG $]^{1}$ was set up in 1987 . The network was intended to function as a platform for all those interested in and working on Healthy Cities in the Netherlands, regardless of pro-

$1[\ldots ., M G]$ in the text are either free tronslations, emphases or additions made by the author about the quotation. 
fession. In line with such a broad mandate, the network had neither participation criteria nor asked its members to make a financial commitment to the network. A national project office organized and coordinated activities and provided information to interested persons. A core group, consisting of professionals, served as a so-called think tank for the initiation of activities. A steering group composed of politicians had political responsibility for the functioning of the network and project office. The network was financially sponsored by the Ministry of Welfare, Health and Cultures until 1994.

Since January, 1995, the newwork has had a horne within the Netherlands Association of Municipalities (VNG) as a sub-committee of the Welfare and Public Health committee. Furthermore, the project "Creating Healthy Public Policy" is for a period of three years (1995 1998) part of the network. The ain of this project is to stimulate innovative local health policy through research and support. Only municipalities can become official members of the national network. In 1997,23 municipalities, out of a total of 572 in the Netherlands, were affiliated with the Network. The sub-committee is comprised of politicians [wethouders, MG] responsible for health. A group of civil servants in participating cities acts as a platform which initiates and implements Healthy Cities activities in localities, assisted by the project workers and other staff of the Association of Dutch Municipalities. In 1996 a core group was created consisting of civil servants and professional consultants in public health. This group steers and assists the project and prepares the meetings of the sub-committee.

The national 'Netwerk Gezonde Steden' is based on the following Healthy Cities principles:

- political involvement in health activities;

- citizens' participation in actions and decision-making which influences factors related to health;

- a social health model (see section 1.4) shows that health promotion interventions are ordinarily multi-faceted. Intersectoral cooperation between the health sector and other sectors is therefore required;

- qualitative and quantitative data as a basis for health activities and policy-making. Generation and integration of data from different sources is expected to facilitate priority setting and decision-making on policy programmes.

Network cities are asked to support each other, to be committed to the philosophy of HFA2000, and to exchange information. Participation in issue based working groups has prowen a popular means of addressing all three responsibilities simultaneously. In principle, all information collected by the network cities, including the results of such working groups, should become available to other cities who show an interest in beginning similar internal processes. Besides the formal network, of course, informal communication continues its role and function in facilitating individual cities' efforts.

The role of the network in national and local health policy-making seems likely to increase with time. The project began in 1995 an investigation to review the progress of the Dutch network. The investigation evaluates the network's progress, and comes up with ideas on how to support local governments in making health policy (Gooskens, Kornalijnslijper \& Veen, 1997).

The five cities that have been selected as case studies in the Netherlands in this research are all current members of the Dutch National Network. Two of these cities, Eindhoven and Rotterdam, are also Project cities of the WHO Healthy Cities Project. In Chapter Two, we will explain how and why we have selected these cities.

Eindhoven. As a response to the highly enthusiastic report of a municipal delegation that returned to Eindhoven after a Healthy Cities symposium, the municipal council of Eindhoven decided in 1987 to apply for membership in the WHO Project. To the city 
council it appeared that participation in the Project would be stimulating to the then existing health activities being carried out within the municipality and would promote the progress of local health policy being developed by the local public health service (GGD). The council's intention was to promote health and health care in its city and to develop an integrated health policy. In addition, participation in an international project was seen as likely to improve the overall visibility of Eindhoven. Coordination of the project would be embedded within the GGD structure, as many of the project's goals seemed in accordance with the mandate of the GGD. In 1988, Eindhoven became a WHO Project city and, in 1993, the decision was made to prolong the city's membership by another five years.

Rotterdam. In 1990, the city of Rotterdam was designated as the second WHO Heallity Cities Project city in the Netherlands. In this case, the process of initiating new activities was made easier by the fact that the Healthy Cities project team in Rotterdam was able to take advantage of already-existing, widespread attention for a concept called 'Social Renewall'6 [Sociale Vernieuwing. MG], which had been promoted in previous years by the city government. Healthy Cities was regarded as a model project of the social renewal activities in Rotterdam. In 1993, the project stage of Healthy Cities in Rotterdam came to an end. Plans have been made since then to move from the promotion of various demonstration projects to the development of policy (Rotterdam Gezonde Stad, 1994). A Project Office tries to integrate 'something from Healthy Cities' into GGD departments and into the reasoning and policy-making activities of other important public and private organizations in Rotterdam.

Tilburg. Tilburg made itself known as a city that intends to work on its health along health promotion lines through its publication of a policy document in 1991 called 'Ten intentions for a healthy policy" (Gemeente Tilburg/GGD). The city tends to remain Heallhy Cities rather low profile, meaning that they do not use this very often as a label for their activities. Tilburg's public health priorities are related to community care and self-care facilities and activities.

Almelo. Almelo employed a different strategy than that of Tilburg. In Almelo, Healthy Cities was used to stress the cities" distinctive features within a national and international context. The intention was to use Healthy Cities as a platform for launching major health related initiatives in such a way that these are seen as interesting and relevant enough that sponsors would provide financial support for particular projects. Ultimately, the aim of such projects is seen in Almeio as a way of increasing awareness for health outside the health sector.

Groningen. After the decision was made by the city council to adopt the Healthy Cities ideas in Groningen, the most important question was 'how do we put Healthy Citties into practice?'. It appeared in Groningen that a so-called bottom-up, community approach, would work better than an organisational (development) approach. The coordinator therefore focused first on health initiatives at the grassroots level. By monitoring the daily activities of community development workers, the coordinator in Groningen has tried to translate their work and interaction with other (professional) workers in the neighbourhood into terms relevant to the design and development of health policy in the city. Such information and analysis, could be useful to the coordinator to approach the local organizations and authorities in order to stimulate discussion on what they think their role could be with regards to appropriate changes in local health policy and their role in carrying that out.

United Kingdom. The United Kingdom Health for All network (UKHFA network) originated from a Local Authority Health Network (LAHN) which became operational in the early Eighties. A small group within the LAEN drew up terms of reference to offer advice and support to those involved in developing Health for All strategies. The Healthy Cities network was inaugurated in 1987. This part of the LAHN network grew very fast and 
soon became independent of its parent organization. As Liverpool was part of the WHO Healthy cities Project, the ciry offered to coordinate the network while the city council provided office space for it. A UK Healthy Cities organising group, an informal committee, supported the development of the network. Organisation of related activities was undertaken by officers from participating cities.

In 1991, the network was officially established and its name changed from United Kingdom Healthy Cities Network into UKHFA network?. This network is a formal association, with working groups, task groups, and a management committee. The management committee, in which all members are represented, is formally responsible for the network. Membership is open to any statutory, voluntary, academic, community, and commercial agency working towards HFA principles at local level (WHO/EURO/HCPO, 1994a) Intersectoral committees, Large Local Statutory Bodies, Academic Bodied, Commercial Organizations, Local Voluntary/Community Organizations, Religious Bodies, Small Statutory Agencies, Trade Unions, Professional Bodies, and Community Groups can receive full member status. In 1997 there are 71 full members of which 28 are intersectoral committees, including a further 267 members. Full membership implies that they have voting rights. Individuals, national organizations, departments of organizations or universities can become associate members. In 1997 there are 37 of them. In total there are 403 members, they cover about 50 municipalities. The network receives financial support to a limited extent from the National Deparment of Health. Other financial resources come from membership fees. In 1995, the network structure was again under revision as the network was in the process of becoming a limited company, which is the case nowadays.

The main tasks of the network are parliamentary lobbying and stimulating discussion on the relationships among. HFA2000, Healthy Cities, and ongoing national health-related documents and policies. Furthermore, the network has a mediating and advocating role for Healthy Cities. The major aim of the UKHFA network is "to facilitate a strategic chonge in health policy at local lewel..." (WHO/EURO/HCPO, 1994a p. 56) The UKHFA network is based on the following principles:

- health is defined as social, physical, and mental wellbeing:

- local collaboration between all parties;

community participation;

empowering people both individually and collectively;

- accountability to the public and service users;

- equal opportunities, taking discrimination into account;

- primary health care;

public services directed towards promoting health;

national and international cooperation.

Its aims are:

- to work together towards reducing inequalities in health and to promote equity both within and among localities;

- to promote a wider understanding of health;

- to develop and put into practice policies to improve health in communities and in society as a whole;

to enconrage and support community participation;

- to encourage and share the experience of collaborative local initiatives on HFA2000 and Healthy Cities, which establish a comprehensive public health strategy and so facilitate the development and implementation of healthy public policy;

- to share ideas, approaches, and skills across the United Kingdom and, internationally, with HFA2000 and Healthy Cities projects. 
The five selected cities from the United Kingdom in this research are members of the UKHFA network. Two of these cities, Liverpool and Glasgow, are also participating in the WHO Healthy Cities Project. In Chapter Two we will explain how and why these cities were selected.

Liverpool. Liverpool started in 1987 as a WHO Project city. The city was active in the health field at least partially because of its poor health statistics. Community work and community projects were not new to the city, so one way or another, participation in the WHO Project was an international formalization of ongoing local activities. Participation made it possible to speed up the process of developing health initiatives and to gain experiences from overseas.

Glasgow. Healthy Cities working groups in Glasgow date back to two public health conferences held in 1988 and 1989. The decision to apply for membership in the WHO Project in 1988 coincided with these conferences: The participation in the WHO Healthy Cities Project represented an international formalization of ongoing local activities. The Project could build on fertile ground where people were working and willing to work on reducing inequalities in health and in social environments (Glasgow Healthy City project, 1992). Although the project is affiliated to the UKHFA network, plans are being made to launch a separate Scottish HFA network.

Sheffield. Sheffield also started working actively on Health for All in the second half of the 1980 's. The initiative was named 'Healthy Sheffield 2000'. The city did not apply for WHO Healthy Cities Project membership. After spending a good deal of time translating the 38 European HFA2000 targets into local goals and objectives, the city's strategy evolved into a large community consultation on "how is health created?'. From this community consultation, the Framework for Action for a Healthy Sheffield was generated (Healthy Sheffield, 1994). This Framework for Action was signed by all major organizations in the city. The main task for Healthy Sheffield now is to work with its partners on the implementation of this framework.

Newcostle. The Healthy City project here began as a result of the enthusiasm of a few individuals working in organizations in various health-related fields. The political climate was neither antagonistic nor particularly supportive to their ideas and initiatives. Newcastle Healthy City tried to stay independent of the local authorities by remaining an independent voluntary organization. Consequently, especially in the first years of the project. maintaining sufficient resources and support from key-decision-makers were important agenda items. Since 1995, Newcastle Healthy City has been a charitable trust. The Newcastle Healthy Cities team has adopted a working strategy of focusing on three demonstration projects, working with community groups, and at the operationall level of organizations.

Winchester. Winchester started in the early 1990 s with HFA2000 initiatives. Like Newcastle, Winchester also had to cope with a lukewarm political climate. Winchester Healthy City is currently integrated into the municipal structures with a permanent post for the coordinator. The project is highly visible within the city but its ideas as such are not as yet part of mainstream activities. Organizational development and expansion of the HFA2000 ideas to the different organizations in the city is on the agenda for the coming years.

In all ten cities and in both networks it is expressed that the fundamental principles are the global strategy for HFA2000 and/or the action areas of the Ottawa Charter for Health Promotion. The European Charter on Environment and Health is mentioned to a lesser extent. The next section will explore these three traditions as they represent underpinning elements of WHO Healthy Cities. 


\subsection{The backgrounds to the ideas and content of the Healthy Cities Project}

\subsubsection{A positive health concept}

According to Ashton and Seymour (1988) the evolution of public health can be broken down into four major eras. The Sanitary Era (1840-1880), the Era of Personal. Prevention (1880-1940), the Treatment Era (1940-1974) and, lastly, the Era of the New Public Health (1974-). The so-called "New public health" stands for a renewed interest in preventive medicine, combined with environmental health, and the development of health promotion. It arose largely as a result of the following:

- greater recognition of the limitations of medical therapy;

- development of research on non-therapeutic determinants of health;

- development of a critical mass of thinking with respect to the role of systemic factors contributing to populational health status, as symbolized by the early Canadian initiatives in this regard, including the Alma-Ata Conference and the development of the Ottawa Charter;

- the relatively high costs of medical care.

Public health is ofien defined according to what the Acheson commission suggested, "the art and science of promoting health, preventing disease and prolonging life through organized efforts of society. " (Acheson, 1988)

Discussions which identify the biomedical model as disease-oriented and which advocate greater resource allocation toward a health-oriented public health model arose as a result of growing attention to the complexity of what determines populational health status. Research has been carried out on the contribution of medicine and medical research to the process of public health improvement (for example Dubos, 1959; Blum, 1974; Illich, 1976; McKeown, 1976; Navarro, 1986). From such research it appeared that the medical model and medical knowledge alone could not fully explain change or progress in populational health status over a number of decades. This is consonant with the health definition of Kickbusch (see table 1.4), which implies that health cannot be measured by morbidity and mortality rates.

A positive view of health, as embodied in Antonovsky's so-called "salutogenesis model" differs from a biomedical one in that it begins by addressing factors that influence and support health the risk factors for health instead of merely determinants of disease (see Kelly, Davies \& Charlton, 1992). A social-ecological health model (see figure 1.1) which is based upon a positive concept of health, includes the social en physical environments, lifestyles, health care services, and heredity. The model is built upon the assumption that these factors can all significantly influence and promote health, and likewise influence each other (see also Kickbusch, 1989a; 1989c).

There is always a risk, however, that a social-ecological model of health is used merely in a rhetorical -rather than genuine- way. Despite discussions in (scientific) journals and during conferences about the complexity and interrelationship of determinants of health (see also Evans, Barer \& Marmor, 1995), the interventions that are developed often address only one of these determinants at a time (see also Nijhuis, 1994) .

The confusion is understandable, for the study of interrelationships and multiple levels of health determinants is antithetical to traditional research practice, and therefore presents grave problems for researchers. Kelly (1992) mentions that if we are to research the 'origins of health' (see Antonovski, 1984; Charlton \& White, 1995), people have to be studied in their daily environment in an interdisciplinary way. The acceptance of a very complex and interwoven society has to be the starting point. 
"Health is a stote of complete physical, mental and social well-being, and not merely the absence of disease or infirmity. (WHO, 1947)

"Health is the expression of the extent to which the individual and the social body maintain in readiness the resources required to meet the exigencies of the future." (Dubos, 1962)

"Health is a relative state that represents the degree to which an individual can operate effectivelly" within the circumstences of his heredity and hïs physical and cultural environment." (McDermatt, 1977)

"Health is a state of optimum capacity for effective perfornance of valued tasks." (Parsons, 1979)

"Health is the extent to which an individual or group is able, on the one hand, to realize aspimations and satisfy needs, and, on the ather hand, to change or cope with the enviromment: (Kickbusch, 1986)

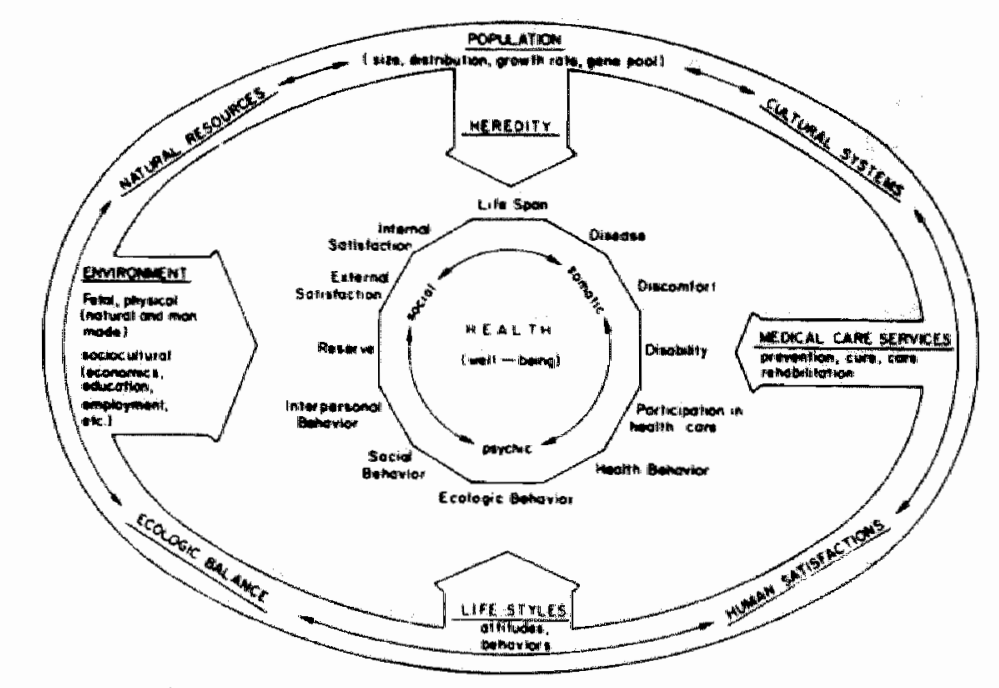

Source: Blum, H. (1974). Planning for Health. New York: Human Sciencas Press.

Figure 1. 1: Sociall ecological health model.

Important stimuli for the development of new public health and health promotion have been the WHO HFA2000 strategy and the first WHO international health promotion conference in Ottawa, Canada. The WHO Healthy Cities Project is primarily rooted in these two elements in addition to the European Charter for Environment and Health (Tsouros, 1991; Tsouros, 1995; WHO/EURO/HCPO, 1988a; WHO/EURO, 1991; WHO/EURO/HCPO, 1992; WHO/EURO/HCPO, 1993; WHO, 1995). That these landmarks comprise the roots of the Project is taken for granted in this thesis. The issue of concern here is to find out how these roots are experienced by those working with the Healthy Cities ideas and principles. 


\subsubsection{Health for All}

"Healthy Cifles projects play a unique role in the city government. They promote innovation and change in local health policy; advaciating new oppraaches to health. They explore effectiwe way to translate the primciples and fargets of the Eurapean HFA strategy into practice in urban settings. They prowide public health leadership through mechanisms that recogmize and mediate the interests of different groups in the communify." (WHO/EURO/HCPO, $1992 \mathrm{p} .7$ )

Due to developments in technology, science, and medicine most industrialized countries have achieved a reasonable if not good health care infrastructure. Nevertheless, there are still many health inequities between and within countries. Within countries there are disparities among, for example, men and women, rich and poor, differing races and ethnicities, and cities or neighbourhoods. Addressing such inequities was not always an explicit goal of public health, nor a focus of its data-gathering capacity. Findings regarding inequities among populations living in industrialized countries were at least partially based upon the experiences of health workers in developing countries, who witnessed clear disparities among rich and poor both within developing nations, and internationally. Such awareness led to a major rethinking of the ways in which it was possible to reduce health problems or prevent them from occurring in the first place. One ensuing debate led in 1977 to the decision by the World Health Assembly (the legislative body of WHO) that the WHO' and her member states" most important goal should be "the attainment by all citizens of the world by the year 2000 of a level of health that will permit them to lead a socially and economically productive life." (WHA 30.43, May 1977 in de Leeuw, 1989a p. 9) This rather idealistic mission was the basis for the policy direction of the WHO which came to be known as Health for All by the year 2000 (HFA2000) (Mahler, 1981).

It should be noted here that Health For All 2000 does not mean that every world citizen should be healthy by the year 2000. What the WHO endorses with HFA2000 is an explicit consideration of health as a criterion within policy formulation and implementation processes worldwide. HFA2000 is a mandate for more fully involving the individual in decisions related to the factors impacting his personal health status. Further, it asks that the community at large be involved in decision-making about the distribution of resources with regards to health. Equity and equal access are emphasized as important prerequisites for the attainment of population health. Local needs are seen as the appropriate starting points for the development of health initiatives. Simultaneously, the WHO strives for the development of international health policy, and for concrete operationalization of such policy within individual member states.

The WHO's European Regional Office (EURO) is responsible for the development of HFA2000 strategy in Europe. At the time of the strategy's inception here, WHO/EURO was not pessimistic about the general health status of the Europeans, but concluded that there were unacceptable differences in health status among, and even within, the different countries (Garretsen \& Raat, 1989; Townsend, Davidson \& Whitehall, 1990). Ultimately, such concern with inequity was reflected in EURO's translation of the HFA2000 strategy in 1986 into 38 targets (WHO/EURO, 1986). This document was updated in 1991 (WHO/EURO, 1991) and again in 1997 the HFA strategy is being revised to adapt it to the circumstances after the year 2000. A complete description of the 38 targets would be too detalled for the purposes of this thesis. However, the 38 European HFA2000 targets and the Health for All strategy are guided by six principles, those being:

- "Equity". Reducing inequalities in health within and among countries.

- 'Health promotion and disease prevention'. Helping people to reach their highest possible physical, mental, and social capacities due through the process of enabling people to take more control of the factors affecting their health. 
- 'Cooperation'. Using intersectoral cooperation to guarantee access to health prerequisites and protection from environmental hazards.

- 'Community participation". Integrating community participation with local, national, and international policy-making is regarded as essential for the success of HFA2000 at the ground level.

- 'Primary health care'. Reorientating the European health care systems from secondary to easily accessible primary health care services.

- 'International cooperation". Emphasizing the importance of international cooperation in addressing health issues, which transcend national borders.

As WHO partners are all national governments of WHO member states, the HFA2000 strategy was originally meant to be developed at each member state national level.

Persuading governments to actually take action within these basic principles has proved to be difficult (see also Curtis \& Taket, 1996). The "Note 2000' (1989) document of the Dutch government is often regarded as the Dutch government's response to HFA2000. Although this document did not receive wide acceptance (de Leeuw, 1989b) other efforts have been made since then, for example Gerondheid met Beleid (1992) [Health through Policy, MG], and Gezond on Wel (1995) [Healthy and Well, MG]. Inequalities in health are also part of a major national research programme on 'Social Economische Gezondheids Verschillen' (SEGV) [socioeconomic health differences, MG] (see for example Mackenbach, 1994). In the United Kingdom the national government's "Health of the Nation" (1991) white paper, was seen as a tardy British response to HFA2000. Both the policy and subsequent local action were criticised for being too limited and selective in their targets; critics claimed both policy and action focused on disease and neglected the social model of health and inequalities (Rathwell, 1992 in Curtis \& Taket, 1996 p. 268).

Within the Healthy Cities context, however, it is the local government which is given direct responsibility for a local HFA2000 strategy. The aim for international health policy becomes herewith transnational (De Swaan, 1995). Characteristic of a transnational society is according to de Swaan (1995) that connections between people, and the networks and relations they establish, cross national borders. These networks contain elements of all nations involved but based on the interaction the networks establish at the same time unique characteristics and identity.

A conceptual framework for developing a HFA2000 strategy was offered by the health promotion programme. This is the subject of the mext section.

\subsubsection{Health promotion and the Ottawa Charter}

wealth promation wass set out to put health on the political agenda. It aimed at creating the climate and the means to reinvent and modernize public health." (Kickbusch, 1995 p. 1)

Health promotion as a conceptual framewrork, including its methodologies and vocabulary. builds upon a social-ecological health model (see figure 1.1) and a positive health concept (see also sub-section 1.5.1 and Hancock, 1992). In 1974, the then Canadian Minister of Health, Marc Lalonde, was one of the first ministers of health in the world to present a health plan based on such a framework. This plan, entitled "A New Perspective on the Health of the Conodians', aimed at planning for a comprehensive vision of health promotion instead of merely for expanding the health care system.

In 1986, the first conference on health promotion was organized in Ottawa, Canada. The central theme of the conference was the question 'what is health promotion?'. The outcome of the conference was a Charter, what have since become known as The Ottawa Charter (see figure 1.2). The Charter is currently one of the major references for all those who work on, write, or talk about health promotion. The Ottowa Chorter defines heallh 


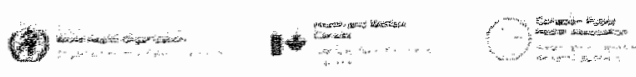

\section{OTTAWA CHARTER FOR HEALTH PROHOTION

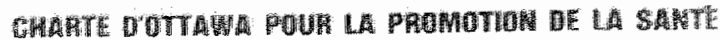

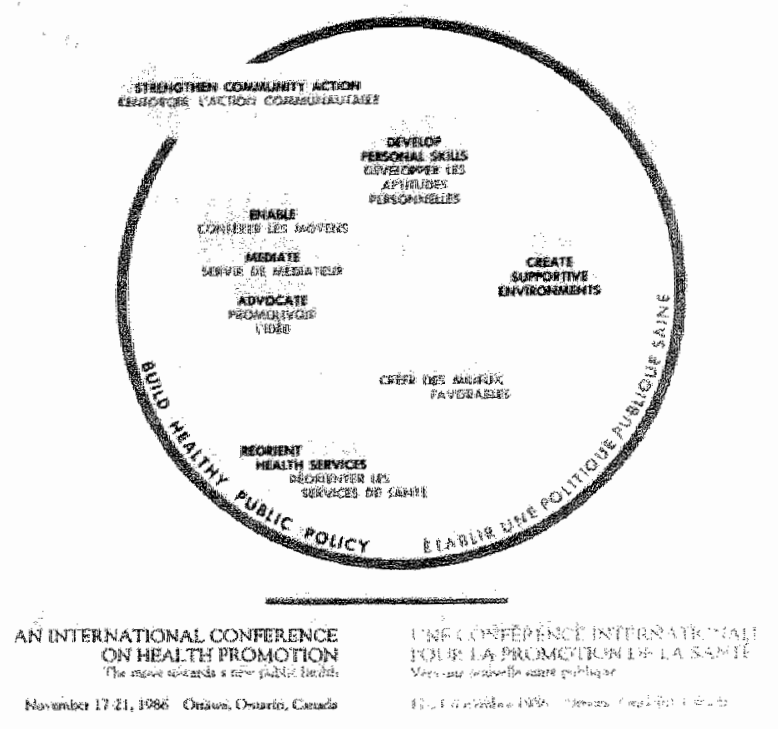

Figure 1.2: Ottawa Charter for Health Promotion.

promotion as follows: "Health Promation is the process of emabling people to increase control aver, and to improve, their health. To reach a state of complete physical, mental and social well-being, an individual or group must be able to identify and to realize aspirations, to sotisfy needs, and to change or cope with the environment. Health is, therefore, seen as a resource for everyday life, not the objective of living. Health is a positive concept emphasizing sacial and personal resources, as well as physical capacities. Therefore, health promotion is not just the responsibility of the health sector, but goes beyond healthy life-styles to well-being." (Ottawal Charter, 1986)

of importance here is the implication that individuals will and must make independent choices. The supporting skills and information that they need can be provided either by professionals or by peers. Major themes in the Ottawa Chorter centner around the words 'enable", "advocate' and 'mediate'. People should be enabled to achieve their fullest health potential. People must be able and confident enough to make choices regarding the factors affecting their health, and they need skills and the proper conditions in which to it. Health as a resource needs therefore to be advotated within different contexts and sectors. The health promotion ideas are not self evidently clear to everybody, so there need to be people who can explain and visualize what is meant by health promotion. As many people, organizations, and sectors with different interests and goals need to be inwolved within health promotion, there need to be as well people who are able to act as intermediaries. The responsibility to mediate between the different interests of all those potentially inwolved in health promotion has been attributed to professional and social groups.

Health promotion should be a goal in itself, according to the WHO, and not a positive effect of, for example, economic growth. This conviction is based on evidence which shows that a growth in the per capita Gross National Product (GNP) is correlated with increased individual health status only in very low income countries 10 . 
There are five major objectives oudined in the Ottow Charter:

- Creafe supportive environments. A social model of health assumes existing links between. people's health and wellbeing and their living, working and social enviromments. Social, economic, and physical environments should therefore provide support for health promotion. These environments should assure that healthy choices are the easier choices on a day-to-day basis.

- Strengthen community action. Through an emphasis on community development and empowerment, people should be given control and ownership over their own aspirations and plans.

- Improve personal skils. Offering information and education is believed to support personal and social leaming. Confidence in decisions enhancing one"s own health are likely to stimulate people's participation in policy-making and in the implementation of activities.

- Reorient health systems. A reorientation of the health system relates to the explicit recognition that hospital based care is only one aspect of a health system. This recognition may at times result in a reorientation of investments in hospital based health care to health promotion and primary health care. A reorientation also influences the education of health professionals and research.

Build healthy public policy. Healuly public policy implies that all public policies are characterized by explicit attention to their consequences for human health. Healthy public policy is aimed at reducing health inequalities and does not fall automatically within the health care sector. It is even recommended to go beyond that sector (World Bank. 1993; Milio, 1986). This means that possible health consequences should be a signifcant topic of discussion in political decision-making in whatever public sector. The concept of healthy public policy will be further explained and illustrated in section 1.7 and in Chaptex Three.

\subsubsection{European Charter on Environment and Health}

Apart from the Health for All 2000 strategy and the Ottawa Charter for Health promotion the European Charter on Environment and Health is the third source of inspiration for the WHO Healthy Cities Project. In the European Charter on Environment and Health the relationships among health, well-being and the environment are explicitly mentioned as a reason for government and public authority action at all levels in the interest of health. Principles, priorities, and strategic elements are mentioned which very much resemble the health promotion and Health for All 2000 strategy. Especially the relation between socio-economic development, urban development, and the effects of these on health and wellbeing are sources of concern. It is argued that the health of individuals and commumities should be a higher priority than a simple definition of economic growth. The Charter advocates the development of (epidemiological) research in support policy development in this direction.

The Charter was adopted in 1989 by European ministers and senior representatives of Environment and Health administrations. Since then, the relation between environment and health has received even more attention at international, national, and local political levels. An example of this international attention is the Rio Conference on Environment and Development (1992). An important document of this Conference was Agenda 21, a document that offers a 'blueprint' on how to reach socially, economically, and environmentally sustainable development. Agenda 21 shows how population growth, consumption patterns and technology are important forces for environmental change (see also Abma, 1995). The general principles of sustainable development are in accordance with the HFA2000 strategy 
(WHO, 1995). The principles include the following:

- dewelopment must be 'equitable' if it is to be truly sustainable;

- an intersectoral approach is required;

- a recognition of intercommunity dependencies, both social and ecological, is essential; - sustainable development is inseparable from economic, health, and social development. Through the relation between health and environment the WHO Healthy Cities Project finds itsellf inherently linked with other city-based European programmes such as the Ecological City programme of the Organisation for Economic Cooperation and Development (OECD) and the work of the European Foundation for the improvement of Living and Working Conditions (EFILWC) (see for example Price \& Tsouros, 1996).

\subsection{Explanations for a focus on health promotion in cities}

\subsubsection{Strategy: Investments in health and a setting approach}

In the previous paragraphs we have explained what the Healthy Cities Project encompasses; how it has matured, and on what grounds it is based. What has not been addressed is the question of why the WHO has chosen to draw attention to health within a specifically urban context. Here, we attempt to explain how and why the Healthy Cities Project is an example of a so-called 'setting approach' to health policy development that fits the WHO/EURO strategy of investments in health.

Investments in health. The World Health Organization considers health a fundamental human right. Therefore, health should be promoted regardless of economic development (see for example Levin, McMahon \& Ziglio, 1993). "The health of individuals and communities should take clear precedence over considerations of economy and trade." (European Charter on Environment and Health, 1989) Through a strategic use of the words investments in health, the WHO aims in the Nineties to increase the visibility of health on public and political agrendas (see also World Bank, 1993; Levin \& Ziglio, 1996). Demonstration projects are carried out by the Health Promotion and Investment Unit of WHO/EURO (WHO/EURO, 1995; WHO/EURO, 1996). Contrary to popular belief, investments in thealth are not primarily made in the health care sector. The health care sector is indeed defined as those activities concerned with the curing of disease and caring for the sick and disabled, as well as the economics of those activities. Howewer, the idea of investing in health concerns all policy sectors.

The WHO recognizes that governments have to make hard decisions on how to spend their money. Due to factors such as aging and advanced technologies it is relatively difficult to prevent the health care sector from consuming an increasing share of the GNP. Whether such an increase in consumption of the GNP is desirable or tolerable calls for principal political decision-making.

Sullivan (1991) places uncreasing spending on health and social care in Canada within the context of the findings of the "Black repart" ( $(1980)$ in Townsend, Davidson \& Whitehead, (1990)). This report reveals that it is almost impossible to demonstrate a relationship between increased spending on health care and improvement of individual health status in developed countries. This seems somewhat in contrast with health care spending in developing countries, where such a relationship is more easily demonstrated. Sullivan argues that the mistake of spending a public dollar as if health care equals health is easily made. He compares expenditures on social and health care with other policy fields in Canada and concludes that the expenditures on non-health core areas of public policy have not kept pace 
with those on health care, even in cases where the health bervefits might be more impressive than thase accruing from spending on health care" (Sullivan, 1991 p. 3) What this means is that investments in health are often made in the health care sector, even if investments in sectors other than health care would lead to larger overall health gain. Sullivan tries to illustrate this conclusion by comparing Canada with Japan and Sweden. Japan spends far less than Canada on health care but nonetheless achieves a higher average individual health status. Because the Japanese lifestyle is not regarded as particularly healthy in terms of disease related factors, Sullivan mentions that the social and physical enviromments may be responsible for their success. He draws a similar conclusion for the Swedish situation, where he mentions economic performance, employment, degree of control, and empowerment, such as for example training facilities and participation in decision-making in the workplace, occupational status, early care, and nurturing in childhood, social support, and social arrangements as influencive to the health record. In light of his analysis, Sullivan advocates that health promotion should be an objective of all public policy sectors rather than a specialization of a department of the Ministry of Health.

The debate between investing in health through disease prevention and health promotion activities as opposed to health care is not about making a 'good' or a 'bad' decision. The health care sector will always be needed, "since health promotion will never replace treatment, care and cure, the issue connot be whether health promotion is better than cure but whether a shift on the margin from cure to health promotion will result in a net benefit increase." (Cohen, 1994 p. 281) The burden put on the health care sector is likely to decrease as more investments are made in preventing people from having to enter it (see also World Bank, 1993). At the same time, there are people who suggest that using health promotion interventions in the end may be more expensive (see Cohen, 1994). By reducing morbidity and mortality, people will indeed live longer; ultimately, this will cost more in terms of care and social services than without health promotion intervention. According to Cohen, the issue is to increase health gain, better quality of life, through health promotion programmes in a more cost effective way than other programmes or interventions can bring about.

Setting approach. Health promotion is not only a useful concept and tool for those who recognize the need for investments in different sectors, such as the economic sector or the environmental sector. It can also be used to advocate health within different settings.

Schools, cities, workplaces, hospitals, or prisons are examples of such settings.

A specific charucteristic of the setting-based health promotion approach is its recognition of the role played by social and physical environments in influencing the health of people. These settings represent a set of existing (social) structures, a shared history, interaction patterns, and common goals. Instead of mobilizing people in the interest of a new and abstract health goal, using these existing networks is generally considered to be more effective for health interventions in terms of time, resources, access to the people, and potential for social influence (see Dolan-Mullen et al., 1995). Health education professionals are stimulated by the setting approach to pay attention to the role of, for example, organizational aspects and governmental policy in health interventions. The idea of targeting individuals indirectly by influencing policy that may prevent or promote certain population behaviour is intrinsic to health promotion, but is nonetheless a rather innovative direction for health education ${ }^{11}$.

To target a specific setting, instead of the more limited scope of specific issues or target groups, or a combination of these two, also has gained roots within the World Heallth Organization. When the WHO European Regional Office updated their HFA2000 targets in 1991, they induded target number 14. This target explicitly asks member states to create opportunities to promote health in "all settings of social life and activity, such as the city, the school. 
the workplace, neighbourhood and home". Examples of WHO/EURO projects on settings are Healthy Schools, Healthy Hospitals, Healthy Workplaces, and Healthy Cities (WHO/EURO, 1993; Franken, 1993; WHO/EURO, 1994; Bullow-Hube \& Morisky, 1987; McLeroy et al, 1988 ).

Arguments for taking a city as an example of a setting approach are (see also Hancock, 1990b):

- Many people are living, or are most likely to do so, in a city or urban enwironment. This trend goes hand in hand with specific problems, e.g. housing problems, criminality, unemployment, which may be solvable in themselves, but are quite difficult to address simultaneously (see for developing countries also World Resources, 1996). Collaboration and coordination between all parties inwolved is a prerequisite for coping with the public health consequences of rapid urbanization.

- The city government has a large influence on the living and working conditions of the people.

- The city can be regarded as an entity of its own, with distinct social, environmental, economic, and governmental systems.

- Community participation in policy-making is important to the WHO (see section 1.5. Chapter Three section 3.4, and Chapter Six sub-section 6.4.2). The assumption is that the local level offers the best opportunities for public participation in policy-making, as the 'distance' between local government and community is expected to be relatively small.

- WHO promotes a "setting-based health policy and health programme approach" (see section 1.6), but in some regards is confined by its international character to primary operation at a super-national, super-urban level. The Healthy Cities Project legitimizes and provides a means for the WHO's involvement in local health policy. The connection between WHO and urban health, particularly related to the Healthy Cities Project, has brought WHO esteen and visibility as an organization involved at the ground level.

\subsubsection{History: Public health in cities}

It is not the growth of urbanization per se or the fact that many people in cities live very close to one another that causes health problems (WHO, 1996). Instead, it is the extent to which an adequate overall infrastructure is provided for handling that density which is of relevance. According to Veldheer (1994) it is local government which should be primarily concerned with city problems like density. More specifically, aspects of care, welfare, culture, housing, living circumstances, public domain, public safety, environment, and public health need a municipal government's full attention.

The recognition of a connection between public health and the quality of the urban environment has existed for a long time, as mentioned in the introduction to this chapter Public health problems often originates in city, urban planning, and urban environmentrelated problems such as epidemics caused by polluted water and a lack of sanitation. Modern cities, which grew very rapidly in the beginning of this century due to the mass migrations associated with that time, were hosts to a number of epidemics. Often, people lived very close to each other under quite poor circumstances. Already before the rapid urbanization begun, the Hygienists, a movement of doctors, lawyers, and engineers, pleaded for better general living conditions, sanitary improvements, water regulation and refuse collection as a means to greater health for urban residents (see also Houwaart, 1991). The Hygienists were concerned about the lack of governmental concern for public health. According to them, many health problems were a result of poor or non-existent public policy. The prevention of health problems was seen as needing to take place outside of the health sector, because the etiology of these problems was seen as being applicable at 
a populational, in contrast to an individual, level. Local governments ultimately decided to improve living conditions and took steps toward ciry renewal, though this decision was not primarily inspired by health considerations (see also van Zon, 1991). Historical analysis has given weight to the argument that it was the power of elite groups and individuals in combination with self-interest which actually led to these decisions (see also De Swaan, 1993). The aversion of local government to take on issues related to public health and health care resulted in the fact that private parties took the lead in these fields (see for example Juffermans, 1982; Ashton \& Seymour, 1988).

It is quite striking that the Hygienists movement very much resembles the ideas currently being expressed under the rubric of Healthy Cities. Healthy Cities may be seen in some ways as expressing a renewed interest in public health in a broad sense (Ashton \& Seymour, 1988). Yet it is also true that the present champions of the new public health have a different perspective on health promotion than their colleagues of a century ago. While the Hygienists pleaded for strong government involvement in health promotion interventions, those promoting new public health give the community itself a core place in health promotion. The new public health advocates government action as only one possible result of community decision-making and action processes.

Local governments in the Netherlands have been responsible for public health since the Municipal Law of 1851. For quite some time after the Law's inception, however, cities did not take their tasks in this field very seriously and certainly limited their efforts to care for the poor, who are most often at highest risk for health problems. Due to minimal public effort in the interest of health, private initiatives flourished in the public health sector. In the beginning of the 20th century the first local (medical) public health services came into existence in the Netherlands, though at first only in larger cities ${ }^{12}$ (see also Kerkhoff, 1994). With the exception of some plans after World War II on district health services, it was not until 1986 that a first serious attempt was made to provide a legal framework through the law on Health Care Facilities (WVG [Wet Voorzieningen Gezondheidszorg, MG]) which requested local governments to maintain municipal and district health services. This law, however, has never been implemented. In 1991, the law an Collective Prevention (WCPV [Wet Collectieve Preventie Volksgezondheid, MG]) was created, requiring local governments to have a local public Health Authority "or to be attached to a joint Health Authority shared with other municipalities. These local and common public health author"ties are called GGD"s [Gemeentelijke of Gemeenschappelijke Gezondheids Diensten, MG] (see also Meijer, 1994). The WCPW also contains an implicit requirement that local governments develop local health policy. It appears, however, that most local governments do not know where to begin with the policy mandate (Goumans, 1994; Goumans, 1995).

In the Umited Kingdom, unlike in the Netherlands, local government has no direct legal responsibilities in the public health sector. Nor are local governments asked to develop local health policy. This was not always the case, however. Local governments in the United Kingdorn did have direct responsibilities for public health and health care unil 1948. It was then that the National Health Service (NHS) came into existence (see also appendix 1). The NHS delegates certain responsibilities to regional and district health authorities. These authorities are meant to take care of health care affairs at the local level. However, they are not, as in the Netherlands, under the control of local authorities. The structure of the NHS has been reorganized several times, but none of these reorganizations has altered the fundamental chain of command structure which ties local health care and public health activities to national, centralized, health planning.

It should be noted, however, that in both countries, local government has legal responsibilities with regard to community care, for example through the Community Care Act in 
the United Kingdom and the law on Services for Disabled persons in the Netherlands [Wet Voorzieningen Gehandicapten (WVG)].

This brief historical overview shows that local government in both countries has experience with public health. But their experience is limited and public health seems to be not their favourite policy area. It can therefore be questioned whether the by WHO required formal city council agreement for participation in the WHO Heallhy Cities Project or a national network, can be regarded as a guarantee for health policy development. We will address this question in thesis. But before introducing the research questions, there is an other thing that needs to be explained first, namely what is meant by health policy in this inquiry.

\section{$\overline{1.7}$ Development of a local health pollicy}

There has been great interest in the WHO Healthy Cities Project during the ten years that it has been operational. This shows in the number of conferences and technical and business meetings which have been organized around the theme, the volume of publications which have been written and the demonstration projects which have been developed. It also shows in the increasing number of participating Project cities, from 11 in 1986 to 36 in 1997, and the development of various forms of Healthy Cities networks, at present, over 900 initiatives worldwide. It would be, however, very premature to call the Project a success only in light of these parameters. As, according to Baum, "the erucial elements in understanding the process of change may not be Healthy Cities suctess stories alone." (Baum, 1993 p. 39)

An important aim of the WHO Project is to give health a visible place on the political agenda and to develop a local health policy such as for example through city health plans, (see section 1.3). If policy development is so centrall to the Project, a study of the policy development process should be a key focus of research. What, it might be asked, is the meaning of local health policy in the context of policy development processes?

\subsubsection{Health policy approaches}

Health policy should be explicit attention to the consequences of policy in all sectors with regards to health. Certainly, health policy should be much broader than health care policy, and should be based on a social-ecological model of health. Does such a vision of heaith policy exists currenty? It appears that health policy is used to label many different activities.

According to Belleman (1994) health policy is used to cover health care, health protection, disease prevention and health promotion. Health care policy is aimed at the health care sector and centres around the care and cure for disease. Health protection is aimed at protecting people from exposure to toxic substances and other environmental hazards. (Disease) prevention policy is aimed at the prevention and/or reduction of diseases and public health damage. This policy includes health education interventions, such as antismoking campaigns or AIDS campaigns. What is the meaning of health policy within a health promotion approach?

If it is simplified, within health promotion two approaches to health policy development can be distinguished. One approach begins from a health perspective. Central to this approach is the belief that health problems can only be addressed if contributions are made from different policy sectors. This approach is also known as intersectoral policy making or facet-palicy (see also figure 1.3). A second approach starts from a sectorall perspective. Central to this second approach is that each policy sector should judge its actions, plans, 


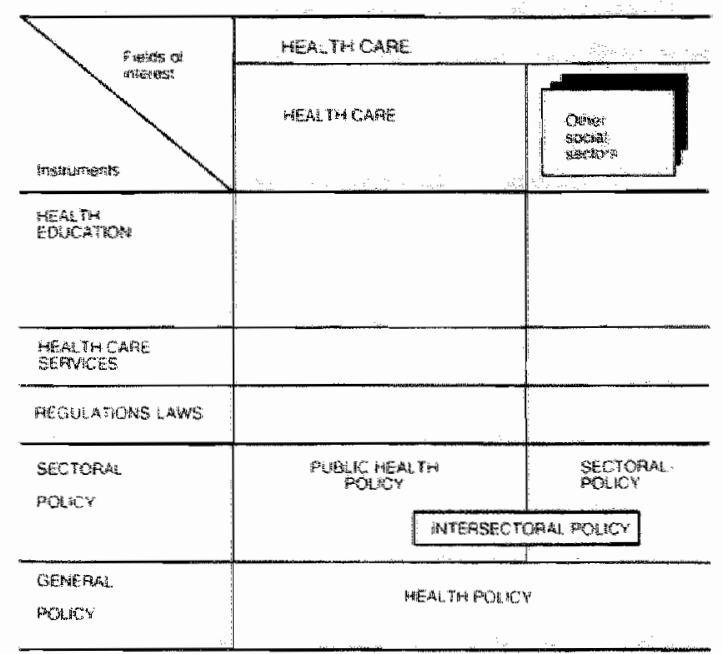

Source: Liedekerken et al.(1990). Effectiveness of Health Education. Utrecht: Lendelijk Centrum voor GVO.

Figure 1.3: A difference between health pollicy, intersectoral policy and public thealth policy.

and policies not only, for example, on economic aspects, but also on possible health consequences. This policy approach has come to be known as a 'healthy public policy' approach, implying that explicit attention for health and equity is given in all policy sectors. In Chapter Three more attention will be paid to this concept.

\subsubsection{Characteristics of health policy}

Hancock (1990, p. 8-9) has listed the following ideal health policy characteristics, which generally represent a healthy public policy approach:

- health policy's consequences are long term as is the underlying vision;

- political commitment is a prerequisite for policy development;

- health policy is created by intersectoral processes and structures;

- public support is necessary;

- development of health policy is a community-driven process;

- health policy represent a broad strategy with various facets;

- credible and skilled initiators and activists are needed for the development of health policy;

- coalitions to create win/win situations must be formed in health policy development;

- health policy implementation implies a cultural shift in organisational management, organisational functioning and policy development;

- health can be used as a vehicle for addressing other issues such as social injustice or environmental issues. It is, however, questionable whether this is true. It appears instead that the relatonship may be the opposite: that environment and social injustice can be used as vehicles for addressing health issues (see as well Ten Dam \& De Leeww, 1993; Fortin et al., 1992). According to Hancock, important characteristics of policy-making at the local level compared with the national or regional level are:

- There is no difference between policy-makers and a policy target group because it is assumed that these policy-makers liwe nearby their work. They will consequently be part of the target group of their own policy. 
- The accessibility of local actors and organizations is expected to be large "due to existing networks and personal contacts among policy-makers and between policy-makers and target group.

- The local level is assumed to be more sensitive to local problems than the national level.

- An active involvement of the local public in policy-making is made possible by delega ting decision-making to the local level.

- Combinations in action and theory are made possible, such as between local policy and activities, global thinking and local action; long term and short term approaches, government and cormmunity activities.

Healthy public policy is a concept whose rather general definition makes it quite capable of being interpreted in a number of ways; this may be its most significant disadvantage. Yet, the generalized applicability implied by its broad mandate is also the power of the concept (see Evers. 1990 p. 200). Despite the broad slogans and rhetoric that surround the concept of healthy public policy and the debate it generates, it is still advantageous that this concept is one which ties the value of health to the flexible emergence of local agendas and policy implementation. Health in "healthy public policy" gives people a rallying theme for motivating to operationalize the value of health in local policy. How Healthy Cities works towards such policy development is a central question posed by the research presented here.

\subsection{Research questions}

Over the years researchers thave raised questions regarding whether the WHO Healthy Cities Project is just another bureaucratic tool (see for example Baum, 1993; Baum, 1995; Kelly, Davies \& Charlton, 1992; Steveson \& Burke, 1991) instead of a social movement that aims for social change and creation of health policy as is argued by Kickbusch (1989b) and Tsouros (1991). Although many concrete projects and activities take place (WHO/EURO/HCPO, 1994b), concern has been expressed that there is a danger that the Healthy Cities Project does not reach further than rhetoric (Goumans \& Springett, 1997). Given the expressed concern, it can be questioned whether Healthy Cities is capable of fostering health policy development, as such development would be a reflection of deeper changes and indicative that a movement may indeed be afoot. The question is also compelling because health policy development, as stated previously, it is an important and explicit aim of the Project.

The purpose of the research presented in this thesis is: To analyze the reaction in cities of two West-European countries to the process of local health policy development, as that process has been proscribed and promoted by the Healthy Cities Project of WHO/EURO.

The leading resenrch question comes from practice, not from theory. It is inspired by the fact that the researcher has been participating in the WHO project and is participating in a research nerwork tied to the WHO Healthy Cities Project related. The leading question "In what way has the WHO Healthy Cities Project, its ideas and principles contributed to the development of local health policy?" is made more concrete in three reseurch questions. First of all, why do cities decide to participate in the WHO Healthy Cities Project and/or to acknowledge and work. according to the Project's leading principles? Does this decision imply a place (attention) for health on the local agenda? Secondly, what is the policy domain of Healthy Cities and local health policy? Which areas are included, what activities are undertaken, and which actors are involved? And thirdly, how are the Healthy Cities processes and key-concepts evaluated by participants? 
In order to find answers to these questions, information has been collected in ten cities that subscribe to the principles and aims of the WHO Healthy Cities Project. Four of these ten cities are currently members of the WHO Project. All ten cities take part in two national Healthy Cities networks. As the information has been collected in two different countries an international comparative component has been included in the research. This component will be explained in the next chapter.

\subsection{How to read this book}

This book is entitled 'Innovations in a Fuzzy Domain' for the following reason.

As will become clear in the subsequent chapters, different things take place under the label of Healthy Cities. Healthy Cities is a broad concept which encompasses a diverse set of activities, approaches, ideas, actors, structures, and strategies. Defining the policy domain by drawing boundaries and deciding what the Healthy Cities activities, actors and structures are, remains a complex task. In cities that are part of a national network of Healthy Cities and/or the WHO Project, local government has pledged itself to work on health promotion in an urban context. Innovation, meaning new and renewed action, in terms of collaboration forms, strategies, and ideas, is needed to accomplish that. It is difficult for researchers and practitioners to come to grips with this rather unclear domain where novelty and innovation are the order of the day.

At the same time, despite these differences, all cities and municipalities are part of the same movement and all can be traced back to the same roots. They are coupled, if loosely so, primarily through a shared rhetoric, origins, principles, and goals. Also, all cities in this research involved in Healthy Cities work on innovative ideas, activities and policymaking .

Mason and Mitroff (1984) and Kingdon (1995) mention in this respect that even messy (highly complex and unstructured) problems, have some kind of inherent or latent structure. Here, an attempt has been made to provide through our research at least some insight into the structure of Healthy Cities policy development.

Within this chapter, the research setting has been introduced. An explanation has been given regarding what the WHO Healthy Cities Project constitutes and what the derived research questions are. The methods that have been used to answer the specific questions will be expounded upon in Chapter Two. Chapter Two also discusses the underlying assumptions of Healthy Cities.

The advent of Healthy Cities within a community brings allong some key-concepts which may be new and unknown to those that are not involved in this Project. In Chapter Three, therefore, a few of the Healthy Cities concepts that are central to this thesis will be explained and illustrated. The empirical research questions, as introduced in section 1.8 , will be elaborated in three chapters which can be read as separate parts. Quotations from interviews have been tabled throughout these three chapters to illustrate and concretize the general messages.

In Chopter Four the focus is on the reasons to participate in Healthy Cities and the position of health on the local (political) agenda. The findings in this chapter have been structured with the aid of an agenda building theory.

In Chapter Five a Healthy Cities domain is unfolded, inspired by theories on policy domain construction. The domain has been defined on the basis of three approaches, namely the actors, the structures, and the activities. 
The central thene in Chapter Six is evaluation of (intended) Healthy Cities processes. Successful implementation of three Healthy Cities key-concepts is evaluated from a participant point of view.

In Chapter Seven, finally, the conclusions of the three empirical chapters will be drawn together and interpreted in the light of the purpose and leading question of the research. What is the (added) contribution of Healthy Cities to policy development for health? 


\section{Chapter

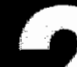 \\ Research framework}

\section{$2.1 \quad$ Introduction}

In the first chapter, an explanation was given of the World Health Organization's approach to Healthy Cities and health policy. Out of this discussion came the research questions and objectives of the inquiry described in this thesis. The purpose in this chapter is to build upon Chapter One's fundamentals by explaining and defending the methodological choices we made subsequent to the identification of the research questions and objectives, as well as to detail how those choices were ultimately put into practice.

Before going into too much detail in regards to methodology, however, it will be important to locate the present research within the scope of academic research conducted sofar in regards to Health Cities. This discussion will be conducted with a critical eye toward some of the underiying assumptions of Healthy Cities. It will then be possible to explain why we assumed a social-interactive policy approach to be an adequate model for analysis of Healthy Cities policy practice, and why we considered a qualitative research design to be the most suitable to the objectives and research questions already discussed. The role of the international comparative element in this design will be further clarified as well. Finally, we will explain how the research population was approached, what sources of evidence were used and how the data have been analyzed. The final section of the chapter concerns the generalisability of the findings of the inquiry.

\subsection{Healthy Cities (policy) research}

In 1992, the WHO Collaborating Centre for Research on Healthy Cities (WHO CC RHC), located in Maastricht, The Netherlands, organized an expert meeting aimed at the establishment of a research agenda for Healthy Cities (de Leeuw et al., 1993). A need was felt to strengthen the dialectical relationship between the Healthy Cities movement and research work in regards to it. The scientific scope and content of the movement required clarification and evaluation. This need made all the more pressing by growing confusion on what Healthy Cities research actually constitutes "Is such research "for", "in" "with", or 'on" Healthy Cities? Or does it cover any research effort at all which claims to be of relevance to Healthy Cities activities? (see also de Leeuw, Breemer ter Stege \& de Jong, 1990; de Leeuw et al., 1993) Figure 2.1 covers the main conclusions of this serninar. The matrix shows the seminar's results, both in terms of the levels and the possible areas of research identified as potentially the most useful and productive. Of course, which elements of this matrix are actually studied is influenced by funders' priorities, the composition of the research team, and political priorities. In turn, these three factors are assumed to be influenced by what the community defines as its needs. From figure 2.1, and from the infor- 


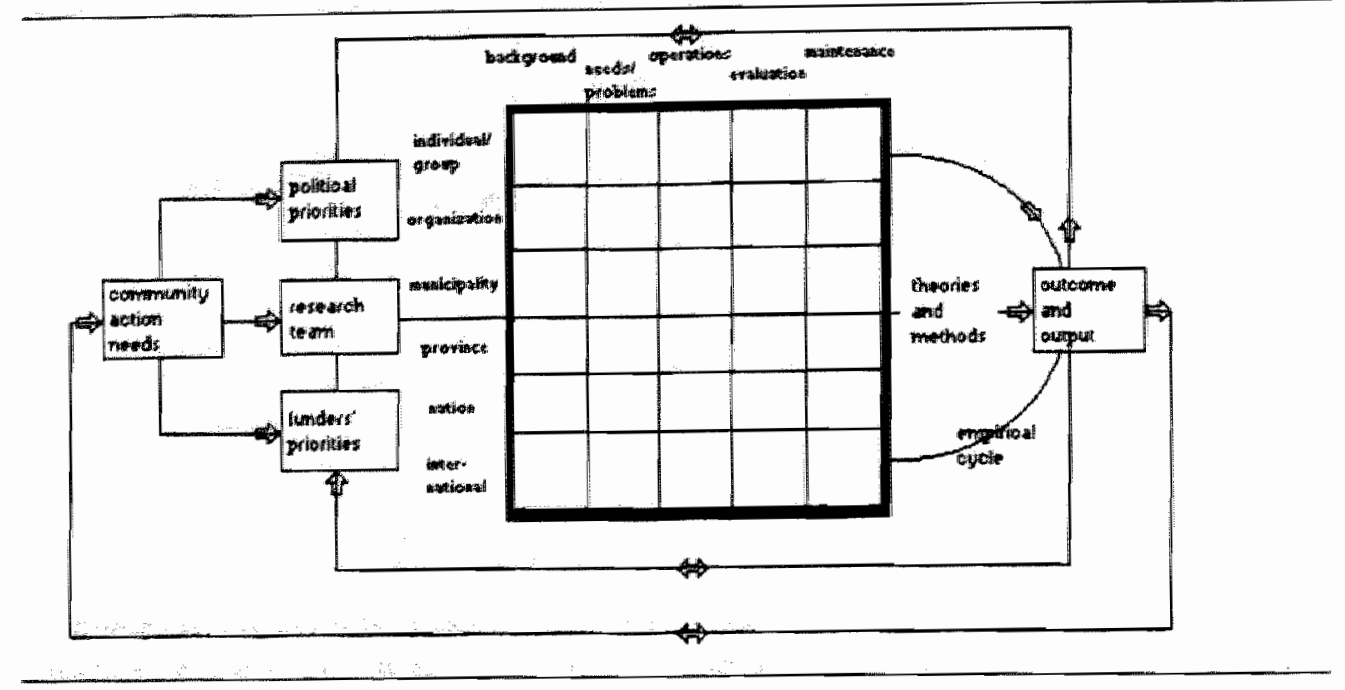

Source: De Lemwiw, E ef al. (1993). Heaithy Cithes Reseorch Agenda. Proceedings of an Expent Panel RHC Monognoph Series nt 2. Manastricht: WHO CC RHC.

Figure 2.1: A framework for research as it applies to the Heaithy Cities projects and movement.

mation provided in the previous chapter, it can be concluded that the Healthy Cities policy research area is difficult to define with any high degree of precision. The question then is how to define the research area so that we can locate the present research within. Our first strategy, therefore, will be to look for guidance in the broader spectrum of all Healthy Cities related research as a means to becoming more detailed in regards to the policy aspects of such research.

While characterized by a diversity in content and purpose, a thorough search reveals that Healthy Cities (academic) research, although growing, is probably still in its infancy. For example, from a survey by the WHO CC RHC in 1992, it appeared that only 40 of the 600 Healthy City Research Newsletter subscribers were involved in research. With regards to the development of local health policy, an analysis of a Healthy Cities research bibliography developed by the WHO CC RHC (over 700 entries from "78-'95) gave 41 entries. Of these 17 were related to preventive policy (alcohol), seven were related to health care changes (insurance), one to health protection policy (noise reduction) and one to Healthy City concepts. A very concrete research addressing both Healthy Cities and local health policy development was carried out by Ten Dam (1997). Unfortunately his work was not yet published by the time the framework for the research presented here was developed.

An analysis of Medline ${ }^{1}$ on this same subject ("83-"96) yielded 11371 entries on health policy and 26 on Healthy Cities. Of these 26 entries, two were related to analysis, three to evaluation, and only eight to health policy. Of these eight entries, two were related to evaJuation, and one to analysis. There was no match found between Healthy Cities and policy research. The combined entries on Healthy Cities and health policy were general descriptive papers on the WHO Healthy Cities Project.

Healthy Cities research can also be found in international journals. Health Promotion Intemational (1986-1996), for example, would be an obvious channel for reporting Healthy Cities research. Numbers if (1) to 11 (1) contain 471 papers. Eighty-eight of them deal with health promotion at the local level. Of these 88 papers, 35 are explicitly related to 
Healthy Cities. These are either general papers on the international Healthy Cities Project or healthy cities movement, descriptive case studies, or evaluation reports of pilot and other types of projects. These case studies deal with elements of Healthy Cities such as community inwolvement, a social health model, geographic information systems, and intersectoral collaboration.

Also available from the WHO CC RHC are a number of Master's theses based on Healthy Cities related research projects. Issues that are dealt with in these reports include, for example, networking, communication strategies, intersectoral collaboration, national networks, implementation studies, and Healthy Cities projects in less developed countries.

Other methods of information gathering used to locate relevant research work were requesting information through the Healthy Cities research network and searching the global Internet on the subject.

A possible breakdown of Healthy Cities related research is traditional health education and health promotion research (see for some examples in WHO/EURO/HCPO, 1994b), non-traditional health education and health promotion research (Ashton, 1991 ; Flynn, Ray \& Rider, 1994; Ten Dam \& de Leeuw, 1993), theoretical research questioning Healthy Cities premises (for example Baum, 1993; Davies \& Kelly, 1992; Nijhuis, 1994), and evaluation research of the movement or its individual projects (see for example Curtice \& McQueen, 1990; Draper et al. 1993; Fortin et al., 1992; WHO/EURO/HCPO, 1993; WHO/EURO/HCPO, 1994b). It can be said that Healthy Cities research takes place at the local, national, and international levels. Generally, it is conducted both by local practitioners and academics.

From the overview of research above, we concluded that very little guidance was likely to be found in research directly related to Healthy Cities which could be of significant help to the development of our inquiry on policy development. "Healthy cities research is thus scarce [ond/or is not much reported on in sources that are available to a larger oudience, MG], scattered over a range of disciplines, much case-oriented and without conceptual consistency." (de Leeuw, O'Neill, Goumans \& de Bruin, 1992 p. 10)

This led us to the idea that perhaps there were useful sources for structuring our inquiry in other fields; and indeed, our broader research uncovered a great deal more. For example, epidemiological research indirectly related to Healthy Cities has been carried out by van Oers (1993) and Reineveld (1995). Epidemiological research is known to inspire policy-makers. It is seen as providing reliable insight. But epidemiological research and policy research are not identical. They start from different roots and work with different theoretical frameworks. Discussions on the relation between policy and (epidemiological) research results are common (see for example Gunning-Schepers, 1992; Van Limbeek, van Alem \& Rengelink, 1992).

Also within the health education field, efforts have been made to promote and carry out (health) policy research (Schwartz, Goodman \& Steckler, 1995). We expect, however, that research and experiences from political and policy scientists and science will provide more innovative and realistic approaches and ideas towards such a research than those suggested by health educators, if not only for the simple reason that policy sciences is still relatively new to most health education training and health education professionals (Voermans, 1996).

Ideas and support for the initiation of research on local health policy are also offered by Milio (1986; 1988), Ziglio (1986), and de Leeuw (1989b). This research, however, has all been conducted at the national level. A compilation of case studies on healthy public policy making is offered by Evers and Trojan (1990). Apart from direct Healthy Citiesrelated policy research or local health policy research, other particular local policy research may also be helpful in developing a research framework. In this respect, research in the 
field of city regeneration or social renewal may be of relevance. The living and working environment of people, important considerations of health promotion, is central to these two activities (see for example, van den Boogaard, 1994; Glasgow city Housing, 1993; Idenburg, 1992; Kense \& Idenburg, 1995).

So far, a brief summary of a literature review on research related to Healthy Cities and local health policy-making has been given. It leads us to the conclusion that Healthy Cities policy research (or even local health policy research) is a field which has hardly been explored. Healthy cities research is a 'container-concept'. It covers many different forms of urban-related, health promotion-based research. Nonetheless, research explicitly aimed at local health policy development in Healthy Cities is scarce.

Given our research questions, the research framework has been inspired by the assumptions of health promotion and Healthy Cities. Furthermore, literature reviews on Healthy Cities and policy science, and prior experience of the researcher in this field have contributed to the creation of this framework. Before we continue with the explanation of the research method, attention will be paid to assumptions related to Healthy Cities (see also Hoogerwerf, 1989; Lehning \& Simonis, 1987) and the policy approach that has been used in this study.

\subsection{Healthy Cities (policy) assumptions}

Healthy Cities is based on certain (causal, final, and normative) assumptions. Such assumptions relate not only to the characteristics of Healthy Cities in terms of its philosophy and practice, but also to the relations between these characteristics (see Hoogerwerf, 1989; Leeuw, 1993; Logghe, 1996; Milewa \& de Leeuw, 1996) 22. The rather abstract model that is presented in figure 2.2 has been developed based on the information sources on Healthy Cities as presented in Chapter One. Figure 2.2 illustrates a possible interpretation of WHO's basic reasoning with regards to the Healchy Cities Project. All cities that are involved in Healthy Cities (activities) would, at least in principle, subscribe to this model. Implementation of the ideas embodied by the model, however, would be and is characterized by local variation. This means that operational models developed at the local level would, in turn, differ from this figure. This phenomenon will be explored and explained throughout this thesis.

In figure 2.2, WHO's starting point is what has been identified as a social model of health. Theoretical grounding for Healthy Cities comes from health promotion, environmental health, and Health for All. On the basis of these, the WHO Project has developed a unique ideology and a number of basic principles. In addition to a supportive ideology, the WHO and the WHO Healthy Cities Project Office have developed strategies, techniques, aims and preconditions. This was done to support participating cities in their efforts to work in the interest of the broader principles upon which Healthy Cities is theoretically based. An important assumption which deserves to be brought to light here is that not only is the following of the Healthy Cities ideology and principles seen as leading to the ultimate goals as expounded by health promotion, envirommental health, and Health For All, but on a more pragmatic level, the following of these principles and ideology is seen as a promising means of putting health on the local agenda. Furthermore, it is expected that, eventually, Healthy Cities efforts will reduce inequalities in health status, while increasing average health status overall. The causal way of reasoning pictured in figure 2.2 suggests a Project development in phases. That practice hardly follows WHO's reasoning as explained in figure 2.2 will appear in the empirical chapters by more concrete descriptions of how the Project's ideas are made operational by individual cities. 


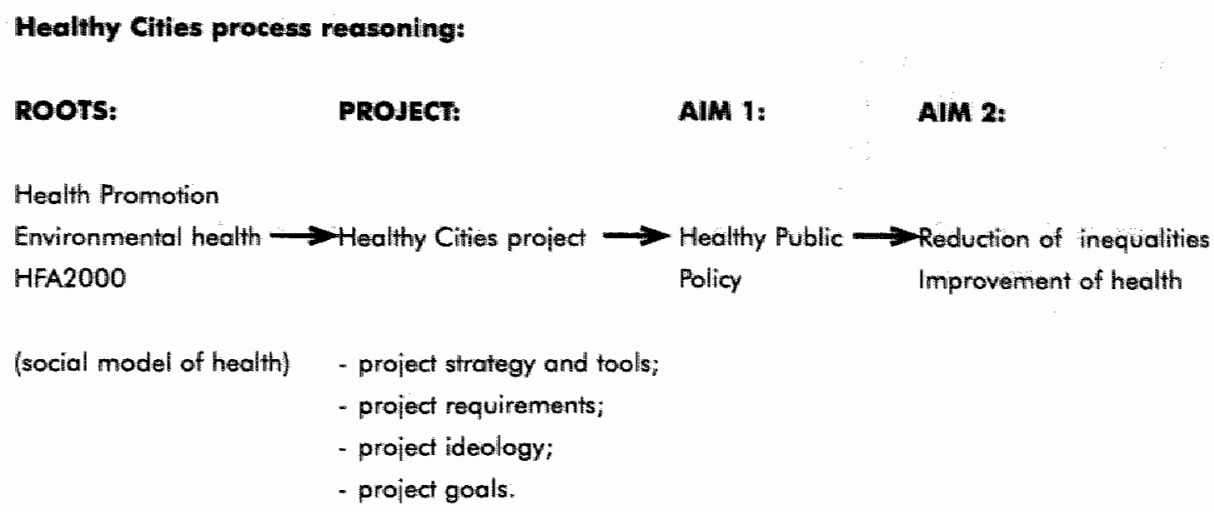

Figure 2.2: Basic reasoning regarding health policy development behind the WHO Healthy Cities Project.

The remaining part of this section scrutinizes some important Healthy Cities assumptions. Some of these assumptions are tied to activities and policy at the local level, such as those in regards to the functioning of the local government and local public health. Other assumptions apply more generally, such as those which concern the importance of health for the community, the necessity or desirability of intersectoral collaboration, and the possibilities for achieving systemic change. An attempt will be made to address the implications of all these assumptions, though only some of them not all, will be included in this inquiry.

\subsubsection{Assumptions about local government and public health}

The WHO Healthy Cities Project is based on the (normative) assumption that local govermment ought to be involved in the public health field. In this respect, the WHO attributes to local government a certain level of competence in the planning and management of public health affairs and a unique capability for solving local problems. The assumption is also made that public health is powerful enough to enter and survive in the local political areno. The question of relevance here is whether this latter consideration is indeed true. Is there, for example, an historical legacy of public health, as a field, being powerful enough to have an impact on local policy-making?

The answer is, in a general sense, no. Since the end of last century, the role of local government in public health affairs has not been overwhelming and has hardly been progressive (see also Chapter One). Can a possible justification for the assumption be drawn from a health sciences perspective? Or is perhaps a public administration or a policy reason available?

WHO assumes local health policy to be inspired by a social thealth model according to which heolth is determined by a diversity of factors. Such an assumption would implicitly argue for local government activities which infuence, or control, these factors. Not everything can be manipulated at the local level, however (see also Hancock, 1990b). For example, mega national and international issues, such as economics, trade, employment, are often difficult to influence at the level of local government. Even if local govermment is perceived as responsible for addressing or solving a given problem, one could hardly argue that this automatically implies they have the authority for doing so.

That local governments may not be authorized to execute certain tasks or that they lack the appropriate competencies for doing so may be used by them as arguments to excuse or justify their reluctance to take on new initiatives in regards to pressing health problems. So 
local governments can deny or run away from responsibilities by legitimizing their passive role as the result of "having no formal authority". In addition, local governmental policies may also be thwarted by central government policy, representing yet another potential confounder in the central assumption that local government should and can effect change.

And what about the implicit assumptions that at the national level the preconditions and general framework are developed for local action and that the local level should in principle be capable of concretizing and talloring (them) to specific needs?" Immediately, we can say that differing political orientation, often expressed in terms of party differences, at Jocal and national government levels can interfere with the validity of this assumption in practice. And such difference do exist in the Netherlands and in the United Kingdom, with a larger diversity and a larger number of political parties in the Netherlands compared to the United Kingdom. Derksen and Korsten (1989) show that local political parties that are represented in the municipal council can be unique to a specific municipality (see also appendix 1). Differences in political make-up between national and local government may cause principle and political problems in implementing national government policies at the local level, or in surmounting limitations to local initiatives imposed by national policy. If there is no fit between national and local policy. Hancock suggests (1990b) legitimizing the development of local (health) policy through participation in an international movement such as Healthy Cities. But even if a city can legitimize its activities from an international perspective, this is of limited use if specific local and national circumstances, whether practical or formal, are not supportive, or worse still, antagonistic. Furthermore, it is assumed that at the local level communication between community, government and organizations is personal, close ond relatively easy to establish. In theory, because the geographic distance between community and local government is simaller than between community and national government, one would expect to see the former link as stronger and more intimate than the latter. This, however, is not always supported by the facts. For example, local election turn-up rates appear to be even lower at the local level than at the national level. The idea that through elections the community influences or is interested in influencing future policy-making at the level of local government is thus somewhat of a misnomer. In practice, it appears that community involvement and interest in local policy-making is minimal and often results in community members becoming informed about mumicipal plans only when they are already at an advanced stage of development (see also Chapter Six; Derksen \& Korsten, 1989). It needs to be mentioned, however, that the issue of public participation in decision-making thas never been taken off the local government's agenda in either the Netherlands or the United Kingdom. In the Netherlands, there are even examples of city councils using community referenda as the basis for the formulation of significant new municipal policymaking initiatives. The mere existence of different opportunities for community participation is, however, not a guarantee that they will be seized; community involveties to make it otherwise (see also creation may remain low regardless of the opportuni-

\subsubsection{Assumptions about community participation and intersectoral collaboration in policy-making}

The WHO also assumes a significant level of involvement of local community in the development and implementation of the public policy processes relation to health. Is it accurate, however, to assume that people are truly willing to work on their personal health promotion? Are people willing to participate in (health) policy-making? From public inquiries it may be conrence for "not health indeed is estimated as important, but it appears that this means a preference for 'not being sick' rather than for pursuing the substantially more ambitious visions 
set forth by the WHO and the new public health movement (see also Fortin et al, 1992) ${ }^{3}$.

Another important assumption is that health policy should be created intersectorally. This assumption includes the idea that both public and private organizations are willing to take responsibility for public health. It also includes the idea that the local government policy arena is willing to include these (new) actors, interest groups and issues. Organizations that are supposed to be involved in public health activities, however, may have difficulties imagining what their role could be $e^{4}$. The majority of them are not acquainted with health promotion models and ideas, and they have difficulties in concretizing these concepts.

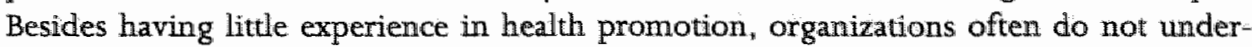
stand or are not political or philosophically able to accept that health promotion activities are high labour intensive in themselves, therefore expensive, and have long-term effects. As a result, health policy development may have a low ranking on the organization's priority list (see also de Leeuw, 1989b). In addition, public sector organizational structures have not traditionally been flexible enough to allow for intersectoral collaboration ${ }^{5}$. For example, a housing director receives budget for housing and will be judged on housing output and not on "health gain". These reasons may explain why organizations and public departments push away responsibilities for health policy development to others, who have enjoyed historical growth or formal responsibilities in the public health and health care sector, such as for example the GGD in the Netherlands (see for example Polman, 1993; see also Chapter Six).

\subsubsection{Assumptions about changeability}

Healthy Cities is also based on the assumption that health, or public health, is important enough for individuals, groups, arganizations and authorities to redirect existing practices accordingly. Changing practices involves changes in thinking, acting, and structuring, and therefore implies political, organizational, and social change. It also calls for a change in policy. The possibilities and the assurned willingness for change will inevitably be disputed by parties who have a vested interest in the status quo, or by those who are simply afraid of the uncertainty change brings.

Changing public policy is notoriously difficult and given a general reluctance towards change (Siler-Wells, 1987) policy maintenance is more the norm than policy change (Pettigrew, 1993). If policy change takes place, it usually does so, especially at the local level "by incremental steps (Nocan, 1989 in Curtis \& Taket, 1996 p. 204). Ideas about changes are also offered by Levy and Merry (1986). They distinguish between first-order change which consists of minor adjustments that do not change the core of an organisation, and second-order change which they describe as 'a multidimensional, multilevel, qualitative, discontinuous, radical, organizational change involving a paradigmatic shift". In other words, such a change is assumed to be dramatic and visible.

What role these assumptions play in practice will appear throughout the following chapters. In the following section, we will address the question of which policy analysis approach was chosen as the most appropriate for analyzing the policy development processes witnessed in the case studies, as well as why this was the case.

\subsection{Policy approach}

Our aim here is to analyze and understand how local health policy is developed in Healthy Cities. From an international perspective, such as that of the World Health Organization. the research described in this thesis may be considered an implementation study of 
Healthy Cities principles in terms of how successful they have been when put into practice (see Chapter One). From a local perspective, however, it is quite simplistic to consider the many complexities of participants" involvement in Healthy Cities as "implementation of principles. Healthy Cities generates new processes and influences ongoing activities in unique ways in all local milieux in which it is "implemented." Existing policy may therefore be as important as the new policy which is initiated in the name of Healthy Cities or a related initiative.6.

Which policy analysis approach could be expected to be an enlightening tool in looking at processes of local health policy development? Teisman (1992) distinguishes three perspectives to policy: (1) a uni-centralized perspective, (2) a multi-centralized perspective, and (3) a pluri-centralized perspective.

(1) In a uni-centralized perspective, it is assumed that policy is formed through sequential, rational decision making e.g. a rational model (Simon, 1957; Allison, 1971; Hoogerwerf, 1989). It is assumed that policy steers processes in certain, consciously determined directions. Characteristics of such policy approaches are, among other things, that a central actor such as a government gathers relevant information, and on that basis makes, enforces, and evaluates policy. Although many different actors are assumed to be involved, all of these act in a rational way and in the end recognize the authority of resulting rules or regulations. In the case of Healthy Cities, such a policy approach would be useful in analyzing how local government implements Healthy Cities as they are guided in doing so through WHO's instructions and decisions. Evaluation of Healthy Cities and policy development would then be carried out in accordance with the official WHO Project goals.

Both the pluri-centralized and the multi-centralized perspective to policy development implicitly argue that, unlike the uni-centralized perspective on policy development which seems to believe policy-making is conducted in a rational universe, policy-making is not an organized and rational decision-making process based on comprehensive, scientifically validated information with clear and consciously formulated goals. Proponents of these approaches see policy-making as an interactive negotiation process, e.g. an interaction model (Kingdon, 1995; Laumann \& Knoke, 1987). This process also involves a range of actors having competing interests, but in this case it is exactly the diversity of these actors which influence the questions addressed by, and nature of, resulting policy and its enforcement. The varying actors, all with unique goals and, more importantly, distinct value-systems, are linked together through a network of activities, decisions, (past) experiences, and motivations (Considine, 1995). It is only through a process of interaction, negotiation, and decision-making between these actors that policy is developed. Policy is not only developed through the outcomes of negotiation processes, however, but is also assumed to be heavily influence during subsequent processes of implementation. Therefore, it can be said that policy is assumed to be formed while implemented.

(2) Competition between actors is a central theme in a multi-centralized perspective to policy development. All actors have their own goals which they try to achieve in the negotiation process. The role of the central government is seen as a minimal, facilitative one. Evaluation research in regards to Healthy Cities efforts which is based on this approach would take place at the city level. Its aim would be to identify and characterize the relative success of various actors with regards to the achievement of their personal or organizational goals and the impact of this upon the local implementation of Healthy Cities.

(3) In a pluri-centralized perspective, goals are seen as being set through an interactive process within a network of local and national participants. Policy goals, as with the multicentralized perspective, are not seen as fixed. These change throughout the interactive
process and do so in a dialectic process and do so in a dialectic manner which changes over time in the preferences, ideas, 


\begin{tabular}{|c|c|c|}
\hline Approach & Rational model & Interaction model \\
\hline \multicolumn{3}{|l|}{$\begin{array}{l}\text { Dimension } \\
\text { pon }\end{array}$} \\
\hline Actors & - central actor (governmentall) & - variety of actors \\
\hline \multirow[t]{2}{*}{ Processes } & $\begin{array}{l}\text { - phases (palicy formulation, } \\
\text { decision, implementation) } \\
\text { - guided by a priori }\end{array}$ & $\begin{array}{l}\text { - conflicting interests and problem } \\
\text { definition }\end{array}$ \\
\hline & formulated gools & - highly dynamic and unprodictable \\
\hline Decisions & $\begin{array}{l}\text { - choosing the best altemative } \\
\text { (minimising cosit } \\
\text { maximising benifits) }\end{array}$ & $\begin{array}{l}\text { - choosing alternatives which } \\
\text { generate support and which can } \\
\text { be linked to problems }\end{array}$ \\
\hline Power & - centralized (central actor) & - divided (many actors) \\
\hline Information/values & $\begin{array}{l}\text { - information obtainable } \\
\text { - values given } \\
\text { (goals of central actor) }\end{array}$ & $\begin{array}{l}\text { - information dispersed and } \\
\text { ambiguous } \\
\text { - values conflicting and unclear }\end{array}$ \\
\hline
\end{tabular}

Source: adapted from Klijn, E. [1994]. Policy Networks: an owerwiew: Rotterdam/Leiden: Erosmus Uniwersiteit \& Rijksuniversiteit Leiden.

and envisioned possibilities of the participants concerned. The results of these processes are seen as highly unpredictable, as they are dependent on the identity, interests, and alignment of the participants involved. With regards to Healthy Cities, such a perspective would acknowledge that the local network in a city is composed of local, national, and international participants, all of whose interests are important to the final policy outcome, and to its implementation.

It seems reasonable then that, given the multitude of possible actors that can be involved in Healthy Cities and local health policy development (see Chapter One), the current research follows a pluri-central perspective on policy. This is an approach which can be further characterized as social-interactive (see also table 2.1). Examples that are based upon an interactive policy approach are, for example, policy network models (Hufen \& Ringeling, 1990; Klijn, 1994; Klijn \& Teisman, 1992; Marin \& Mayntz, 1991), the policy arena model (Koppenjan, 1993), or the policy stream model (Kingdon, 1995)? Characteristic of this approach is a multitude of actors, assumed complexity in the nature of actors relationships and interests, and a dynamic, unpredictable process of negotiation. Table 2.1 provides a comparison between a rational and an interactive policy approach.

Given our currently available knowledge of Healthy Cities, an interactive approach seems likely to best apply to the process of local health policy in connection with Healthy Cities initiatives. The model also seems particularly well suited to elucidating differences. among the ten localities which were included in the study addressed by this thesis. Healthy Cities, after all, claims to exclude no sector or actor from participation in the process of policy development. There are many potential actors with at least as many ideas 
and goals, as well as negotiation and interaction possibilities and capacities. Potential actors in local policy development will be identified in Chapter Five. The WHO Healthy Cities Project provides these actors with guidelines for health policy development and project actiwities through its promotion of warious ideas and principles, as has been shown in Chapter One. WHO thereby also becomes an actor in the process, of course. Each of these ideas and principles, however, needs local interpretation in order to make it concrete and operational. This interpretative process, based primarily in dialogue at the local level, results in local differences in the processes and outcomes of policy development. Despite the fact that we know who might be involved at the local level, and according to what general ideas they would work if they become involved, we are not able to predict, ultimately, which actors will be involved in any given locality or to what degree they will do so. Nor do we know how these actors will interact or how they will individually or collectively interpret the Healthy Cities ideas. On a more general or abstract level, however, despite the vast variation in possible local approaches to the implementation of Healthy Cities, we hope to demonstrate that it is possible to define a framework for the comparison of unique local health problems and the development of Healthy Cities efforts to address them.

The theories that are used to structure and analyse the research findings may seem rather eclectic upon a first review. They are not as diverse at it may seem, however. All have been selected based on correspondence with an interactive policy approach. Furthermore they seem the tools which most powerful reveal the significance of the findings presented here. In fact, the presentation of the research findings demonstrates quite clearly why an interactive approach to policy development suits the Healthy Cities practice.

It is not argued that the findings and relations regarding local health policy development that are presented in the following chapters are the only possible relations deserving attention. But they are the relations that appeared to be of importance in this particular research setting.

\subsection{The method}

The present research is a qualitative, multiple, explorative case study with descriptive and analytical, and some evaluatiwe, components (Stake, 1994; Yin, 1990). "Qualitative cose study is characterized by the main researcher spending substantial time, on site, personally in contact with activities and operations of the case, reflecting, revising meanings of what is going on." (Stake, 1994 p. 242)

The researcher tries to undlerstand why and how it is that a certain phenomenon occurs as it does, and this implies researching a particular phenomenon in terms of the meaning it assumes within its context (Yin, 1990). In a case study research design, the researcher investigates one or more cases thoroughly by focusing on what has been called their complexity, or non-linear dynamics, both terms used to describe the web of cause-and-effect interactions which take place among significant actors within a particular social and work
environment.

A qualitative research methodology was chosen in this study because the nature of the problems and questions addressed required in-depth, contextual appraisal of human and organizational interaction. The traditional choice between a qualitative and quantitative research method was in this case never a matter of contention, if only for the simple reason that quantitative research would have been a fundamentally inappropriate tool for gaining the kind of insight sought here. Additionally, in this case both the research 
domain and its related concepts were vague prior to beginning the research. It is impossible to measure something concretely if where and what to measure are unclear. Here, therefore, an attempt is made to understand and describe the perceived relevance of the Healthy Cities Project to local health policy development:

Likewise, we have chosen to use a case study method because this was also best suited to the defined questions and purposes of the research. Additionally, using case studies provided boundaries to the research environment, and in some ways to the domain of the research itself. Multiple cases -as opposed to a single case- were chosen based on the assumption that something is to be learned from them in a dialectic fashion in understanding local health policy-making. Additional arguments that supported the choice for a case study design are that Healthy Cities documentation is fragmented and case oriented, and the difference between the cities working according to Healthy Cities were expected to be large. In terms put forth by Rogers (1995) it can be argued that most cities are still, in terms of the so-called 'innovation curve," in the position of "early adopters'. Essentially, this means that Healthy Cities is not yet part of mainstream politics or public policy. This, then, explains the explorative character of the inquiry.

Figures, which are hardly available, are generally not very revealing regarding health policy-making in the different municipalities. In order to learn why and how policy is developed, it is necessary to hear and see what is happening. What processes take place and how are these evaluated by those involved? Therefore the researcher needs to enter the research setting in order to experience the situation first-hand, and to listen and talk with those involved at the time of their involvement (cf. Hammersly \& Atkinson, 1991).

Komter (1983) attempts to explain why it is not only the content of the subject under study (the research question or knowledge of the field), but also the perspective on social reality that plays a role in choosing a research method. Are people rationally reasoning actors, who are therefore predictable and explainable, or is each actor to some extent quite unique within each situation? More critical streams in social science stress the inconsistencies, changeability, history, and activities of people. In addition to displaying varied behaviour in highly similar situations, such streams emphasize that people are likely to state different reasons to explain and legitimize their behaviour (see also Schwartz \& Jacobs, 1979).

Due, then, to the content and complexity of the issue under discussion, the present research fits, with an interpretive research paradigm. Interpretive research is based on interactive processes, multiple layers of reality, and interrelatedness, and aims for variety and differences (see also Denzin \& Lincoln, 1994; Mason \& Mitroff, 1984; Mitroff \& Enshoff, $1979)^{9}$. It is acknowledged that although the researcher is committed to this research paradigm and aims to let the cases tell the story, "it is the researcher who decides what is the case's awn story, or at least what of the case's own stary she will report. More will be pursued than was volunteered. Less will be reported than was leamed." (Stake, 1994 p. 240)

\subsection{International comparison}

Comparative research is interested in comparing different issues, situations, cases, organizations, etcetera with each other against the background of given theoretical or practical criteria. It is expected that differences and/or similarities will be found which will lead to increased understanding and insight of the elements under study. In international compa rative research, the researcher complicates the comparison by introducing an extra dimen- 
sion, namely the question of whether elements that can be attributed to national characteristics or culture influence the outcome. A researcher engaged in international comparative resiearch is therefore inevitably compelled to confront the question "can differences or similarities in project implementation be contributed to country specific characteristics or not?"

What are the mosit common reasons for designing an international comparative research project? Antal, Dierkes and Weiler ((1987) in Korsten et al., 1995) mention three purposes. A first reason is to pursue a theoretical interest in developing concepts and generalisations that are currently applicable to or valid for all societies, at the one extreme, and for a specific community of cultures or nations, at the other extreme. A second is to generate knowledge on bow different countries cope with similar problems. Particularly effective strategies for dealing with certain universally-experienced problems may be detected. The conditions under which policy-makers may adopt policy alternatives from other countries might be specified. A third reason for doing research with an international comparative character is that problems are likely to transcend borders such as for example, drug smuggling or air pollution. Not only internal problems, but the policies of other countries may influence a nation's policy. It can therefore be quite useful and relevant to have comparable data on subjects, policies, and problems from different countries in order to formulate, for example, joint approaches to problems of mutuall concern.

This investigation is mostly revealing of the second advantage because it supports the exchange of information in regards to the similar problem of developing Healthy Cities efforts and the institutionalization of those efforts in local health policy development. The reason for involving two countries in this research was the desire to address the hypothesis that working on Healthy Cities would not so much be influenced by national standards as it was by differing local situations. In other words, the assumption was that the variation between cities, regardless of country, would be larger than the variation between countries. In more concrete terms, it was hypothesized that it was not so much the national characteristics but local circumstances and practices which are important in predicting whether and how a local health policy will be developed. Efforts are made throughout the empirical chapters to evaluate this expectation with data which generally confirm its validity. This assumption implies for Healthy Cities as a large international movernent not that (inter)national guidelines are superfluous but that local variety is its most intrinsic and defining characteristic.

Ii was decided not to first detect country characteristics that would be tested on their explanatory power with regards to the 'success' of local health policy development. Instead, the starting point was a focus on local practices. National elements were brought in where they were considered to be appropriate. Such de-emphasis was given to "national characteristics" because, generally, these are so common and general that their relation to the underlying research in specific terms is sketchy at best. Though countries are indeed the "context' of research, the prime interest here is in smaller entities, individuals, and organizations in localities (cities and mumicipalities). As data have been collected at the individual level, it would not at all be wise to generalize them to a national level (see also Hofstede, 1995). It is clear from previous research experience that when results are aggregated, mistakes are easily madle. Differences between individuals and organisations are easilly confused with, or attributed to, differences between countries. Hofstede (1995) has called this the 'fallacy of the wrong level'.

It is therefore not assumed here that it is possible to compare 'the Netherlands" and "the United Kingdom'. It is, however, assumed to be possible and legitimate to show differences at the local level between cities that are located in two different countries. However, it is the intention here that, if these differences can or must be attributed to country specific, 
both national and local, characteristics, this will be mentioned. The expectation, however, as aforementioned, is that this is not usually the most revealing or legitimate analytical approach.

The United Kingdom and The Netherlands were selected for accessibility of data, their involvement in the WHO Project, and due to the differences in their health systems and in the admimistrative organization of their governments (see also appendix 1).

Due to differences in the health systems and the administrative organization of (local) governments between the two countries (see appendix 1), the working environment and responsibilities of the Dutch and British actors inwolved in the research were not similar by definition. Furthermore, there is also a difference in language, Dutch and English. Concept validity, a shared interpretation of a concept (word) by all actors involved in the research, is therefore estimated as weak. Even within one country, or within one city, the concept walidity between different sectors may be low. Although people use the same words, they do not tend to speak a 'similar language'. They contribute different meanings to the words they use. At the same time, they are all joined by a shared WHO and WHO Healthy Cities language.

There may be a danger of "ethnocentric bias" as well. The researcher is not equally acquainted with both nations and the research was first set up and tested in the Netherlands. Ethnocentric bias means "being more confident with the country of residence than with the other country involved in the research'. In this case, such bias may originate in the facts that the researcher has no established networks or contacts in the United Kingdom, is better acquainted with the Dutch language than with the English, and is inevitably less familiar with the national and local customs of the United Kingdom than those of the Netherlands. One strategy for limiting these problems is to live in the unknown country for some time and start to develop contacts, both professionally and socially. This strategy has been followed to some extent with respect to this inquiry: the researcher lived in the United Kingdom for a period of ten weeks.

\section{$\overline{2.7}$ Research population, sources of evidence, and data analysis}

\section{Research population}

The sample of ten cities has been selected by virtue of the cities' performance and visibility as Healthy Cities and the amount of time that the cities had dedicated to the initiative. Being involved in Healthy Cities, either in a national network and/or in the WHO Project, was seen as an indicator for willingness and efforts to develop health policy.

Selection criteria included:

- membership in, or involvement in, the WHO Healthy Cities Project and/or national network of Healthy Cities. In order to participate in the WHO Project and/or a national network an official city declaration is needed. This city declaration must be endorsed and signed by the Lord Mayor and an official representative of the city council, expressing the political will to work on health promotion in the city.

- at least three years (or more) experience with Healthy Cities principles. It takes some time to get acquainted with what Healthy Cities means. It also takes time to develop ideas and approaches on how to integrate Healthy Cities principles within a specific locality and to test them in demonstration projects. It is not realistic to expect cities that are involved in Healthy Cities only for a short period to already have clear thoughts regarding the resulting discussion or initiatives, let alone to have developed a supportive 
healih policy. And policy development, after all, is the central theme of this research. evidence that the city or municipality is working or is willing to work according to Healthy Cities principles. This criterion relates to the first. But an official statement alone does not make a Healthy City. Making the consequences of this statement visible for outsiders such as the researcher through development of projects, setting up structures, and hiring new staff and/or giving people explicit responsibilities regarding Healthy Cities, for example, was seen as expressing a willingness to work on Healthy Cities:

- recognition by other network members as a 'Healthy City' and/or mentioned by peers as "an example of good practice". It is thereby assumed that cities/mumicipalities that are involved in Healthy Cities and who are active at the program's forefront, which means they are estimated by others involved in Healthy Cities as 'very active and visible', are expected to have developed a (clear) idea of where to go, why to go there, and how to proceed with regards to health policy development.

As Healthy Cities research and practice are in a rather preliminary stage, focusing on 'examplles of good practice' seemed the most obvious way of finding aruswers to the research questions.

There was no direct interest in comparing large and small (scale) cities, or cities with differences in socio-economic or health status. It was also not the purpose to compare 'Healthy Cities' with 'non-Healthy Cities'. This research happened to be one of the first that focused on local health policy-making in Healthy Cities, and the prime idea was to focus on diversity among the cities in this respect. What different examples could be found and what could be learned from cities that are considered, by those involved in the Healthy Cities movement, as 'innovative' and 'examples of good practice'? Finally, the cities were not selected because they form a representative sample. They were selected because they were (said to be) 'promising' and were expected to show a local variety (heterogeneity) in approaches to health policy-making. These selection criteria are derived from van der Zee (1983) who distinguishes four ways of case sample selection: representativeness, heterogeneity, fairness, and legitimacy [representativiteit, heterogeniteit, veelbelovendheid en legitimiteit, $\mathrm{MG}$ ]. At an abstract level however efforts will be made to generate analytical generalizations based on this variety (see section 2.8 ).

The coordination centres of the national networks. who have lists of 'members' of the network and personal involvement of the researcher in Healthy Cities since 1990"0 served as a starting point for selecting the cities. First, a general selection took place based on reports of projects, minutes of meetings, and booklets on the several national network and WHO Project cities as available in the two coordination centres and as sent on request of the researcher by the cilies. Subsequent to this preliminary selection, cities were further culled. In the Netherlands, the WHO Project cities were selected first, and the other three cities were selected based on geographical diversity. In the United Kingdom, two of the three WHO Project cities showed interest in participating in the research 11 . The three other cities were selected based on geographical diversity. Although this was not an explicit selection criterion, the non-WHO Project cities differ in city size, resulting in each country in two large and one relatively small city.

As it is in qualitative research not the quantity of cases but their quality that is decisive in the data collection and analysis, a limit has been set at ten cities. This amount is large enough to make comparisons and small enough to analyse them all with the same intensity required. As explained there was chosen to compare local variety between localities in different countries because it was expected to provide additional benefit to the research. The minimum requirement for comparison is two countries. The decision of two countries 
was made because two is enough for the purpose of our research and two is not too much for still being able to work with the selected research method.

\section{Sources of evidence}

Data have been derived from three information sources, namely interviews, participation and site visits, and secondary information sources.

Interviews. Key-informant interviews took place in the United Kingdom from March through July, 1994, and in the Netherlands from March through August, 1993. A checkup has been carried out in the Netherlands between January and February of 1995. It is not only the local government, but any actor that can be regarded as a key-informant regarding local health policy development who was considered eligible to be interviewed. In Chapter One it was shown that any actor can be involved in health policy-making. In this research key-informants have been selected based on their personal or professional strong involvement in Healthy cities or on their strong political involvement in or responsibility for local health policy. This has resulted in a sample of $60 \mathrm{key}$ informants, all of whom clearly show an interest in, and/or have a clear opinion about, the relative possibilities for local health policy development and the role of Healthy Cities in that respect ${ }^{12}$. The key-informants were found based on a snowball sampling method. Healthy City coor* dinators or responsible persons were contacted by telephone and in writing. They were introduced to the purpose of the research and were asked for their cooperation. Through them, and with the assistance of those already approached, other relevant key-actors could be identified and approached.

Formall 13 key-informants $\left(n=60^{14}\right.$ ) were: politicians (responsible for public health: Alderman, city council member, or member of regional council) $(n=12)$, assistants to Alderman $(n=2)$, assistant chief executive of city administration $(n=1)$, assistants to chiefexecutive of the city administration $(n=2)$, directors of public health of the Health Authority (HA) $(n=4)$, director of planning HA $(n=1)$, directors of the municipal (or common) public health service (GGD) $(n=5)$, directors of social affairs local authorities (LA) $(n=2)$, head environmental health department LA $(n=1)$, heads of a health promotion department HA $(n=2)$, director of a private company $(n=1)$, senior environmental health officers LA $(n=2)$, health policy officer HA $(n=1)$, assistant to politician $(n=1)$, National Health Service development worker LA $(n=1)$, researcher $(n=1)$, health promotion officers $H A(n=2)$, public health officers $H A(n=2)$, social service officer $L A(n=1)$, housing officer $\mathbb{L A}(n=\mathbb{1})$. Healthy City coordinators/responsible persons ( $n=10)$ and team members $(n=3)$, (demo) project officers/coordinators/volunteers $(n=5)$.

The interviews followed a semi-structured list (see appendix 2 ) that was piloted in five cities in the Netherlands (Goumans, Kruijff \& Wevers, 1993). The interview list proved to be adequate for our purposes. A point of concern, however, could be its length. This list was adapted to the United Kingdom situation with the aid of staff of the Liverpool John Moores University " the UKHFA coordinator, and through a pillot interview in the United Kingdom. Adaptation was needed in terms of the formulation (and translation) of interview questions. In the Netherlands, no major adaptions were needed after the pilot.

The interviews were the main source of information in assessing the key informants' opinions regarding Healthy Cities as an initiative and its (estimated) impact on their local health policy development ${ }^{15}$.

Participation and site wisits. In the Netherlands, the researcher participated in meetings of the national network of Healthy Cities. The researcher lives in the Netherlands and is professionally involved in the national Healthy Cities network and research. That is why she had the opportunity to collect information through informal channels and ad-hoc meetings. In one 
city in the United Kingdom, the researcher was able to attend a management group meeting and a genterl public health form. The researcher also had the opportunity to visit two demonstration projects in the United Kingdom. When collecting information in the United Kingdom, the researcher spent about one week in each cities' project office. She had the opportunity to observe and participate in the daily working processes of the project teams.

Other (secondary) informotion sources. From all cities over hundred reports of activities, such as seminars, conferences and workshops, and descriptive reports and evaluations of demonstration projects were collected and analyzed. In addition, in the United Kingdom cities four years of minutes of local project team and steering committee meetings were studied. This information provided insight into the generall background of the development of Healthy Cities initiatives within the specific locality. It also included information about the project structures that had been set up, strategies that had been chosen (and used), and discussions that had been going on regarding 'how to go about implementing the Healthy Cities principles'. A check of two years of minutes of city council meetings in three cities provided insight into the way public health issues were or were not being discussed in these meetings. Furthermore, a more general literature review, as presented in Chapters One and Two, provided information related to health policy development and research, as well as to Healthy Cities.

\section{Data amalysis}

The interviews described above were recorded on tape and transcribed in full. Analysis of the data took place on the basis of these transcriptions.

In a first general analysis of the interviews, the purpose was to detect key concepts and sub-categories within these key-concepts. We thereby made use of the guidelines, techniques and examples, such as drawing, highlighting, creating boxes, as provided by Silverman (1993) and Maso (1989). Based on these key-concepts and research questions, the decision was made to conduct a thorough analysis of the interviews, guided by policy theories. It was decided that the most appropriate analytical theory combination would be a discriminating theory from the agenda building realm, a theory from the policy domain area, and a theory from the policy process evaluation area. The theories are rooted, to some extent, in an interactive perspective on policy, and generally do not reject fundamentally the idea of strategically reasoning actors. Between these theories there are differences in the extent to which and nature of how actors are allowed to steer or to specificalily influence society.

The analysis of data has resulted in six main focus points related to the research questions which are discussed in three empirical chapters in this thesis. These focus points are:

- support style (Chapters Four and Five)

- support platform (Chapters Five and Six)

- integration into (existing) structures (Chapter Five)

- integration of paradigm (Chapter Five)

- conceptualization of Healthy Cities (Chapters Four and Five)

- evaluation of Healthy Cities key-concepts (Chapter Six)

The other data sources have been used mainly for clarification, better understanding, and illustration of the above mentioned focus points.

A last remark that needs to be made is in regards to the issue of generalization. What expectations can be based and which benefits have the results of this research for those who are deciding on their involvement in Healthy Cities and local policy-making with a
focus on health? 


\subsection{Generalization}

Representative case studies do not exist, acconding to $\operatorname{Yin}(1990)$. There is no set of case studies which can overcome the difficulty of generating generalizing results from one case study research to a larger population or to an other case study. His solution to this problem is to focus on analytical generalization instead of statistical generalization.

Statistical generdization means that within a certain confidence level the results of the investigation are applicable to a larger population. If case study results support a previously developed theory or propositions, or if a (preliminary) theory can be constructed based on case study findings, this has been called analytical generalization. The experiences from one or multiple cases are used to discuss more general theoretical issues. The research report is consequently based on these general issues and illustrated by the experiences of the particular case studies. In the interest of providing for analytical generalization, this is the manner in which this thesis has been constructed.

Mitroff and Turoff (1973) provide a more theoretical explanation to this aspect of generalization. They recognize that people want to use what has been learned in one situation, in this case in regards to local health policy development through Healthy Cities, in a future situations. "A good forecaster should therefore be a good historion." (Mitroff \& Turoff, 1973 p. 71) Mitroff and Turoff show that the different "forecasting methodologies" based on what has been learned in the past are grounded in a certain "image of reality". Not only the methodologies but also the researcher hold a certain image of reality, although often denied or not explicitly mentioned. Based on these images, different questions are at stake in the different methodologies 16 .

Although all cities work with similar principles and ideas, this inquiry emphasizes local variety. The limited possibilities for generalization are not a question of 'valid' or 'false'; rather, they are the result of doing research based on a certain tradition. Our research would in that respect fit with a Kantian- and Singerian-based methodology ${ }^{7}$. Characteristic is that many alternatives are shown and that predictive power is low.

How do these explanations concretely relate to this inquiry? No single case studies are presented. Instead, the thesis synthesises the lessons learned from the multiple case studies, when taken as a whole. Case study parts are used as evidence and illustration of the issues and mechanisms that are presented in the following four chapters. A "Healthy Cities health policy cookbook' is not provided. What is offered are elements and mechanisms and suggestions for use. The ambition of the investigation is that the results are perceived as relevant by those involved in local health policy-making and Healthy Cities (cf. Patton (1978) who emphasises the importance of perceived relevance of research results by the target audience). The target group of this thesis are hopefully offered new or different perspec tives on their current and future work through the presentation of general mechanisms and elements critical to the process of Healthy Cities and health policy development and for which the case studies are illustrative examples.

Based on our research results, we make an effort to show in Chapters Four, Five, and Six both this local wariety and the general theoretical elements and mechanisms in working with Healthy Cities towards health policy development. 


\section{Chapter Rhetorical strength \\ and scientific evidence}

\section{Experience with the key-concepts of Healthy Cities}

\subsection{Introduction}

The Healthy Cities Project was developed on the basis af a number of key concepts. Some of these concepts were quite new when the WHO Healthy Cities Project began, or were at least new in the way they were applied to the health sector. It was thus difficult for many people to grapple with how one could best work with or implement them. Additionally, the fundamental concepts of Healthy Cities were for the most part not introduced on the basis of their scientific validity. Rather they were used because they fit in with the WHO's HFA2000 strategy and programmes, and because they were believed to embody sufficient rhetorical strength to mobilize cities to take action in the interest of population health.

This chapter contains an analysis of research findings on concepts central to the Healthy Cities Project. Of course, not all concepts important to the Healthy Cities Project are central to the main questions of concern in this thesis, so the analysis here will be limited to those which fall under the broad rubrics of healthy public policy and participation. Participation is here divided into the three categories of political, organizational, and community participation. Whether and how all of these concepts are used in practice was also investigated, and these findings are presented in Chapters Four, Five; and Six.

There are several reasons why this chapter has been included in the thesis. First of all, it seems important to provide those not familiar with health promotion rhetoric with more insight into the specific scientific meanings of given terms and the context in which they are used. Another objective is to reveal how, at the start of the Project when there was not yet much experience with implementing what were seen as the most compelling concepts, visionary rhetoric won out over scientific based evidence. It appears, however, that in the years since the insight, knowledge, and experience on these concepts has grown considerably, as has the consideration of their scientific foundations. Thirdly "there was an interest in identifying through the present research and already existing experience of the author the nature and operationall characteristics of the concepts which are taken to be at the heart of the Healthy Cities Project. Having such information will provide the opportunity later on in the thesis for creative reflection on the research findings presented. It is however not our ambition to strive for completeness. This would be a too large undertaking in this research which aim is first and foremost to focus on policy development.

First, the most central Healthy City concepts are listed. In subsequent paragraphs atten tion is given to community participation, intersectorall collaboration, political commitment, and healthy public policy. 
The following concepts have a central ploce in Healthy Cifies:

a Local Dota. Information should be collected af local and ward level. Such dato provide insight in the relevant issues, needs, and problems. Having this infarmation and insight will facilitate a toilored approach to address specific situlations.

b Political commitment. Health should receive a high place on the political and social agendo. This is important becouse health consequences of all decision-making must be considered. Local government support for the Project (and/ar its activities) will stimulate the process of moking health a piriority issue in political decision-moking.

c Innavation. Action should be innovative. New ideas, methods and strategies are needed to incorporate the Healthy Cities ideas into moinstream business and to achieve change.

d Intersectoral collaboration. Health is influenced through activities and decision-making in and outside the health care secter. Health promotion and disease prevention can successfully be realized through effective colloboration between sectors.

- Community involvement. Cammunities should be actively involved in (decision-making in) areas, services and activities that influence their health. Community input in pollicy development and implementation is key to a positive impact and acceptance of the Project.

\# Visibility. Concrete and visible activities can show and illustrate where and how health is created and damaged. These concrete examples are necessary to provide evidence that the Healthy Cities approach works. Furthermore, they can stimulate and camvince others not (yet) involwed in the Project to start working accordingly.

a Equity. Differences in health status between individuals and the inequities between and within locelities should be lowered. To reduce these diffierences is an important aim af WHO in the light of the HFA2000 strategy and programmes.

h Cooperation. Everyone should assist in moking the Project succesful. Joint work should not anly take place at lacal and national level. Also at internatianal level individuals, organizations, and governments need to work together because health (related) problems transcend borders.

i Reorientaton. The health service system should be adjusted to Primary Health Care ideas and practice. It is important that not only strategies and programmes are in line with H.MFA2000. Also structures need to change to be in accordance with this: strategy.

i Personal skills. People shauld be confident enough to make use of their own capacities and competences. These personal skills can be achieved and improved through training and education. Making use of personal skills is impartant for active community inwolvement in activities and decisionmaking.

k Susteinability. Social and economic development should meet the needs of the present without hindering next generations to meet their own meeds. In that respect, social and economic dovelopment should be supportive to human development (health).

\subsection{Healthy City key-concepts}

We have analyzed the Ottawa Charter, the Health for All strategy, and the European Charter for Enviromment and Health, which were presented in Chapter One, on their central concepts. From this analysis table 3.1 was created. As these three documents are central to Healthy Cities, it is assumed that their major concepts are also central to Healthy Cities. From this table it appears that working on Healthy Cities requires the involvement of many people 
and organizations. Additionally, such work requires commitment at a number of levels, from the political to community. Political and community actors have to work in new ways, with new or renewed methods, strategies, and activities. Activities must be visible and tailored to local needs and priorities. What is needed locally is generally ascertained through the gathering of data at community level. All these innovations demand a reorientation of public service, not in the least of the existing health service systern. And the changes that take place should be stable and long-lasting in tune with each other, and should be implemented with an eye on the future.

What is lacking, however, is more concrete planning tools for those who want to work with, or according to, these concepts. Providing specific guidance remains difficult, because the concepts sofar lack widely recognized models of operationalization, it is hard to describe the concepts other than in a general, rather abstract, way. Often, of course, these descriptions are too general for those who intend to work with them, as will appear from quotations in the empirical chapters. Actors ask for concrete examples and clear indicators. This seems to argue that research findings should not only provide guidance and theoretical support on content, strategy, and organization, but must be presented in a way that addresses the questions and possibilities of putting them into practice.

Policy development or project management are easily described in the abstract, but trying to describe the nuances of implementing them in a real context is a fundamentally different task. In 1988, Duhl and Hancock developed a first framework relating to the process of evaluating Healthy Cities (WHO/EURO/HCPO, 1988c). This first framework was, typically, not wery specific. Like the approach that has been chosen in this research, it was based on key-issues and concepts of HFA2000 and health promotion. But Hancock and Duhll could not possibly have come up with a more detailed and specific framework at the time. In 1988, the Healthy Cities Project was only in its early stages of development. They therefore contributed a preliminary framework as an inspiration to begin developments in the Healthy Cities evaluation arena. Interestingly, even eight years later in one of the most recent Healthy Cities publications on the measurement of important Heallthy City indices (such as Garcia \& McCarthy, 1996) none of the original motivating concepts, such as for example intersectoral collaboration or community participation, has been operationalized fully in terms of 'measurable' units. The major concepts thus remain as mobilizing and educational abstractions fairly removed from the substance of the Project.

The concepts as presented in table 3.1 can be divided into three process categories which represent the types of activities which take place in Healthy Cities: social processes, organizational processes, and political processes.

Social processes involve communication and learning aspects, such as participation of community, training and education, and establishing support groups and a supportive environment. Organizational processes cover the organizational efforts that are operational in the case studies to implement Healthy Cities. Examples of such efforts are the creation of structures. and the establishment of intersectoral relationships. Political processes are those processes that involve political discussions and negotiations concerning and/or related to Healthy Cities and agenda building and the generation of political commitment (see also Goumans, 1995). The research has focused on one key-concept in each process. Concretely, this means that in Chapter Six the evaluation results of community involvement, intersectoral collaboration, and political commitment will be presented. Hancock and Duhl (in WHO/EURO/HCPO, 1988a p.39) agree that participation by citizens "involvement of a broad based intersectoral coalition or network, and commitment of municipal gowernments, are the most important requirements for Healthy Cities. Furthermore, these three concepts are part of the national network criteria in the Netherlands and the first and. 
second concept are also explicit part of the UKIFAN criteria. It will appear that these keyconcepts are also recognized by key-figures in the local implementation of Healthy Cities as central to Healthy Cities. They were also recognized in all cases studied here incorporated as part of local goals and local projects (see also Chapter Four).

Furthermore, the concept of healthy public policy receives in this chapter extra attention because it is a central concept to this research. The findings on healthy public policy will again be used in Chapter Seven to reflect on the conclusions of the research.

In the following sections we further explain the meaning and experiences that have been gained on these four concepts through research. In the three chapters thereafter, especially in Chapter Six, findings are presented on the practical experiences and evaluations of these key-concepts. In Chapter Seven we will return to the above statement and the role played by these concepts.

\subsection{Community involvement}

\subsubsection{What is community involvement?}

According to Bracht and Gleason (1990) citizen involvement or participation -these terms are used interchangeably- is one defining factor of community life, regardless of geographic and community structural determinants. In this section, we address citizen or community involvement insofar as it relates to action in the interest of health. WHO views community involvement in health as a norm. Although Feuerstein (1980, p. 31) shows that even by 1958 a WHO report on Health Education had referred to community development (WHO, 1958 (TRS156)), community involvement in health has been especially promoted by WHO and UNICEF since 1977 as part of Primary Health Care (WHO, 1977).

Community involvement in health has made use of experience gained with this concept in other sectors, for example from the social planning movement (Robertson \& Mirkler, 1994: Rifkin, 1980), and community development work (Watt, 1986) of the 1960's. Community development work aims to reduce social inequity. According to Watt (1986), it does so by assisting people in gaining access to places where decisions are made which influence their lives. Similarly community development work on health has aimed at redu cing inequalities in health status.

Descriptions of community involvement reveal a broad spectrum of opinions on the subject. According to Robertson and Minkler (1994) such variety is not due merely to the various definitions which can be given to the concepts of community (see also de Leeuw, 1997), but also to the fact that participation can have different meanings. Arnstein (1969). for example, came up with a participation ladder, varying from control by citizens to manipulation of citizens. Rifkin et al. ((1988), in Robertson \& Minkler, 1994: P. 305) give a definition of community participation that is compatible with control by citizens, the top of Arnstein "s ladder, suamely: "Community participation is a social process whereby specific groups with shared needs living in a defined geographic area actively pursue identification of their needs, take decisions and establish mechonisms to meet these needs." But community participation can also be defined at the bottom of the ladder, with citizens being externally motivated by professionals: "Professionals convincing the community to take responsibility for and to carry out activities to address these [a professionally defined health agenda, MG] issues." (Robertson \& Minkler, 1994 p. 305) From the three categories as defined by Evers (1989) community health projects as self-help groups and projects fit with the first definition and community health projects as institutional and professional endeavors fit with the second definition of community participation. 
An important difference between the two definitions is the role played by the people of the community itself. In the first definition their role is active; such a wiew assumes citi zens" independent inwolvement in defining and addressing problems. In the second, citizens are seen as passive recipients or participants in a project of external genesis. This spectrum is described quite well in a helpful overview of different meanings and issues in regards to community involvement in health provided by Oakley (1991).

Green and Raeburn (1990) attach the concept of community participation to the "enabling" mandate referred to in the Ottawa Charter. "At the heart of the enabling approach to health promotion is the concept of retuming power, knowledge, skills, and other resources in a range of health areas to the community." (Green \& Raeburn, 1990 p. 38) In light of this definition, it is not strange that Braithwaite, Bianchi, and Taylor (1994) noticed an increased association in prevailing thinking about citizens" participation in planning, assessment, and implementation of community-based health initiatives and the concept of "empowerment". According to Minkler and Robertson (1988), health promotion should be identified and linked with empowerment because there is enough scientific evidence that indicates a relationship between health status and the extent to which one perceives him- or herself as having the power over the factors defining one's life.

What can be understood by the term "community empowerment" was subject of a forum in the journal Health Education Quarterly in 1994 (Bemstein et al, 1994). A general definition of community empowerment was not a result of the forum, but most forum participants agreed that central to the idea of empowerment is the gaining of power capable of effecting real change. Community empowerment is consequently the process by which a given community gains such power. Empowerment is thus not something which is given from the outside; rather it is a learning process within communities. Of course, empowerment not only involves the taking of personal power, but also the renegotiation of interpersonal and political power.

\subsubsection{When community involvement?}

Van Assema (1993) has identified three dimensions of community participation in health projects, calling these extent, phase, and number. With extent she points at the various degrees and types of participation which exist among projects, a similar breakdown to what is described by the participation ladder of Arnstein (1969). Further, participation can take place at different stages (phases) in a project, from initiation to implemention. Finally, the number of participants involwed can indicate a certain participation degree. This number provides, however, neither information about the intensity of participation nor about the motivation for that participation. And according to Rifkin (1980 p. 29), it is not a matter of degree of participation, but the reason for participation that matters. Ten Dam $(1997$, p. 85) adds to the three dimensions as described by van. Assema the aspect of scope. In other words, is it about participation in terms of project content, finances, organization, or combinations of these?

Bracht (1990) does not refer to the concept of empowerment, but sees participation as a means to achieving a given health-related behaviour. Based on a compilation of experiences, ideas, and theories on community participation as these relate to health promotion, he identified the following three elements as central to the issue of community participation in health activities: (1) The idea that behaviour is formed and influenced by the living and working environment. Arnong other things, social forces are powerful in influencing behaviour. (2) Communities themselves can be mobilized to act as change agents to achieve certain social and behavioral outcomes. The commumity can legitimize values and norms which favour the desirable behaviour. Using existing community net- 
works and the integration of (health) professionals in these networks helps to increase community ownership and support for the activity. (3) Early and sustained participation by community members and leaders is necessary for the reallization of community ownership and program maintenance.

Strongly related with the three elements mentioned by Bracht (1990) is the so-called community approach in health education. The aim of this approach is to target groups in their natural setting rather than targeting individuals (see for example Bracht, 1990). According to Brown (1991), this approach integrates social change and behavioral change theories. It does so because the approach is strongly rooted in the ideas that health interventions, social and behawioral change, prevention campaigns, or health promotion activities should match with community structure. Concretely this means that an intervention must be consonant with, and start from, existing community values, possibilities, and leadership styles. Flynn, Ray, and Rider (1994) show that with regards to Healthy Cities the establishment of a local Healthy City committee stimulates community empowerment through learning (see also Lugo, 1996; Wallerstein \& Berstein, 1994). This committee needs to meet on a regular basis, and should have a clear agenda and good leadership. Especially grassroots-style participation was enhanced by having community members with leadership skills who kept the ball rolling. Csepeli (1989) shows another examples how to match with community structure. In Hungary the strategy is to stimulate community health projects by popularization and support of self-help initiatives and mutal-aid groups (see also Cartwright (1989)).

Trojan (1990) and Blennerhasset, Farrant, and Jones (1989) stress in their research on cornmunity involverinent the importance of creating a link between community (health) initiatives and the policy-making process. Solving the question of how to give sustainable life to community involvement, according to them, goes hand in hand with generating political support for community initiatives. This importance of having such a relationship is also stressed in the reports of two important international conferences that were organized on this issue: the Adelaide recommendations (WHO/EURO, 1988) and the Sundsvall Statement on Supportive Environments (WHO/EURO, 1992). Furthermore it was the subject of the 3rd Vienna Dialogue -discussions on the challenges in the field of public health- in 1988. So called community health projects were discussed in the light of Healthy Cities and the creation of supportive environments. A volume of the journal Health Promotion (1989, vol. 4 (3)) wras devoted to the conclusions and recommendations of this Dialogue.

Another lesson learnt from community participation programs is that intersectoral collaboration is necessary to achieve community goals (Bracht, $1990 \mathrm{p} .19$ ). This is the subject of section 3.4 .

\subsubsection{How community involvement?}

It is not the intention to provide here a complete overview of all the different existing models and ideas with regards to community participation. It is enough to recognize that diversity exists in approaches to community participation and that these are rooted in different ideas about what community participation actually constitutes.

Van Assema"s three dimensioms of extent, phase, and number can be used to analyze community initiatives. Furthermore, they can be used in setting up a community initiative. Braclat and Kingsbury (1990) developed a five-stage model for community programs which reflects the three central elements of community participation as described earlier by Bracht (1990). Their model is largely based on the experiences gained and the research that has been carried out on community projects during the years. The five stages are: 
- Each program should be based on an analysis of the current situation and a community profile.

- There should be a supportive structure in place that is compatible with already existing community structures, values and beliefs.

- The community should understand and support the desired change.

- A workplan and multiple strategies must be developed and the results must be disseminated widely in order to increase visibility for the effort.

- Last but not least, the community profile needs an update every now and then and one has to think about the continuity of the project.

The five-stage model as developed by Bracht and Kingsbury is often used to initiate and evaluate community projects. It is, however, not the only existing model for such processes. Particularly deserving of mentioning are models which are more connected with the concept of empowerment. For example, in action research models, communities are represented as having a central role in defining issues, problems " and solutions. Flynn, Ray "and Rider (1994) show how action research is used in Citynet Healthy Cities as a tool for establishing community empowerment. Other examples with regards to Healthy Cities are offered by Polland (1996) and by Smithies and Adams (1990). In the past four years, Health Education Quarterly (vol. 21, (3)) has published a number of alternative models and case studies, such as those of Labonté (1994). Braithwaite, Bainchi, and Taylor (1994), and Lugo (1994).

Ten Dam (1997) shows that local health projects and policy should take into account the movement and changes in the neighbourhoods. Furthermore, ten Dam mentions that participation cannot be created by professonals simply by pointing at neighbourhood health indicators or health problems. Because most of these data do not take into account the resident's experiences and health perceptions.

In Health promotion (vol. $4,(3))$ a number of case studies are published on how in different countries community health projects are put into practice, for example O'Neill (1989), Villalbi, Costa, and Oller (1989), Csepeli (1989) and Svoboda (1989). As impor tant prerequisites for realizing community health projects were mentioned: having supportive policies and supportive funding, establishing local information and resource centres, providing local support, providing training, and last but not least creating supportive structures in terms of partnerships and linkages between community health projects and other social projects.

Community participation in health promotion research is also addressed by Allison and Rootman (1996) from a more critical angle. In their research questions are raised as to whether scientific rigor and community participation are compatible. The effectiveness of the community approach in terms of behavioral change seems indeed difficult to prove in concrete terms (see for example van Assema, 1993). The question is whether this is a matter of the inadequacy of existing methodology or whether the effectiveness of community participation is at its root not a feasible research topic. This latter point may indeed be the case. After all, regardless of approach, the direct contribution of an intervention toward populational health status is unmeasurable in most ways and unprovable due to the absence of a controll group (see also in Chapter One, section 1.4). Even measuring change can be difficult. Thompson and Kinne (1990, p. 46) mention that this applies at the community level as much as it does at the level of the individual. Despite the fact that such measurements are difficult to take and validate, however, the community approach seems to have taken a permanent position within health education and promotion practice. According to Fortmann et al. (1995) this can be explained by the fact that the aggregate of these studies supports the effectiveness of community-wide health promotion. In that 
Tlable 3.2. Core elements of three approaches to organizing community involvement in health.

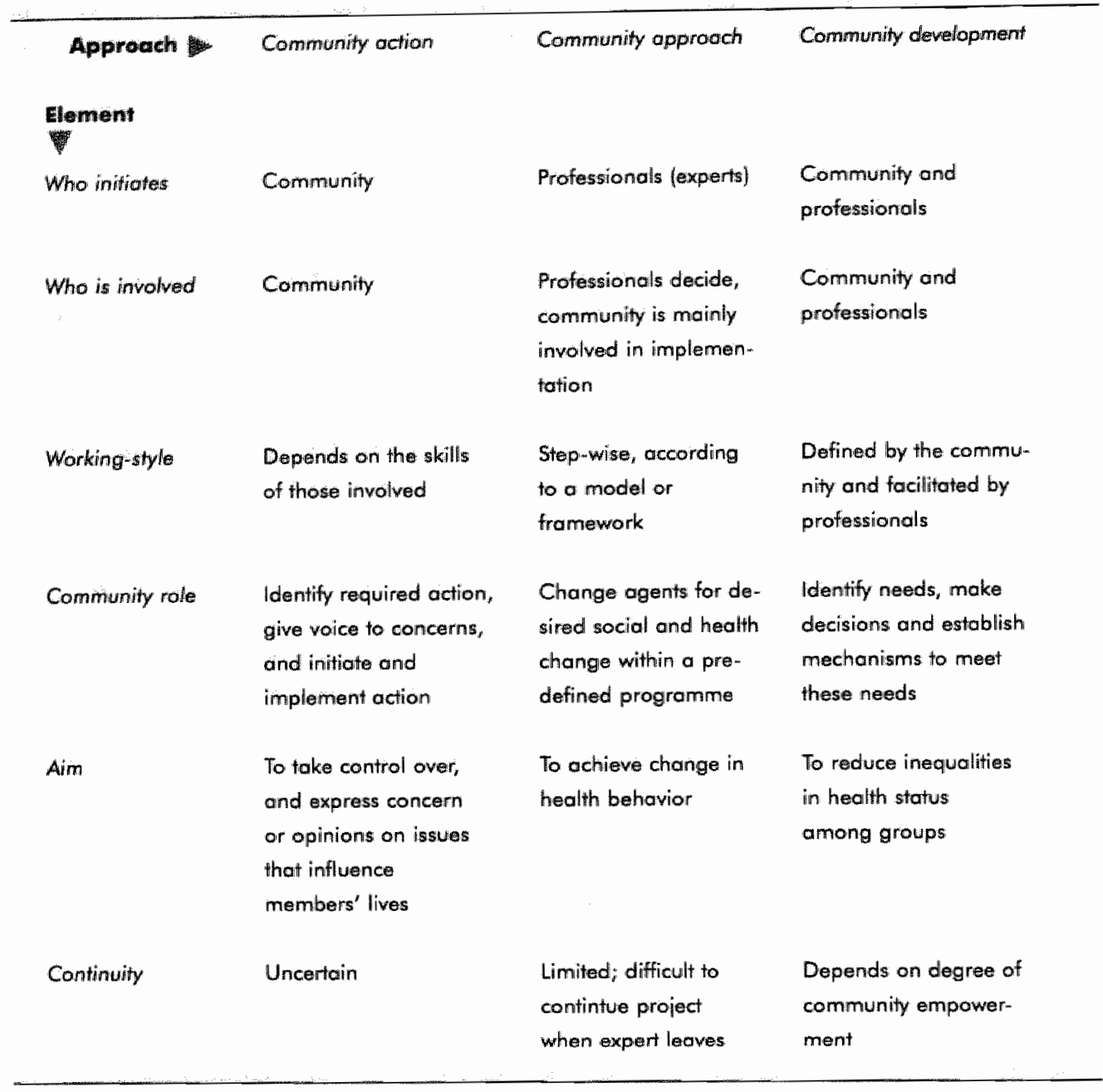

sense this is no longer an interesting research question. Instead they recommend investing in understanding the determinants of population-level change. O'Neill (1989) argues that the potential for community health projects to improve health is availalble only if they are only very loosly controled by govermment. In other words, too much eveluation and control may undo these community health projects, and thus the community, from their power to improve public health.

In table 3.2 the main elements and methods of community involvement that have been identified in this section are summarized. The WHO Healthy Cities. Project has not mandated one specific approach, and therefore represents individual projects which use one or more of the methods summarized below. The discourse used in writing and speaking about community involvement, however, is very much used in regards to Healthy Cities as will become clear in the empirical chapters. 


\subsection{Intersectoral collaboration}

\subsubsection{What is intersectoral collaboration?}

The requirement for intersectoral collaboration or action within the Healthy Cities Project is a direct result of the definition of health advocated by the WHO and its health promotion units. Since it is believed that health is more than "merely the absence of disease and infimity" "it is also beliewed that health is the product primarily of factors which have traditionally been perceived as laying outside of the health (care) sector. Cooperation between various sectors in the larger society is therefore required to positively condition those determinants of health and sickness which, for example, are related to economic, social, or political conditions.

Saan (1988 p. 93) describes intersectoral action as "an action developed between sectors through o series of negotiations, where personal face to face contacts play an important rale to work through processes of problem solving, policy development, procedural tuning, personal and institutional relationships, within a relatively closed time-frame and a specific sacietal context."

Intersectoral collaboration can take place at different levels, and among different spheres. So, for example, collaboration can take place between individuals working in different sectors but also between multi-nationals and governmental institutions or governmental institutions and non-profit organizations. Mention is made of intersectoral collaboration whenever individuals or organizations represent different sectors. If two or more individuals or organizations from the same sector work together on a project, for example, this would presumably take the "intersectoral" out of the expression. From a more general standpoint it is helpful to keep in mind that central to all forms of collaboration is the exchange of resources between actors.

\subsubsection{When intersectoral collaboration?}

Typical reasons for beginning collaborative efforts are market forces " such as efficiency or public relations, governmental requests for collaborative efforts, and the perception among relevant actors of problems of sufficient complexity and multi-facetedness to warrant the involvement of parties in different sectors.

In practice, it appears that experience with intersectord collaboration is larger in the private world than in the public sphere. Though example of collaboration in the public sphere do exist, they are somewhat rare. On example can be found in the city of Liverpool, where the Health Authority uses a community based planning system to deliver high continuity of care (Liverpool District Health Authority ${ }^{1995)}$ ). The city is divided into areas which have their own health team or health centre. Van der Zwaan (1979) mentions that public interest, maybe even more than organizational interest, may influence the decision for collaboration among health and welfare organizations. This implies that sometimes these organizations collaborate even when there is no obvious benefit to themselves. Given the value for money idea that is evidently present in the private sector, a relative absence or hesitation by private sector organizations for involvement in such collaborative efforts may therefore be expected.

As health problems are complex and interrelated, there is little dispute that collaboration needs to take place to tackle complex health issues (see also figure 3.1). Even if, as mentioned by de Leeuw (1989a p. 20) it is difficult "to give all [possible, MG] interrelations between as many conditions and the largest contemporary health problems." At the same time, having this recognition of the need for collaboration, $O^{\prime}$ Connor (1995) has shown that, often, such efforts are re-inventions of the wheel in the sense that coordination between different intersectoral efforts is missing.

From Eisinga (1994) it appears that the majority of collaboration within health promotion takes place on a project-by-project basis, and in accordance with what was mentioned 


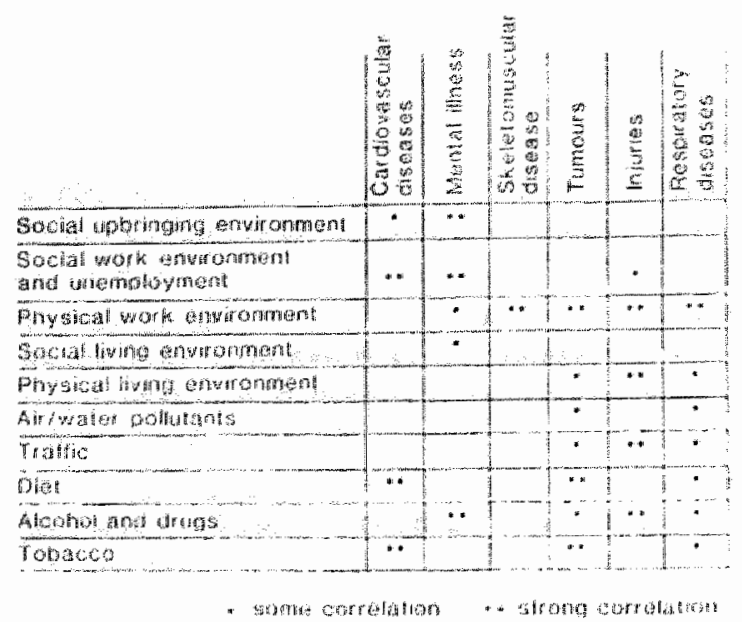

Source: The Swredish Health Services in the 1990 s (1984) in De Lasuw, E. [1989]. The Sane Revolution. Assen: won Gorcum, p 21.

Figure 3.1: Correlates between (environmental) determinants and health stafes.

by Van der Zwaan (1979) that these efforts are mainly negotiated between the welfare and health care sectors. Furthermore, from the case study report on reducing smoking behaviour by Hunkeler et al. (1990) it appears that it is easier to recruit organizations that already have a commitment to improving health than organizations which would seek to involve or serve the target group in other ways.

It also appears that for collaboration in the health field to be successful, it needs to be based on consensus building and cooperation rather than being mandated from above through legislation or incentives (Taket, 1990). The United Kingdom national government's requirement that local governments work in alliances with one another is, in essence, a forced form of collaboration, and may suffer for it. Still, Fumnel, Oldfield and Speller (1995) indicated and investigated some successful case studies which involved forced or externally-motivated collaboration. Based on their research, which was carried out in the United Kingdom, they developed a supportive framework for creating and working in alliances. This framework was again tested in practice and commented upon by experts, resulting in an agreed upon framework for creating alliances.

\subsubsection{How intersectoral collaboration?}

Heijtkamp (1996) shows that different forms of collaboration among organizations can be distinguished based on: (1) formalization of the collaboration, (2) autonomy of the organizations, (3) time-frame in which the collaboration takes place, and (4) the number of organizations that are involved. Table 3.3 is adapted from Heijtkamp (1996). In this table the different forms of collaboration are presented on a scale. At the left side of the scale the collaboration is informal and short term and at the right side the collaboration is formal and long term. In informal collaboration the partners involved maintain their fundamental autonomy. When partners relinquish a portion of their autonomy, this is defined as formal collaboration. All the forms of collaboration involve at least two partners, or even more in the case of networks and alliances. Contacts and agreements, however, most 
Table 3.3: Collaboration forms at a scale from informal and shortterm (at the left side), to formal and lang-term (at the right side).

$\begin{array}{lr}\text { Contact " Network - Coalition - Agreement - Alliance - Joint Venture - Acquilitions - Margers } & \text { Formal } \\ \text { Informal } & \text { No outonomy } \\ \text { High autonomy } & \text { Long term } \\ \text { Sart term } & \end{array}$

Source: Heiltkamp, P. (1996). Global Heolth Promoting Partherships in WHO's Organizational Perspective. (Maskers thesis Health educotionl. Moastricht: University of Maostrictht.

often involve only two partners; one often hears of a "bilateral" agreement or contact. Flements central to these eight collaboration forms are:

- shared values in regards to the need for and nature of cooperation:

- common goals; and

- an exchange of resources.

It is not of course organizations themselves which cooperate with each other, but the people who work in those organizations, the so-called 'organizational representatives'. Although it seems obvious, this fact tends to be somehow neglected in organizational collaboration theory. Springett (1995) emphasizes the importance of the human factor and informal networking in organizational collaboration.

In 1988, an expert meeting on intersectoral collaboration took place (Taket, 1990). Out of this meeting emerged a consensus that the rhetoric of intersectoral work was stronger and further developed than intersectoral practice. Additionally, the point was made that although collaboration rhetoric assumes that actors are "equal" (i.e. have equal power in the collaboration itself), actors most often have quite varying degrees of power due to underlying structural inequities, such as access to money, knowledge, or power. Power inequities are especially of importance when actors have slightly or significantly different goals outside of those they share. Important elements in intersectoral action that were defined in this expert meeting are to be opportumistic and flexible. It is also necessary to understand or speak each other"s longuage and to have adequate and up to date informotion and argumentation. Last but not least, people need to be trained. At the 1988 meeting, case studies were also presented. These in combination with the discussion gave rise to an important outcome of the meeting, which took the form of a checklist designed to facilitate intersectoral projects. Saan, Ellenkamp and Van den Boogaard (1994) have used this checklist and adapted it to the Dutch situation. Important elements of this checklist are:

- to identify the partners. What is known about the partners? How does each relate to the issue or problem of concern?

- to define the objectives. What is asked of the potential partmers? What can this collaboratiwe effort bring to them? What do they themselves expect from it?

- to negotiate the problem definition among all partners involved. Get to know each other's ideas and agendas. Come to agreements about such things as decision-making procedures, strategies, agenda-setting, and degrees of formality.

to identify the conditions and circumstances within which the collaboration has to take place (for example financial resources, politics, important events).

- to discuss the time table of the collaboration. How much time is each partmer willing to spend on each step in the process? 


\subsection{Political commitment}

\subsubsection{What is political commitment?}

In a modern democracy, policy is developed through a process of interaction and negotiation among many actors. These actors shape policy through their argumentation, criticism, ideas, negotiations, and interests. There is always a subtle balance of opposition to and support for the placing of issues on the agenda and the creation of policy to address them. There are interest groups and pressure groups trying to bring issues to the public's and policy-makers' attention. Some attempt the opposite: to prevent given issues from receiving too much attention. Politicians, representing gowernment, obviously represent one of the major partners in policy development. But government is not in a hierarchical position to other actors. Nonetheless, formal decision-making power on public policy proposals and projects remains their responsibility. For example, at the local level it is the city council who ultimately decides about public policies and activities. It may therefore be helpful for those in favour of certain issues or project proposals to receive support from city council members.

Political commitment can be defined as "an expressed interest by politicians in a certain issue as signified by words and/or resources." An issue's chances of surviving and being translated into some kind of policy are generally far higher by the time the issue has become the subject of formal city council discussions and decision-making. In the extreme case, an entire city council can be committed to the development of an issue. But commitment is more often limited to an individual council member or specific politicall party because it generally embodies a specific political interest.

\subsubsection{When political commitment?}

Within Healthy Cities or health promotion research it appears that research on political commitment has hardly been undertaken. Political commitment seems to receive attention only as an aspect of research on other topics when related to Healthy Cities or health promotion.

Taket (1990) shows that in research on intersectoral collaboration, pollitical commitment is presented as a pre-requisite for development of a project and, ultimately, for the integration of the results of such a project into mainstream activities or long-standing policy structures. Scott-Samuel (1989) and Bloom (1985) also argue that political commitment is essential for the development of and success of initiatives. Janabhai, Coovadia, and Abdool-Karim (1986), however, show that the difficulty is that the existing political system and political practices may not be supportive to provide this support in tangible, or even symbolic, forms.

Though political commitment is undoubtedly a critical factor in predicting the success of local initiatives and the level to which they are put on the political agenda, other aspects such as pollitics and political representatives also have a central role in decisionmaking and agenda-building research. So-called agenda building theories (for example Cobb \& Elder (1983); Kingdon (1995)) show that the likelihood of achieving political agenda status for an issue increases quite significantly when there is governmental interest in an issue.

From Kingdon (1995), it would appear that in order for an issue to receive political attention or support, the political climate needs to be ready for a change. For example, in the months leading up to an election, or in the months after an election "politicians are most open to new issues. Sudden crisis is also very likely to mobilize political support for a particular issue of concern (Pearson, 1991). It may also be that a certain issue receives 
attention by politicians or key decision-makers due to the fact that they share a personal interest in the issue. It must be mentioned that personal efforts of visible participants, such as for example important politicians, can result in the ranking or a change in rank of an issue on the governmental agenda. According to Kingdon (1995), however, if this is the only support an issue receives, attention for the issue is only likely to last onlly for a short while. It will eventually fade away, because issues attached to individuals are not likely to become part of the priority agenda of government, the so-called decision agenda. Specific details about this aspect will be provided in Chapter four.

It may also be the case that an issue achieves political support from the time of its very first policy proposal. This is most likely the case when the issue (policy proposal) is promoted or initiated by government, by a certain political party, or by politicians themselves. Cobb and Elder (1983) speak in that situation of an inside-initiative model or a mobilization model. This will be further explained in Chapter Four.

\subsubsection{How political commitment?}

What would appear to be the case from Milio (1988), Kingdon (1995) and also from Cobb and Elder (1983) is that political commitment may be established through personal efforts. Issues can be brought to politicians' attention by people who know how to play the political game. These people need to have access to high level decision-makers. Furthermore, they can use the media to present ideas to a wider public for discussion, feedback, and implementation. The exact role of the media in gaining political commitment and agenda setting remains unclear. Some authors (Cobb and Elder, 1983) attribute a large role to the media. Other authors (Milburn, 1991; de Leevw, 1989b) suggest that the impact of media on agenda setting is not as strong as is asserted by Cobb and Elder.

According to these theories, policy advocates (Milio, 1988) or policy entrepreneurs (Kingdon, 1995) have to submit ideas and proposals at an advantageous moment in time, in the 'right political climate'. Waiting for the right climate means that the policy advocate must monitor the environment continuously. Laumanin and Knoke (1987) show that having access to information sources and monitoring of the environment are crucial to influence or change policy. The policy adwocate has to define what constitutes the "right political climate' as well as what sorts of specific opportunities it may provide. But can policy advocates accurately assess this correlation? And is there only one specifically determined climate that applies to all policy change situations? A climate that can be described in terms of preconditions, actors, and processes? At this moment we tend to give a negative answer. In advance of the findings as presented in Chapter Four, it cain be mentioned that what may be an ideal political situation for one issue may be a threat for another.

\subsection{Healthy public policy}

\subsubsection{What is healthy public policy?}

A variety of meanings of health policy were addressed in Chapter One. In the research presented here, we will simplify the complexity of this topic by distinguishing between two prevailing health policy development approaches within health promotion.

On the one hand, health policy implies making investments in policy sectors, including the health sector, in order to address a specific health problem. This policy storts from a specific health issue perspective. It addresses the promotion of health and prevention of disease and asks for input from other sectors (see for example de Leeuw, 1989b). This type of policy 
encourages politicians and policy-makers to realize what effects their decision-making has on health. Apart from health professionals and governments, many other people have to be involved in the making of this type of policy. These actors can represent, for example, social welfare, industry, education, econorny and trade, media, and communities at large. What is asked of policy-makers is that they "recongize the importance of setting in process now step-wise policies which will lead to the desired outcomes two and three decades from now (Siler-Wells, 1987 p. 830).

On the other hand, and that leads to second approach, health policy can also mean that all public policy sectors evaluate their policies among other things on possible health effects. Milio $(1986,1988 ; 1991)$ has elaborated on this idea and has given this the name healthy public policy. "A healthy public policy is characterized by an explicit concern for health and equity in all areas of policy and by on accountability for hedth impact: (WHO/EURO, 1988). A healthy public policy contains a vision on health aimed at health promotion. It demands intersectoral and interorganizational collaboration, and community participation. It requires political commitment, and use of qualitative and quantitative data to support agenda setting and decision-making. The main difference with the first policy approach is that here the starting point is different. The starting point for this policy is not a (public) health problem, as is the case in the first policy approach, but can be any issue, for example, economics, traffic ar safety.

According to Milio, policy-makers generally consider the consequences of their decisions only for the area in which they work. They most often do not fully consider the consequences outside these boundaries. In addition, an overall view of how activities, decisions, and policies relate and influence one another in both positive and negative ways seems to be lacking. Milio's idea (1986) therefore was to promote health by investing and working in (policy) fields other than that of health care. See also figure 1.3 (Chapter One) in which the relation between, for example, health education policy and a healthy public policy as meant by Milio is illustrated. Policy-makers, regardless of the policy field they represent, should be aware of the possible health implications (effects) of their decisions and activities. Sullivan $(1991$, p. 3) agrees; in considering health promotion one must view improvement in health status "as a specific objective of public policy rather than as a collection of important speciality programs from a small and zealous health promotion group within a ministry or health organization". In practice, however, it is representatives of the health sector who judge other sectors' policies in terms of their potential consequences for health. This appears, for example, in the report written by a Dutch Committee (Commissie Versterking Collectieve Preventie, 1996) which was asked by the Ministry of Health to investigate local health policy development, Sectors other than health care seem, therefore, not yet to have taken on the role which would be assigned them by Milio.

\subsubsection{When healthy public policy?}

Is it, then, possible to develop a health policy but not to call for healthy public policy? As noted above, there is not yet much evidence that in policy sectors other than health care the possible health effects of decision-making are considered. This raises questions in regards to the place of health on the agenda of organizations and other actors operating outside the health sector. For example, Dutch drug policy, which gives explicit attention to its own impact upon health, has experienced a great deal of resistance in being accepted at the European level, which may imply that its most apparent advantage-explicit consideration for the health impact of drug policy-is not found compelling within larger policy sectors. Especially the French government, whose drug policy emerges mainly out of a public order perspective, seemingly had great difficulties in giving explicit attention to health concerrs in relation with drug abuse. 
In 1991 Farrant came up with a list of prerequisites for successful healthy public policy development (Farrant, $1991 \mathrm{~b}$ ):

- The presence of a clearing house that collects and provides information on the matter of concern. Clearing houses on Healthy Cities and health promotion, such as for example the WHO CC for Research on Healthy Cities, collect and distribute information on health, though that is not their exclusive working area.

- Provision of training. Currenty, training is provided on how to start health promotion. activities, research, and project management by health promotion centres through such organizations as, for example, the Netherlands Institute for Care and Welfare [NIZW, MG] or Netherlands Institute of Health Promotion and Disease Prevention [NIGZ, MG]. Also, university departments of health promotion and public health, along with summer courses on these topics, are helpful in training health and health promotion professionals either generally or specifically.

- The presence of health policy consultants. Health promotion consultants are available who can assist professionals and policy-makers in defining their role. At present there are however very few consultants who can provide assistance in local health policy development.

- Building a supportive infrastructure. That means creating new funding policies, along with new structures and mechanisms.

Furthermore it needs to be acknowledged that, as put by Pinder (1990) "any major policy shift can take 10-20 years. The inevitable frustration must be used as a source of energy, not discouragement and cynicism." (Pinder, 1990 p. 212). It must also be acknowledged that there is an inherent contradiction between the meed for quick results to satisfy groups and constituencies and the requirements for the success of a long-term strategy. Success can be stimulated according to Farrant (1991b) by having:

- support from media and voluntary organizations;

- convergence of interests in social, economic, and health promotion areas;

- an interdisciplinary approach of the team;

- the initiatives of the WHO/EURO;

a supportive national government.

In any case, this policy development cannot be disconnected from issues such as reorganizations in terms of the tasks and responsibilities of national and local governments, public organizations, and communities in policy development. Farrant (1991b) puts it quite bluntly in saying that "It [Healthy Public Policy development, MG] requires a major transformation of political processes and structures, and ultimately implies a fundamental shift in the distribution of resources and power within and between societies. The constraints to and contradictions of pursuing such a goal within the political and economic dimate of the 1900 s connot be overstated. At the same time, the rapid growth of the intermational and national healthy cities/communities movement is an indication of the widely perceived need for a radical rethinking of public health." Healthy Cities blazes a trail for this policy development. Researching the Healthy Cities policy development process brings out a variety of experiences. It is the challenge of the researcher to gain from those experiences insight at a more aggregate level which are helpful for others in starting and managing policy development within a Healthy Cities context.

\subsubsection{How healthy public policy?}

Milio (1991) formulated two basic questions for making healthy public policies: "What policy options will make healthy choices easier for society to make in the continuous creotion of goods, services and environments?" and "How can options for health public policy be made easier for policy makers and their supporters to choose?". The first question mainly addresses the qualitative and quantitative 
measurement side of health and the effects of existing policies on health. The second question addresses the study of policy-making and policy implementation. In her earlier work Milio analyzed four case studies of policy development in terms of the ways they integrated health into their approach. Her main conclusion (Milio, 1988 p. 310-311) was that politicians only perceive a change of policy as necessary wher 'business as usual' is no loinger efficient. "Then government support and sensitive hondling of the discourse fovoured policy development." (Milio, 1988 p. 310 ) "Policy for health took a new direction when the economic, political, social and demographic climate made a potentially major change feasible and when long-time advocates saw and toak advantage of the chance to propose a new course." (Milio, 1988 p. 310) This new direction was presented in economic and political terms and was brought to the politicians" attention by people who knew the political game. In a second stage the media were used to present the ideas to a wider public for discussion, feedback and, ultimately, for effective implementation. In the meantime the policy adwocate, who has been identified in section 3.5 , has to create links with organisations and groups that are potentially affected by the new policy. Other characteristics of policy advocates, according to Milio (1988) are:

- to hawe skills and knowledge to engage in strategic planning;

- to have a recognized authority;

- to be relatively independent in resources and structure;

- to have sufficient public and political support to provide leadership.

According to Milio (1988), case study research, like the one carried out by herself, should lead to the development of methodologies of policy change: Ideally, case studies would have taken place in different countries and would be based upon explicit attention for the position of the researcher. The question here is how this conclusion can be enriched by the findings of this inquiry on health policy-making in Healthy Cities. Because Milio (1990b) indicated the research such as that described here as an appropriate laboratory for such policy development.

From a literature review that has been carried out on health policy research it appears that much research has been reported on health policy aspects, heallth systems, health service policy, health care policy, etcetera. But it appeared also that since Milio came up with the concept of healthy public policy (1986), not much direct scientific research has been reported on it. From a search on Medline (1983-1996), only 17 articles explicitly referred to healthy public policy. Most of these articles are on theoretical and methodological ideas which support the development, implementation and evaluation of healthy public policy (see for example McKinlay, 1992; McKinlay, 1993; O'Neill \& Pederson, 1992). Evident case study examples on healthy public policy are those (as already mentioned) on food and nutrition policy (Milio, 1988; Milio, 1990a; Ziglio, 1986). Another concrete piece of research on this issue was presented by de Leeuw (1989b). She has investigated the feasibility of healthy public policy in the Netherlands. What appeared was that although the ideas from HFA2000 may be inspiring, they did not receive the necessary political commitment and priority to make broadly integrated health public policy a reality. From an evaluation study of Van de Water and Van Herten (1996) it appears that HFA2000 did not become a formal policy. Instead health oriented policies which resemble HFA2000 ideas were initiated (for example Healthy and Well, the Framework of Health Pollicy 1995-1998).

Another example of a healthy public policy in practice is the policy of reducing the use of pesticides (Labonte, 1989). And Barnett and Smith (1995) suggest that the relation between unemployment, work, and health is yet another opportunity for developing healthy public policy. This has so far not yet been developed. Furthermore, two major inter-national conferences have been organized on the subject of healthy public policy. 
The conference reports of the Adelaide Conference (WHO/EURO, 1988) and the Sundsvall Conference (WHO/EURO, 1992) provide also many case study examples. Also Health Promotion (vol. 3 (2). p. 187-236)) contains some of these case studies from Finland, Hungary, Canada, and the United kingdom. It appears that it is more common to start with health policy development and thereafter to consider the contributions that can be expected from economic policy, social policy, or environmental policy, than that a comprehensive healthy public policy is developed all at once.

\section{$\overline{3.7 \quad \text { Conclusion }}$}

In this chapter a very brief overview was provided of knowledge and interpretations by researchers of concepts central to Healthy Cities. It appears that there are in fact no uniform ideas and methods on these concepts. Still there is reasonable knowledge in regards to theoretical and methodological issues. And given the fact that much has been written on these concepts, their rhetorical strength, at least, seemed sufficient to have been tested.

Intersectoral collaboration and community participation seem to have received more attention from health promotion researchers than political commitment and healthy public policy. Research on healthy public policy seems to be carried out and stimulated by a rather limited number of researchers. One possible explanation to this may be that policy and political research are areas where health education and health promotion professionals have traditionally received limited training. It may also be explained by the complexity of healthy public policy and political commitment and the scarcity of case studies that are available for research. Furthermore, it seems to be the case that intersectorall collaboration and community participation appeal to individuals' common sense to a more significant degree than do the ideas of political commitment and healthy public policy, which remain rather vague abstract concepts. Healthy public policy becomes a more tangible concept when a more specific label is put on it, such as, for example, food-policy.

From the presented overview appears that different interpretations and ideas exist on some of the concepts and assumptions that are at the core of Healthy Cities. Empirical evidence for the assumptions on Healthy Cities as made in table 3.1 , however, are more difficult to obtain. It is doubted that within Healthy Cities there has been chosen for a specific approach to the three concepts which have been discussed in this chapter. What that implies for putting them into practice will be shown in the following chapters. 
4 Getting health on

the political agenda

\begin{abstract}
"The policy-making process (...) begins with awareness of a "problem", especially" one which exisfing policies are failing to cope with at even a "satisfying" level." (Hogwood \& Gunn, 1984 p. 108)
\end{abstract}

\title{
4.1 Introduction
}

Why do certain issues sometimes receiwe sudden, unexpected attention from the media, the general public, or in political arenas? Examples of events which cause a media hype or claim excessive attention are an airplane crash or a leaking oil tanker in the ocean, a political or election scandal, war or "mad cows'. Such events draw attention to topical issues like national safety, the environment, credibility of political systems, public services, human rights, and health. It is " however, not only issues with high media coverage that are subjects of discussion in the political arena and thereby receive a so-called political agenda status. Many other issues which receive very little public attention, are discussed and decided in terms of policy implications in, for example, the Parliaments of Western Europe. So it are not only perceived 'problems', as written in the above quotation, but also opportunities, threats, and trends which initiate public policy renewal and new public policy development. Throughout this chapter it will become clear why we disagree with Cobb and Elder (1983) and Stone (1989). These authors argue that public policy will (only) be developed if a situation is defined as "a manageable problem" and if the government is perceived as responsible for tackling the situation in question.

As explained in Chapter Two, this first empirical chapter addresses the issue of agenda building. The place and priority of an issue on the political agenda is an important factor in the policy making process. Two aspects are central to this chapter.

First of all, attention is focused on the reasons why individuals, groups, or a city council start to work on Healthy Cities. Why is it that these parties express interest in Healthy Cities initiatives with explicit, innovative ideas about health policy development? Is it because a city faces serious health problems or are there other important reasons? In other words, what is the impetus behind a Healthy Cities initiative? What can be said from the start is that it is not a statutory duty for local government to develop a local health policy based on health promotion and HFA2000 premises. Only national governments of WHO member states are committed to developing national HFA2000 strategies. Furthermore, local government in the two countries that are involved in the present research cannot lean on established traditions and fully developed infrastructure for health promotion activities. Health promotion and health policy development are a relatively new terrain for local government, at least in the Netherlands (see also appendix 1). The WHO Healthy Cities Project which begun in 1986, has been the first international project of its kind which emphasized the role of the local government in working on the HFA2000 strategy. A 
second aspect related to the question of why Heallthy Cities initiatives emerge is political commitment for the specific concept embodied by the "Healthy Cities" mowement or philosophy. In other words, why is it, or is it not, worthwhile to spend political time, discussions, and resources on Healthy Cities?

Theoretical support for this chapter comes from agenda bwilding theories which focus on the process side of agenda building. We follow authors who consider the political agenda to comprise two parts, a systemic (general, large) part and a decision-making (specific. smally part. The two theories considered here can be used both in complementary as well as in contrasting terms. Using two theories has the dual advantage of allowing both a greater breadth in consideration of the relevant policy issues, and greater depth, through what has been referred to in the literature as theoretical triangulation, in the comparison of differences and similarities in the results.

The chapter is organized as follows. First, we explain what is meant by agenda building in this inquiry. Second, two different agenda building theories are introduced, namely, the Agenda Building theory (Cobb \& Elder, 1983) and the Policy Windows theory (Kingdon, 1984; Kingdon, 1995). Both theories are well-known in the policy analysis literature but have distinct roots and thus provide two different analytical methods. Although both theories are based on research at national and federal govermment levels, we assume that the mechanisms and elements that are central to these theories are also of relevance at the local level. After the theories have been presented, two empirical questions are addressed. First, atrention is paid to the question of why relevant parties decided upon participation in Healthy Cities; and second, the process of establishment of political support for Healthy Cities receives attention. Political support is regarded as one of the most significant indicators for political agenda status for Healthy Cities. In the last part of the chapter, the empirical findings are analyzed separately, using each of the two theories, in order to draw conclusions on the political agenda status of Healthy Cities. It will be demonstrated that although the theories support the same conclusion, a loosely structured and non-sequential theory fits the Healthy City agenda building practice best.

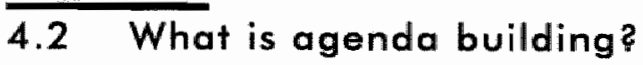

What is agenda building? In day-to-day language it can be seen as constructing a schedule or list of items to be attended to (Collins English Dictionary, 1989). If an issue is on someone"s. agenda, it means that it is a subject of importance to him or her. It is something to talk about and to work on. In political language agenda building means constructing a schedule or list of items to be discusses and to prepare possible action and policy on that basis. Hogwood and Gunn (1984) use the phrase "issue processing capacity of public organizations" for political agenda building in policy science. What does this mean? Organizations have to be able to recognize the issues, whether problems, threats, opportunities, or trends, that demand attention in terms of new policy or change of existing policy. Recognition is based on the information available in the internal and external environment of the organiZation but political skills also play an important role (Hogwood \& Gunn, 1984 p. 110).

At every organizational level, from administrative assistant to top-management, people take up issues which are of relevance to them and/or to their work. A decision-making process always follows. Some decisions can be made immediately. Others have to be discussed with superiors because they may have major implications. Still others have to be discussed in board meetings due to their politically sensitivity or complexity. Some issues 
are consistently a part of the agenda, some come and go very intermittently, and now and then a new issue is put permanently on the agenda. For example, legislatory demands are always part of the political agenda as well as economic and busineiss related issues.

Although finances are always important, financial issues are especially on the agenda when the fiscal year ends and when decisions have to be made on new budgets. With regard to "soft" items, as health is often seen, it will be argued throughout this chapter that it is not self-evident that health issues are a part of the political discussions on a regular basis.

Van de Graaf and Hoppe (1992 p. 181) suggest that in Europe, attention for agenda building as part of the policy making process is a result of discussions about democracy in Western society. The main point in these discussions is the implicit opportunity offered by democracy to all people to play a part in policy-making. Van de Graaf and Hoppe (1992 p. 181-203) give two caveats to this conclusion. First of all, the political decisions made do not allways represent the problems that are perceived by the general public. Secondly, it is naive to suggest that everybody who would like to be involved in policy-making really is actually involved, or that everybody who is not currently involved is satisfied with the status quo. Additionally, it is questionable whether the groups involved in political decision-making truly represent their commumities and whether communities always want to play a part in policy-making.

In this investigation, agenda building means: "the process that leads to a place for Healthy Cities. on the political agendo of local govemment". The focus will be primarily on a description of the roads leading to the inclusion of Healthy Cities on the local governmental agenda (see also Allison, 1971; Teisman, 1993). In following chapters, more attention will be devoted to what happens after the decision is made to get involved in Healthy Cities. The agenda definition used in this chapter is in accordance with Kingdon's definition (1995 p. 3): "the list of subjects (issues) or problems to which governmental officials, and people autside of govemment closely assaciated with those officials, are paying serious attention at any given time". As explained before, issues can arise because they are perceived to be opportumities, threats or trends. Healthy Cities will be regarded as a new issue which presents innovative ways for health policy development and through which political agenda status for health is sought at the local level.

Before the concrete Healthy Cities situation will be addressed, it is essential to provide a condensed description of the two theories that will be used in analysing the agenda building processes in the case studies. In the following paragraph the essence of these two theories on agenda building is described and the theories are compared to one another.

\section{$\overline{4.3}$ Two Theories on agenda building}

\subsubsection{The Agenda Bullding theory}

The Agenda Building theory of Cobb and Elder (1983) was inspired to a large extent by the barrier model of policy development by Bachrach and Baratz (1970). In the barrier model, policy development is considered as a sequential, or circular, activity. It demonstrates that whether, and how, a next phase in the policy process will be reached depends on the ability of the issue to surmount certain barriers (see also Dahl, 1961; Van der Eijk \& Kok, 1975; Glasbergen, 1984). In Bachrach's and Baratz's opinion the policy process is initiated as a result of the ideas and wishes of individuals and groups. These ideas and wishes are transformed into policy demands. If decision-makers agree that such demands should receive political attention, the issue concerned reaches the political agenda. Achieving political agenda status is a first step in the policy development process. With 
regards to health policy, this agenda building theory has been used by de Leeuw $(1989 \mathrm{~b})^{2}$.

Cobb and Elder hawe researched how to overcome barriers that prohibit an idea from becoming the subject of political debate and subsequent policy-making. They addressed the question of "how does an issue receive a policy status and who is imvolved in getting an issue on the institutional political agenda". This process was identified as issue creation. Emphasis was placed in particular on the role of the public at large and of the media in raising awareness for an issue. Cobb and Elder define an issue as " conilict between two or more identifiable groups ower procedural or substuntive matters reloting to the distribution of pasitions or resources." (Cobb \&. Elder, 1983 p. 82)

Not all issues reach agenda status. An issue needs a so-called 'trigger device' as well as a group of supportive people. The support of relevant persons is the result of either personal benefit, or perceived benefit for a specific target group or entire community. Triggers can exist in the place or country under study as well as outside its borders. Cobb and Flder give as examples for domestic triggers natural catastrophes or technological changes. An international conflict in which the United States, which is the country were they did research, is in combat or has a mediating function is mentioned by the authors as an example of an external trigger.

Cobb and Elder distinguish two agendas: the systemic agenda and the institutional agenda. A systemic agenda "consists of all issues that are commonly perceived by members of the palitical community as meriting public attention ond as involving matters within the legitimate jurisdiction of existing governmental authority." (Cobb \& Elder, 1983 p. 85). The governmental or institutional agenda is the "set of items explicitly up for the active and serious consideration of authoritative decision makers." (Cobb \& Elder, 1983 p. 86). Their iclea is that a public problem first reaches systemic agenda status, and in a later stage reaches institutional agenda status.

Cobb and Eder have developed three models on agenda building: the outside-initiative. model, the inside-initiative model, and the mobilization model. In the outside-imitiative model an issue can reach systemic agenda status if it is perceived as problematic by the majority of a given public, requiring action that falls within the boundaries of a governmental authority. Under certain circumstances and with wide-spread public attention and pressure, the issue will eventually be placed on the institutional agenda. If an issue has received a place on the institutional agenda, it is very likely that formal political decision-making and policy development will take place in regards to the issue. In this model, the initiative to push an issue onto the political agenda comes from outside the political system. In the inside-initiative model, it is not the general public but policy makers within a governmental bureaucracy who put an issue on the institutional agenda. This model is used to describe situations in which political agenda proposals come from inside the political system. These proposals are very concrete. The implicit intention is not to involve a larger public. The mobilization model starts with policy proposals that are developed within government. Support is sought for these proposals among the public. The idea is that public support is needed for a policy proposal to become a fornal policy. Support is also assumed to be needed for successful implementation. This model is in accordance with the policy network and policy arena approaches as referred to in Chapter Two.

In the outside-initiative model public attention and recognition through media are regarded as prerequisites for an issue to achieve agenda status. Cobb and Elder (1983, p. 105-106) distinguish the following four types of publics: identification groups or primary stakeholders, attention groups or issue publics, attentive public or generally informed population, and the general public. Cobb and Elder give large explanatory power to access to media (see also Laumann \& Knoke, 1987) and symbolism in the process of issue expansion. Issue expansion means that the attention for an issue expands from being limited to conflicting parties only to a larger public. Groups contact the media themselves or let other (well 
known) people, such as opinion leaders and political leaders favoured by the media, act on their behalf. It has, however, been suggested elsewhere (see also Laumann \& Knoke, 1987; de Leeuw, 1989b; Milburn, 1991) that the impact of media on agenda setting is not as strong as suggested by Cobb and Elder. Contacts with political parties may also be of help in raising political attention for an issue. Through issue manipulation stake-holders try to enlarge the significance of an issue.

If an issue has reached the systemic agenda status, policy-makers will consider giving it a place on the institutional agenda. Achieving that status is likely to happen when issues:

- are defined equivocally;

- are perceived to have a high social relevance;

- have long term relevance;

- are not technical or technocratic;

- are unique (Cobb \& Elder, 1983 p. 96-97).

De Leeuw (1989 p. 58) mentions that with regard to these five aspects, it is not so rnuch facts but perceptions that matter. It must be said that attaining the institutional agenda status is not by definition an indicator of the subsequent development of policy. Political leaders in particular are said to have a large influence in the negotiation process about institutional agenda content. How can such people be reached? In theory, of course, all public groups have access. The resources and status of the group; the issue under discus sion, the personal interest of involved politicians, and the strategic position of the group influence the process of gaining attention within the political arena, however. "New issues/demands from particular disadvantaged groups are therefor least likely to receive attention." (Cobb \& Elder, 1983 p. 93 ).

In the inside-initictive, issue expansion is limited as the policy proposals are concrete and support is sought only among a concerned public. Issue manipulation is not highly signiffcant because policy proposals are very concrete and the parties who are involved are very likely to have similar interest. The mobilization model is based on the recognition that in order to successfully implement policy proposals, support is needed from the general public. Issue expansion takes place from government to issue identification groups and the general public. The government hopes to initiate a public discussion on the issue of concern. Often it appears that most groups never have given serious consideration to this specific issue before the launch of the proposal by government.

Following this brief outine of the most important points of the Agenda Building theory, the next section will describe the Policy Windows theory. The Policy Windows theory is also concerned with agenda building processes, but unlike the Agenda Building theory; is not based on sequential reasoning.

\subsubsection{Policy Windows theory}

The stream model forms the basis for Kingdon's Policy Windows theory. This model (Cohen, March \& Olsen, 1972) was developed on the basis of an investigation of decisionmaking and policy-making processes in organizations (universities). The universities concerned could be characterized as:

- having unclear or inconsistent goals, as they were generated by activinies:

- using unclear technologies;

- facing unstable participation.

Kingdon elaborated the stream model and constructed the Policy Windows theory for investigating policy processes ${ }^{3}$, and more specifically the political agenda setting process. He was inspired to a large extent by Cohen, March, and Olsen's idea to de-empliasize a strict relation between a problem and a certain solution. In his research it appeared that 


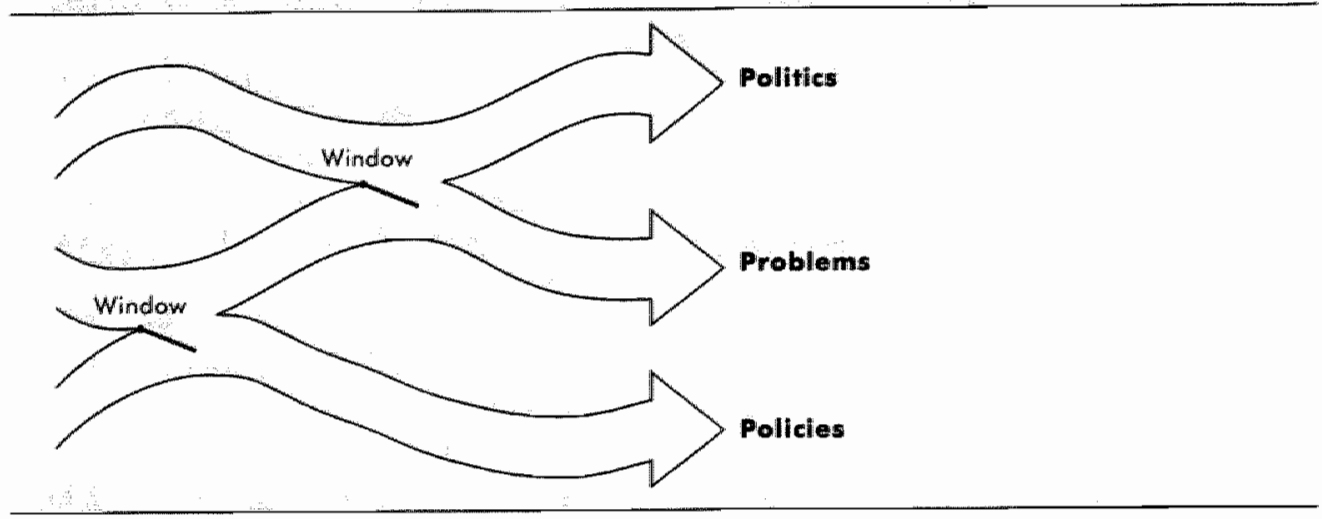

Source: adapted from Koppenjan, ل1. (1993). Manogement wan de belieidsworming. Den Hoog: VUGA.

decision making approaches to policy development could not, or only partly, explain what actually occurred and he therefore decided to develop an alternative theory 4 .

The Policy Window theory basic theoretical characteristics ${ }^{5}(1995$, p. 224) are:

- a goal of discovering from local, contextual, rules a structure in dynamic processes and phenomena;

- the inability to predict and/or discover all parts of the structure, due to 'residuall randomness;

- a dependence on initial conditions, either chosen at random or not, and events.

Kingdon's research addresses the question 'why is it that certain issues and solutions receive political attention and others do not and why this attention, and thus the agenda, change?' Obviously, this question resonates rather strongly with the central question under consideration in this chapter, namely, the question of why it is that Healthy Cities receives attention under particular circumstances. He seeks the solution to these questions by researching agenda building processes and the role of the participants in these processes.

The political agenda is composed of a governmental agenda with issues that receive political attention, and decision agenda containing issues that are ready for political action and decision-making. Kingdon distinguishes three so-called "streams" which. influence the agenda setting process in federal government 6 ; politics, problems, and policies (see figure 4.1 ).

Issues can reach., or increase in, decision agenda status by coupling these three processes. If only two streams are connected (i.e. if a problem is attached to a policy without having political commitment; or if a policy initiative has political commitment but there is no problem to address) chances of the issue gaining decision agenda status are small.

An issue can reach govemmental agenda status or increase its ranking on this agenda, through activities or efforts in either the problem stream such as an (environmental) disaster or budgetary problems, or in the political stream such as a new city council or a shift in management positions. Also personal efforts of visible participants, such as for example important politicians, can impact the rank of an issue on the governmental agenda. Therefore, in order for an issue to receive decision agenda status it has to be recognized as a problem, opportunity or threat, there has to be a solution available, and the political climate has to be ready for a change.

We will now describe Kingdon"s three streams and their respective participants separately. 
The political stream. Political in this context includes, but is not limited to, party political motivations, elections, national mood such as 'anti-government' or 'a strong environmental concern', and changes in administration or pressure groups. This stream directly influences the governmental agenda. The governmental agenda may change due to a change in government which brings along a new administration and staff, and which often results in new agenda items. Other possible reasons for change are a priority change by senior decision makers, or a change in formal responsibilities ('jurisdiction'). In order to mobilize a majority of people for a certain issue, coalitions are built through a process of bargaining.

The problem stream. How does a problem receive attention? Governments, of course, do not operate in a vacuum. They monitor their environment. They also have indicators such as statistics and financial figures on various items in all political fields. A change in the indicator may point to a problem. It may be that these indicators do not automatically call for attention or be seen as needing 'a push ${ }^{8}{ }$, or in the extreme, they may represent an existing or impending disaster or crisis. Kingdon (1995, p. 95) has found that such extreme variation hardly counts for the health care sector, however. His explanation is that health already has a natural place on people's agenda and that crisis in the health sector often occurs at the individual rather than societal level. This level is not visible to the general public . Kingdon's explanation, however, does not fit something like the BSE-affair ("Mad Cow disease') as it evolved into a crisis in Europe in 1996 because the disease was perceived as threatening to the health of the general public. Also it can be questioned whether it is actually health that is on the individual's agenda or simply a preference for not being ill? In accordance with what we have mentioned in Chapter Two, and keeping in mind that Kingdon"s research focused on the health care sector, we believe that the latter option is more likely to be the case.

Other reasons for raising and increasing problem awareness are the use of powerful symbols or personal experiences of politicians or others. The latter reason however, although often believed to be so, seems also to bot be very influential in the health sector (Kingdon, 1995 p. 96). Kingdon mentions that a crisis or problem recognition alone is not sufficient for an issue to gain governmental agenda status. Other elements which play a role in that process are the policy goals, the costs, the (unanticipated) consequences, the (mis-)fit with existing legislation, the perception of the intended change and the fit with the existing agenda items. Also the problem definition largely influences the attendance of agenda status. What Kingdon illustrates with this point is that public problems and public policy are not directly related. He also notes that when policy is developed, it is never possible to please everyone. Alternatives favour some people but at the same time are disadvantageous to others.

Kingdon mentions that in order for new issues to enter the governmental agenda other issues have to lose agenda status. For example, issues may lose agenda status:

- if there is a feeling that enough attention has been paid to them or if government has failed to tackle the problem;

- if other more interesting and inspiring issues come up;

- if high costs or frustration has arisen around the existing issues;

- or, if an issue is not fashionable anymore.

A remark has to be made, however, on the name of this stream, the problem stream. The definition of what an issue is seems to be problematic in this respect. Cobb and Elder define an issue as a public conflict, a problem. But could it not be the case that the problem $_{\text {intream }}$ also describes issues which float around and are not perceived as problematic. but instead represent perceived opportunities, or fashion, or just as an 'innocent' issue? And Kingdon mentions that recognition as a problem is not enough to reach general 
governmental agenda status. The definition of the ussue matters and so do other policy goals, costs, and the existing agenda. So might this stream be better described by the name "subject stream"? Though this unfortunately does not fit the triple "p" of policy, problem and pollitics Kingdon has provided. The name "subject" refers to the content or the situation that receives attention.

Policy stream. The last stream is the policy stream in which ideas, policy proposals, and alternatives float around. "In contrast to a problem-solving madel, in which people become aware of a problem and consider alternative solutions, solutions float around in and near government, searching for problems to which to become attached or political events that increase their likelihood of adoption. These proposals are constontly in the policy stream, but then suddenly they become elevated on the gowernmental agenda because they can be seen as solutions to a pressing problem or because politicians find their sponsorship expedient." (Kingdon, 1984 p. 181) These proposals are developed by people like (academic) researchers, specialists, interest groups, or people involved in evaluation of ongoing policy. Some of them are generalists, others have detailed and specialized knowledge in one policy field "such as health, environinent, or interior affairs. A group of these people is called a policy community. Such professionals develop ideas, write about them, deliver speeches, educate people, adapt the ideas a bit, try them out, consult the public at large, and consult small specialist groups. Some policy commumities are very fragmented, others are quite close. According to Kingdon (1995, p. 118) the health policy community belongs to the latter group.

We question, however, whether Kingdon means a health care policy community or a health policy community as we understand it in our research. A health policy community could be fragmented as so many potential actors can be detected (see Chapter One). Another remark is whether there is a difference between policy communities at local and national levels. One might assume that at the local level a policy community would be relatively closer and tight-knit than at a national level. After all, communication and geographical distance between the participants at the local level is smaller than at the national level. Whether such a health policy community exists and, if so, how it is composed, will be investigated in Chapter Five. Kingdon mentions that in a fragmented policy community, participants differ in thinking and acting, do not necessarily have common problem areas ('common paradigm'), and their communication system is poor. The more fragmented a policy community is, the more likely it is to experience an abrupt agenda change.

Kingdon names this process of persuasion and diffusion by the policy commumities 'softuning up' (Kingdon, 1995 p. 127). The ideas are pushed forward in a process that takes a few years (minimum of two), during which the ideas find ground on which to develop. Through such a process, it is expected that an idea becomes more and more part of the governmental agenda. During this process, however, the ideas do not stay the same. They change over time, and this is called recombination of available elements. This contrasts with. mutation, the appearance of a totally new idea, a phenomenon less likely to happen in policy, according to Kingdon.

Participants. In all three streams, political, problem, and policy, participants are active. Any participant can be positioned in any stream. Some, however, can be more often found in a particular stream than in another. Researchers, for example, are most likely to be part of the policy stream, as they often come up with new initiatives based on the results of their work. So called entrepreneurs play a prominent role in the coupling of two or even all three of the streams. Entrepreneurs are committed people who are generally respected, are high profile, are enthusiastic and creative, and are willing to inwest their time and energy to promote a certain issue and create an opportunity for the issue to receive political agenda status. Characteristics of such persons are (see also Duhl, 1995): 
- they are visible and have an opportumity to make their voice heard, as for example a chairman or president;

- they have strong political and communicative skills;

they are persistent and excellent negotiators;

- and last but not least, they are creative:

These characteristics as defined by Kingdon resemble very much the characteristics of a policy advocate as described by Milio (see Chapter Three sub-section 3.6.3). The core characteristics of both entrepreneurs and policy advocates are that they have certain skills such as communication, negotiation "political, and creativity, and they are high profile. Duhl's ideas on social entrepreneurship resembles the descriptions of Kingdon and Milio. But these last two authors stress more explicitly than Duhl that ultimately the entrepreneur expects future personal benefits from his or her activities; their entrepreneurs are very strategic reasoning actors. Duhl"s central theme is the role of the entrepreneur in facilitation of social change processes, democratization and empowerment.

These entrepreneurs, or policy advocates, are not only working in the health care sector, they can be traced in any policy sector. The modus operandi of entrepreneurs is to wait for a promising opportunity and summon appropriate resources to capitalize on the opportunity. A comparison is often made to surfers waiting for a wave. The surfers do not make the waves, but they are indeed able to ride them. Anti-entrepreneurial activity also exists, of course, which can be described as the process of trying to prohibit a policy window from opening.

Agenda change. Now that Kingdon's theory has been explaimed and the separate elements have been described, we move on to how they interact in the agenda building process. In other words how does agenda change take place?

A change in the political stream or a pressing problem in the problem stream which receives attention from the gowernment opens a so-called "window". Advocates of certain policy proposals seize their opportunity and rush to take advantage of the change or newly relevant problem. They press their solution or alternatives through these windows and thereby become coupled to the events in the political stream or to problems that float in the problem stream. This coupling changes the governmental agenda. For example, when a river is about to flood its banks, the resulting publicity opens a window for advocates of better water control mechanisms. The opposite may also happen. For example, when government decides to build a new air strip at a local airport, enwironmentalists will be more fanatic to prevent this from happening and researchers may put opposing researcli in front of the government. These environmentalists act thus as so-called 'gate keepers" or "anti-entrepreneurs" in a sense that they attempt to prohibit certain couplings between streams. Problem windows and political windows are related. When a window opens because a problem is pressing, the alternatives generated as solutions to the problem are better if they also meet the tests of political acceptability. It is difficult to predict exactly when a window will open or not. However, some significant events can be predicted far in advance, such as elections, change of government, decisions on budgets, and expiration dates of programmes.

It is not passible to contral the process of stream coupling because the opportunity for one issue to rise to the fore represents the discouragement of another. There is, however, room for changing and influencing the process of stream coupling. Although some events cannot be predicted, the entrepreneur makes sure that certain problems and solutions receive more attention than others. This is done through a process of dramatization and demands creativity (see also Edelman, 1988; Gusfield, 1981). Entrepreneurs create support for certain proposals, a policy, or problems, and facilitate coupling between the streams when the win- 
dows are open. The role of the entrepreneur within the theory of Kingdon illustrates the influence individuals and personalities have on gaining (political) attention for issues.

\subsubsection{Comparing the two theories on agenda building}

What are the main differences and similarities between the two theories on agenda building as presented in this chapter?

Both theories address the process side of agenda building. Both consider the political agenda to comprise two different parts, a large general part and a small decision making part, though the theories use different names to label these agendas. We will use in this investigation general agenda to mean the large general governmental agenda and decision agenda to refer to the direct priorities and action agenda.

Both theories mention involvement of specific groups of participants, either visible in particular streams or invisible. Both theories emphasize that stakeholders and entrepreneurs play a role in the process of agenda building. Both allso acknowledge the importance of political involvement in the issue if it is to receive agenda status.

Both theories show that it is important to enlarge the size of the audience to some extent and to widen the scope of the issue in order to increase the chances of receiving agenda status. They name this "issue expansion and issue manipulation" (Cobb and Elder) or "softening up" (Kingdon).

The major differences between the theories can be categorized under the following four headings: policy view, research topic, research question, and participants.

Policy view. The two theories originate from different policy approaches. The agenda building theory of Cobb and Elder (1983) is based on a conception of policy-making as a decision-making process. Policy can only be formulated if conflict barriers have been overcome. Their theory simplifies and structures the policy making process into steps. Agenda building is the first phase in the policy process. The agenda building process itself can also be divided into steps. It appears that their theory is less suitable to the study of complex policy processes (see also de Leeuw, 1989 p. 60-61 and p. 126-136; Koppenjan et al., 1987). The theory of Kingdon (1995) is based on an interactive policy approach. Uncertainty and complex policy enwironments, power, influence, argumentation, benefits, interpretation, and content are all mentioned as central concepts of this framework as an approach to the study of unstructured policy processes (see also Koppenjan, 1993 p. 30 31). A change in the political agenda can occur whenever the streams, political, policy and problems, are coupled. Agenda change is not bound to a specific moment in the policy process; it is more dependent on the circumstances. The attractiveness of Kingdon's theory is its attention to 'fluidity and unpredictability' of policy processes and -in particular- of agenda setting (Macciaroni, 1992 p. 482). Macciaroni mentions, however, that there is a danger that the focus is only, or mainly, on situational factors and that structural factors are neglected.

Research topic. Cobb and Elder focus on conflict situations between groups, whereas Kingdon focuses on problems, politics, and policy alternatives. In the process of agenda building, according to the theory of Cobb and Elder, issues have to pass barriers. Kingdon, on the other hand, seeks windows of opportunity in the agenda building process.

Research question. Cobb and Elder's most important research question is how issues receive agenda status. Kingdon addresses the question why, or why not, (new) issues receive agenda status.

Participants. Both theories mention the participants involved in the agenda building prow cess. Although Cobb and Elder mention that certain individual issue stakeholders, such as visible politicians, opinion leaders, and active entrepreneurs, play important roles, they 
also give significant attention to groups. Kingdon "however, explicitly stresses the role of individuals, especially entrepreneurs, gate keepers or anti-entrepreneurs ${ }_{\text {in }}$ in the agenda building process. Another difference between the theories in this respect is that interest groups are said by Cobb and Elder to have an influence through the generation and promotion of ideas. Although Kingdion generally agrees, he stresses the role groups often play in preventing ideas from receiving political attention. Besides blocking new ideas from receiving agenda status, interest groups are also likely to make substitutions or alterations to issues that are already on the agenda (Kingdon, 1995 p. 49-51). Kingdon further concludes that "hidden" participants such as researchers, civil servants and Congress staff, are involved in making and presenting alternatives while "visible" participants, for example the President, administrative personnel or members of Congress, are deciding on the political agenda. And lastly, where Cobb and Elder attribute great power to media, Kingdon considers the role of media in influencing the political agenda to be limited ${ }^{10}$.

We have touched upon political agenda building in general terms and we have given a brief overview of the two theories that which will be used to analyze the practice and promotion of Healthy Cities in regards to policy. In the following section, we will present the findings on two empirical questions. Although our main aim in this chapter is to analyze the agenda status of Healthy Cities, we are also interested in finding out why the decision is made to become involved in the Healthy Cities. Project in the first place. This will be discussed in section 4.4 . Section 4.5 is organized around the issue of political commitment for Healthy Cities. Political commitment, as will be shown, is mentioned by interviewees and WHO and appears from agenda building theory to be an indicator for possibilities in regards to achieving agenda status for Healthy Cities.

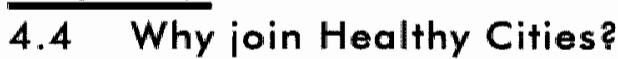

"It is definitely not the shortest raad to go through politics, but it is necessary and in the end you will reach exactly what you want...." (politician, De)

Why would a city join the Healthy Cities Project or a national network of Healthy Cities? This question has been addressed in interviews with local politicians, management representatives, health professionals, and Healthy City team members. From their stories three short descriptions were compiled (cases A, B, and C) which illustrate the reasons why municipalities decide to get involved in Healthy Cities.

\section{Cose A:}

Out of curiosity, a number of health professionals employed by a municipal health authority in the Netherlands went to a conference on the WHO Hecithy Cities. Project and became enthusiastic about the ideos and initiatives brought to their attention. When they came baick they were eager about get" thing Healthy Cities started in their cify. But the question was how to do so. This graup of people ob. tained permission from their Board of Directors to wark oul a plan on how to establish a Healthy Cifies initiative in their city. In addition to giming this permission, the city council decided, as a result af being encouraged by the enthustasts, to apply for membership in the WHO Healthy Cities Project. Participation in this Project would give the city af least two things. On the one hand, the city would get European visibility in the health field, and on the other, membership could be regarded as confirma. Hion of the work they had dome so far on heatth promation. Sharing their enthusiasm, the cify initiated meetings on the Healthy Cities subject in the Netherlands and made other people interested. 


\section{Coise $\mathrm{B}$ :}

The city had always been a city with a rather bad reputation dve to bad health indicators, higher than average viotence and powerty, a poor economic situation, high unemployment and bod housing. A housing survey was done and the outcame indicated that the big probliems were poverty and a dispority in health experience between different neighbourhoods in the city. These problems would have to be tackled anyway, whether the city became part of the Healthy Cities Project or nat. Closely related to these fecionomicl problems health entered the ogenda of both the health outhority and local authiarity.

A few people in the city who thought that becoming a Healthy City would give the issue of health more impetus, more access to resounces and would provide better structures for collaboration. Many intiatives on health and housing and personall serwices were already operational. As a resulf of the personal involvement af certain individuals in the city in the WHO Healthy Cities Project itselfi, it was more or less expected that the city would become part of the WHO Project. However, ot the precise moment in time wherl the city councill said "yes" "and when they were asked to participate in the WHO Profiect, the city had neither clear objectives nor an idea of how to finance the whole thing. Both authorities ultimately decided to finance a portion of the project and to provide in kind help. They agreed on a decllaration to work for the health of the citizens for which the Healthy Cities Project provided on implementation framewark. Though active in the community, the Project was perceived as a politically neutral body.

\section{Case C:}

In this city, the local political climate is embodied by the statement "wo do things this way because we have always done them this way". Such an attitude meant that if was a difficult elimate in which to initicte a new concept like Healthy Cities.

The director of one of the departments of the Health Authority had a wision. The director was very much an initiator as well as persulasive, good with words and able to talk to other directors. The local authority and the Health Authority as a whole did not share the director's vision and did not know about WHO's Health for All strategy. Therefore the director thought about the relationship between Healthy Cities and national policy. Because both authorities were interested in achieving particular national health targets, they would finance a Healthy Cities initiative if it would help them achieve those targets. By working on the targets through Healthy Cilties they would show to the national government that they were in conformance with national goals and policy. Healthy Cities, therefore, was used and promoted as a vehicle for implementing national policy.

The tradition of pramatism in the city was one of the reasons behind the original cynicism towards Healthy Cithes, and behind the city council's appaimiment of a project coordinator on a short term contract to manage and carry out lacal projects. They did not see the coordinator's position as a strategic post and they would never hawe thought that the coordinator wauld ewentually be affered a permaneni post, and that the committe that wauld be set up to support the coordinator would become important and jaintly fumded by the two couthorities.

Neither Case A, B, nor C represent one particular city studied in our research. Each case has been formulated here for the purpose of illustrating the variety of ways in which Healthy Cities has gained visibility in the cities under study. They also reveal a number of real strategies people have attempted to use to get Healthy Cities onto the local agenda. In table 4.1, reasons for involvement in Healthy Cities as mentioned by interviewees are listed (please note that one interviewee can provide several reasons). A unique combination of factors stimulated each city"s participation in Healthy Cities. Not all the elements are of equal importance and influence in all situations. There was no systematic difference between the United Kingdom cases studies and the Netherlands case studies. In all ten case 
The reason why cities got imvolwed in the Healthy City Project and/or a nationall notwork is a mixtune of some of the following elements:

(Interviewees between (): the number of answers given; HCT=Healthy City Team member:

$\mathrm{Pr}=$ Professianal; $M=$ Manager; $P=$ Politician)

\section{The content and ideos of the Project}

- to attach the Healthy Cities ideas to ongoing health promotion research and activities and increase the credibility $\left(2 \mathrm{HCT}_{*} 1 \mathrm{Pr} ; 4 \mathrm{M}_{i}\right.$ I $\left.\mathrm{P}\right)$

- to arise awareness of where and how health is created $(2 \mathrm{HCT} ; 1 \mathrm{Pr} ; 2 \mathrm{M} ; 1 \mathrm{P})$

- it brings new ideas olong (1 M)

- to provide examples of health (related) activities (1 M)

Local/national issues and policies

- having bod thealth and sacial statistics (5 HCT; $1 \mathrm{M} ; 5 \mathrm{P}$ )

- having to implement a national policy document ( $3 \mathrm{Pr} ; 2 \mathrm{M} ; 1 \mathrm{P})$

- due to reorganization and changing enviranments (4 HCT; $4 \mathrm{M})$

- seeing a possibility to attach Healthy Cities to other (high profile) issues ( $1 \mathrm{HCT} ; 1 \mathrm{M}$ )

- facing palitical pressure (regional and national gowernment) (1 M)

Prowision of a working structure

- it provides possibilities to establish local and (inter)national linkages, coalitions and contects (2 HCT; II Pr; $\left.7 \mathrm{M}_{;} 2 \mathrm{P}\right)$

- it is a framework for activities (1 HCT, $1 \mathrm{Pr} ; \mathrm{M} ; 1 \mathrm{P})$

- to exchange information and experience and to learn from each other $\left(4 M_{i} 2 P\right)$

- it legitimatizes ongoing activities $(2 \mathrm{M} ; 1 \mathrm{P})$

Persanal commitment and enthusiasm

- due to individual commitment and personal efforts and/or efforts of one organisation (5 Pr; $5 \mathrm{M} ; 2 \mathrm{P})$

Pragmatic reasons

- to develop the city (city ambition/profillation)(1 $\mathrm{HCT} ; 1 \mathrm{Pr}_{;} 1 \mathrm{M} ; 4 \mathrm{P}$ )

- it is an interesting flag/label (1 HCT; $4 \mathrm{Pr} ; 2 \mathrm{P}$ )

- international initiative (2 HCT; $1 \mathrm{Pr} ; 1 \mathrm{P})$

- to avoid waisted duplication (1 $\left.\mathrm{Pr}_{;} 1 \mathrm{M} ; 1 \mathrm{P}\right)$

- it is perceived as a not politically threatening initiative (3 HCT)

- to expand the portfolio of political responsible $(3 \mathrm{M})$

- to receive money for projects (2 P)

- it is a passibility to undertake extra activities (1 M)

- it provides an added value (17M)

- having connections with the WHO (1 M)

Other

- it was a matter of coincidence (1 M)

- it was good timing and there was a right climate. (1 HCT; 1 M)

- it was a form of curiosity (2 P) 
studies interviewees gave a broad range of arguments to legitimize their personal and cities' involwement in Healthy Ciries. In section 4.7, the elements will be linked to, and discussed in light of, the agenda bullding theories discussed earlier in this chapter. Here we will confine ourselves to a short explanation of each of them.

Content and ideas of the Project. All interwiewees agree that participation in Healthy Cities networks and activities stimulates and accelerates the process of raising general awareness of where and how health is created. Healthy Cities was also perceived to accelerate other local initiatives and as an interesting flag or label for ongoing activities. In that respect, coordinators and project team members in particular expressed their concern that Healthy Cities may easily be regarded as "flavour of the month". In that case, they were generally referring to situations in which people are able to speak a Healthy Cities language, but that are not capable of -or do not have the intention of- putting Heallhy Cities into practice as it is outlined by its major theorists. The danger of Healthy Cities becoming simply a new rethoric or bureaucratic instrument is real in such a situation (see also Baum, 1993).

Local/national issues and policies. Three case study cities were already very much involved in health promotion activities before they entered the WHO Healthy Cities Project. At the time of joining the Project, the cities had either an academic research institute in their municipality or individuals within the health authority working on health promotion. Becoming part of the WHO Healthy Cities Project and making it explicitly known that the city council provided support for that effort was felt as recognition of successful prior work. The label 'Healthy City ...' was fell as a recognition of ongoing activities as much as a call to new ones.

The prevalling belief among interviewees is that health has a low ranking on the city council"s (decision) agenda. Concrete demonstration projects and/or a Healthy Cities label attached to a concrete issue that is already part of the existing decision agenda, however, are seen as likely to engender political support. Healthy Cities, in the opinion of the interviewees, receives a place on the general political agenda and possibly a place on the decision agenda to the extent that it is seen as connected with or responsible for such concrete activities. We might call this the "hitch-hiking concept", to describe the way Healthy Cities "hitches" a ride on the back of a significant political issue in a given community or city. It is, however, striking that only one Healthy City team (in the Netherlands) was visibly creative in finding a fit between Healthy Cities and high profile issues which were already part of the political discussions regarding social regeneration, housing , and safety. They were aware that these issues may decrease in political importance as well. If this happens, Heallhy Cities in the city would theoretically decrease proportionally in political importance and visibility.

In cities with a poor economy and generally low health status, health is often given a more prominent place on the local political agenda than it is in more affluent cities or municipalities. The city governments under study were often reluctant to get involved in yet another initiative; they did not know exactly what it would cost to get involved, and whether it would bring better health to the city. On the other hand, they saw possibilities for using Healthy Ciries to raise the attention for where and how people and organizations could help the local government in tackling the issue of ill-health. In the United Kingdom it appears that part of the support provided by the city governments and Health Authorities for Healthy Cities can be explained by the fact that involved professionals saw the initiative as an opportunity to work on a national policy document, for example the United Kingdom national government's Health of the Nation white paper. In the Netherlands this argument was not explicitly mentioned, which was unexpected due to the fact that local government in the Netherlands has an explicit responsibility for local health policy development, as detailed by the Collective Prevention Act (see also Goumans, 1994; Goumans, 1995). 
Furthermore, it was expressed by managers and Healthy City team members that Healthy Cities project are generally judged on the basis of their potential for facilitating and aiding change processes. Changes are now seen as necessary in both countries of study, due to reorganization of the National Health Service in the United Kingdom, and reorganizations within local government and their responsibilities regarding health and community care in the Netherlands.

Provision of a working structure. In table 4.1 it is clearly illustrated that Healthy Cities was expected to create possibilities for establishment of (intersectoral) linkages and networks at a local, national, and international level. This seemed to be a very important incentive for joining Healthy Cities, one especially mentioned by managers. Apart from the fact that city governments themselves may have reasons for starting collaborative work, the national government in the United Kingdom at least pushes municipalities and cities very hard to work in alliances. Local, national, and international networks make it possible to exchange experiences and information. The exchange of information is largely issue specific; like the Multi-City Action Plans ${ }^{11}$, or based on organizational and planning aspects, e.g city twinning 12. Being part of a network of cities and municipalities who all work towards a joint goal according to shared principles is often mentioned as a stimulus to local Healthy Cities work. Especially when the issue -in this case Healthy Cities- is perceived as difficult to concretize, all visible examples are of help; networks allow the exchange of successful, visible examples. Furthermore, participation in these networks was also felt as a legitimization for activities and health policy development which were already ongoing before getting involved in Healthy Cities. It appeared that involvement in these networks not necessarily led to a change in activities. Instead old activities continued to take place but under a different label.

All five cities studied in the United Kingdom have a so-called steering group and a Healthy City planning team or support unit. Only one city in the Netherlands has these support mechanisms. Another Dutch city used to have a planning group during the first five-year phase participation in the WHO Project, but no longer did at the time of research. For our purposes here, there are two important questions related to steering groups representatives. First of all, do these representatives truly represent an organization, or are they participating out of personal interest? Secondly, are these representatives able to communicate the messages of the steering group to their organizations or parties? In other words are these enthusiastic representatives able to turn symbolically supportive organizations, parties, and associations into committed and active ones? Answers to these questions will be given in Chapter Five on the domain construction of Healthy Cities.

Personal commitment and enthusiasm. The Healthy City initiator(s) almost without exception has specific personal skills for convincing other people of the opportunities Healthy Cities offers their municipality. This personal commitment and enthusiasm is a characteristic that is not limited to the initiating phase only. Even after more than seven years of participation in the WHO Healthy Cities Project or national network, personal commitment and enthusiasm is still generally the engine that drives a Healthy Cities initiative. Sometimes, of cowrse, the earliest initiators in a city leave and are followed-up by a coordinator, or a project focal point is appointed. New people take over the initiator's role. Like the initiator before them, they attempt to make people realize where and how health is created. They also try to explain how personal health and health of the city in a broad sense can be promoted within daily activities.

What is remarkable is that this element of personal efforts was mentioned by all interviewees except, generally, for those who are part of Healthy Cities 'teams'. In practice, however, it is precisely team members who display the strongest sense of personal 
commitment in their work. It is these team members which are the engine on which the intiatives seem to be running. They are often held personally accountable for the success of Healthy Cities in their municipalicy.

If the success of Healthy Cities primarily depends on the personal commitment of managers, politicians, or project workers, this may have serious implications for Healthy Cities projects in regards to continuity. If coordinators leave their posts, if politicians are not re-elected, or if managers find another job, a Healthy Cities project may not only lose a part of the credibility it had built up to that point, but may even find its very existence endangered. This illustrates one of the main reasons why it is difficult to ensure a (permanent) place for Healthy Cities on the political and public agenda.

Pragmatic reasons. Healthy Cities is judged on what it can possibly offer to a city. These possibilities may be expressed in terms of reducing ill-health, but they can also be expressed in terms of the benefits of being part of an international network. Participation in an international initiative facilitates, for example, the possibility of preparing a bid for (European Commission) project money. In addition, Healthy Cities may offer city promotion. It brings cities international recognition and visibility on the map of Europe, and beyond.

Labels may lose their power and Healthy Cities promoters (the individual 'enthusiasts' as mentioned above) felt that it was not the nome that was important but the message that is attached to Healthy Cities. They realized that it was necessary to focus on the message rather than the name. They all recognized that the interest in the title "Healthy City" would ewentually fade away. In the cities that have been working for more than five years. now in the WHO Project, it appears that the name 'a Healthy City' is losing its power. Yet, none of these cities has decided to search for a new name, a new label, for the things that have taken place and have been developed under the current flag of Healthy Cities. It needs to be mentioned here, however, that in the United Kingdom the national network of Healthy Cities has changed its name into United Kingdom Health for All newwork (UKHFA). The main reason for this change was that the name "Healthy Cities" was seen as discouraging non-cities to participate and develop activities. Healthy Cities team members think that politicians perceive Healthy Cities as a politically innocent and not dangerous initiative. This argument, however, is not one based on fact, especially in the United Kingdom. Due to the administrative structure in the United Kingdom, either Health Authorities or local authorities are suspicious when the one stimulates the other to get involved in Healthy Cities. In the Dutch case studies, on the other hand, such suspicion was not expressed. What happened in the Netherlands was that in a few cases the idea of working on Healthy Cities came at a very opportune moment for the local politician responsible for health. Healthy Cities was used during election time or was used to extend the portfolio of the politician responsible for health.

Other. Coincidence, timing, the right climate, and a sort of curiosity among politicians for new intiatives were also mentioned as possible elements which influenced the decision to get involved in Healthy Cities.

The information in table 4.1 shows that the arguments expressed by the case study cities in both countries in support of their involvement in Healthy Cities are numerous. The potential of ameliorating or solving health problems is a possible argument for participation in Healthy Cities. Most arguments for participation, however, are not embedded in health problems. In other words, the arguments that are given for participation are not pre-dominantly related to the stated goal of furthering health status in the cities. Pragmatic reasons, structures, and local/national issues and policies were most often mentioned as reasons for involvement. Managers stressed the structures offered by Healthy Cities as desirable. Politicians apart from local/national issues and policies also primarily mentioned 
pragmatic reasons for involvement. Professionals were involved due to personal enthusiasin and pragmatic reasons. And Healthy City team members were mostly involved due to local/national issues and policies, and for pragmatic reasons.

Once a city is involved in Healthy Cities, the question of whether involvement also implies political support comes up. As will be explained in the following section, polliticall support (or commitment) is regarded as an important determinant for achieving agenda status.

\subsection{Political support}

\subsubsection{The visualization of political support}

Within Healthy Cities an important role is attributed to political support. The agenda building theories teach us that political support plays a role in the agenda building process. Kingdon shows that the likelihood of achieving agenda status will increase if an issue receives political support. Cobb and Elder also show that governmental interest in an issue strongly promotes the achievement of political agenda status.

Ahy prierities that have no political cammitment and resources are not pritorities. Because you cannot mele them hoppen." (Management locall authority, Gd)2

Wif We whole lacal authority has a budget cut and they still make sure that the Healthy Cities activities caincontnue that is one of the measurements of having politicall commitmemt. (Manageiment HA/GGD, E⿰冫)

If the tocal authority finances the health authority and gives them more money than strictly necessary far porforming fheir legol tasks, it proves that they find it important that the health authority does more than only theth legal tasiks." (Politician, Ae)

Box 4.1: What is political commitment?

WHO considers political support to be crucial for the Healthy Cities Project and for healih policy development. WHO allso assumes that adoption of the Healthy Cities principles arid the expression of official political support to the Healthy Cities Project implies the intention of future municipal health policy development. WHO's reasoning is that through such support health receives a high place on the political agenda. If health and Healthy Cities are part of this agenda, explicit health policy will be developed and other policies can be judged on possible health concequences, according to WHO. Therefore, apart from meetings for WHO Project coordinators, meetings are also organized for local politicians who have responsibilities in regards to health and health rellated issues. Every city that wants to participate in the WHO Healthy Cities Project has to show at least a written declaration in which the city council and Mayor express their support for the Project (see requirements, table 1.3, Chapter One). They must also appoint a politically responsible person for the city's participation in the WHO Project.

The question, however, is what the value of political support is if it does not reach. further than a written declaration and participation in meetings. Political support may fulfil 
Political support for Healthy Citties is made visible through:

(Interviewes between (): HCT=Healthy Cities Team Member; PraHealth Professional; M=Manager; $P=$ Polificion

\section{Activifies and policy development}

- The construetion of a city healty plan (HCT; $\mathrm{Pr}_{;}$M)

- Healthy City is part of other policy initiatives $(M ; P)$

- The organization of (Healthy City) activities (HCT)

- The HCT has credibility with groups and is asked for advice $[H C T)$

- Healthy Cities has been mentioned in (local and nationall) governmental acts and publications (M)

- A shift in couneill's thinking/policy $(\mathbb{P})$

- Healthy Cities is part of the municipal warking plan and council agreements $(P)$

Lagistic arrangements and decisions

- A permanent post for the Healthy City coordinator ( $\left.\mathrm{HCT}_{3} \mathrm{M}\right)$

- Availabillity of money/resources/office space to continue activities $(M ; P)$

- An increase in staff of the Healthy Cities team (HCT)

- Contracting new (heolthy city) staff $(\mathrm{Pr})$

- Healthy Cities has nat been hit by lacal government budget cuts (M)

Organizational arrangements

- The steering committee is composed of senior representatives of arganizations and a responsible policion $\left(M_{i} P\right)$

- More than one political responsible person for Healthy Cities (HCT)

- A recagnition of the importance and possibilities that joint warking offers $(M)$

- Politicians as chairpersons of committees and/or meetings $(M)$

- Healthy Cities has survived the re-organization perils (M)

- The director of the health autority/ggd is part of the lacal government policy group $(M)$

- Meetings on city health for senior Chief-Executives (HCT; M; P)

Structural arrangements

- Healthy Cities is integrated in the organization and is no longer a separate bureau (M)

- The reorganisation/set up of a new irfersectoral committee $\left(P_{r} ; M_{s} P\right)$

- The establishment of intersectoral workinggroups (HCT; $\mathrm{P}$ )

(political) Negatiations

- Healthy Cities is part of the political discussions $(N ; P)$

- The city council starts to talk about Healthy Citties, there is awareness with councillors (HCT)

- Healthy Cities has been defended and a stand has been taken against opposites (M)

- Healthy Cities has been discussed in city council committee meetings (P)

Symbolism

- Used as legitimation for certain activities (HCT)

Selthing torgets

- The need is felt to expand the idea (Pr)

- A change of corparative abjectives $(M)$ 
a symbolic function when the support is given in order to be able to participate in the international Project or a national network. Real or tangible support means providing support in terms of resources or defending project proposals that are made in the light of Healthy Cities.

Also it is questionable whether an expression of political support for an issue, for example by means of a formal city declaration, automatically implies a high place on the political agenda for the issue. We will try to illustrate the argument that political commitment is not automatically the same as having health on the political agenda with the following example. Some cities of the first five-year-phase of the WHO Project applied for participation in the second phase. Among these cities was one in which; at the end of the first five-year-period, municipal elections had taken place and new people came into key positions. The municipal workplan suddenly changed, and health was not automatically considered to be part of the main discussion. This happened in spite of the fact that the Mayor and the new city council had signed a document that expressed the city"s political will and commitment to participate in the WHO Healthy Cities Project. Although they expressed their commitment, they did not seem to have reserved a place on the political (decision) agenda.

From the interviews it appears that all interviewees agree with the WHO that political support is necessary for Healthy Cities to survive competition with other initiatives (see quotations in this chapter). Some interviewees do state that Healthy Cities receives this support, though other interviewees claim the opposite. What are the arguments given by these two groups? In tables 4.2 and 4.3 their arguments are shown.

What can be concluded from both table 4.2 and table 4.3 is that there seems to be general political support for Healthy Cities. This commitment is made visible (see table 4.2) mainly through the provision of working structures, some organizational arrangements such as regular meetings, the development of (demo) projects and logistic support in terms of employment of Healthy City staff. At the same time it can be concluded from table 4.3 that these examples are, however, not yet convincing enough to refute the idea that support is more often symbolic and unstable than tangible and stable. For example, table 4.3 shows that not all seats of special committees are taken, that Healthy Cities is often left out of political negotiations, that projects still end, or that there is a general lack of understanding among key figures and groups of what Healthy Cities is all about:

The conclusion that commitment, and particularly political commitment, for Healthy Cities is more often symbolic than tangible, was endorsed by most interviewees in all ten case studies. Strategies have been developed, especially by Healthy City team members or responsible persons, to increase both the tangibility and stability of support. Examples of these strategies are organizational development efforts, demonstration projects, the active involvement of individuals, of organizations and local government services ${ }_{\text {nd }}$ and last but not least, of the city council. In Chapter Six some attention will also be paid to these strategies for increasing real political commitment. In the following section we will limit ourselves to the presentation of a few examples of ways for establishing political support as they occurred in the case studies. 
That Healthy Cities receives no for limited political support is made visible through:

(Interviewaes between 1 ) HCT $=$ Healthy Cithes Team member; $\mathrm{Pr}=$ Professional; $M=$ Mancger;

$\mathrm{P}=$ Politicion)

\section{Perception of health}

- There is a lack of understanding, a misconception (PM)

- Health is not regiarded as important (M)

Logisfic arrangements ond decisions

- Healthy City (and/or health) was not meritioned in, for example, a regular (departmental) bid for moniey (HCT)

- Things are beginming to change, but still projects end (Pr)

\section{Structural arrangerments}

- Not oll seats in the intersectoral committee are taken (HCT)

(political) Negotiationis

- If compared to other issues discussed in council meetings, Healthy Cities looses all the time (HCT)

- Healthy Cities scores vary low in prioritizing (M)

- Health is not part of the criteria for setting political priarities (HCT)

- It is not mentianed in local government's long-term policy or "Ferspectives Act".(P)

- Policy is not judged on health concequences (P)

- There is hardly stimulation and/or evaluation (P)

Symbolism

- If a city council expresses that they are willing to participote in the WHO network alnd/or a national network they think 'theit is it' and continues with their dally job (HCT; M)

- Compared to other cities fin other countries), Healthy Cities in this city receives little or no political suppont (HCT)

- Healthy City received political commitment through personal commitment and efforts, but these people leff and so did the political commitment (M)

- The stamp seems on it, but there is no drive behind it (M)

- We can speak some Healthy City language, but we do not undertake action (P)

- No "loud words" are spoken on this subject (P)

\subsubsection{The establishment of political support}

providing information is a possible instrument for increasing political support. In order to make decisions, the city council needs information, but-paradoxically-it often does not want to be bothered with details. A balance has to be found between the active participation of politicians in health activities and communication between project workers and politicians about health matters.

As health is a relatively new policy field at the local level, politicians in general revealled. that they felt they experience a knowledge gap in regards to health and health policy. A reduction of this gap can take place through organization of small and lively presentations, with involvement of service providers, for example the local government environmental department and the Health Authority, and the city councill (or commitree). At these meetings, participants can discuss their ideas and possible solutions to health-related problems. The information provision on ongoing demonstration projects can also happen through short reports. These reports need to be to the point and also seemingly quite important, need to be wrapped in a "nice coat". 
TPeople do dent bethewe you unless you can show that something works. I do not thimk it is a goad idea to preech without practice." (Business representotive, Jo4)

But you cannot demand enthusiasm, you hawe to gemerate it. You do not do that by statutes. You do thot by persuasion and infecting them with entusiasm." (Mancgement local authority department, Je)

Peoples sirterest has to be attracted, because Healthy Cittes is a llong term process. You have this problem that individwals are committed in stead of a group or a whole organization. Just having an interested individual does nat make a difference in the long term. We beliewe that organizations need to be developed as well." (Healthy City Team member, Fo4)

Box 4.2: How to make people enthusiastic?

Other ways of getting politicians involved in health affairs are the organization of site visits for politicians, or asking them to work as chairpersons of health (related) meetings and conferences. Participation in international conferences and separate meetings for politi cians on the concept of a Healthy City may also stimulate their commitment. Examples of what a Healthy City may mean for a specific municipality can in this case be explained to politicians by one of their colleagues and not only by 'political outsiders". What also seemed to work in this respect is to invite politicians from other municipalities to the city, preferably those who are enthusiastic and who are able to explain health affairs and policy in their own municipality.

What appeared in the case studies is that each individual committed politician represents one possible route for Healthy Cities to expand in political relevance. Efforts were therefore made to increase the interest of individual politicians. These politicians can then assist the Healthy City team members and others in communicating the possible relevance of Healthy Cities for the community to the city council.

In order to "soften up" the political system, Healthy City promoters read political papers and minutes of council or committee meetings. They must do this to keep themselves informed about what councillors see as important. They constantly react, spontaneously or at request, on what they read and hear from a Healthy Cities point of view. From table 4.1 and the boxes with interview quotations in this chapter appears that: (1) personal efforts, (2) the emotion, (3) the persuasion, (4) proactivity, (5) sending in new ideas, (6) timing, and not to forget: (7) marketing and (8) sales techniques, make a difference. $\mathrm{A}$ given proposal is often repeatedly submitted before its successfully adopted, because (see also Kingdon, 1995, sometimes a climate is ready for the change such a proposall represents, and sometimes it is not. The issue must fit the 'circumstances' and vice versia.

It is recommended that these eight aspects are part of the personal skills of those who want to put Healthy Cities on the agenda. Additionally, they need excellent political skills, meaning that he or she understands politics and is capable of communicating with the other players. This does not have so much to do with having a senior position or not, but has everything to do with knowing how to play the game. Such a person has to have visibility within organizations and the city council. The coordinator can present her/himself by going to (political) meetings, by making comments on Healthy Cities, and by explaining how Healthy Cities can assist and provide help to ongoing projects. This personal and active approach has been very influential in the case studies.

Furthermore, they need to have some knowledge of or experience in health promotion and public health. This leads to the conclusion that a Healthy Cities coordinator needs to 
have policy skills, political skills, networking and communication skills, markering and sales skills, as well as financial skills. He or she needs to be sensitive to what are hot items", needs to be persistent, persuasive, creative and needs to have knowledge of organizations. What can be concluded here is that such a multifaceted person will be difficult to find. A relevant, though disturbing, observation is that most health promotion workers, which represent the majority of Healthy City team members and individual enthusiasts, are not educated and trained in all these fields.

What answer can be given, based on the findings as presented so far, to the central question of this chapter, namely what is the agenda status of Healthy Cities?

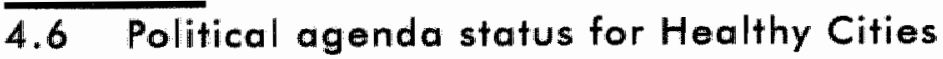

A generalization of the findings from the case studies reveals three different ways through which Healthy cities receives agenda status. First of all, Healthy Cities receives political agenda status when Healthy Cities is attached as a label to issues that are already part of the political agenda. It also receives political agenda status through the personal efforts of influential persons. A third way of achieving political agenda status is through formal decision-making of the city council on participation in the WHO Project and/or a national Healthy Cities network. However, there were not only multiple possibilities in terms of how Healthy Cities reaches agenda status but also in terms of what is put on the political agenda. Healthy Cities is put on the political agenda as:

- activities (projects);

- a (policy) framework;

a representation of the formal decision to participate in the WHO Project and/or national network.

WW made lise of another praject; a horse to ride an. But it took us a lat of efforts to get on this horse." Mencgennerit Health Authority/GGD department, Ac/ $/ \mathrm{c}$

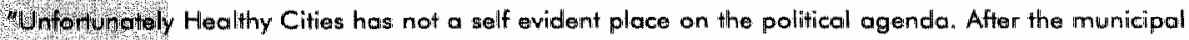
Q ectione the municipal workplan changed, and the thorse the project used to ride on disappeared"."

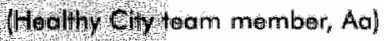

91 Weallitwould be really an issue at the lacal political agenda, it wowld be discussed more often in the eit) councl, niesting." (Management HAVGGD, De)

Whik one of the problems we had iri the council [was, MG] that has been very much oround mididudul nepresentatives of the departments and their own commitment. Quite a lot of key-people have mover ed they do and there are new people moving in. We have to start the process again of davoloping their rale and aworeness. It is not clear that we have an impact on the way departments are moking therp plans. We need to concentrate much more on trying to influence the policy and planning cyclowithin terch department. And also the corporate planning." (Healthy City team member, Ha)

The Horlyychtes ideology is not self generating. We will never reach the stage that people will have diroy, the line of Health for All in front of them. It is naive to think that." (Healthy City team member, Fa4)

Box 4.3a: Healthy Cities and political aganda as it appears fram interviews 
Activities, such as short term issue-based Healthy Cities demonstration projects, are very likely to be part of the general political agenda. Depending on the relevance of the subject that is addressed by a given project, the project itself may even receive decision agenda status. The personal skills and efforts of Healthy City promoters, such as the coordinator, steering group members, or enthusiastic politicians, play an important role in identifying health dimensions in issues that are part of the decision agenda. It is questionable, however, how long a high rank for Healthy Cities on the agenda will last when the attention is created through successful hitch-hiking with issues and persons (see box $4.3 \mathrm{a}$ ). Attention. for issues declines after awhile, and important persons move on.

Healthy Cities as a (policy) framework (see also Chapter Three, section 3.6) could only be visibly detected in three case studies in the United Kingdom. In these cities the concept of Healthy Cities is used as an umbrella, a framework, to link the different public health (related) strategies and activities that take place. If Healthy Cities is used as such a policy framework, it is obwiously part of the general political agenda. It may even be moving towards decision agenda status through development of health plans (see Chapter One). Interviewees expressed the expectation that the likelihood of using Healthy Cities as a policy framework will increase with time. Also the attainment of a permanent place on the general, and even decision, political agenda is perceived as likely to increase in time. Increased political attention for Healthy Cities happens not only due to the length of time a project has been in existence. It may also happen when (demo) projects demonstrate success, showing visible and concrete examples, and when health plans are successfully taken up and implemented.

City councils have to make a formal application both for participation in the WHO Project and in national networks. Healthy Cities is therefore explicitly brought under the attention of city councils. Because formal city council decision-making is required, it might be successfully argued that a place is reserved for Healthy Cities on the general political agenda. When seen from a more realistic perspective, it is likely that in this situation Healthy Cities is a label that represents the decision to participate in a Project or network (see for example Box 4.3 b).

Cit Counclil Decision: to take the policy paper on participation of the municipallity of Eindhoven in the second phose of the WHO Healthy Cities Praject ('93-'97) as the starting point for policy development:" City Councl sessian or. 220, 23 November 1992 in Cosiin, d. (1993). The application of the City of Endhoven lor desigination to participate in the 1993-1997 phase of the WHO Healthy Cities Project. Edworon $6 \mathrm{GD}$.

Politicel commitment: Healthy Cites policy is explicitly part of the lacal gowernment policy. Ht has been deflned os one of the core activities of the municipality of Almelo. It is an essential port of the social renewal policy." (Zaal, K., Ooijendijk, W. (1993). Gezonde Steden Beleid Almelo. Leiden; NIPG/TNO)

7The Healthy Cities Project facilitatied a collective approach to the City Health Plan. The Health Plan process Wos purposely started with the major agencies in the city, as real commitment from them wos necessary if the plon wosto be anything more than a "wish" list. An indication of the importance that agencies placed on this fdea $1 \mathrm{~s}$ that wery busy departments gave valuable time to make comments on the draft version. The Cty Hoalth plan has been adopted by the three statutory agencies in Glasgow theaith boord, district council and regional councill) and they have agreed to dewelop the work, ideas and issues found within." (Glasgow Hecityy City Project (1995). Working together for Glasgow"s health. Glasgow: Healthy City Project.)

Box 4.36: Healthy Cities and political agenda as it appears from official documents. 
The overall conclusion, however, is that in all case studies considered in the present study, Healthy Cities has a position on the general political agenda. If Heallhy Cities is part of the decision agenda, its position on that agenda is very likely to be unstable. Table 4.4 provides possible explanations to what hinders Healthy Cities in receiving a solid, stable and sustainable, place on the political agenda. The elements that are shared by all interview categories as important in the agenda building process are the conceptualization of Healthy Cities and health, expectations, commitment, and logistical factors. Organisational factors, experience, politics, and political negotiations are also mentioned by a majority of the interviewee categories. In general, managers stress structural aspects as elements that influence the agenda status of Healthy Cities.

There is a limited understanding of what can reasonably be expected from Healthy Cities. What are the possible benefits of such a project, what are the investments, how can progress be proven? The fact that participation in a national network or the WHO Project itself most often does not result in additional financial resources for a city means, also, that there are minimal concrete incentives for even inquiring into such issues. Also, due to organisational aspects such as time constraints or heavy workload, it may be difficult for organizations to get involved in yet another initiative or committee. The Healthy City team members seem to recognize that personal commitment alone is quite limited in helping a Healthy Cities initiative receive agenda status. Indeed personal efforts and a pragmatic way of reasoning have a major impact on the decision to get involved in Healthy Cities and the reception of political agenda status. However, Healthy Cities ideas are in that case not structurally integrated within organizational goals and efforts. We can therefore conclude that if a city signs up with the Healthy City Project due primarily to the efforts and skills of certain individuals of, for example. Healthy Ciry team members, agenda status can indeed be achieved but remains quite vulnerable. As already mentioned, ambitious and inspiring people tend to move on, managers change jobs, enthusiasm sometimes fades away, and politicians may not be re-elected.

Local government provides logistic support in terms of permanent and temporary staff and financial resources for Heallhy City projects. However, projects are often fixed-term and when it comes to political negotiations, it turns out that Healthy Cities has low priority. This low priority in itself can be explained by some of the other elements in table 4.4 :

- Healthy Cities is new:

- health promotion ideas are aimed at long term results;

- the results are not self evident;

- experience with Healthy Cities is low;

- it is not clear what can be expected, etcetera.

The conceptualization of Healthy Cities, how the concept is understood and what it means for individuals, for a city, for an organization, seems therefore a decisive factor in development and receiving agenda status for the initiative in a municipality. The WHO and local Healthy City project teams already provide a great deal of information and examples to involved cities. A way of overcoming this 'barrier' in the agenda building process must be sought in time, through gained experience, and through the learning-process of locallyinvolved actors rather than through the provision of still more information.

A low or high ranking on the general political agenda and/or an unstable decision agenda status has been explained by interpretations of the interviewees' personal ideas and experiences. We will now reflect in section 4.7, from an agenda building theory perspective, upon the question of why it is that Healthy Cities generally holds a relatively low rank on the political agenda. Besides this explanation based on process characteristics of agenda building, an additional explanation of the conclusion will be given based on intrinsic characteristics of Healthy Cities. 
Elements that influence the lachievement of political agenda status of Hedithy Cities are:

(Interviewees between 1): HCT=Healthy City Team Member: Pr=Professional; $M=$ Manager; $P=$ Politician)

\section{Conceptuolization/perception of Healthy Cities}

- For example, something extrafon top; an organisation that runs projects; people that talk nice to each other; a framework for city policy development; guidelines for intersectoral collaborative work; a framework for health policy development; the HA/ggd; other (HCT; Pr; M; P)

- The way Healthy Cities is brought under the city councill's attention (HCT)

- There is o lack of credibility (Pr)

\section{Conceptualization/perception of health}

- The question is asked what constitutes health (HCT; Pr; P)

- Health is not perceived os "interesting' (HCT; Pr)

- Health has a low status within the municipal apparatus (M)

- The subjects that already receive attention leg. for care and cure it is eassier to receive commitment than for health promotion and pirewention/ (P)

Logistic aspects

- The availability of resources (HICT; $\mathrm{Pr} ; \mathrm{M}_{i} P$ )

- It is on the egenda in theory, but not whem it comes to money (HCT)

- There is not much money involved (M)

Organizational aspects

- The situation of organizations $(\operatorname{Pr} ; M)$ (for example economic situation, owerworked or not nesources, changeability)

- The difficulties in feeding it into the work of individual partners (Pr)

- The existing traditions and unwillingnes to change $(M)$

- The steering committee turns out to be a very loose alliance (M)

- The different local autharity departments are not judged on Health(y Cities) activities (M)

- The reorganisation within gowernment and the health field $(M)$

- A lack of contral and evaluation systems and stimulation mechanisms (P)

Structural aspects

- The national/local government structures and responsibilities (M)

- The historical grown and formal relation between the heaith authority/ggd and the lacal authority (M)

- The conceptualization, reputation and formel tasks of a ggd ar health authority (M)

Politics and (political) negotiations

- Councillors are ruled by their agenda's $(M ; P)$

- It is difficult to score (on short term noticel with thealth in a political perspective (HCT)

- The political compasition/make up of the city council (M)

- There is hardly debate, hordly defence and no position is taken with regard to health (M)

- The position and attitude of the (potentiall actors (M)

- There ore so many things that need explicit attention (P)

Expectations and commitment

- There is al general lack of faith (HCT; Pr; M)

- The time perspective and the expected evidence is unclear $(M, P)$

- There is hardly organisational commitment (HCT; $\operatorname{Pr} ; M)$

- The benefits and perceived relevance is low (or questioned)(M, P)

- There is personal commitment only $(\mathrm{HCT})$

- Managers of organizations or departments show a lack of interest (M) 
Experience and knowrledge

- There is a general lack of understanding ( $\mathrm{HCT}$; Pr; M)

- Experience and knowledge in this field is poor (HCT; M)

\subsection{An explanation of the political agenda status of Healthy Cities}

\subsubsection{The political agenda status explained by the Agenda Building theory}

Cobb and Elder distinguish among two agendas, the systemic and the institutional. In order for an issue to reach systemic agenda status, it must be perceived as problematic by a public at large and require action that is perceived to fall within the mandated boundaries of a governmental authority. Cobb and Elder have developed three models which illustrate the ways agenda status can be reached. An issue can reach agenda status through a public conflict (outside-initiative model), through governmental activities supported by a limited concerned public (inside-initiative model), and through governmental activities supported by a large public (mobilization model). An examination of Healthy Cities and political agenda status in terms of the Agenda Building theory from Cobb and Elder yields the following results.

Healithy Cities is not perceived as problematic, and is not supported by the public at large. Instead Healthy Cities is initiated and promoted by a relatively small group, most of the time composed of representatives of the Health Authority/GGD. This group can be expanded by representatives of local government services, politicians, and representatives. of local groups and organizations. This support group, a project team or a group of individuals, can be labelled as the identification or primary stokeholders group. They support Healthy Cities because they find the concept personal compelling and of significant potential and real benefit for the whole community. The attention groups are those who are involved in issue based (demonstration) projects. These groups see Healthy Cities as a valuable concept, but their active support is generally limited to the content of the demonstration project. An example of an attentative public would include a specific neighbourhood which is very much involved with promoting the well-being of its residents. Information gleaned from the case studies revealled that the general public most often does not know that its city is a Healthy City. Often they did not even know that such a programme exists.

Issue expansion of Healthy Cities is not created by having a public conflict between groups. Instead of conflicts. short term demonstration projects are used to increase visibility and show evidence. When a special Healthy Cities event is organized, such as an international conference, or the launch of a book or a specific activity, there is generally media coverage. In some cities the Health Authority/GGD is very active, setting up health information stands, and using local newspapers, local television, or cable information facilities to get their messages to the public. It is through such mechanisms that Health Authorities provide not only general health information, but information specific to Healthy Cities. Most cities are not yet so developed that they have a public relations strategy in this respect.

Also individuals play an important role in the presentation of ideas throughout the process of agenda building (see table 4.1 under personal commitment and pragmatic reasons). Cobb and Elder only pay attention to individuals when those are visible opinion leaders or 
political leaders who play a large part in agenda building. As mentioned earlier, they tend to focus primarily on groups.

Opinion leaders and political leaders are used by the people who chamnel a Healthy Cities initiative towards agenda status to raise awareness for the issue. Political leaders are also lobbied as a potential means of giving Healthy Cities agenda status. It appears that most political leaders were easy to reach for Healthy Cities Project coordinators. Often this is due to the fact that most coordinators or project contact persons already had excellent political skills and high profiles within their respective city councils when the Healthy Cities initiative began.

Some politicians supported Healthy Cities in order to upgrade their personal portfolio; some wanted to plant a visible flag before election time. Especially in the United Kingdom it appeared that newly elected political parties were willing to use Healthy Cities as a concept for change in the city. In the Netherlands, there was no explicit change in thinking on Healthy Cities due to a change in the composition of the ciry council or due to a change in the ruling political parties at the same level. In general the influence of the political climate was not large on the agenda building process of Healthy Cities, but in the United Kingdom it can be said that a Liberal democrat and Labour climate were more favourable for the Project than a Conservative climate.

The support group aims through issue monipulation to define Healthy Cities in a way that fits into the existing political situation in a given municipal environment. For example, they make sure that Healthy Cities actions, such as safety projects, elderly projects, environmental health projects, relate to governmental authority responsibilities. The aspects of conceptualization of Healthy Cities and health (see table 4.4) and symbolism (see table 4.3) play a role here. At the same time, it is realized that it is a statutory duty neither to work on Healthy Cities, nor to develop an explicit health policy based on HFA2000 premises. Issue manipulation is a possible way of overcoming barriers (as mentioned in table 4.4) such as limited experience or political negotiations.

Healthy Cities as a concept is not powerful enough to receive agenda status sporataneously. It thas to be brought explicitly to the attention of politicians and public groups by a group or by individuals. In table 4.1 elements are shown which could be considered as trigger devices for Healthy Cities. Not all elements listed in this table, however, are explicitly mentioned by Cobb and Elder. For example, the content of a project is difficult to place within their theory. Personal commitment could be linked with the role Cobb and Elder see for opinion leaders, but from section 4.5 it appears that personal commitment can also be found among many individuals who would not be described as opinion leaders. Other examples of trigger devices are attendance at conferences, a pressing local problem, local elections, visits of representatives of outside Healthy Cities initiatives, or of the WHO itself, a perfect fit of Healthy Cities with existing municipal policy, personal preferences, and the need for a local working structure which is offered by Healthy Cities.

The above analysis leads to the conclusion that the outside-initiative model does not fit the Healthy Cities agenda building practice. It seems that it is rare for Healthy Cities to be pushed forward by an informed public and the public at large. Healthy Cities is most often introduced by a small (public) identification group, the so-called primary stakeholders group. This group first tries to obtain recognition from relevant and important groups and from the ciry councill. But the aim of the identification group is not to inform only at limited public about Healthy Cities, but ultimately to aim for a much larger expansion of the issues generated by the presence of Healthy Cities. This would make, from the two remaining models, the mobilization model, more than the inside-initiative model, a valid instrument for considering Healthy Cities agenda building practice. 
Based on the inside-initiative model and the mobilization model, Healthy Cities would be considered part of the systemic political agenda if the issue is initiated or supported (see also in table 4.2) from inside the governmental apparatus. The issue would reach decision agenda status if it is attached to an opinion leader or politician, or if through effective issue manipulation Heallhy Cities is perceived to have a connection with something that is part of the decision agenda. Based on the outside-initiative model, however, Healthy Cities is not likely to receive systemic agenda status, because conditions such as general public awareness of the issue, the perception of the issue as a problem by the general public and the involvement of the media, are not met. The fit, using this model with the Mad Cow Disease as it rose to general awareness in early 1996 as a healththreatening issue is far better than with Healthy Cities. There is also a fit with discussions in the Netherlands about extension of the national airport related to health questions which touch upon public problems. It appears that when something is perceived as an unknown but potential threat to public health, health receives through the issue a place on the decision agenda.

There is thus a fit between elements of the Agenda Building theory and agenda building practice in Healthy Cities. It is therefore not implausible to use the Agenda Building theory to explain and predict agenda building processes in the case studies. For example, issue expansion, achieved through support group efforts such as demo projects and issue manipulation, does indeed enlarge the attention for Healthy Cities. From the three models, the mobilization model is most likely to provide explanatory power to Healthy Cities agenda building practice. Efforts are made to mobilize a (larger) public for Healthy Cities.

Elements from the Agenda Building theory can be traced in Healthy Cities agenda building practice, such as support groups, opinion leaders, issue expansion, and issue manipu lation. But these elements do not reveal the whole picture. For example, it is difficult to use this theory to explain involvement in Healthy Cities for pragmatic reasons. It is also difficult to show the combined effect of several elements, such as a combination of structural and personal aspects, political climate, and conceptualization of the Project. And these elements play a role in the Healthy Cities agenda building process (see for example in tables 4.1 and 4.4). Cobb and Elder focus more on single elements than on combinations, and they leave no room for the idea of good timing or having the right climate.

In section 4.3 it has been shown that Kingdon's theory is not consonant with models that are entirely based on sequential reasoning. The theory offers the possibility of considering different events that happen parallel and sequential to each other. What this perspective offers for the interpretation of the results of sections 4.5 and 4.6 will be shown in the following section.

\subsubsection{The political agenda status explained by the Policy Windows theory}

Kingdon starts his book with the phrase "Greater than the need of mighty armies is an idea whose time has come." (Kingdon, 1995 p.1) This was precisely what was mentioned by several interviewees when they where asked why it was that Healthy Cities was given political attention, that it was an idea whose time had come.

Like Cobb and Elder (1983) also Kingdon (1995) considers the political agenda as comprise of two parts: a general governmental agenda with issues that receive political attention "and a decision agenda containing issues that are ready for political action and decision making. Furthermore he distinguishes three so called streams: a problem stream, a policy stream, and a political stream. Changes in the streams create so called windows. Due to a coupling between either the policy stream and the problem stream or between the political stream and the policy stream it is possible to change the governmental 
agenda. If all three sireams are coupled it is very likely that issues will receive decision agenda status. What can be mentioned about these streams?

The political stream. This stream directly influences the general political agenda. The general political climate in the case studies varied from "we are in the mood for innovation" to "we do things because we have always done them this way". From tables 4.3 and 4.4 it can be concluded that political negotiations and political support for Healthy Cities indeed take place, meaning that Healthy Cities is part of the general political agenda. For example, in one case study, a new city council committee was set up as a result of Healthy Cities. Furthermore, the personal commitment of the politician responsible for health ensured for some case studies a place for Healthy Cities on the general political agenda. But this attention would fade away if the politician in question did not make continued personal efforts to increase the visibility of Healthy Cities within the city council and local government. Also, local political elections (for this research, relevant elections took place between 1990 and 1995) caused in some case studies a renewed interest in Fiealthy Cities. This interest resulted in a relatively high ranking on the general agenda. In two case studies, however, local political elections caused Healthy Cities to be taken off the decision agenda and thereafter received a low ranking even on the general agenda. In both countries national legislation required that local governments undertake efforts in the interest of health. In the Netherlands the Act on Collective Prevention (1991) requires local government action, but this Act does not explicitly mandate that local government develops thealth policy, let alone a healthy public policy. The United Kingdom national government's white paper 'Health of the Nation' (1992) and the Scottish equivalent 'Scotlands Health a Challenge to us all", requires that all local authorities to work on five public health fields: Cancer. Heart Disease, Mental illness, HIV/AIDS Sexual health, and Accidents. Local government is asked to work together with a Health Authority to plan health care in these fields through joint efforts. Some cities in the United Kingdom do this under the umbrella of a Joint Consultative Committee. This committee, consisting of representatives of local government and Health Authority, was originally set up to provide for the joint planning and financing of community care. That these national government requirements indeed can play a role in the involvement in Healthy Cities can be concluded from table 4.1 under local/national issues and policies.

There are some political tensions associated with the concept of Healthy Cities because a lot of people (politicians) still associate health with health care and hospitals. People may easily get confused by the implication inherent to Healthy Cities that more attention for health does not necessarily mean more hospitals. An example of that is the remorganisation of the National Health Service in the United Kingdom. Another political problem is that Healthy Cities works with long-term objectives. Politicians prefer to work with medium or short-term goals as they are elected for a fixed medium-term period.

Table 4.1 also demonstrates that some local governments, in particular in the United Kingdom, saw in Healthy Cities a way of avoiding waistful redundance and as a means of generating money for projects and of establishing greater collaboration. Collaboration is somerhing generally made necessary by budget cuts imposed on local governments. Though municipal governmental entities are the major service providers at the locall lewel, they recognize the needs and opportunities for working together with private organizations. In particular, collaboration with the private sector can be lucrative due to the fact that European funding is often given contingent upon collaboration between public and private initiatives. Healthy Cities, as an international initiative, may be perceived as an ideal tool for achieving such collaboration, and thus for delivering the chance for European funding. 
The problem stream. The problem stream can also directly cause changes in the general politicall agenda. In the case studies, different issues were either mentioned as health problems and/or health related problems or as issues that received attention from a political and/or professional perspective. Table 4.5 prowides a general overview of the (health) problems that were mentioned in the interviews. It appears that in the United Kingdom general issues such as poverty, housing, deprivation, and lifestyles are mostly mentioned as health problems. In the Dutch case studies, however, it was group specific issues, such as elderly, youth, immigrant, and lifestyle issues which were mentioned as important health problems. If Healthy Cities demonstration projects were organized around issues that were politically interesting, the place for Healthy Cities on the general agenda increased. In some cases Healthy Cities could subsequently reach decision agenda status, either because the issue it was attached to was already part of this agenda and/or because that issue entered the agenda at an opportune moment.

Other problems that float around in this stream are organisational, logistic and structural. Such problems influence the decision to get involved in a demonstration project, or the provision of political support. From the information in tables $4.2,4.3$, and 4.4 it can be concluded that these problems/aspects play a role in the agenda building process of Healthy Cities. Political tensions and difficulties also could be given a place in the political stream as part of the 'political mood'.

The Policy stream. Healthy City demonstration projects float in this stream, together with other ideas and policy and project initiatives. The idea of 'softening up the system', as mentioned by Kingdon (see also sub-section 4.3.2) to describe the persuasion and diffusion of new ideas, is exactly what is observed in the case studies. Healthy Cities ideas and principles are tested by means of short term demonstration projects. Conferences and small business meetings are organized to share successes and failures, where people from other Healthy Cities, even from abroad, are invited to talk about their experiences. Lectures are given by promoters, which is most of the time a small policy community of about five to twelve people. Especially community development and organizational development methods are used in the process of softening up. How these methods are used by these groups will be described in Chapter Six. It appears from table 4.4 that there is limited experience with Healthy Cities and that there is limited understanding of what can be expected from Healthy Cities initiatives. Softening up plays an important role in diminishing this limited understanding and experience.

Healthy Cities can be regarded as a solution, for example, to health problems related to unemployment. It may also be regarded as a way of tackling problems related to the low socio-economic status of certain populations within a city. Healthy Cities can also be regarded as providing the possibility of international networking. which delivers greater experience and possibly even international resources. Healthy Cities can be used to promote the activities that take place in the city with regard to health as well. And Healthy Cities may aid some cities in increasing their visibility.

Healthy Cities can also be regarded as an alternative, for example, to politicians looking for a new "flag" or a visible project to work on. Or initiatives could be used to promote the financing and use of a new health-related technology (like geographic information systems). Healthy Cities can even function as a project for which a local government seeks a grant. An option that is indirectly mentioned by Kingdon when he says that policy options that meet each other do influence each other, is that Healthy Cities could be attached to another policy option floating in the policy stream which is more likely to receive attention. 
Table 4.5: issues that are perceived as health (related) problems at local level floating in the problem stream.

These issues were mentioned by interviewees as health (related) problems. We hove marked with 1, 2, and 3 between () the top-three of health problems in the Netherlonds and United Kingdom.
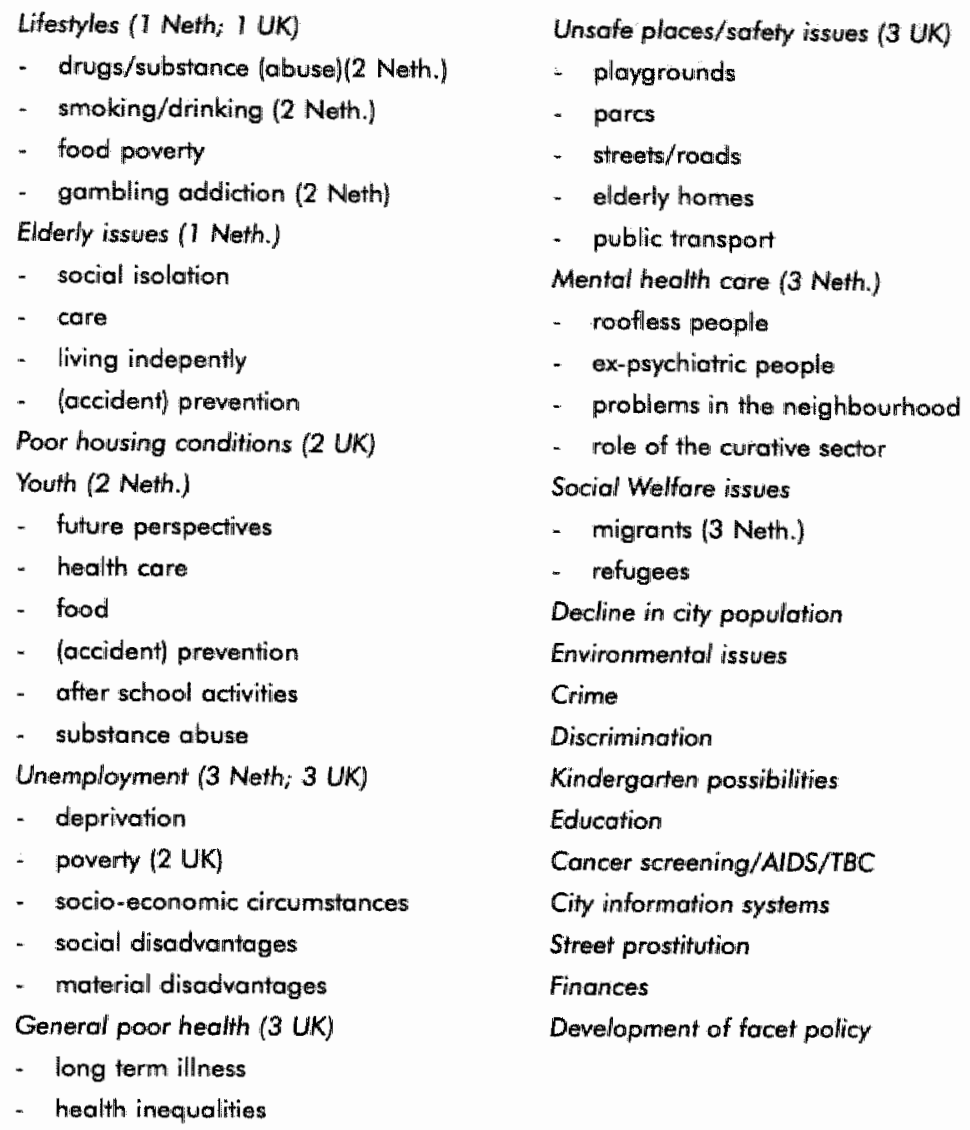

Or the national. government may requests that the local government work on health, whereby the local government can decide to use Healthy Cities as a vision or framework with which to work. How Healthy Cities is operationalized and what activities are undertaken under this label differs therefore from locality to locality. To our opinion operationalization. resembles 'recombination'. Recombination also takes place during the process of 'softening up'. The concrete hands and feet that are given to Healthy Cities (the conceptualization, see table 4.4) depends mostly on local circumstances and participants' perceptions.

Participants. As a separate chapter (Chapter Five) is devoted to actors and activities, we will limit ourselves here to a brief description of the participants in the streams. The Healthy Cities coordinator or contact person is very much comparable to the description and characteristics that Kingdon attributes to entrepreneurs. Such people are waiting continuously for the opportunity to push Healthy Cities. Entrepreneurs have the skills and creativity to find a fit among policies, participants, problems, and Healthy Cities. They often receive support from a policy community, at the local as well as at national and international levels. 
The organizations and individuals inwolved in this policy community generally share a personal commiment to Healthy Cities ideas and principles, but may also be policy professionals enthused by a certain issue based project or for strategic reasons. The most important participants in this policy community are Healthy Cities steering group and support group members, politicians, academics, WHO Healthy Cities project office members and community group members. It is not easy to depict a health policy community. because so many different actors and policy sectors can be inwolved. This is characteristic of facet policy and intersectoral collaboration (see Chapters Two and Three). It is allso central to an interactive policy approach (see Chapters Two and Five). Chapter Five details the composition of the policy community, its activities, and the structures in which it operates. A concluding remark which should be made is that all these organizations and individuals which are part of the streams have their own characteristics, experiences, perceptions, ideas, enwironments, structures, and decision-making systems. These characteristics influence the way they act and behave in these streams and ultimately result in agenda change.

Policy windows. The (recombined) ideas that survive the consultation process in the policy stream demand governmental action. At the same time, the community has to be interested and the idea sustainable. It is precisely here that the difficulties of Healthy Cities begin. Healthy Cities as such has survived consultation processes so far, but discussions on the feasibility of Healthy Cities continue. Healthy Cities is perceived as neither sustainable (yet), nor as a subject of interest to the public at large. It appears that politicians find it hard to consider Healthy Cities as a concept that should influence mainstream policymaking. When it comes to small-scale short term projects, with visible and concrete outcomes, it is far easier to attract attention.

It is, therefore, most of the time either a window between the political and policy stream or a window between the problem and policy stream which provides the opportunity for Healthy Cities to move on the general political agenda. Kingdon shows that having alternatives or ideas is not enough to gain a place on the decision agenda. "That should imply that although Healthy Cities is regarded as an interesting concept that receives political commitment (see table 4.2 ), it is not self evident that it also receive a place on the decision agenda.

It is only in some of the cities that are involved in the WHO Project for a second fiveyear-period that the possibilities for achieving decision agenda status for Healthy Cities as policy framework comes up. These cities are in the process of health policy development and are trying to achieve a mainstream status for the activities undertaken in the interest of health. However, time involved in the Project must not be confused with stages of deveJopment or the performance of certain activities. What happens in a localiry is not only a matter of time, but also a result of a combination of other factors, as explained in this chapter and such as will be explained in other chapters. As mentioned earlier, Healthy Cities can also receive decision agenda status if it is attached to a concrete issure that is already, or very likely to become, part of this agenda. In these situations agenda status is dependent on the political attractiveness of the host-issue.

It is difficult to predict exactly whether and when a window opens or not. In the case studies it appeared that it could happen during local political election time two months before and one month after the elections, at conferences varying from during the conference to two weeks after the conference, or when a city faces pressing problems.

The Policy Windows theory offers a gentle way to structure the research findings. It offers possibilities for analytical generallization of the case study specific findings. The case studies show that most of the time not "crisis' but other activities take place which open 
the window. For example, an individual creates the opportunities, or a pragmatic concern triggers the elevation of Healthy Cities to the political agenda. It is not so much the Healthy Cities content but the local (and national) circumstances and individual actions and decisions that have a large influence in the agenda building for Healthy Cities. The elements that are visible in the Healthy Cities agenda building practice, such as personalities, persuasion, enthusiasm, profile, negotiation, communication, coincidence, and pragmatism, can all be explained in terms of Kingdon's theory.

The previous two sections have shown that based on process characteristics of the agenda building practice, the political agenda status of Healthy Cities can be explained. From this explanation it appears that the content and ideas of the Project are not regarded as very important elements in the agenda building process. Other elements such as individual commitment, the conceptualization of the Project and the expectations, structures, political support, organizational or logistic arrangements play a larger role. In the following section we will demonstrate that, although Project content does not play a large role in the agenda building process, Project intrinsic characteristics can also explain Healthy Cities' position the political agenda.

\subsubsection{An explanation of the political agenda status of Healthy Cities based an issue characteristics}

The process characteristics of the Heallhy Cities agenda building practice can explain why it is difficult for Healthy Cities to receive agenda status. Here, we will show that an additional explanation can be derived by using our theoretical lens to focus upon issue, or intrinsic, characteristics.

There are authors (among them are also Cobb \& Elder, 1983) who explain and predict agenda status achievement by focusing on the intrinsic rather than process characteristics of issues (see also Hogwood \& Gunn, 1984; Rogers, 1983). For example, Cobb and Elder mention in their work that, in addition to process characteristics that influence the agenda bualding process, issue characteristics such as specifity, social significance, relevance, degree of complexity and categorical precedence can also be involved. Cobb and Elder $(1983$ p. 89$)$ also found that political agendas consist mostly of old issues. Interestingly, concerning new issues, the ones that come up spontaneously seem to be more compelling than those that are carefully planned and pushed forward by a group. Hogwood and Gunn (1984) mention particularity, the extent (scope), the emotive associations, power and legitimacy, fashion, and impact as decisive factors in reaching political agenda status. Rogers (1983) focuses on comparability, relative advantage, trialability, complexity and observability. Rogers uses these characteristics in his theory on 'Diffusion of innowations'.

Because we regard innovation as an intrinsic aspect of Healthy Cities, we will use the characteristics as defined by Rogers ${ }^{13}$ to illustrate our point in this section.

Comparability is the fit between a new idea and existing beliefs, experiences, and working methods. The more a new idea differs from the existing situation, the more difficult it is to introduce it. Examples of this characteristic for the Healthy Cities situation can be found in table 4.4 under experience, structural aspects, and organizational aspects. Also in table 4.1 under content "local/national issues, working structure, and pragmatic reasons, elements are mentioned that illustrate that there was a fir between Healthy Cities and other (ongoing) activities. Some cities are involved with the Healthy Cities Project due to activities that already had taken place within the Health Authorities and/or universities with regard to health promotion. In fact, they regard being part of the international Healthy Cities Project as recognition of the work that was already in progress or completed. For the majority of the cities, however, the fit between the ongoing work in the health field 
and the ideas as promoted through the Healthy Cities project is not (yet) optimal.

Relative advantage is the perceived advantage of a new idea when compared with existing initiatives. The advantage of being a Heallhy City can be subdivided into advantages for the city as a whole, and advantages for certain groups or individuals (see for illustrations in table 4.4 under expectations and Healthy Cities conceptualization and the elements that are mentioned in table 4.1). For example, being part of an international project can enhance bids for project money at the level of the European Union. By participating in the WHO Healthy Cities Project, it becomes possible to travel to other cities in Europe and beyond in order to learn from each others" experiences. Another reason for participation is that a cilty wants to be "on the European Map" not only for economic reasons, like local industry, but also for its health activities. Healthy Cities can also be used to enhance collaboration or as a framework for structuring existing policies and activities within a city. Politicians may find it a new and interesting flag to give local initiatives more colour. They can use Healthy Cities as a vehicle to trigger new things and initiatives.

Trialability is the possibility of testing the idea on a small scale. In fact this is done among Healthy Cities initiatives in the so-called demonstration projects. It appears that all the cities had short and/or middle term demonstration projects that were specifically aimed at giving concrete and visible examples of what the Project was trying to achieve and which working methods it was using to do so. A demo project first has to prove itself worthwhile before a city council will consider long-term funding and commitment for Healthy Cities. It has been said that the WHO Healthy Cities Project as a whole is a test case for the implementation of health promotion ideas in practice. This logic might be extended to assert that in each individual municipality, an activity (demo project) based on Healthy Cities' ideas is a test case for health promotion as well.

Complexity deals with the extent to which the idea, the innovation, is understood. From table 4.4 under experience it appears that Healthy Cities is perceived by many people as an interesting idea which, however, would be difficult to put into practice. Questions are raised on "what is it all about?", "how to translate the ideas into practice?" and "what are the benefits?'. Healthy Cities asks for input from many sectors and persons and demands a reorganisation of existing structures. It is certainly a rather ambitious endeavour.

Observability, finally, is the degree to which implementation of a new idea leads to visible output. As health promotion is targeted towards results and changes over the long term, it is rather difficult to have visibly significant output within a short term period. Cities show visible output and working mechanisms through demonstration projects. But the success of a short-term project does not mean that the results can be repeated, or will become business as usual 14. This characteristic is also illustrated by the elements of conceptualization of health, the conceptualization of Healthy Cities, and experience in table 4.4 .

Although Healthy Cities shows reasonable results on some characteristics as defined by Rogers, it is clear that the overall results are weak. The reason why Healthy Cities has not (yet) received a sustainable place on the political agenda is that initiatives have, thusfar, a limited fit with these characteristics. Another explanuation is that Healthy Cities is, or at least was for most cities, a completely new concept. The unfamiliar idea is then channelled towards agenda status by a relatively small, enthusiastic, policy community (process characteristic). Cobb and Elder (1983) found that agendas are mostly comprised of old issues. New, chamnelled, issues, are said by Cobb and Elder (1983) to experience difficulty in receiving agenda status. Careful planning is required to push a new issue onto a formal political agenda and keep it there, unless that new issue reflects a short term crisis (Pearson, 1991). And it appeared throughout this chapter that Healthy Cities does not reflect a short term crisis. 


\subsection{Conclusion}

In this chapter efforts have been made:

- to find out why cities get involved in Healthy Cities initiatives;

- to show the political commitment for Healthy Cities, in other words does it receive for example resources and support for activities?;

- to analyze whether Healthy Cities is part of the political agenda, for example, is it discussed at a regular basis in for example city council meetings?

Participation in the WHO Project or a national network can often be explained by personall (enthusiasm), pragmatic (city promotion), policy (fit with national governmental requests or local issues) and structural (provision of a working framework) reasons. These are reasons that could, in theory, be given for participation in any project: they are not Healthy Cities specific.

In general, politicall commitment for Healthy Cities is provided (see table 4.2), although in some cases also the opposite was claimed by interviewees (table 4.3). We conclude from these findings that it is the Healthy Cinies demonstration projects which receive tangible political support. Healthy Cities as a framework for linking different city based (health promating) policies and activities, is more likely to receive symbolic political support.

In terms of both the Agenda Building theory and the Policy Windows theory, it can be concluded that the political agenda status of Healthy Cities is low. If Healthy Cities is part of the decision agenda, it is because of personal efforts and/or due to successful hitchhiking. Hitch-hiking, as discussed, means in this case attaching Healthy Cities to powerful persons and/or to issues that are already part, or very likely to become part, of the politicall agenda. Examples of issues that were used in the case studies are quality-assurance, safety, or economic regeneration. As it appeared difficult to promote health as an independent issue for local government policy, this last method seems to represent the most effective strategy. Pointing at health aspects in existing policies and activities in the end is exactly what was described by Milio (1988) as Healthy Public Policy. At the same time, as was expressed in section 4.6, because Healthy Ciries ideas are not (yet) embedded within organizational goals and efforts, even if Healthy Cities reaches agenda status by efforts of individuals or due to attachment to other issues, this position may be quite unstable in the long-term.

We have also mentioned that Health Authorities/GGD and local government have specific (legal) responsibilities for disease prevention and prevention of health threats. This means that although we promote healthy public policy, it may be necessary to simultaneously develop specific preventive health policy. We will elaborate on this aspect in the conclusion of the thesis.

The conceptualization, how Healthy Cities looks like as revealed by projects ineetings, vision, policy framework, structure, depends both on local circumstances or the local agenda and the persons involved. Certainly, how Healthy Cities is conceptualized influences its position on the political agenda. Besides conceptualization, other determinants influence the agenda building process of Healthy Cities, the most important determinants found in this research are listed in table 4.6.

Political support, experience, and knowledge of health policy development and Healthy Cities "personal and organizational commitment to the Project"s ideas and goals, and the way this is visualized, and the perceived relevance of the Project can be mentioned as other determinants in the Healthy Cities agenda building process. These determinants influence the structures that are set up, the logistic and organizational arrangements that are 
Healthy Cities

conceptualizotion:

Perceived

relevonce of Healthy Cities:

Commitment to Heolkhy Cities

(projects):

Experience and knowledge

of healti promotion, heolth

policy public herolth: lsisue based (demonstration) projects

Vision, (policy) framework

Provision of structures

Metch with existing its wes and policy

Other (pragmatic espects)

Personal (individuals: stakeholders, entrepreneurs)

Organizational (organizations, groups, associations)

High (much experience and knowledgel)

Low (no or limited experience and knowledge)

Symbolic (support in words)

Tangible (support through prowision of resources (and words)]

provided to Healthy Cities, and the activities that are ultimately developed and carried out. These determinants in and of themselves are of course also influenced by a variety of elements such as power configurations, politics, economic situation, organisational circumstances, national/local issues and policy, and the existing agendas. But those elements are not Healthy Cities specific, and would influence any similar policy development situation.

(Re)conceptualization through a process of softening up (Kingdon) or issue manipulation and issue expansion (Cobb \& Elder) is at the core of Healthy Cities agenda building. practice. Issue expansion and softening up are important, but there can also be other reasons why Healthy Cities becomes part of the local agenda. In other words, the findings are not contradictory to Cobb and Elder"s models, but their theory is limited in its explanation. It is rather a combination of elements, which do not necessarily fit with the sequential models developed by Cobb and Elder, which are telling in determining agenda status. Variation in the mixture of these elements causes differences in appearance of Healihy Cities in the case studies. In Chapter Two we acknowledged that national differen ces between the countries under study and national developments influence what is or can be done locally. Indeed there are differences between the case studies from the Netherlands and those from the United Kingdom. But these differences were generally already in existence before Healthy Cities and/or they are not Healthy Cities specific. This chapter therefore supports our hypothesis that it is not so much national factors but local factors which are explanatory of differences among the case studies (see Chapter Two). The chapter not only supports our hypothesis, it also adds to it. The reason that Healthy Cities looks different in the case studies, although there are also similarities, can be explai-ned by at least two elements: (individual) conceptualization and local differences. That means that even if localities are comparable, it is likely that the way Healthy Cities is put into practice, is defined, operationalized, and organized will also show differences. For example, if Healthy Cities is conceptualized as a large city regeneration framework with major plans and intersectoral activities, it means something different than when Healthy Cities is conceptualized as a keep fit program for elderly people. The conceptualization of 
Healthy Cities is different, although the name and the initial intention may be or have been the same. It gets even more complex when it appears that even within one case study participants have different understandings of what Healthy Cities means.

The Agenda Building theory (Cobb \& Elder) is not implausible. It may even suit particular agenda building processes in some of the cities. Especially the mobilization model seems to have validity. We sympathize to a greater degree, however, with Kingdon's theory, which has a better overall fit with the Healthy Cities agenda building practice as observed in this study. Apart from issue expansion or softening up, the theory focuses on several elements at the same time. It explains why local differences between case studies are always likely to be present. Furthermore it also explains why the Project cannot follow a blue-print but should be given a flexible path for development. 


\title{
Chapter The Fuzzy Domain
}

\author{
A reconstruction of the Healthy \\ City domain based on activities, \\ structures, and actors
}

\begin{abstract}
"Membership in a policy domain is a continuing collective social canstruction by the domain actors." (Laumann \& Knoke, 1987 p. 12)
\end{abstract}

\subsection{Introduction}

An example of good practice in terms of a Healthy City activity:

The Drumchapel Community Health project of Glasgow Healthy Cilty has travelled the world sharing their stories as 'examples of good practice' of Healthy Cities. Presentations have been made and discussed at Healthy Cities conferences and business meetings, in regards to the praject as a whole or specific cispects thereof, in words and by wideo tape, on its content as well as its technical working mechanisms. The project staff and City Council of Glasgow were very proud that they could show that professionals working with a local comimunity could really make a difference. In this concrete example, collaboration was aimed at neighbourhood renewal. In Drumchapell, a cammunity lives, most of the time works, and receives its primary education. The idea of having some control over what was going to happen within the community resulted in the creation of a perceived sense of responsibility in residents for keeping the neighbourhood "in shape". Subsequently, this local callaboration led to collaboration at all levels, including top level of organizations.

Drumchapel is a rather deprived area of Glasgow, with a declining population, relatively poor housing conditions, and high unemployment rate (45\%). Above all, the general health statistics are far from stellar. An area management team ("The Drumchapel Initiative') was the refore established in 1985 by the Glasgow City Council, Strathclyde Regional Council, and lacall community to work on improwement of the area in a broad range of areas. One of these aspects was health, for which a spocial committee was set up in 1989.

Thus, many community health activities were canried out before the Drumchapel Haalth project started. Field wrorkers of the Health Board departments, local autharity departments and voluntary orgamizations were inwolwed in issues sweh as womer's health, HIV awareness, mental health, and the creation of a health profile. Things that were already happening fitted perfectly in the fromework and ideas that came along with the WHO Healthy Cities Project, in which Glasgow was ane of the participating cities.

The Drumchapel Community health project started off with a survey in which peiople were asked what their perceived health needs were. The interviewing was done by local trauned valunteers, supported by people from the Healthy Cities Project and Health Board. The survay provided the inspiration source for future activities, such as a health market, establishment of a small health library foudio and visual mate. rials), drama and arts, personal training and development, self help, HIV and addiction, mental health, child safety (inhouse, play grounds), living conditions and housing improvement, and healthy eating.

With regards to basic primary health care actiwities, a public health centre was built. Primary health core workers have a base in this centre and the community has ils own local community Healthy City offica. It encourages exchanges in both directions: while visiting general proctitioner, people can also enter the community office. While visiting the community office, a visit to a social worker is just o step away. The office acts as a sort of basis where volunteers together with some professionals initiate and organize activities around issues that are perceived as important or problematic in a particular area of the neighbourhood or lin the neighbourhood in general. 
Being a demongtration praject of Healthy City Glasgow meant that some new structures were provided or were $u$. The project is accauntable to a lacal management/executive group with representatives of the local community, the District council (councillor), the Strathdyde regroinal council (councillor, Chief executive departmenty, the Drumchapel Initiative, the Health Board (health promotion, nursing, sector management), the Glasgow Healthy Cities project office, the University, and the Community Organisations Council, Lth. The lacal management group reflects very much the composition of the city-wide Healthy Cifies steering graup. Furthermore, there exist a working group and project staff. Both project staff and working group con. sist of volunteers and field workers from the arganizations represented in the management group such as for example health promation persannel, development warkers, health wisitors, a sacial worker, a housing officer and representatives of Adult Education, Community Education, the Volunteer project, and the Health Baard health promotion depariment.

The project has thusfar been funded through Urban Programme money ${ }^{1}(1992-1996)$, the Heolth Boordz by secondment of two staff, the Drumchapel Initiotive, and the Glasgow Heallihy Cities project office. Research and evaluation have been carried out alangside Drumchapel activities. Even in the first year of the Cammunity health project, a researchar wos seconded from the Department af Public Health of Glasgow's University, Additionally, the project coordinator received some funding of the Scottish Home and Health Department to sel up a so called participative evoluation.

In 1993, the people involwed in this community project tried to write a report on the development, process, progress and impact of the project during its first three years (1990-1992)(Kennedy, 1994). They tried to provide an overview of who had been involwed, the working principles and working mechanisms, the formal structures and the activities. In reading the report, it is not difficult to detect a ronge of input from the diverse organizations and associations. The team attempted to shaw the structures and leading principles of Healthy Cities. When they had to write the chapter describing activities, hawever, let alone the effect and impact of those activities, it appeared to be slightly more difficult to provide a comprehensive and readoble chapter. Our question is why this was so. Affer all, the activities could be presented around issues, settings, impact, risk groups, governmental policy sectors, project functions, and combinations of these. The reason why it was so difficult was that boundaries appeared to be fluid.

The Drumchapel project is illustrative of how a Healthy City activity can evolve. It shows that involvement in Healthy Cities and its achieving a place on the political agenda can be explained by local circumstances and personal efforts. This process was demonstrated already in Chapter Four. In fact, as we have seen, the Drumchapel project had started already before the City of Glasgow entered the WHO Healthy Cities Project. But due to Healthy Cities, the activity received new momentum. New people showed interest; structural and logistic support was provided. And after some years, efforts were made to evaluate the process and to define recommendations for future activities.

The lessons learned from such activities play a role in policy-making. Policy-making, after all, can be seen a little more than to think, negotiate, and plan an appropriate direction with regards to a specific issue, field, or organization and to consider and choose among the possible ways of getting there.

The question for Healthy Cities is whether demonstration projects, such as in the example, can influence mainstream activities and policy-making or contribute to the development of overall healthy public policy. In Chapter Four, it was argued that having substantive attention and political commitment for an issue and considering a place on the political agenda are important elements in Healthy Cities policy development. Also mentioned as important factors in that respect are concrete activities, examples, structures, and committed people.

In processes of policy development or evaluation, it is critical to have a broad overview of all activities, structures, and involved or otherwise relevant actors. Creating an owerview and having insight into which actors are operating in the field and how they are doing so, 
including their goals, relationships, and strategies, is the focus of policy development and analysis models like policy network theory. In these models, policy-making as a solitary activity steered by government is implicity rejected in favour of a whole view which sees policy development as taking place within a network of private and public actors, of which government is only one (see also Chapter Two).

It is our hope to discover how health policy is developed within; through; or by Healthy Cities. Ideally, it might be possible to construct a standard Healthy Cities domain based on experiences from the case studies. Likewise, the analysis of agenda building practice, also a domain construction, could deepen insight into thealth policy development. More concretely, we would know who to approach, what activities to undertake and which structures to set up, in order to facilitate policy development:

In this chapter, the aim therefore is to find out whether it is possible to indicate a standard domain. Domain construction is not a particularly exciting business, but it is necessary in order to learn and understand more about local health policy development. How is the Healthy Cities domain constructed in this inquiry? We assume that participation in a national network or the WHO Project reflects at least an intention to work on public health issues at the local level. Furthermore, the selected ten case studies are labelled as 'examples of good practice' (see Chapter Two). Discussing examples of good practice inevitably involves a look at health projects (activities) within these case studies. These (demonstration) projects are analyzed on participants and project structures. Separate attention is paid to the question of whether or not and (and if so, how) Healthy Ciries is integrated or organized in a locality. Not only through an analysis of activities, but also through analysis of organizational structures, Healthy Cities participants are identified. Although the involvement of national and international actors in the case studies is recognized, the research primarily focuses on local actors.

The case study example in this introduction shows that findings on activities, structures, and participants are linked, revealing an underlying interactivity (see also Teisman, 1993 p. 29). However, these three aspects will, for analytical reasons, be discussed in separate sections. First activities, then structures, and lastly participants are analyzed. Subsequently, efforts are made to interpret the findings in relation to each other, specifically with respect to the implications for health policy development. In accordance with the previous chapter, however, a justification will first be given as to what is meant with domain in this respect and what its relevance is to the present inquiry.

\subsection{Domain construction}

\subsubsection{What is a domain?}

Those who are responsible for policy development generally seek to maintain control within a more or less defined area; derivative to this goal is an attempt to create within that arena, at least from their own perspective, a relatively predictable situation. A view of policy-making as the product of a rationally reasoning and acting actor; who has adequate information and knows what to do in order to reach stated goal has long been a cherished ideal of policy theorists. In the policy development and analysis models which have received attention the last few years, however, the aspect of linkages between government, public, and private actors have received significant attention (for example network models (Klijn, 1994; Marin \& Mayntz, 1991; Van Tatenhove \& Leroy, 1995), or arena models (Koppenjan, 1983; see also Chapter Two). These models can be summarized as sharing a 
social initeractive policy approach. In such models, the vision of a rational, fully-informed, and independenty acting hierarchical government which measures and improves sociery is seen as a rather poor description of the reality of policy-making, which seems far more complex. The contention of these social interactive models is that the success of policy rides on its creation, acceptance, and continuing support by all actors concerned. A constant process of adaption or revision of existing policy, depending on changing and complex circumstances, as well as upon actors' activities and perceptions, is seen as the norm. Policy is thus seen as continuously in the process of being developed by all these actors, from inception through implementation and evaluation, and back again.

Policy network research addresses (see for example Hufen \& Ringeling, 1990; Kenis \& Schneider, 1991) the influence of linkages between actors on policy development.

Through policy network analysis, it is possible to investigate, for example, the stability of the network, its openness, diversity, or the power distribution between actors related to it. Klijn (1992) shows, however, that network linkages are not stable and may have different meanings depending on the issue under discussion or depending on a change in the actors" perceptions. It was once believed that it might be possible, for example, to draw boundaries around the health care policy dornain and to detect all possible actors and the linkages between them. Laumann and Knoke (1987) have shown, however, that for each separate issue within this domain, another network can be determined. As actors may change their activities and ideas, and as issue environments tend to be unstable, domain and sub-domain composition change over time.

The instability of a Healthy Cities domain might be presumed to be large due to the temporary nature of demonstration activities and the diverse groups involved in collaboration. Detecting a Healthy Cities domain will therefore likely prove to be difficult. In Chapters One and Three an explanation has been provided of what is meant by health policy and Healthy Cities. According to Milio (1986), health policy development should concern anybody and all policy sectors, because it is part of any issue. She introduces the concept of healthy public policy. A healthy public policy domain would embrace all public policy domains. Theoretically, therefore, a healthy public policy domain or a Healthy Cities domain are rather devoid of, or rather, overwhelmed with, meaning, as they concern everything. These concepts have linited discriminating power. An investigation of Healthy Cities in practice can. however, deliver more specific insight with regards to domain composition around specific issues taken up in the Healthy City context.

The definition of policy domains and the research work of Laumann and Knoke (1987) will be used as guidance for the construction of the Healthy Cities domain in the ten case studies. A policy domain is "... a subsystem identified by specifying a substantively defined criterion of mutual relevance or common orientation emong a set of consequential actors concerned with formulating, advocating, and selecting course of action (eg. policy options) that are intended to resolve the delimited substontive problems in question." (Knoke \& Laumann, 1982 p. 256 in Laumann \& Knoke, 1987 p. 9-10) Laumann and Knoke investigated the role of corporate actors in State ${ }^{3}$ policy-making. These corporate actors have different interests in regards to a range of issues. All nonetheless have significant resources and information at their disposal. Furthermore, each is part of several networks. Laumann and Knoke found that it was not so much government, but the influence and involvement of these corporate actors in events (and their collective actions) which eventually determines State policies. Policy, in the eyes of Laumann and Knoke, is a result of negotiation, power and of availability of resources and information to corporate actors. Laumann and Knoke analyzed the substantive relevance of corporate actors on State policy-making by analysing corporations" networks, the relations between separate events within a policy domain, and by analysing the relation between the actors and events.

The reason for using the research of Laumann and Knoke as a reference is that their 
research is very compatible with an interactive policy approach (see Chapter Two; see also Kingdon's ideas on policy-making in Chapter Four sub-section 4.3.2). Furthermore, the findings of a preliminary analysis of the case studies showed a fit with elements of their research. First of all, for example, Laumann and Knoke showed how only certain organizational components or representatives (individuals) are involved in policy issues, rather than entire organizations. Secondly, they found that participation related to one issue alone is not a valid predictive parameter for participation in relation to another issue in the same domain. Furthermore, it appeared that the intensity of involvement of the core group ${ }^{5}$ of policy actors interested in a certain issue is likely to be stable. The intensity of involvement, however, is likely to differ from event to event within an issue. These three aspects will therefore be the main elements in the Healthy City domain construction:

the importance of individuals and organizational components;

a difference between occasional and permanent involvement;

and the intensity of involvement.

There are, however, two substantial differences between our inquiry and the research work of Laurnann and Knoke. First of all, they defined a priori the boundaries of the thealth policy domain. In the current investigation it would not appropriate to use a similar strategy "If policy is developed through interaction, policy research is aimed at detecting the actors involved, their activities and strategies, and explaining the interactions which take place among them. Certainly, a domain needs to be defined. But what are the Healthy Cities domain boundaries? As has been explained elsewhere in this section, any sector can be involved in Healthy Cities policy-making. It is exactly because of the impossibility of drawing sharp lines which makes it especially interesting to address the empirical question of domain composition, but which forbids concrete conclusions before investigation. Additionally, we believe that within the framework of an interactive approach to policymaking, domain borders should not be defined before the start of the research, or should at the most be defined in a very flexible manner. Domain borders are being formed when policy is developed (see Chapter Two), namely when activities are undertaken and people and organizations interact. In other words, to show the sectors that are actually involved is. a result of the research, not something which can be determined and defined beforehand. Secondly, Laumann and Knoke's methodology for defining the actors was very much prestructured and took place within the already defined boundaries of the policy domain ${ }^{6}$. Their research was intended to be explanatory. Their purpose was to explain the involvement of actors in an event and consequently the influence of those actors on policy development, in terms of characteristics of the organizations and of a particular event. In this research, however, the first priority was to construct the Healthy Cities domain boundaries and define its borders by first investigating the activities, actors, and structures which define it in reality.

\subsubsection{Discovering the Healthy Cities domain}

A number of approaches were used to discover the Heallhy Cities domain because this allowed the possibility of contrasting and comparing the findings (data-triangulation). The domains that are presented in this chapter are based on the combined efforts of all case study analyses. Individual case study domains can be found in appendix 3 .

Elements from Laumann and Knoke's theory will be used as a framework to structure the findings. The working definition of a Healthy Cities policy domain will be "a subsystem identified through analysis of expressed interest and participation in Healthy Cities activities and structures among (semi)public and private actors who promote health and/or Healthy Cities and formulate and select courses of action (eg. activities and policy options) intended to increase the sustainability and support for the issue in question."

The following three approaches are used for domain construction. One approach is to 
analyze the content of activities that take place under the Healthy Cities banner. These findings are presented in section 5.3. A second approach to constructing the domain concerns the structures used to integrate Healthy Cities into a municipality. It is acknowledged that departments, organizations and other public or private initiatives have developed working relationships and currently operate in networks in order to be able to perform their tasks. The discussion here is limited to the structures which are explicitly mentioned as being of relevance to and/or established with respect to Healthy Cities. In section 5.5 , a third approach to constructing the domain is presented. In this approach the domain is constructed through the identification of the participants inwolved in Healthy Cities. Expressed interests and participation are made operational through the following: involvement in a Healthy Cities (related) steering committee or planning group; involvement in a working group; participation in activities; providing financial resources or resources in kind; and providing politicall support by signing an official document related to Healthy Cities, for example. Additionally, the various interviewees were asked to name the core people and/or organizations with regards to Healthy Cities in their locality.

\subsection{Healthy City activities}

"Action speaks louder than words" (politician, Fe)

On its face, existing case studies on Healthy Cities, such as for example Healthy Cities (Ashton, 1992), or Action for health in cities (WHO, 1994), may tempt the reader to think that Healthy Cities is health education. Further along in her reading, the reader may think, 'Oh I see now, Healthy Cities is a nursing project'. If the reader has time to finish the book, she may then discover that she was wrong; surely Healthy Cities is about environmental health, or not? It appears that people want to categorize Healthy Cities. With a traditional label, it is possible for a group to run away with Healthy Cities and position itself as 'owner". Healthy Cities, because of its multi-sectoral nature and flexible, adaptive structure, is thus also quite vulnerable to becoming anything and being owned by anybody. One of the interviewees explained this phenomenon as follows,

"Healthy Cities should be a healthy virus tha" should infect everything. It is a way of thinking and you have got to get lots of people in different settings with different backgraunds doing different things with this way of thinking. It does not belong to anybody. "I is actually about giving [ownership, MG] away all the time." (Management HA/GGD, GC)

The WHO requirements for Project Cities (Chapter One, table 1.2) provide only general guideline for cities in regards to what activities should be undertaken by a Healthy Cities project. Specifically, the following are mentioned:

- to develop a city health plan that addresses equity, environmental, social, and health issues;

- to take active steps in the implementation of the European Alcohol Action Plan and the

European Tobacco Action Plan and other WHO/EURO strategic action priority areas:

- to create a health profile;

- to address the needs of most vulnerable and disadvantaged social groups;

- to participate in at least one MCAP.

In the first five year phase, Project cities had to work towards annual themes related to the Health For All Strategy (WHO/EURO/HCPO, 1988). These were: inequalities in health; strengthening community action and developing personal skills; supportive physical and social environments; reorienting health and environmental services and public health; healthy policies for Healthy Cities (see also Tsouros, 1991). The national network require- 
ments of the Netherlands and the United Kingdom are not very explicit with regard to the activities cities are asked to undertake. In the Netherlands, participating cities are supposed to participate in one of the existing issue-based working groups. In the United Kingdom, it is explicitly mentioned that participants have to reduce inequalities in health and to promote equity between and within localities.

Based on the available information so far, it can be concluded that the requirements, ideas, and principles attached to Healthy Cities leave the participating mumicipalities with a great deal of freedom to choose which activities they wish to implement under the rubric of the Project. A catalogue of concrete examples of activities undertaken in the ten case studies will be provided with illustrations from exemplary cases. It will become clear that, while the illustrations may at first look alike, they in fact differ significantly from one another.

In the introduction to this chapter, the Drumchapel project was presented. In this project, a variety of activities took place under the Healthy City label; these included housing renewal, safe playgrounds and a health library. In. Eindhoven, the Healthy Cities project has developed a health library which has been called a 'gezondheidswijzer' [health information board, MG]. The library is located in the GGD-building and has some on-site annexes in neighbourhood centres. A weekly information page in the local newspaper and a page on the tele-text of local television form part of the information arm of this "health information board." Unlike Glasgow, Eindhoven has no Healthy City projects which specifically address safe playgrounds or housing renewal under a Healthy City label.

From the introduction to this chapter it would appear that within the broad rubric of Healthy Cities, activities can address child safety as part of a community project. (Child) safety can also be the only or main theme upon which Healthy Cities is based. The latter is nearly the case in Almelo. Almelo is working under the label of Healthy Cities on accident prevention for young children and elderly persons. In Almelo, Healthy Cities was started with the creation of a safety policy for elderly persons aimed at the living environment, lifestyles, general health status, and mobility. Another activity which was organized is a "Safe-Season" programme. The fire-brigade sets up stands at Christmas-shopping events, for example, to educate passers-by about how to prevent and solve fire problems when preparing 'oliebollen' (a typicall Dutch holiday treat). The GGD has developed education materials on safety for primary and secondary school children. Lectures on fireworks are delivered by the police and a local action committee on a regular basis.

Typical lifestyle issues such as nutrition are also targeted. For example, in Rotterdam, community centres have organized healthy cooking events for children. And Eindhoven and Liverpool participate in the SUPER project. SUPER is a Multi-City Action Plan on nutrition. Other examples of lifestyle issues are the heart health projects in Sheffield and Liverpool and participation, at the time of this research, in the Sports and Active living MCAP by Rotterdam and Eindhoven ${ }^{7}$.

In Winchester, a project targeted at travellers and poor sleepers which aims to improve aspects of psycho-social health was developed under the name of the STARS project.

In Eindhoven, a number of Healthy City activities for elderly people were created, including a keep moving programme and loneliness-amongst-the-elderly research. The keep moving programme is not only targeted towards lifestyles, but is seen as having a social component as well, in the sense that attending the keep fit classes provides a possibillity to meet other elderly people. In Newcastle, loneliness amongst elderly people was addressed through the development of keep fit classes and traffic programmes. Changing the local bus route and replacing a bus $\sim$ stop may on the one hand relieve a traffic congestion problem. On the other hand, however, it may cause isolation and reduced mobility among elderly persons who can no longer use the bus-stop they used to. 
Table 5. 1 a: Nlustrative examples of Healthy Cities activities: starting from a group perspective, addressing within these groups certain issues and, if possible, faking place within certain settings.

The figure stiould be read from left to right, row by row. The first column is the starting point of the activity. The second and third column provide additional information to the first column. Between (1): in how many case studies this activity was explicitly mentioned and in which country (UK=Unifed Kingodom, $N=$ Netherlands). If no number or coumtry is atiached, it means that it was mentioned as general concrete example of a Healthy Cities activity.

\section{A. Group (who)}

Women $(2$ UK: $1 \mathrm{~N})$

\section{Issule (what)}

\author{
Womer's (health) centre \\ Women's policy \\ Self help groups
}

Wellbaing

Care facilitiles

Loneliness

(ethnic) Minorithes, migrants

(3 UK; $4 \mathrm{~N}$ )

Health (care)

\section{Settiling (where)}

Youth

Future perspective

Compared to tables $5.1 \mathrm{a}$ and $5.1 \mathrm{~b}$, table $5.1 \mathrm{c}$ shows that issue content is most often the starting point for an activity. For example, lifestyle issues were rather ubiquitous as Healthy Cities activities. A concrete target group that was mentioned with regards to lifestyle activities was youth. This group was especially reached through their schools. Although youth is often explicitly mentioned as a target group for lifestyle activities, this is not intended to indicate that there are no other target groups.

An effort has been made to categorize these above-mentioned activities, and an analysis of these categories was made to construct a Healthy Cities activities domain. Based on the data we collected, all major projects and activities from the ten case studies are listed and organized based on issue content, target group, and setting. These findings are presented in tables $5.1 \mathrm{a}, 5.1 \mathrm{~b}$, and $5.1 \mathrm{c}$. It is not the purpose to provide a complete and up to date overview. The tables are designed to give a good indication of the range of activities which were taking place at one given time. Tables 5.1 a, 5.1 b, and $5.1 \mathrm{c}$ are each divided into three columns and several rows. In the first column of each table the starting-point of the activity is located. The second and third columns may provide information which supplements that in the first column. If there is no information in the second or third columns, no specification or example was provided to the issue of concern in that row.

In table 5.1a, the activities are organized by group. For example, elderly people were mentioned as an explicit target group for Healthy Cities activities. Examples of issues that received attention in that respect were overall wellbeing, care facilities and loneliness. Also, youth was mentioned as an explicit target group. A concrete example of an issue that was primarily directed towards youth was perspective toward the future.

From table $5.1 \mathrm{~b}$, it appears that with the noticeable exception of schools, we did not find other clear examples of Healthy Cities activities which explicitly originated out of a setting-based perspective. 
Table 5.1 b: Illustrative examples of Healthy Cities activities: starting from a setting perspective and addressing within this setting certain issues. Certain groups may be adressed.

The figure shauld be read from left to right, row by row. The first column is the starting point of the activity. The second column provides additional information to the first column. Betwen ( ): in how many case studies this activity was explicitly mentioned and in which country (UK=United Kingdom, $N=$ Netherlands).
B. Setting (where)
Issue (what)
Group (who)

Schools $\left(2 \cup K_{i} 4 N\right)$

Clean/safe environments

Own responsibilities

Table 5.1 c: lllustrative examples of Healthy Cities activities: starting from an issue perspective, aimed at specific groups, and, if possible, taking place within specific settings.

The figure should be read from left to right, row by row. The first column is the starting paint of the activity. The second and third column provide additional information to the first columm. Between (1) in how many case studies this activity was explicitly mentioned and in which country (UK $=$ Unitid Kingdom, $N=$ Netherlands). If no number or cauntry is ettached, it means that it was mentioned as general concrete exomple of a Healthy Cities activity.

\section{Issues (what)}

Environment $\left(4 \cup K_{;} ; 2 \mathrm{~N}\right)$ :

- air pollution

- traffic control

- food hygiene

- recycling

Research (3UK; 3 N):

- project exaluation

Mental/sociol health $\left(2 \mathrm{UK}_{\mathrm{j}} 2 \mathrm{~N}\right)$

Homeless people

Nightshalter

Homeless hostels

Community development

(4UK; $1 \mathrm{~N})$

Community work/neighbourhood work $[3|N|$

Heart health (3 UK; 1 N)

Concer (1) UK)

Lifestyles $(4 N)$ :

Youth

Schools

- aids $(3 N)$

- smoking $(3 N \mid$

- food $[2 \mathrm{~N}]$

- drinking (3N)

- sparts/active living (3N)

- (child) injuries (2 UK) 


\section{Issues (what)}

Care facilifies $\left(3 \cup K_{r} 4 \mathrm{M}\right)_{\text {; }}$

home improvement/

- adiustments

- day care facilities

- self care/hielp

- community care (3UK)

Unemployment (I UK; I N)

Working conditions (1 UK, I N):

- workplace health (2 UK)

Poverty (4 UK)

Siafety (4UK; $3 \mathrm{~N})$

- publïc safety

vandalism (2N)

Housing conditions (4 UK, $3 \mathrm{~N}$ )

Inequalities ( $3 \cup \mathrm{K}$ ):

- racial equalities (2 UK)

- equal apportunities (1 UK)

- discrimination (T UK)

Crime \& fronsport (2 UK)

Health foir (1 UK)

Leisure services (1 UK)

Economic development (1 UK)

Addiction (3N)

- drugs (2N)

- gambling (3N)

Social renewol (3N)

Health information service (2 N)

Secondary health care (2 N)

Pr/booklets/information on

Healthy Cities $(5$ UK; $5 \mathrm{~N})$

Dentol health [1 N]
Setting (where)

Living environment

(houses, eldierly homes, nursing homes,

neighbourhoods:

Working enwironments

(workplace, schools)

Home

Traffic

Playgrounds

Living environment

Youth 
Public sofety

Child accident prewention Solfie plovgrounds

Faotboll vand alism projact

Homelessnos:

Neighbourhood self-mamegement

Public sudety

Nerighbourhood work

Enwironment

Clean and sofe erivironments

Environmental herith: air pollition

controll, food sygien, recyeling

Envilonment \& havalth

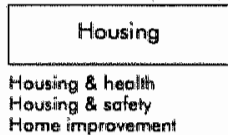

\section{ANDS}

Heattin fauris

Heatsth education

Drinking

Gambling

Smolking:

Loy core

Home care

Rinfugee hasitth

Migrant hecolithy

Chitd injury prewsentio

Psycho-sotiol heatth

thomeless hostiels, doy \& night whetter

Care facilities: thom improwement, day core

Foond intoke, food powenty (SUPER project)

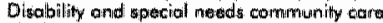

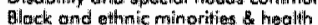

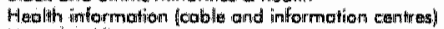

Hecint heolth

Derital con

Pritratry health eare

Serendary thealth care

Public heraltin

Colition

Comimustity core

Discolsutitios

Mheritol nealth

Solf core

Fitygien stomdorols

Cancer
General offairs

Legal affoirs

\section{Traffic. Roods affoits Public transport}

Transport is crime?

Road traffic (stafety, regullation, acciotentsi

Accidlent preventision

Bincolelo promotion

Public tronsport

\begin{tabular}{c}
\hline $\begin{array}{c}\text { Education "Culfure, } \\
\text { Recreation, Arts }\end{array}$ \\
\hline
\end{tabular}

School hedith fohysicol octiwithy tood choices, own responsibullfities] Sports

Active liwing

After school forcilities for youth

Educotion

Youth

\section{Eronomics, Business,} (un) Employment

Working ctricumstancoss

Economic developrnent

Workiplace health

Unemplloyment

Figure 5.1: Healthy City domain (general) based on activities.

Figure 5.1 is a Healthy City domain based on the activities identified in the ten case studies. The meaning of the abbreviations used in the figures and tables throughout this chapter can be found in the list of abbreviations after the table of content. The activities, mostly demon- 
stration projects, have been categorized along 11 public policy sectors in order to make the diversity between the activities visible. Appendix 3 contains figures about domain composition based on the main activities in each separate case study (figures $5.2 \mathrm{a}$ and $5.2 \mathrm{~b}$ ). It also contains nationally-based Healthy City domains (figure $5.2 \mathrm{c}$ ). In this chapter, only an overview of the main activities is provided (see tables 5.1 a, 5.1 b, and $5.1 \mathrm{c}$ and figure 5.1). Ulustrations from the case studies will be used to make this overview concrete.

The reasons why these particular issues were chosen as Healthy City project are similar to those that are mentioned in table 4.5 in Chapter Four. For example, the idea that a new label could give an old initiative renewed momentum, or that the issue lends itself to a demonstration of Healthy City principles such as the reduction of inequity, community development, or intersectoral collaboration.

On the question of how prionties are set between issues which all require action, the following was answered. In a (project) initiation phase that contains limited political interference, the content of the issue, national developments, expected effects, and community requests are decisive factors. Financial cost/benefit ratios and political cost/benefit ratios were mentioned as deciding factors when decisions were made on how to spend the annual municipal budget. The content of the plans has to meet the tests of political and financial acceptability. These factors are closely trailed by local political pressure, sense of reality of the plan, position and charisma of those who are involved in the presentation, the debate, and decision-making on the contents of the plan. The law, the media, pressure groups, statutory duties, or national governmental pollicy were least mentioned as important factors in priority setting.

Specific arguments for issue selection differ from subject to subject. For example, for some issues it is enough to have a political argument to initiate consideration for or the carrying out of an activity. For other issues having a professional argument is more decisive. At the same time, public serwice providers need to behave like entrepreneurs. This is needed in order to survive in an environment which is becoming more and more competitive and indeed shows the public sector as increasingly resembling the private. This implies, for instance, that certain public screening activities are undertaken in such a way that a profit can be made. This profit can then be used to finance other activities that are less or not profitable.

In the meantime, in the decision-making process on issue selection for activities of the Heal th Authority/GGD, the focus is more and more on outcomes. An additional complicaling factor, at least for the Health Authority/GGD, is that in the public sector, it is difficult and not yet mainstrearn to have a clear product description and to define the quality-price relationship. But individual capacities and efforts are also decisive factors in issue selection and priority setting.

"If you ask me, the mos" important factor is the peaple, those with charisma, those who try to sell the idea. The other orguments go along, the law, the vision." (Management HA/GGD, BC)

From the analysis of the Healthy Cities activities (see also appendix 3) it can be conclu ded that there is a great variety in activities carried out under this banner. Most of them take place as demonstration projects with project (short term) funding. The merit of demonstration projects is that they can reveal what Healthy Cities means in practice (as mentioned already in Chapter Three). The impact of a project is, however, rather short term, as illustrated by the following quotation.

"But the thing that we did learn is that (...) pilloting something means nothing if it did" not enter the mainstream thinking of the arganizations. So the pilot projects could have been wonderful and they could have been wanderfully successful, but then they come to an end. And that was it. Nathing then happened. It just finished, fizzled out." (Member Local Authority, Gd) 
The domain based on activities in both countries covers all public policy sectors except for city planning, general affairs, and public affairs. The content of the activities in all ten case studies centres very much around public health (lifestyle) and social welfare issues and to a lesser extent around traffic (public transport) and public safety. For the other public policy sectors, the main difference between the countries seems to be the frequency and intensity of the activities undertaken. In the United Kingdom case studies, much more explicitly than in the Dutch, attention is paid to (general) issues such as economics (poverty, unemployment), (poor) housing, environment, and community development. In the Netherlands, the (lifestyle) issue addressed by health education and the target group of youth are more directly targeted under the Healthy Cities label than in the United Kingdom. There are allso case studies which have relatively few activities, but are quite extensive and last for a few or more years. Others have many small short-term projects at the same time. Note, therefore, that although figures and tables such as figure 5.1 (and figures $5.2 \mathrm{a}, 5.2 \mathrm{~b}$, and $5.2 \mathrm{c}$ in appendix 3 ) and tables $5.1 \mathrm{a}, 5.1 \mathrm{~b}$, and $5.1 \mathrm{c}$ show a variety in activities, they cannot be used to judge the intensity of these projects. The aspect of intensity has not been investigated. The focus point per case study differs. In some case studies (see also appendix 3) one or two themes are central, for example safety or environmental health. Others develop a variety of different activities which are organized under a Healthy Cities label. In still other case studies target groups, elderly and youth are the starting points for the majority of activities, regardless of the issue. The national network and WHO requirements cannot be explicitly traced within the content of the activities. But it is clear that activities are generally aimed to fulfil them.

\subsection{The structures}

\subsubsection{New, existing, integrated, and separate structures}

"Although everybody signed it, this board has no formal accountability." (Management local authority, Hd4) Just as there are requirements for the nature of activities a project must carry out, the WHO Project also has formulated requirements in regards to the structure and organiza tion of Healthy Cities (projects) as a whole. Examples of these requirements are:

- to collaborate and to exchange experiences and information intersectorally and (inter) nationally:

to set up an organizational structure, an intersectoral steering group and intersectoral officer group;

- to establish a managerial structure, such as a project office;

- to develop close links with political and decision-making bodies in the ciry and having official contact with one or more politically influential persons.

The steering group of a project is responsible for monitoring the project's activities and for assuring the project achieves a measure of political support in the city. The steering group ideally represents all parties and organizations in the city, including city govermment. The planning group is held responsible for the organization and implementation of project activities at the operational level.

The case study description in the introduction to this chapter will be used again here as a starting point for discussion. The Drumchapel demonstration project is integrated in an overall Healthy City structure which fully fulfils the WHO's requirements. Glasgow Healthy City has a steering group, an intersectoral officer group, a project office with staff among whom are a coordinator and a communications officer, a community development 
unit, working groups, and a person responsible for political relations. The Glasgow Heallhy City project office is integrated into the administratiwe structure of the local government and is treated as a special city council committee. This is not without reason. "If Healthy City would become a separate entity, it would never be able to influence cauncil policy. Within the organization they have the opportunity to put papers on committee desks and even to put things on the committee agenda. You can get the papers through the political system. If it was just Healthy City and the WHO trying to influence the palicy [in this city, MG], I don"t think they would be able to change council policies." (Polifician, Fe)

The integration of Healthy Cities into existing structures is one way to organize Healthy Cities in a municipality. What (other) ways are used? From the case studies findings we identified the following two approaches:

establishing new structures such as a steering committee or a planning committee; - using existing (revised) structures such as city council committees, a Joint Consultative Committee, or management board meetings.

Moreover, Healthy Cities as part of both new and existing support structures can operate either separate from or integrated within other local structures as is the case in the Glasgow example. For example, management committee meetings can function in a manner comparable to a steering committee for discussions of Healthy City activities which take place on a regular basis. But if the members of this committee do not establish links with the ongoing, mainstream activities of the organizations and services which they represent, Healthy City remains a very separate, unconnected initiative.

In table 5.2 the main characteristics of the structures and organization of Healthy Cities in the ten case studies are presented. The presence of a certain characteristic in a city is marked with a cross $(x)$ in the table.

In table 5.2, it can be seen that Almelo in the Netherlands and Newcastle in the United Kingdom each has a number of unique characteristics when cornpared with other projects within their countries. Also, when the two clusters of case studies are compared at country level, some differences can be observed.

New structures. The Dutch case studies revealed that hardly any new structures are set up in the Netherlands for Healthy Cities. In all five United Kingdom case studies, however, new structures were put into place because of, or related to. Healthy Cities. Examples of these structures are steering groups, planning groups, and project offices.

Integration into existing structures. In most case studies, Healthy Cities is attached to existing structures as a project (office), as part of a department, or as part of an officers" responsibility to the Health Authority/GGD and/or local authority. An exception is Newcastle Healthy City which, although it has office space in a local authority department, remains a small independent enterprise. There is one large difference between the Netherlands case studies and the United Kingdom case studies in this respect. In the Netherlands, the majority of the Healthy Cities projects are attached to a department of the GGD. In the United Kingdom case studies, however, Healthy Cities was always attached to the local authority. In one case in the United. Kingdom, Healthy Cities was also attached to the Health Authority.

If Healthy Cities is attached to the Health Authority/GGD, it is either part of the department of health promotion (such as is the case in Sheffield. Eindhoven), attached to a policy officer of the GGD (Groningen), integrated into all departments (Rotterdam), or attached to the management team (Tilburg). If Healthy Cities is attached to the local authority, it is either part of the central policy unit (Liwerpool, Glasgow), the department of Health \& Consumer services (Sheffield), the deparment of environmental health (Winchester), or to a policy officer of the local authority (Almelo) ${ }^{8}$. 


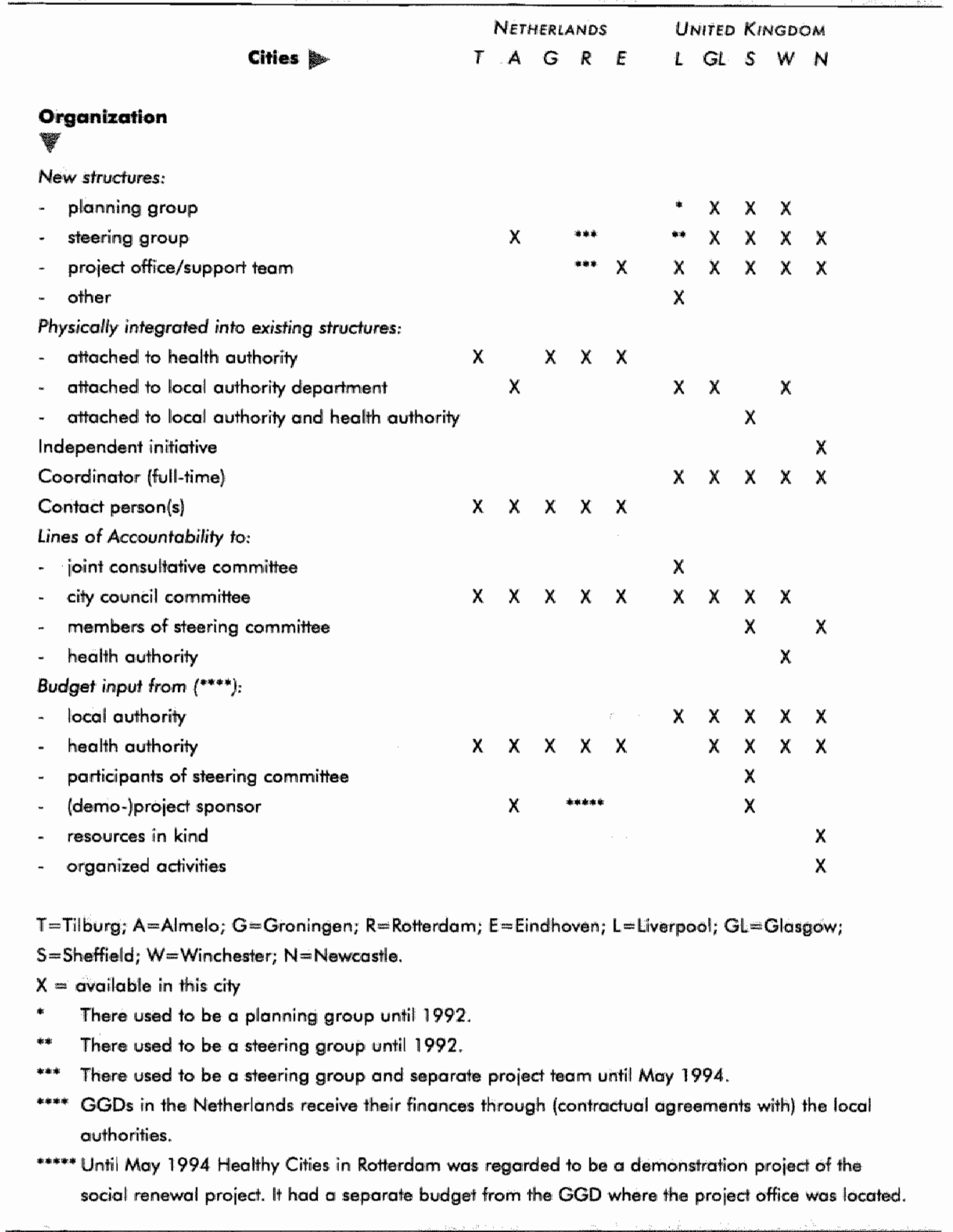

Lines of accountability. The chief officers of the above mentioned departments or the entire management team are the persons directly responsible for the activities undertaken in the mame of Healthy Cities. They are responsible for the performance of the coordinator/contact person. Besides having accountability to the "host" organization, the Healthy Cities project 
office of Liverpool is also accountable to the joint consultative committee. The project offices in Newcastle and Sheffield are likewise accountable to the steering commitree. It appears that in both countries Healthy Cities is accountable to the city council and/or city council committees who seem to maintain the ultimate political responsibility for Healthy Cities.

Coordinotors/contact persons. In the Netherlands, officers from the GGD or local authority act as contact persons for Healthy Cities as part of their regular jobs. In all five United Kingdom case studies, however, full-time coordinators are in function.

Budget. In the case studies in the Netherlands, applications for financial resources for demonstration projects were submitted to the "social renewal' budget. In Almelo, the project managed to receive money from two Ministries, Healith and Traffic, for a demonstration project. In general, the budget for Healthy Cities comes through either the local authority and/or the GGD. Healthy Cities may have a separate budget or may be a benefi ciary of a so-called 'host-department'. The GGD in the Netherlands can negotiate with the local government for extra financing for special activities under the Healthy Cities label and/or for other types of funding.

In the United Kingdom, case studies money comes both from the local authority and from the Health Authority. In one case study, additional budgetary resources come in the form of in kind assistance, contributions from sponsors, and through money generated through the organization of activities. In Sheffield 'partmer agencies' pay an annual financial contribution, the amount depending upon whether the partner agency is a statutory or voluntary body. Other partners pay according to their budget. A large part of the finances comes, however, through the Health Authority and local authority and until 1994 through Urban Programme Money for projects. The Health for All coordinator in Winchester is financed through joint funding of the local authority and the Health Authority. The local authority provides office and equipment. The Healthy Cities project in Newcastle is considered an 'enterprise'. This means in terms of financing that only about half of their budget is received through funding of the Family Health Service Authority, the local authority, trusts and voluntary agencies. The other part of the budget is raised by "selling" products and services. The local authority offers office space. A proposal was drafted by the management group to change the organizational structure of the project into a Company limited by Guarantee which was approved by the members in 1995. In order to safeguard income, a special fundraising sub-group was working in 1994 to develop a three year partmership with the local authority and Health Authority. The Liverpool Healthy Cities project is financed through a Joint Consultative Committee of the local authority and Health Authority. Office space is obtained through the city council. Finances for the Healthy Cities project in Glasgow come through the health board and the city council. The coordinator is employed by the city council, so these wages are paid from a separate budget. The city council also provides an office and support facilities. The Glasgow Healthy Cities community support unit is funded through central government Urban Aid money. The three projects operationall under this support unit's responsibility are also funded by external, national government, sources.

In addition to the overall infrastructure of a Fealthy Cities project, each separate demonstration project may have a working group, steering group and/or planning group. Unlike the example given in the introduction to this chapter, the majority of the Healthy City demonstration projects tend to operate independent of ongoing, mainstream activities. We will provide two examples of WHO Project cities in which those involved at one time. structured and considered Healthy Cities to be an organization which primarily planned. and carried out projects. Subsequent invalvement of these cities in the second phase of the WHO Project took place with revised structures. In both cases, reorganization took place 
because of the recognition of the importance of sustainabillity and integration of the Project's ideas and principles into ongoing and mainstream activities and policies (Crumbly, 1992; Gezonde Stad Rotterdam, 1994; Lipman; 1992).

\section{Examples: From new and separate, to renewed and integrated}

In the United Kingdom, a joint committee between the local authority and Health Authority is in place for the purpose of planning and obtaining financing for joint (care) activities; this committee is referred to as the Joint Consultative Committee (JCC). A JCC committee can be used to link the two authorities for a variety of objectives, such as, for example, a joint public health and health promotion initiative. In Liverpool, the JCC has served as an umbrella for the development of a joint public health plan as well as joint public health activities between the authorities. In fact, the membership of the committee was even enlarged in order to make it a so called "intersectoral committee" and give Healthy Cities a place in the local authority structure.

In July, 1992, a Performance Rewiew Team (PRT) recommended that changes be made in the structures and strategies which had been used up to that point by Healthy City Liverpool. Changes were seen as needed to increase visibility, to work more efficiently to avoid duplication and 'projectism", and to secure adequate funding. It was expected that changes would assist Healthy Cities in becoming part of mainstream programmes and that it would increase the project's attractiveness to (private) organizations in the city. Moreover, ways had to be found to construct a so-called inter-agency approach to public health. This approach, it was thought, would aim at the city of Liverpool as a whole rather than only at specific project areas. The PRT recommended that Liverpool continue in its changed form as a WHO Project city. Liverpool therefore started the second five-year phase of the WHO Heallthy Cities project with a revised structure, one which was based on the existence of a JCC between the local authority and Health Authority. Under the JCC, a Joint Public Health Team (JPHT) and a Joint Care Planning team (JCPT) are currently operational. The make up of the JPHT is intersectoral, and the members meet four times a year. The JPHT core team, of which the Healthy Cities coordinator is a member, is made up of representatives of the City Council and Health Authority and meets monthly.

The JCPT had existed previously and had been responsible for writing a community care plan and had five action groups: children and young people, elderly, learning difficulties, physical handicap and mental health. The JPHT followed this structure, and had five task groups: Heart disease, Cancer, Accidents, Housing and Sexual health. Each of them produced a part of the public health plan (Liverpool Healthy City, 1995). The task groups were composed of representatives of organizations, associations and community representatives in Liverpool. It appeared, however, that the compilation of each group differed. The Liverpool Healthy Cities project team was coordinating the task groups; the overall. plan 9 comes under the responsibility of the JPHT.

The intention was that, in the end, this structure would lead to a reallocation of funding. Thusfar, however, the two authorities have not reallocated their budgets. They have, rather, merely decided to spend money that has been given for joint care facilities on public health activities.

The Liverpool structure is intended to assure the accountability of Healthy Cities to key structures such as the JCC. Therefor the Healthy Cities Office is part of the local authority structure, and the Healthy Cities coordinator is part of the central policy unit team. This attachment of the Healthy City Project office to the central policy unit also facilitates the integration of a health perspective into all policies of the local authority. The central policy unit is a unit of the local authority whose prime task is to develop policy and generate 
corporate plans. At the same tirne, the JPHT and task groups fit in quite well with the WHO Project requirements for intersectoral collaboration and the development of a city health plan. Furthennore; they are in line with the United Kingdom national government's request for joint working 10 .

A second example comes from the city of Rotterdam which, like Liverpool, started with a revised Healthy City structure upon entry into the second phase of the WHO Healthy Cities Project: In the first phase, Rotterdam Healthy City was located in the GGD's health promotion department as a separate entity. Healthy City Rotterdam was in itself regarded as a project. It had its own budget and its own project office. On a day-to-day basis, the project tearn was responsible to the head of the department. The formal lines of accountability, howewer, were to the city-wide social renewal steering group. Rotterdam Healthy City was a demonstration project of social renewal" ${ }^{11}$. The project was expected to function as a vehicle for raising awareness of and attention for health in a very broad sense. One of the interviewees put it as follows:

"So you create o project, you find some extra finances, you appaint a coordinator with good ideas and this person will gather some more people around him. In the end it will run, but it also has to find ways to impoct the system." (Pollitician, Ae)

In May, 1994, social renewal came to an end in the sense that the city-wide steering group broke up. From then on, the initiative had to be carried forward by the various associations, organizations, and community initiatives in the city. The lead of ongoing projects was given to individual organizations. This implied the end of the Healthy City project office, as their project. funding came to an end.

"If project money comes to an end and one has to continue [project octivities, MG] within mainstreom activities, this could lead eventually to a reorientation of the regular budget." (Politician, Ae)

This means that project activities are given a place within other, already existing, activities. From then on they are financed from the regular budget. With the slogan 'From project to policy" the project team, together with the management team of the GGD, developed plans to continue Healthy City Rotterdam as a mainstream activity within existing systems (Rotterdam Gezonde Stad; 1994). In this plan the responsibility for the development and maintenance of health policy, and thereby also for Healthy Cities, has been given to the management team of the GGD. Each member of the GGD management team is responsible for a certain geographical area. Each area manager has a part-time colleague responsible for the development of health policy in that area of the city and/or municipality. The city council, however, retains ultimate responsibility. At the same time there is still a small Healthy Cities project office at the GGD to encourage and stimulate all these other parties to take on board Healthy Cities ideas and methods.

Referring back to the conclusion of Chapter Four, the above two examples indicate a tendency of Healthy Cities to move from mere project status toward greater integration with existing policy structures. Based on the ten case studies which we have researched, we expect that separate structures will be replaced by integrated structures when municipalities decide to continue to work on Healthy Cities after their first few (five) experimental years. This process is supported by initiatives of a visible Healthy City office, steering group, support group, or city council committee. A different approach to establish integram tion is to have an independent Healthy Cities office acting as a Fealthy City consultancy on projects and training. which consults with different organizations and authorities in a municipality. Such an approach is visible in Newcastle.

Integration of Healthy Cities within existing structures, and moreover within existing strategies and thinking, is mentioned by interviewees as the best method for making. Healthy Cities mainstream. There are, howewer, barriers which hinder such an integration. 


\subsubsection{Barriers hindering integration}

The barriers that were mentioned as hindering Healthy Cities in receiving political commitment also seem to limit the creation of a supportive environment and the integration of Healthy Cities into previously existing initiatives and structures. Barriers mentioned indude the conceptualization of Heallthy City, personal efforts, money, low priority of health, and statutory duties. Besides these barriers, a number of other things were mentioned.

Minutes from meetings of Healthy City steering committees demonstrate that structures and ownership were often, either implicitly or explicitly, a point of discussion. Managers want to control and therefore talk about structures and ownership. Many are motivated by the desire to know how their money is going to be spent, and whether involvement in Healthy Cities (activities) has any chance of success in concrete terms. Such discussions make it difficult to talk about health policy in terms of goals, philosophy, values, ideology, and vision. Involvement in a fixed-term Healthy Cities demonstration project is thus easier to decide upon than to consider the possibilities of using Healthy Cities as a framework for policy development which promotes the health of the population of a city:

Another aspect which may hinder integration is that, besides the Healthy Cities initiatives, other partnerships may already be in existence. These may be more attractive than Healthy Cities to potential actors, and therefore diminish the attention given to Healthy Cities or its potential. And it seems that it is difficult to use them for other purposes.

"There is a growing interest in health generally, there is a growing realization that one needs to work in alliances. The Regeneration alliance on economic development and housing, where agencies try together to build up the economic life of the city, is probably going to be more influential than Healthy Cities. It is part of a city wide process." (Community worker, $\mathrm{Fb}$ )].

The above quotation illustrates that if a separate Healthy Cities intersectoral steering committee is started, there is a danger of duplication. Rather than Healthy Cities taking a leading role, of course, it is possible that Healthy Cities ideas could instead be interweaved into the ideas and activities of intersectoral activity such as embodied by this Regeneration alliance.

It appears from the case studies that the Health Authority/GGD has significant intluence on the dissemination of Healthy Cities ideas in the cities. The way this authority is organized, however, influences this dissemination process. For example, a Health Authority/GGD can work for one city but also for a region. If a Health Authority/GGD works for a region, it seems not to be the case that all cities they are working for are stimulated to take an interest in Healthy Cities. On the other hand, in the local administration of small cities, one person is often responsible for several policy areas. This reduces (based on Chapter Four) the chances that health activities and thus Healthy Cities will receive high priority status.

Within the case studies, a mixture of basic Healthy Cities structures has been identified. Within the distinctions new or existing and separate or integrated, most structures can be given a place. The structure of Healthy Cities can centre around a theme, or it can be used as an umbrello or a project organization. If two case studies use a comparable structure, it is not evident that they also work on the same activities. And if case studies do work on the same activities, they may have quite different structures for doing so. With regards to the WHO requirements for project structures, it can be concluded that the case studies in the United Kingdom fit these requirements more closely than those in the Netherlands (see also table 5.2). A passible explanation for this finding is that the national network in the United Kingdom has been in formal existence for a longer period than the similar body in the Netherlands. 


\begin{tabular}{|c|c|}
\hline District/Local Health outhority/GGD & Local Authorityllity Councill linduding the Cily \\
\hline chairpersonidirectar & Council committees) \\
\hline department of public health & (ass.) chief excecutive of centrol policy unit \\
\hline director & department of environmental health \\
\hline srofficer & director \\
\hline department of health promotion & sri officer \\
\hline director & department of leisure trecreation \\
\hline sro officer & sr. officer \\
\hline deporment of planning & department of houising \\
\hline$\therefore \quad$ director & sr. officer \\
\hline Regional Health authority & department of road traffic \\
\hline deportment of public heolth & sit. officer \\
\hline director : & central policy and resource unitit \\
\hline Universities & director \\
\hline deportment of public health & Social Services \\
\hline profiessors & Fomily Health Service Authority \\
\hline sir. staff & Lacal Indusity \\
\hline Council of tenants associations: & County Council \\
\hline Community coumcil & Regional Council \\
\hline Chamber of commerce & Convenor \\
\hline Trade union : & \\
\hline
\end{tabular}

Table 5.3: Members of a Healthy City steering committee.

\subsection{The actors}

\subsubsection{Categories of participants}

"If you ask me what is most important, I would say it"s the people. The people with charisma."

(Management HA/GGD, Be)

In this section the aim is to identify the Healthy City actors and construct a domain. Actors are identified through an analysis of Healthy Cities structures and activities in which the question 'who is important here?' is posed. Most projects are carried out in line with the WHO's Project requirement of intersectoral collaboration. Table 5.3, which presents the typical make-up of a steering group's actors, reveals the nature of what is meant by intersectoral composition. Intersectorality in itself, however, does not predict much more than a group"s actual composition such as, for example, the number of participants, the specific types of participants, or the intensity of their involvement. The project group on child safety in Newcastle as presented in section 5.3, for example, has a quite different composition from the child safety group in Alnelo, which differs again from the group that supervises the Child Safety project in Drumchapel (Glasgow). This means that even knowing the content of the activity addressed by the intersectoral project group is a limited predictor of the identity and role of participants. Additionally, in section 5.3 it has been shown that not all case studies have the same or even similar demonstration projects. It seems that the projects themselves display a rather large diversity of actors and activities.

In this section, all participants have been listed per case study. For each case study these participants have been categorized by organizational type and policy sector. The case study and country specific figures are presented in appendix 3 (figures $5.4 \mathrm{a}, 5.4 \mathrm{~b}$, and $5.4 \mathrm{c}$ and figures $5.6 \mathrm{a}, 5.6 \mathrm{~b}$, and $5.6 \mathrm{c}$ ). Figures 5.3 and 5.5 provide a general overview of organiza- 


\section{Cily planning}

Deportment of city planming

Public sofety

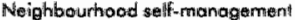

\section{Environment}

Deportment of enwironmsert

City council commentifter on enwirenment and heolth

City council committen on antironmental health

City council commiltere on consumer protection

\section{Howsing}

Council of tenants: s: aciations

R⿴囗十 [swapont unit inhobitants

Steering group experiments with housing

Department of housing

\section{Public health}

Higelith outhority/GGD. Depertmeint of public health, Department of

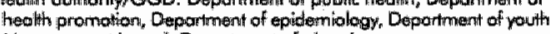
Monegemeat boord, Deportment of planning

Home care services

Crossi assocation

Heallty care Fimancerss

$\mathrm{NH}$ HS develapment work

Community Heolithi Kouncil

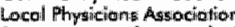

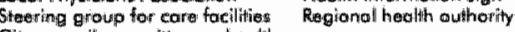

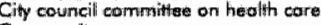

Cormmunith cone growp

Potivent sienrice des:

Sichool phypgicitur

Sichool thuse

Piturchogers

CAD

RIAGC

CGM

Hospitals

Geurerol offolirs,
Legal affoirs

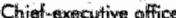

Centrol goliker uni

Communitiny council

Aldarmon of public healith

Nafmocentent board

Roghiond counc:

Ciny counes!

Assistant to aldermuan of public heolth

City coume il committe on polidy and resourcios

\begin{tabular}{|c|}
\hline $\begin{array}{c}\text { Traffic, Roods affairs } \\
\text { Public tronsport }\end{array}$ \\
\hline 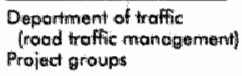 \\
\hline
\end{tabular}

\begin{tabular}{|c|c|}
\hline $\begin{array}{l}\text { Education, Culfure } \\
\text { Recreation; Ants }\end{array}$ & \\
\hline 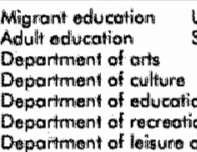 & $\begin{array}{l}\text { University } \\
\text { Schools }\end{array}$ \\
\hline
\end{tabular}

Economics, Eusinosis,
(un) Employment

Sorüal workploci

Locol amploymant service

Tradias couneil

Locol industry

Deporthment of worth

Department of economics

Depertment of employmen

Chomber of commerice

\section{Social and \\ Welfare atfairs}

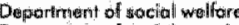

Diaportment of socitill secturita

Dieportment of socici stectrits

Deportment of Fiomily onid Commiunty corte

Sentor cithen: grousp

Association for wellfore of eliderly perisons

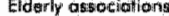

Neighthourhood work

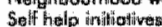

Fomily and communtity dervitices

Assaciotion of country wormen

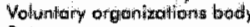

Rotary

Equol apponturiftien counc

Volunitory weiffore orgarizactioris

Consumer service

Back community

Consumer and sulisty organization

Community devidapmient commitio

Youth service

Commonit esupport uriit

Migronl work

Figure 5.3: Healthy City domain based on actors (1); 
tions/associations and departments that were most frequently mentioned by interviewees. and cited in the other sources in relation with Healthy Cities. In order to create figures 5.3 and 5.5 the individual case study specific domains have been compiled and integrated.

Figures 5.3 and 5.5 show that the general Healthy City domains based on actors cover all public policy sectors and organizational categories as defined by the researcher. There is, howewer, no single case study Healthy City domain based on actors which covers all. public policy sectors and/or the organizational categories. In other words, the case study specific domains show differences in composition among each other. What then are these differences? The country specific and case study specific domains structured by public policy sectors (appendix 3, figures $5.4 \mathrm{a}, 5.4 \mathrm{~b}$, and $5.4 \mathrm{c}$ ) show that in all case studies, actors from the public health and social welfare sectors are represented. They also reveal that in a majority of the cases, actors from education "culture, recreation and arts, and general affairs are represented. From an organizational perspective (appendix 3, figures $5.6 \mathrm{a}, 5.6 \mathrm{~b}$, and 5.6c), the Health Authority/GGD services, local government services, and the volunteer sector, e.g. community and selfhelp groups, are also represented in all case studies.

Differences between the two countries can, once again, be at least partially explained by the frequency with which certain types of actors were represented in the case studies. In the United Kingdom, the majority of the case studies involve actors from the priwate sector (economics, business, industry, trade), the housing sector, and the environmental sector, which is not true in the Netherlands. On the other hand, secondary and primary health care representatives are more often mentioned and are more diverse in the Netherlands case studies than in the United Kingdom. In both countries, however, the traffic sector, city planning, public safety, and public affairs are represented in only one sector or not at all. The general domains based on actors (figure 5.3 and figure 5.5) provide, however, a very reasonable indicator of 'the' Healthy Cities domain. A city specific Healthy City domain based on actors may resemble this general domain in many ways, but is likely to encompass fewer sectors and/or organizations.

A few remarks are in order to sum up the analysis thusfar. First of all, if all public policy sectors are covered and/or if all organizational categories are represented by the domain of a specific project, this does not necessarily indicate that a broad range of activities also takes place in the city. A municipality may carry out only one activity but do so with a broad, intersectorall group of organizations and individuals. Secondly, the categories that have been used are general. Who exactly composes or fits within these categories may, however, differ between countries due to existing differences in the distribution of tasks and responsibilities within public administrative structures and health systems. One difference between the case studies in the United Kingdom and the Netherlands, for example, is that the Netherlands has no special Family Health Service Authority. Furthermore, in the Netherlands, unlike the United Kingdom, there are no Community Health Councils ${ }^{12}$ and no Joint Consultative Committees ${ }^{13}$. But we found also in line with our assurnptions of Chapter Two that local circunstances, so regardless of country, caused differences in domain composition.

Examples of aspects that cause differences among cities, regardless of country, are: the existence of local voluntary, community, or private initiatives or private-public networks that are unique for that locality;

a change in vision and/or management of (potentially) participating organizations in the case study;

a change in the career (jobs) of the representatives of the organization;

a change in local politics: 


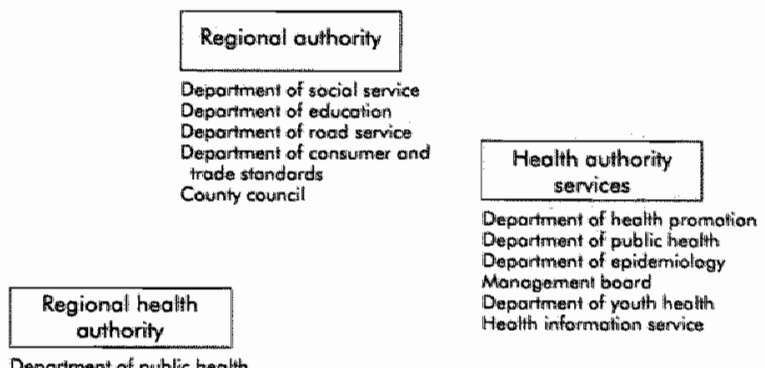

Primary health core Chilldren consulfetion desk
CAD

RAGG

CMG

FHSA

Home cere

Physicitions

Crass assacation

Local Phissicitions Association

\section{Secondlary thealth core}

Sickness fund

Boord of hielth care facilities Potient senvice clesk

Hospitals

Heaittin core financers.

Education, Training

FAO |reduction of inequallities

Universtites

Adull education

Migront educotion

Pitirnary and gaccondary schools

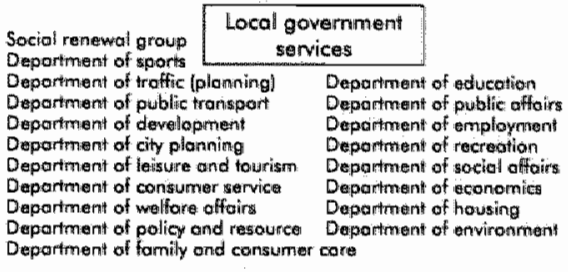

Woluntary grousps,

Cgmpunity groups,

Assoccitions of welfore/'wellibeting of elderly persians

Voluntary action coordination body Lay core tinitiatives

Patient and consumer orgamization Self help inithiothers

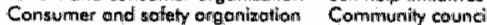

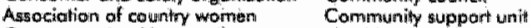

Conmminity health council Neightowithood groups

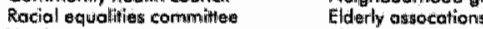

Youth groups Block corrumbing

Womens group Voluntory centres

Ratary

No

Industry, Trade

Trrades council

Enployment affice

Cherriber of commerce

Lotal entrepeneaurs

Locol industio

Individuol

Volunterers

Community particiacints

Social and Welfare

organizations

Children support

Commonity (dewelapmanit) work

Com artunity

Andust woibs

Welfores organ izwitores

Foundation of wetibeing of olderly parople

Higrant ossocation:

Teonagio work

Figure 5.5: Healthy City domain based on actors (II)]

- the content of demonstration projects;

- a change in composition of the project team and support structure.

Thirdly, although figures 5.3 and 5.5 provide an indication of a general domain composition, a city specific domain composition and the actors involved in each activity differs from this figure (see appendix 3 ). In other words, the expectation that the domain is not fixed was confirmed. 
Lastly, and this is in line with a conclusion of the research of Laumann and Knoke (1987), the figures in this section (and in appendix 3) show the representation of sectors and organizations in the domain. What they do not show, however, is how these sectors and actors are represented. What does it mean for each case study when an organization is mentioned as a participant and/or when the domain covers a majority of the public policy sectors? These questions are central to the remaining parts of this section.

\subsubsection{Core and peripheral}

From official reports on the case study activities, as well as from interviews, it appears that often only organizations are mentioned as Healthy Cities actors. But both the interviews and other evidence clearly speak to the importance of the role of individuals and small groups. The resullts of the analysis of the actors correspond with the findings of Laumann. and Knoke (1987), who pointed out that it is not so much the entire organization, but an organizational component or a representative individual, who actually participates in activities. Laumann and Knoke focus on the role of corporate actors. They mention that individuals only play a role in public policy-making or in influencing policy when they act on behalf of the organization, for example, when they have a mandate.

That an organization is merely mentioned as a Healthy Cities participant by others or by representatives of the organization is not an indicator for the intensity of involvernent. Likewise, a Healthy City logo on an organization's own letter head or the organization's logo on Healthy City letter head provides limited information about the intensity of the organization's involvement. Being mentioned as a Healthy City participant could mean, see also table 5.4:

- (enthusiastic) individuals who represent their organization without having a mandate; individuals who represent a department of this organization;

individuals who represent their organization and have a mandate to do so;

- participation of an entire department;

- participation of the entire organization as is, for example, expressed through contribution of resources, or by having a vision on the health of the city incorporated in their long term planning.

Participants representing departments or entire organizations without decision-making authority and, to a lesser extent, the participation of an entire department of an organization, are the most common means of organizational representation in Heallhy Cities projects. The question is what this distinction in participation means for domain construction and policy development.

An important feature in domain construction is to identify who is involved with an issue and the roles those involved parties play or can play. From table 5.4, it can be concluded that for the Healthy Cities situation it is very likely that:

participants/representatives in Healthy Cities projects are unequal in the amount of formal authority they posses. This implies that those who want to stimulate or manage a certain policy process need to very carefully identify the interests of potential collaborators. This means to carefully identify, at an early stage, what exactly the formal position and authority of the various participants is, will , or may be.

- having no equal formal authority influences the decision-making process and policy development, as it is known from policy science.

Also the level of decision-making, top-management level or operational level, is influenced by the constellation of the participants involved and their formal authorities. Sometimes people are not in the position to decide on certain subjects on behalf of their department or organization. Nonetheless, they may be authorized to make decisions with regards to 
Table 5.4: Different meanings of a Healthy City participant in relation to the amount of formal authority and decision-making power they posses.

\begin{tabular}{|c|c|c|c|c|c|}
\hline Healthy City Particlipants & 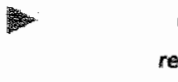 & $\begin{array}{l}\text { tividual } \\
\text { esenting: }\end{array}$ & & Unit: & Organization: \\
\hline $\begin{array}{l}\text { Formall authorlty } \\
\text { Vil }\end{array}$ & $\mathrm{him} / \mathrm{herself}$ & Unit & Org. & & \\
\hline Formal commitment/mandate & & $x$ & $x$ & $x$ & $x$ \\
\hline No formal commitment/mandate & $x$ & $x$ & $x$ & & \\
\hline
\end{tabular}

Table 5.5: Core people who are pushing the Healthy Cities Bandwagon.

Core Participants

- responsible politician for health/Healthy Cities

- (part of the members the steering committee

- (part of) the members of the monagement committee

- the members of the project team

- the (assistant) project coordinator/contact person

- members of project teams related to health

(for example sacial renewal or city regeneration)

- [academic] researchers

- officers of the local Health Authority/GGD

- senior staff and management of the Health Authority/GGD

(especially health promotion and public health departments) - operational/governmental

- volunteers/local people

- representatives of the health broard (UK only)

- officers of the local authority

- senior staff and management of the local authority

(especially housing, social welfore, recreation, enwironment)

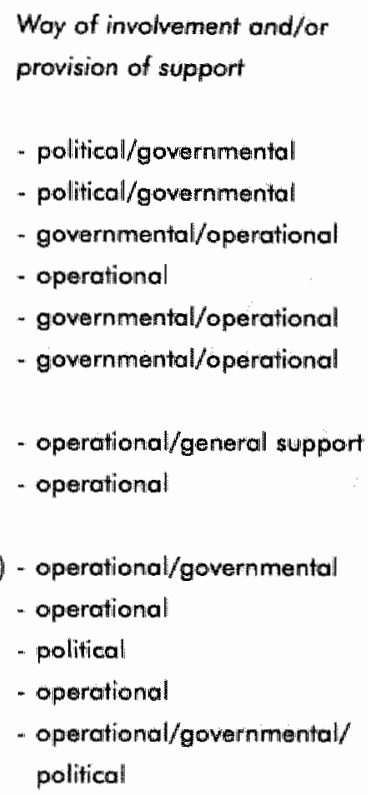

their personal participation as a representative of that organization within a concrete project. It must not be forgotten that at the operational level, different issues are at stake than at the top-management level. Whereas at the operational level the feasibility and practical possibilities of a project may be the issue, at the top-management level the project is evaluated in light of organizational goals, potential, and concomitant responsibilities.

Based on what Laumann and Knoke mention about the frequency of involvement of actors in events, we can distinguish between a core group of actors and a peripheral group. The core group are those who are very closely involved in Healthy Cities. They support Healthy Cities mainly because of its ideas and principles. They see Healthy Cities as a valuable concept for promoting the health of the city and its inhabitants. In table 5.5, an overview of these core people is provided. Such participants are the engine for the projects 
and are the persons trying to give Healthy Cities a high profile. They use Healthy Cities as a means for advocating collaboration or visibility for the city, and as a source of arguments for convincing other, less or unenthusiastic, potential actors. They participate in projects and activities regardless of the content. Their involvement can bring along political or governmental support or they can provide operational support due to their organizational and/or professional capacicies. Their support and the roles they play may vary among the activities carried out by one Healthy City project; for example they play the role of ordinary group nember, chairperson, facilitator, or advisor.

The other group of participants has been called the peripheral group. The peripheral group: of participants represents those whose support and participation depend on factors (or combinations of them) such as:

- the content of the projects that are developed;

- the visibility Healthy Cities (demo projects) brings along;

- the potential for establishing international linkages;

- the coincidence with national government demands;

- problem areas in the city;

- whether they are asked or not;

their skills and experience;

their contacts;

their resources;

the availability of project money;

efficiency considerations, e.g. to avoid redundance.

For core participants, involvement may change over time, but the subject of activities merely predicts how they will be involved. For peripheral participants, involvement may also change over time, but the subject in this case predicts whether or not and how they are involved.

Laumann and Knoke also distinguish between core and peripheral actors. According to them, core actors form an elite group with decision-making power which is generally able to control the domain. The peripheral group is the group who wants to be involved but who must and does operate on the edge. They are not so-called key players. The Healthy Cities core group cannot control the domain. But comparable to the core group as defined by Laumann and Knoke, they do seek to influence other (potential) actors'thinking and policy-making. The question, however, is whether they are powerful enough to exert influence. For example, our research revealed that it is not the core group which decides whether peripheral players are part of the domain. The peripheral players decide themselves whether there is an opportunity for them to be involved. This represents a departure from Laumann and Knoke's findings. It may indicate that the peripheral group does not perceive a compelling need to involve itself in Healthy Cities. This in contradiction to Energy and Health Care, the case study fields of Laumann and Knoke. In Chapter Four, we found that the direct benefits of involvement in Healthy Cities is for those traditionally not involved in health matters sometimes difficult to imagine, so it may indeed be the case that this difference exists for motiwational reasons. The motivation for occasional participation based on pragmatic reasons is that most organizations already participate in several networks and initiatives where they can exchange information. There is the danger that these actors will therefore regard Healthy Cities projects as merely another network or initiative. At that point, the project is perceived either as 'an extra burden' or as an "extrat stimulus'. For most organizations, it is not their statutory duty, except for the Health Authority/GGD, to integrate a health perspective into their regular activities. So because it is obligatory to organizations to participate in a steering group of an initiative which aims 
to develop a health (y) (public) policy, questions that come first are therefore what does it cost and what do I get out of it?'. And if the peripheral group exceeds the amount of core participants by far and/or if the core group is very small, making Healthy Cities a mainstream business will be

"...extro difficult, it will demand extra effort. Because if you get money based on the label that you are a "Healthy City", you can do same temporary activities. Because people will be enthusiastic about the money, it motivates opportunism." (Chief officer HA/GGD, Cc/a)

In the final analysis, it is difficult to discover exactly why agencies link together. The researcher has a difficult time pinpointing whether involvement is due only to Healthy Cities, to a governmental request, or to other reasons? What can be said, however, is that for some cities it was the first time that senior representatives of different organizations met (Healthy Sheffield, 1994). For example, in the United Kingdom collaborative work between the two authorities has been going on at an operational level but senior health partmerships are rare. This is mainly a result of the separation of the local authority from public health affairs, first begun in 1948 with the creation of the NHS and furthered in 1974 in a reorganization of the NHS. That senior representatives of two important authorities get together is for some cities unique.

"Without Healthy Cities the Health Authority would still regard care as the one and only priority and the Local Authority would not go any further than its statutory functions. This means that little ar no preventive or health promotion work would be done. The beauty of Healthy Cities is that it brings many organizations together and gets a lot of smoll groups together, samething that would not have happened without Healthy Cities." (Healthy City project coordinator, $\mathrm{He} / \mathrm{a}$ )

We have indicated in table 5.4 what being mentioned as a Healthy Cities participant actually can mean. These six different meanings of being a Healthy Cities participant can be divided into a core group and a peripheral group. Naturally, instability among participants implies an unstable domain composition. Indeed, core actors are defined as being permanently present. But it will appear in sub-section 5.5 .3 that all participants, whether they are part of the core group or peripheral group, play different roles through time. Furthermore, they play different roles from place to place, issue to issue, and according to municipality-specific domain composition. An unstable domain composition may nonetheless influence long-term city-wide policy based on Healthy Cities premises: it is not unlikely that for some concrete issues it is possible to develop policy based on the experiences of the demonstration projects. At this moment in time it is only possible to speculate as to whether or not the aggregate efforts of these concrete projects will lead ultimately to the use of Healthy Cities as a city-wide policy framework.

\subsubsection{Roles}

The Healthy City core participants, including the WHO, are often referred to as owners of the Healthy Cities and health policy development in a municipality. According to Gusfield (1981) ownership of an issue or problem have those who are able to influence issue definition and who are consulted by others. Indeed, Healthy City owners are able to influence the definitions of a Healthy City and are consulted by other people. With regards to healthy public policy or health policy, it is not so much the core participants as defined in the case studies, but especially the academics working in universities and/or WHO Collaborating Centres ${ }^{13}$ or other organizations, and the WHO which should now be regar ded as owners. They play an important role in the definitions of healthy public policy and health policy. They secured this position on the basis of research, projects, articles in journals, and the conferences. However, it is not unlikely that the role of Healthy City core participants as defined in the case studies, and even peripheral participants, will increase in 
this regard as soon as health policy development is more integrated into local mainstream thinking and practices. It is especially the representatives of cities involved in the first fiveyear-phase of the WHO project who had, and still have, a major influence on the way Healthy Cities has developed.

Political responsibility is described by Gusfield (1981) as having responsibility for solving a problem ${ }^{14}$. For our research it means having the formal responsibility for developing health policy and solving health and health-related problems (or to make sure that this will happen). At present the Health Authority/GGD and the local authority are the main actors who have such political responsibility. Generally, core actors attempt to enlarge the number of people with political responsibility for working on Healthy Cities and health policy development. For example, in 1994, the chief executives of key organizations in Sheffield signed the so called "Fromework for Action" for health (Healthy Sheffield, 1993). The implementation of the framework was to be a joint partnership, but each partner was expected to take responsibility for a particular issue.

"By giving the lead to others, one assumed that it would enter into the hearts and minds."

(Management department HA/GGD, He)

The process is coordinated by the Healthy Sheffield Board (steering committee). The chiefexecutives of the partner organizations decided that in the first years three activities from the framework would receive priority based on the chances of having short term (visible) success:

- carer's health [a carer is someone who provides care to others, MG] whereby the Family \& Community Services deparment of the local authority is the leading agency; - mental and emotional well-being whereby voluntary action Sheffield is the leading partmer; - work whereby Sheffield and Rotherham Chamber of Commerce is the leading partner. What can be said with regard to the roles the local authority and Health Authority/GGD are expected to play?

The roles which the local authority can play is the broker and facilitator role, "We have a broker role: we bring different parties, institutions and financiers together. It is highly" appreciated. It is in fact o whole new opproach compared to our previous approach." (Politician, Be) If the local authority takes up the broker role, it can become a partner in new networks. For example, whereas the local government in the United Kingdom has for some time participated in metworks built around care facilities, this is a rather new and fast growing area for local government in the Netherlands. The idea that was expressed by representatives of the local authority is that a local authority must not produce things by itself. Instead, bringing people together is seen as likely to be more effective. A local authority does not need to be an expert if somebody else is better equipped for performing certain tasks.

The Health Authority/GGD plays a large role in initiation and implementation of Healthy Cities. There is a danger, however, that Healthy Cities is perceived to be an equivalent of the Health Authority/GGD. This is a result of the fact that it is often persons employed by a Health Authority/GGD who are very active in the promotion and implementation of Healthy Cities. Often a department of the Health Authority/GGD takes a leading role in promoting Healthy Cities. Whether it is a Health Authority/GGD department or not, however. it does appear that a leading department and/or person is needed. Healthy Cities is not self-generating; rather, it needs active stimulation. Similar to the role of the local authority, the Health Authority/GGD role is not necessarily active, but can nonetheless be facilitative. In order to attract attention and to work in an efficient way to advise others, they need to make use of existing networks, experiences, and to give themselves profile.

The Hedthy Cities coordinators or contact persons play a crucial role in the development process 
of Healthy Cities initiatives in a locality. Their role is strategic and they are very often high profile figures within the local authority and key-organizations in the city. Communication skills, political skills, and persistency are important characteristics and prerequisites for a coordinator seeking to attract the attention of decision-makers. Key-people and coordinators do move on, and this can be both positive and negative for Healiliy Cities. The down side is that it can mean that a project has to start all over again. Actual situations in which this happens are illustrative of the difficulties Healthy Cities has in receiving a stable position on the political agenda and the difficulties there are in getting it to be regarded as a mainstream activity. On the positive side, if people move on either to new positions within the same organization and/or to other organizations, they may be able to give strong voice to the initiatiwe from their new position.

Three separate domain compositions have been presented. In section 5.2 it was mentioned that this separation was only for analytical reasons because the activities, structures and participants are, as appeared also in the separate sections, strongly related. Therefore, before this chapter is concluded, efforts will be made to compare and integrate the findings of the three preceding sections.

\subsection{A Healthy City standard domain}

\subsubsection{Comparing the domains}

It has been noted in previous sections that if the domains based on actors, structures, and activities from the research are aggregated, all public policy sectors and organizational categories are covered. The domains referred to here are those which have been constructed and presented in the previous paragraphs (and appendix 3). This observation, however, does not hold true for the individual case studies. When the domains are compared on the basis of coverage of the public policy sectors (see appendix 3, figures 5.2a, 5.2b, $5.4 \mathrm{a}$, and $5.4 \mathrm{~b}$ ), it can be concluded that public health and social welfare are present in all case studies domains because in all case studies, activities are undertaken that fall under the label of public health or social welfare. All case studies have actors from the public health or sociall welfare sectors as well.

In the majority of the case studies in both countries, activities are undertaken in the traffic sector (seven cases). Although traffic is mentioned as an area in which many activities take place, the actors who are involved are not necessarily representatives from the traffic sector. Actors from this sector are represented only in two case studies, as can be concluded from figures 5.4 and $5.4 \mathrm{~b}$. The same conclusion can be drawn for the public safety sector, where in only one case study was an actor from that sector explicitly mentioned, though in the majority of cases (seven), activities were taking place in that sector. Representatives from education and general affairs can be found in the majority of cases (in nine and eight cases, respectively). Examples of educational activities were, however, only explicitly mentioned in two case studies in the United Kingdon versus four cases in the Netherlands. Actiwities covered by general affairs, such as policy development and Law, were never explicitly mentioned in the case studies. Public affairs was discovered in only one case as activity and in one separate case in terms of representative actors. For the other public policy sectors, economics, public affairs, housing, and enviromment, it can be concluded that if activities are undertaken in those sectors, participants from these sectors are represented. The economic sector is with regards to actors and activities more often mentioned in the United Kingdom (both in five cases) than in the Netherlands (in one and 
two cases, respectively). Also the housing and environment sectors are with regards to actors and activities more often mentioned in the United Kingdom (both in four cases for actors; and both in four cases for activities) than in the Netherlands (in one and two cases, respectively, for actors; and both in one case for activities).

It can be concluded that the general Healthy Cities domain compositions (figures 5.1 and 5.3 ) are slightly more convincing in their representation of the overall United Kingdom case study domains than that they represent those from the Netherlands (figures $5.2 \mathrm{c}$ and $5.4 \mathrm{c})$. The reasons for this difference can be partly explained by differences in formal responsibility distribution for public health amongst the actors. The National Health Service in the United Kingdom gives the Health Authorities responsibilities with regards to primary and secondary health care. Within the Dutch health system, these responsibilities are not unified within one body (see also appendix 1). It is therefore more difficult or artificial to distinguish among primary health care "secondary health care, and Health Authority services in the United Kingdom, than it is to do so in the Netherlands (see figures $5.6 \mathrm{a}, 5.6 \mathrm{~b}$, and $5.6 \mathrm{c}$ ).

The relatively few activities and absence of representatives of industry and the economic sector in the Dutch case studies (see for example figures 5.2a, 5.4a, 5.6a, and 5.7a) may be explained in a number of ways. First, it may indicate either a hesitation by industry and the economic sector to get involwed in public health as opposed to health care or pharmaceuticals where this sector is alleady involved. In Chapter Four and in section 5.5, limited experience and limited understanding of public health were also mentioned as reasons for such hesitation. It may, however, also indicate that they are neglected by the more traditional public health actors for example the GGD, and actors from the environmental sector, the housing sector, or social welfare sector. At the same time, however, being identified as a Healthy City actor provides no information about the reasons and intensity of involvement. For example, do representatives actually turn up at meetings, or do they take responsibility for Healthy City activities?

The fir between the individual case studies and the general Healthy Cities domain compositions (figures 5.1,5.3, and 5.5) differs according to the situation. The domains illustrate that although some country specific differences can indeed be observed, at the specific case study level, it is not interesting to distinguish between countries. Some case studies from different countries are relatively equal each other, some case studies within a country differ from each other. If, for example, figures $5.7 \mathrm{a}$ and $5.7 \mathrm{~b}$ are compared with figures $5.6 \mathrm{a}$ and $5.6 \mathrm{~b}$ and $5.6 \mathrm{c}$, it is illustrated that for each concrete activity there is a specific domain. What can then be concluded about the possibilities for creating a standard domain?

\subsubsection{A standard domain}

Before we move further we first need to explain what we mean by "standard" and how this differs from "general". In this chapter we have presented three general Healthy Cities domains (figures 5.1,5.3, and 5.5). General means that these domains do not belong to any specific case study. The question is now can we use these general domains as a standard for all domains in any (other) Healthy City? Standard means that elements from such a domain can be detected in any Healthy City, no matter which country.

The general Healthy Cities domains (figures 5.1, 5.3, and 5.5) are not standard Healthy City domains. What these figures show is that at a generall level, based on all case studies and by compiling these three figures, the Healthy City domain indeed covers all public policy sectors. However, the domains at country level, and even more at individual case study level, differ from these general domains. 
What seems to be standard in domain composition is the involvement of representatives of the Health Authority/GGD services, local government services, voluntary groups, community groups, and self-help groups. Social and welfare organizations, primary health care services, and education and training institutes are also represented in the majority of the case studies in both countries. The public policy sectors that are covered in the majority of the case studies in both countries, both in activities and through involvement of actors, are the public health sector, the social welfare sector, and educational sector. Other public policy sectors, such as public safety or traffic were represented more specifically with regards to activities than with regards to actors. General affairs was more specifically represented with regards to involvement of actors whereas no activities were undertaken in this field. This illustrates that although a standard domain may be helpful to initiate or analyze an activity, in order to create and interpret a case study specific domain, it is necessary to investigate what is going on locally. It also explains why the differences between the individual case study domains both within and between countries, indicate that the specific local domain compositions are influenced by local processes, circumstances, and actors (individuals).

It is possible to indicate elements standard to a Healthy City domain. But at the same time, they are so general that they are not very informative. It is also possible to show case study domains general or overall as well as for a particular activity. These domains do indeed contain elements of what we have indicated as a sort of standard. However, the specific domain composition, the core and peripheral actors and the roles they play, changes over time and may even differ between activities. It is therefore only possible to show Healthy City domains and to compare them by freezing them at a particular moment in time. This is perhaps comparable to a matrix-organization. At a very general level in the matrix, all possible actors can be distinguished. For each concrete activity, however, it is possible to show a subset or specific domain of those actually involved. As soon as new activities are begun, the (sub) domains or networks change.

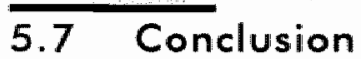

"We do mot deny the existence, and the frequently substantial importance, of processes internal to the legislative and executive decision-making arganizations, but our focus is on the contribution of social structural wariation in policy domains to an understanding of ultimate policy decision. "Laumarin 8 Knoke, 1987 p. 18)

From the figures provided, it can be concluded that indeed the Healthy City policy domain composition is influenced by actors, structures, and the activities that are undertaken. And as actors, structures and activities change, the domain composition is flexible. The boundaries of the domain are thus not fixed. In fact, if "the domain does exist at all, it must be described as quite fuzzy.

Elements standard to a Healthy City domain can be identified nonetheless. These are the public health sector, the social welfare sector and educational sector, some Health Authority/GGD services, including primary health care services, local government services, social and welfare organizations, voluntary groups, community groups, and self help groups.

The domain composition per case study is more limited than the general domain composition. The specific Healthy City domain composition among individual case studies varies. Sometimes differences among the case studies are only very marginal; sometimes, 
howewer, they are substantial. Not only between the cases, but also within a case there can be differences in domain composition. For example, the general Healthy City domain that was composed for a case sudy conld show differences with, for example, the domain composition of a specific activity in that same case study (see appendix 3 and compare figures $5.7 \mathrm{a}$ and $5.7 \mathrm{~b}$ with figures $5.2 \mathrm{a}, 5.2 \mathrm{~b}, 5.4 \mathrm{a}$, and $5.4 \mathrm{~b}$ ).

Health policy research, therefore, cannot start with a definition of the Healthy Cities domain which sets the boundaries of such a domain beforehand. What exactly constitutes his domain in any given city must be constructed based on an interpretation of, and participation in, the available structures, the activities, the involvement and ideas of actors. The findings and conclusions of this chapter nonetheless do provide some guidance and points of attention for domain construction.

The aggregate of the domains as reconstructed in this chapter cover all public policy domains. Also the aggregate of all domains with regard to actors covers all public policy domains. But the sum of the domains with regard to activities, does not show this overall coverage. Some sectors are not covered at all, such as city planning and general affairs. And others are only covered in a few cases, such as public affairs in one case and environment in four cases. This means that when activities from a particular sector are mentioned, it is not necessarily also the case that the actors who are involved come from that sector.

We constructed two general domains, one based on actors and one based on activities. The general domain coverage for activities and actors is comparable. If the country based domains are compared there are some differences, but at the case study level the differences are substantial between activity and actor domain composition. Between the case studies as well as within one case study differences between actor and activity domain composition can be found. In the majority of the cases it is not possible to predict the actors based on the activities taking place, nor to predict vice versa. A broad representation of Healthy Ciry actors is not a guarantee of a broad range of activities. It is the sectors that are involved which give Healthy Cities a certain "face" and visibility. For example, safety, environment, or housing, fulfil this function. As activities may and do change, just as active involvement may and does change, the visibility and/or "face" of Healthy Cities is also quite open to change.

Healthy City actors can be divided into core and peripheral actors. What can be mentioned more, is that of course the group of core actors of each single case study includes the actors which we have indicated as standard elements of a Healthy Cities domain. It is, however, not unlikely that an individual case study has core actors involved which are not mentioned in the standard domain; a good example is industry. The role that is played by the core actors and the intensity of their involvement may change from activity to activity. but they are always involved. Peripheral actors' involvement is dependent upon pragmatic reasons. Also; it differs from activity to activity as to whether or not they are involved. The policy community of Healthy Cities (see sub-section 4.3.2) is therefore not very tight. Although the core group is tight, the substantial peripheral group is fragmented and the case study specific Healthy City domains show differences if they are compared with each other.

We question whether the Healthy Cities core group is comparable to the core group, elite policy group, as defined by Laumann and Knoke (1987 p. 14). This group is credited by them with influencing policy. This group is also seen as having the power to exclude the peripheral group from entering the policy field. This is, however, not the case with regards to Healthy Cities. If members of the peripheral group are not involved in activities, they have decided themselves not to be involved, not because the core group has the power to exclude them from involvement. 
For the majority of the organizations who have signed-up to work. Healthy Cities it is not a statutory duty to work on such an imitiative. It is a social obligation to the city. And although organizations and departments are mentioned as Healthy City actors, it is moreover their (individual) representatives who actually are involved. If these actors are to influence policy development, it is crucial that they indeed represent an organisation and/or act on behalf of an organization (cf. Laumann \& Knoke, 1987). The importance of having organizational involvement appears from the following two quotations

"Healthy Cities is not yet explicit in terms of the vision or the strategic abjectives of their organizations." (Healthy City project member, Ga)

"Healthy Cities has not been owned by mainstream organizations and I think that has been ane of the major drawbacks. If you have not owned Healthy Cities as the core business inside your whole organization and mainstream money gets squeezed by government and other pressures, it is easier to say "nice to have tried that one, but...". And"I think that was whot was happening. "(Management HA/GGD, Hic)

Interpretation of the figures as presented in this chapter (and appendix 3) should be conducted with caution. These figures only show the variety in activities, structures, and involvement. They do not show the meaning of involvement for individual participants. The meaning of being mentioned as a participant and consequently its influence on policy-making, should be further explored. Methods that can be used in that respect are in-depth interviews with representatives of these organizations or analyses of the activities they undertake. It is also recommended to undertake a retrospective analysis of the results of these activities.

The structures that have been chosen to work within are comparable between the case studies. An exception to this conclusion is that in the United Kingdom case studies, the WHO structure requirements seem to have been taken more seriously than in the Netherlands case studies. It cannot be judged at this point, however, whether or not either approach to structure favours Healthy City in becoming mainstream. If Healthy Cities is not regarded as an initiative separate from local government, the interviewees expect its possibilities for influencing mainstream policy-making to increase. Separate means parallel to other ongoing, already existing mainstream activities in the city.

There was a general fear of "projectism", meaning a fear of doing only demonstration projects. As a possible solution to this problem was mentioned: that project based working could become mainstream. The financing system "lines of accountability, and organizational structures have in that case to be re-organized accordingly. Elements that are supportive in moving from these projects to policy are:

- to integrate Heallthy Cities and its activities into existing structures which are not necessarily those that are recommended by WHO;

- attachment of Healthy Ciries to issues that are part of the political agenda;

- to receive support from key decision-makers;

to have a core group of actors.

Despite the variety that has been shown, an effort has been made to indicate the structures, activities and actors which may be helpful for those who want to explore Healthy Cities and policy development. Also, insight into the domain complexity and the relative positions of the case studies to each other is provided. Having insight into and an understanding of what domain complexity means is a cruciall factor, as explained in section 5.2, in the development of policy. Knowing the board, the players, and the rules of the game are, according to Teisman (1992 p. 77) and Kingdon (1995), important prerequisites for playing and understanding the policy game. The result of the play, however, can only be seen in retrospect. 


\title{
Chapter Pathways of development
}

\author{
How successfully \\ are concepts \\ put into practilice?
}

\begin{abstract}
"The success of Heolthy Cities projects is reflected in the degree to which policies that create settings for health are in effect throughout the city administration. (...) political decisions, intersectaral action "community participation, and innovation promoted through Healthy Cities projects work together to achieve healthy public policy." (WHO/EURO/HCPO, 1992 p. 8)
\end{abstract}

\subsection{Introduction}

Throughout the previous chapters the history and core concepts of Healthy Cities have been presented. Attention has been paid to the reasons cities become involved in Healthy Cities and establish its position on the political agenda. An effort has also been made to show the domain compositions, in other words, to describe what activities take place within which structures, and who is involved. These aspects were targeted because they are the most promising in terms of providing insight and information in regards to the health policy development process.

Information for policy development or policy change is also found by looking at evaluation processes. The purpose of evaluation is to investigate the nature and relative effectiveness of a programme with an eye toward its goals, concepts, and ideas as those are put into practice. Evaluation asks how and to what extent these latter descriptive characteristics are valued by the various actors involved in the programme. The outcome of an evaluation should lead to an increased understanding of the programme. One might expect, for example, that an evaluation process would provide more and deeper insight into the way a programme's key-concepts are operationalized. This process can also show the ways in which they are implemented and developed, the intended and unintended activities that take place as a result of the programme, and the extent to which its goals are reached. This knowledge could be recycled and used as input for the continuation of the programme or could be put to use in developing other, similar or dissimilar, programmes.

The achievement of healthy public policy which results in a reduction of populational inequalities in health and health improvement are important goals of the Healthy Cities Project (see Chapters One and Two). But in our evaluation we cannot confine ourselves merely to an investigation of goal attainment and Project output. Such a static evaluation approach would not generate the kind of insight into the processes of policy integration sought here. It is our conviction that the interpretation of goals differs among participants. Goals may even change. It is therefore more interesting to know why and how certain outpur has been reached rather than only to know that certain output has been reached. We therefore use a policy analysis approach which implies a focus on the why's and how's of given output as opposed to simply establishing the existence of such output. 
The main question addressed in this chapter is how have the key-concepts of the Healthy Cities Project been put successfully into practice in any or all of the cities under study, and why have these concepts been more successfully implemented in one particalar arbon environment than in another? In this case, it should be noted that the definition of 'success' was mainly left to the interviewees. Similarly, how key-concepts of the Healthy Cities Project are used in practice will be described and evaluated from the participant's point of view.

In the next section, we will go into more detail in regards to how exactly we dealt with the issue of evaluating and what are considered to be the key-concepts of Healthy Cities and their corresponding labels. First, however, the evaluation method used in this reseanch will be described. Then, the Healthy Cities key-concepts evaluated by the participants will be explained. The results of these evaluations will be presented in three separate sub-sections: - concepts and processes in the social sphere,

- concepts and processes in the organizational sphere;

- concepts and processes in the political sphere.

It was our aim to investigate the meaning of these concepts to the participants, not only through testimony on the subject, but also through information on how those concepts were operationalized within the cities' initiatives. Furthermore, the participants" perceptions of the relationship between Healthy Cities and these key-concepts will be illustrated at the end of the sections in which these concepts are discussed. In the last section the perceived successes will be compared with the theoretical expectations and insights as presented in Chapter Three and assumptions as presented in Chapters One and Two.

\subsection{Evaluation}

\subsubsection{Process evaluation}

Evaluation means to ascribe value to a given phenomenon. In the case of Healthy Cities, evaluation has been seen as contrasting international, national, and local efforts against certain criteria (see for example Palumbo, 1987; Graaf \& Hoppe, 1992; Bressers, 1993). Several evaluation approaches based on different methodological traditions and scientific paradigms have been developed (for overviews see for example Abma, 1991 and 1993; Bressers \& Hoogerwerf, 1995; Francke \& Richardson, 1994; Lehning \& Simonis, 1987 ; Patton, 1990).

These varying evaluation approaches have differing focal points 1 . For example, evaluation of Healthy Cities might focus on any or all of the following: (1) content, (2) processes, (3) output, and (4) outcome (see figure 6.1) (Bressers, 1993; Graaf \& Hoppe, 1992). In figure 6.1 it is shown in a simplified way what the relations are berween these evaluation fields. In content evaluation, intrinsic characteristics of the project, programme, or policy are addressed. (Intermediate) output evaluation is targeted at the direct or shortterm results of the project, programme, or policy. In other words, this type of evaluation seeks to explain what happened due to the project, programme, or policy. Not only evident causal relations but also perceived results can be evaluated. Outcome evaluation is geared toward establishing effect or goal-attainment. Suppose, for instance, that a programme's aim was to increase the mobility of elderly people through participation in a keep-fit programme. Outcome evaluation in that case might aim at defining and measuring an increase in mobility of the target group. Lastly, in process evaluation the focus is on the pathways of development which are used when working on (intermediate) output and outcome. Examples of aspects that can receive attention in process evaluation are the 
Input (confent)

(1) (intermediote) output

(3)

Processes

(2)
Outcome

(4)

=input evoluation; 2 =process ewaluation; $3=$ (intermediatle) output evaluation;

4 = outcome evaluation

Fügure 6.1: Evaluation approaches.

working methods, the negotiations, the structures, the barriers, and the communication approaches and patterns of the environment under focus.

The evaluation results presented in this chapter focus on Healthy Cities processes and to a lesser extent on intermediate output. Why these approaches have been chosen will be explained in sub-section 6.2.2 In selecting the evaluation methodology, it was to our understanding important that it should fit with the overall research design and qualitative method. Furthermore it had to be compatible with the policy approach that was used (see Chapter Two).

According to Greene (1994, p. 537) qualitative evaluation research is most often characterized by the following:

- the use of case studies;

- an emphasis on context in the interpretation of the meaning of the evaluation results;

- the use of quallitative methods;

- an acknowledgement of the presence and influence of the researcher on the evaluation;

- a practical programme understanding.

These characteristics, of course, differ in their relative presence and importance among various qualitative evaluation methodologies and theories. Within qualitative evaluation research, Greene (1994) distinguishes between: pragmatic approaches (such as Patton, 1978), critical normative approaches (such as Guba \& Lincoln, 1989), and interpretive approaches (such as Guba \& Lincoln, 1981; Stake, 1975).

Evaluation methodologies based on a pragmatic approach start from an issue or set of problems which needs to be evaluated rather than from an overarching philosophical framework. The main goal of this group of evaluation methodologies is to provide information which assists decision-makers in making choices with regards to a programme's goals, utility, and quality. In other words, the evaluation is mainly carried out to support and facilitate programme management. Evaluation methodologies based on a critical normative philosophical framework represent the "nomative turn' in social science. "The feminist, neo-Marxist, critical, and other theorists in this genre promote "openly ideological" forms of inquiry that seek to illuminate the historical, structural; and value boses of social phenomena and; in doing sa, to catalyze political and social change toward greater justice, equity, and democracy:" (Greene, 1994 p. 533) This evaluation approach is substantially rooted in politically inspired ideologies such as empowerment, democratization, and a reduction of inequities. Furthermore it seeks to identify relationships between a programme's goals and an ideological perspective (for examples see Abma, 1996). The third group of qualitative evaluation methodologies mentioned by Greene is characterized by an interpretive scientific framework. "..these approaches share a common grounding in a basically interpretative philosophy of science (...) a walue orientation that characteristically promotes pluralism in evaluation contexts, and a cose study methodological orientation with on 
accompanying reliance on gualitative methods. Part of the responsive tradition in program evaluation, these approaches seek to enhance contextudized progrom understanding for stakeholders closest to the program (...) and thereby promote values of pluralism as well as forge direct channels to program improvement." (Greene, 1994 p. 533) A typical evaluation question for this third group of evaluation methodologies is 'how is the programme experienced by worious stakehalders?'

The description of these three groups of qualitative evaluation methodologies shows that "what importontly distinguishes one evaluation methodology from another is not methods [those with which data are collected, MG], but rather whose questions are addressed and which values are promoted." (Greene, 1994 p. 533) The evaluation methodologies that have the best fit with our research questions and design are those based on an interpretive approach. In the following paragraph it will be explained why has been chosen for a process evaluation based on such an approach.

\subsubsection{Healthy Cities evaluation}

\subsubsection{Why a process evaluation}

One of the reasons why we decided to use a process evaluation with attention for intermediate outcome, is the problem of causation. Cities involved in the Healthy Cities Project are supposed to translate Project principles into concrete action (see Chapters One and Two). The success of Healthy Cities according to WHO/EURO is assumed to be reflected in the extent to which participating cities develop healthy public policy. This follows from the quotation presented at the beginning of this chapter. Specific Project requirements, tools, and structures are recommended (see Chapter One; Tsouros, 1995; WHO/EURO/HCPO, $1988 \mathrm{~b}$; WHO/EURO/HCPO, 1988c) to facilitate the translation of the principles into concrete action and to develop policy thereafter (see also figure 2.1 in Chapter Two).

Ultimately, all Healthy Cities activities at all stages are geared toward a reduction of population-based inequities in health and an improvement of overall populational health status within the city. From WHO"s perspective, then, an evaluation of the use of these structures, tools; and requirements would be a window for estimating the future attainment of Project goals. Namely, effective evaluation would provide information about the abovementioned overall increase in populational health status and reduction in health inequities. Such evaluation results are considered to be indicators ("proxies") for other and larger-scale future changes (outcome) (see also Dror, 1968; Maarse, 1995). But with currently awailable research tools and resources, it is simply infeasible to consider 'measuring and proving' that Healthy Cities have contributed to any one given improvement in health indicators. Health is the product of a multitude of determinants as described by the socioecological standpoint discussed in Chapter One of this thesis , a number of which are addressed simultaneously by the Healthy Cities Project. Thus, not only are the practical limitations to comprehensive Project evaluation in terms of time and money very real, but outcomes research, in the traditional sense, is as yet unprepared to deal intellectually with such complex questions. These questions threaten to overwhelm current research technology with the seemingly endless 'confounding factors' which arise in such situations of multiple and simultaneous causality.

Beyond the issue of the impossibility at this point of comprehensively assessing the cause and effect of Healthy Cities activities, there is of course the issue inherent in the fact that the goals and processes promoted by the Project sometimes purposely leave significant room for interpretation. This issue has been illustrated in earlier chapters. For example, it has been shown that different occurrences may at times receive the same label. Also, it must be acknowledged that processes which occur as a result of or under the rubric of 
Healthy Cities cannot be disconnected and researched separately from other ongoing processes in a municipal community. Although cities may subscribe to Healthy Cities principles and (WHO/EURO) criteria, at the same time other criteria, other goals, and (unexpected) effects may be of greater importance than those advocated by Healthy Cities. Consequently, effects that are attributed to, or perceived as, a result of being part of Healthy Cities, may therefore as well be partly or wholly the result of unirelated efforts. In other words, because of the impossibility of isolating the independent variables in Healthy Cities contexts, it is difficult to show the specific contribution of Healthy Cities as that relates to ongoing issues, policies, problems, and solutions.

Furthermore, simply answering the question 'did we achieve our desired outcome?" may be considered by some as 'the' bottom-line evaluation question. Such a question neglects, however, other, unintended processes and effects that happened due to or as part of a given Project. For example, it may occur that none of the programme goals as interpreted and described by the programme initiators are achieved, which would normally result in the programme's likely being negatively evaluated. This, however, may be far from the whole story. Research needs to have an eye for the possibility that programme goals may be interpreted differently by other participants. Although the programme may be negatively evaluated by the programme initiators, for example, programme participants may have different opinions. The opposite may also occur, with programme initiators feeling that all goals were reached, while participants express disappointment with the results. Beyond the issue of differing evaluations of process and outcomes, however, it the fact that goals often do not anticipate the effects of Healthy Cities efforts. Thus, evaluation simply of anticipated goals will miss what have been called the 'unintended' impact of programmes on community processes and even on alternative health measures themselves. What, then, is success, and what might define failure? This depends on whose perspective and on whose behalf the evaluation takes place. In other words, whose questions goals, and criteria are at stake becomes the defining factor for outcome research. If we want to learn about Healthy Cities, it is therefore the opinion of this author that the information which explains why a certain outcome exists is even more useful than whether a predetermined outcome exists at all. A process, descriptive approach has the additional advantage in that it provides a deeper understanding of the complexity involved in working with Healthy Cities, and may allow insight into that complexity. For instance. Healthy Cities processes reveal the complex contextualization of health's determinants, but also give us clues as to how we might go about developing more sophisticated outcomes research fit to handle such multifactorial community 'intervention' or 'action'. Finally, process analysis allows us to more fluidly induce connections between local action and the creation of local policy, as it allows for an open-minded approach to those connections, which do indeed tend to differ from one community to another.

Werna and Harpham $(1995 ; 1996)$ mention at least one significant additional argument in fawour of doing process evaluation in regards to Healthy Cities instead of impact or effect evaluation. This is rooted in that fact that it is often necessary to show short term visible results, or evidence of change, in order to keep financial and organizational mecham nisms in place and people motivated. Through process evaluation it is possible to show such changes and detect problems at rather short notice, in comparison with effect evaluation. Financiers and politicians need this kind of information because it shows a benefit to their involvement and this may stimulate their commitment. This argument will also be illustrated in subsequent sections, where it is shown that demonstration project evaluation results stimulate or reinforce the political commitment for Healihy Cities. 
At the same time, based on our own observations, we argue that positively evaluated demonstration projects have a limited capacity to predict the sustainability of Healthy Cities at a city-wide lewel. In this case, sustainability relates to the question of whether or not the perfomance of Healthy Cities can continue after the WHO Project has come to an end or whether Healthy Cities is still used when the city no longer participates in the WHO Project and/or national network: It also relates to the continuity of commitment for the city programme. Is commitment demionstration project based, or does it go beyond projects? Another contribution from process evaluation is that it is possible to evaluate whether or not Healthy Cities Project ideas are picked up by local actors. Werna and Harpham seem to assume that having committed local individuals equals having committed organizations. In Chapter Fiwe we have pointed at the essential difference berween individual and (assumed) organizational commitment for Healthy Cities. This difference, it seems, influences the integration of the Healthy Cities paradigm and the sustainability of its ideas. The relation between projects and policy plays a central role within Healthy Cities. We will address this aspect in the concluding Chapter (Seven).

In summary, it is our opinion that one could start a rather endless discussion in regards to most contentions that, at a social level, phenomenon A causes phenomenon B. Such a discussion is not only often inconclusive, but moves away from the most important issue: namely, the question of what, in fact, bappened? We therefore do not address the question of whether or not goals are achieved. We are also not interested in finding out whether or not certain activities that happen in Healthy Cities are so called 'proxies' for future health outcomes. We leave that discussion for another forum. We instead try to provide insight into what happened (process and output) and how this is evaluated from the participants' point of view. Anything mentioned on the relation between the evaluated key-concepts and Healthy Cities represents the perceived contribution and the perceived benefit as mentioned by those involved in Healthy Cities. This is the critical factor, it is argued here. For it is this perceived value that has a large influence over whether a project or policy is going to succeed (see de Leeuw, 1993; Maarse, 1995).

\subsubsection{Why a process evaluation based on an interpretive approach}

We do not use evaluation methodologies based on politically inspired ideologies because in this research the ideological underpinning of Healthy Cities is not brought under discussion. Also, the question of whether or not WHO's reasoning as represented in figure 2.1 is valid or open to question is not part of the present research's domain. Instead in a Healthy Cities evaluation based on an interpretive approach, the purpose is to find out how the participating cities use and value the principles and ideas attached to Healthy Cities. It is not the actual health status of the resident population or the attainment of the Healthy Cities goals and ideas from a WHO/EURO perspective that were of concern to this research. Instead participants were asked here to evaluate the meaning of certain of the key concepts of Healthy Cities, or its goals and ideas, as they were embodied by local Healthy Cities processes. It was assumed that the outcome of such an evaluation would lead to an increase in the understanding of the WHO Project. In this context, understanding means, for example, having more insight into the way the Project's key-concepts are operationalized and the ways the Project is being implemented and developed in the various cities under study.

It was decided that a process interpretive evaluation best fits the overall research design and the policy approach. The policy approach and research design are based on the idea that interaction, negotiation, and interpretation play a large role in activities, decisionmaking and policy-making. As appears from figure 2.1, WHO's reasoning behind the 
Healthy Cities Project largely takes the form of a conditional statement (if..then), If certain principles and targets are pursued, then a reduction of inequalities in health is expected to be realized. As mentioned already, cities subscribe to this statement; but there is no guarantee that the cities operationalize these principles in an identical or comparable way among themselves. They are more likely to reason with the addition of multiple qualifiers: for example, cities" thinking in regards to Healthy Cities seems to often include the ideas expressed by if...then...but....when...although... perhaps... not necessarily, etcetera. Within cities this disparity exists as well. Participants in any given policy process may subscribe to similar goals, but at the same time, it is very likely that they differ in their interpretation of the meaning of the city Project's goals and principles, and how to work accordingly. The conclusion is therefore that although the roots for Healthy Cinies efforts may be equal for all cities, very different results will emerge depending on the soil, the climate, and environment. The evaluation methodology that is used to evaluate elements of the Healthy Cities Project should be capable of addressing such disparity.

In doing this evaluation, it is possible, for example, to construct an understanding of how and why differences and similarities exist among, for example, the different interviewee categories: politicians, management, professionals, and Healthy City team members. It is also possible to focus on differences between the different case studies within one country and between countries.

In order to keep the evaluation manageable, only three concepts that are central to the Project have been selected. The key-concepts that are going to be discussed in the subsequent other sections will be introduced and explained in the following section.

\subsubsection{Healthy Cities processes: a selection of key-concepts and their evaluation}

Werna and Harpham (1995) address the discussion of Healthy Cities evaluation based on local versus international indicators. We have made use of international concepts (indicators). These concepts are used and known in the case studies. It provides us the possibility to compare the case studies with each other. At the same time we acknowledge that interpretation and meaning of these concepts in each case study may be different. We could also have used our multiple case study design to construct general undicators based on the available local indicators. In this process the indicators lose their specific local meaning but the researcher can compare the different cases. However, if the aim of the research is to acquire information about the specific individual situations, it is better to do an evaluation based on local indicators in an in-depth study of one or two case studies.

In Chapter Three we listed in table 3.1 important Healthy Cities key-concepts. We divided there these concepts into three process categories which represent the types of activi.ties which take place in Healthy Cities: social processes, organizational processes, and political processes. We explained in Chapter Three (section 3.2) that we will limit ourselves here to highlight only one key-concept in each process. Concretely, this means that the evaluation results of community involvement (social), intersectoral collaboration (organizational), and political commitment (political) will be presented.

The remaining part of the chapter is organized around these three key processes and concepts. They were evaluated by participants of the case studies based on their (professional) experiences with and involvement in, Healthy Cities "Interviewees have been asked to explain the meaning of these key-concepts to them. How do they experience them and how do they value them? In other words, although the key-concepts are based on WHO Project criteria, the definition of success and failure is based on the participant's criteria. Also the added value of an initiative such as. Healthy Cities to them was covered by the evaluation questions. 
Not only the interviewees but also the researcher plays a role in this evaluation. The rescarch findings are interpreted and valued by her, based on her involvement in Healthy Cities, her knowledge of the fiveld, the interpretation of other information sources than interwiew transcripts, such as minutes of meetings and reports, as well as her academic background in health sciences. The evalluation of the Healthy Cities processes by the interviewees took place earlier in time than the evaluation by the researcher. At maximum there was one year difference? ${ }^{2}$. Another remark concerning the evaluation is that work on the key concepts that are evaluated in this chapter is a continuing process. Changes in their meaning and usage may have taken place by the time this chapter is completed, published, and read. Interpretation of the specific evaluation results at a higher, abstract, not case specific level, however, is expected to deliver information of lasting value which increases the tunderstanding of local health policy processes.

First, the findings of the evaluation based on participant's criteria will be presented. An interpretation of these findings in the light of scientific insights and relevant knowledge (see Chapter Three) takes place in section 6.4.

\subsection{The evaluation of Healthy Cities processes}

\subsubsection{Social processes: community involvement}

"Due to Healthy Cities, community development work receives money; without it, community development work would not have been discussed at all. It [Healthy Cities, MG] generates efforts to put community development work on the agenda." (Professional, $\mathrm{Hb}$ l)

In the case studies, three main approaches were used under the banner of community involvement: community consultation, community participation, and community development. These approaches will be illustrated bellow.

Within local governments of the ten case studies, the ruling policy was to inform the community about political decision making. In some places, this meant that public hearings were organized. In others, it meant that target groups or a community representative body were consulted. Still others provided the public with the opportunity to read a draft of a proposed plan.

An example of a community representative body is the Community Health Council (CHC) in the United Kingdom. These councils have no statutory power but do have the right to comment on decisions made by the local government and on resulting papers and initiatives. These councils are supposed to represent the community in discussions on health related affairs. In the Netherlands there is no equivalent to such a council , except for patient and consumer organizations. These organizations serve a similar purpose, namely the representation of consumers and patients in discussions. Whenever these organizations were involved in activities and decision-making there was community participation. At least, such was the opinion of most politicians and management representatives. For our purposes, however, this may be considered a narrow perspective on community participation. Community participation can also mean the active involvement of local citizens in activities, planning, and policymaking. This is what is promoted through Healthy Cities (see also section 6.5). Community participation is said to require

"c tangible entity that [communities, MG] are working fowards. Whether it is a building, a service or jobs. It [Community participation, MG] is not the same as [asking people, MG] "what do you think about the neighbourhood plan?"." (Management Health Authority/GGD, Gc) 
On the one hand the community itself needs to be stimulated to become actively involwed. On the other hand, organizations must be stimulated to open up to the idea of conmunity participation. Success is the result of these two steps receiving parallel attention. In other words, community participation needs a "two-tiered approach". This means stimulating and helping community member in developing appropriate new skills while making them comfortable with participating in activities, planning, and policy-making. At the same time, organizations need advice on the possibilities of integrating community involvement into their activities. They need assistance with regards to how to develop an attitude and approach to community involvement.

\section{therpool}

We have stiong community initiatiwes in our city. For example, if we listen to what a community wants if may bo nof Iffestyle issues but something to do about powerty and a lack of access to services. That mecans 1 a Health Authority still wants to work on their statutory duty of lifestyles they need to integrate this nos ower appraach. If a single mother, who has low income and lives in a rather old house, smokes. the Integrated approach could includle childcare, housing conditions, job perspective or reedication. Besides that, also information can be provided about the relation between heath and smoting

Box 6.1: Community based, meams an integrated approach.

Community development was explained as a broad process of joint work between professional workers and communities to encourage the community to identify needs, to give them more control over their health, their environment and their lives, and to train them in the development of their personal skills (Healthy Sheffield Support Team, 1993a).

\section{shoffield}

Even 1hoigh many enthusiastic indiwiduals were involved, the approach that was used to dewelop a city Tealth Jjan sfill was recognized as rather top-down. It was decided that the approach should be more partiogrop

This resulted in the development of the Our city our health initiative. A public consultotion document Should encourage the public debate on the development of a health strategy and public piaticipation.

The consultation strategy' searehed for common ideas and beliefs around health and foctors that Ifithence beelth. It could be considered as a needs assessment.

The ondy ils of the responses provided the basis for the framework for Action.

Box 6.2: Bottom-up policy development through community involvement.

The idea of community involvement in professional activities and planning is gaining ground in serwice provision departments and organizations in all ten of the case studies presented here (see for example the anmual report of the director of Public Health Liverpool, 1994), if one accepts a broad definition of the concept.

Interviewees mentioned as reasons for community involvement in activities and planning, and for working with community approaches:

- to increase "client" satisfaction;

- to increase efficiency, the fir between (community) service demand and service provision; 
- or to reach those groups which easily slip through the mazes of the traditional health service web, for example, homeless persons, prostitutes, or drug addicts.

Geographic information systems and community (health) surveys lend a helping hand in this matter (see for example in the REBUS system in Rotterdam (van Oers, 1993), the GLOBE project in Eindhoven (GGD Eindhowen, 1996) ${ }^{3}$, or the Our city - Our health survey in Sheffield (1991) (see also box 6.2)). Service providers use this information to a large extent to tailor their services to the needs of a specific locality. A so-called neighbourhood planned service prowision and purchasing is developed. The major form of work on cormmunty involvement as it appears from the case studies is community (development) projects. Some projects focus specifically on health issues, the so-called "community health projects", while others are more broadly oriented (Castlemilk partnership, 1994). In the case studies in the Netherlands, unlike in the United Kingdom, community work was more often labelled as part of "Social Renewal'4 and 'city regeneration" than through Healthy Cities (projects) (see for example box 6.3).

\section{Tilburg, Rotterdam and Eindhoven}

The thedint of their social renewal pallicy, inifiatives that resembled neighbourhood self administrotion tdeas were deve oped in Tilburg, Rotterdam and Eindhoven.

Nelghourhood self administration could mean in concrete terms that a neigbourhood has its own Uteerng committere'. This committee discusses problems and tries to come up with sollutions; if possible in collaboration with public and private service providers. An example of collaborative effort between the 10ibhbourhood and locall government services is a 'do it yourself project' in Tilburg were small housing molnhenchere activities were carried aut by people of the neighbourhood. Some additional support was provided $6 y$ municipal services temporarily located in a community centre.

Box 6.3: Sacial renewal and community projects.

The reasons for choosing projects and how these are valued may be explained from four perspectives: experience, expectations, support, and pragmatism.

Experience. The fact that a city has a tradition of community development work appears to be little guarantee that Healthy Cities efforts in the same city will take on a similar emphasis, as the broad range of influences in Healthy Cities efforts can water down the community development orientation found, for example, in the public sector in social work and welfare departments. We found that active community groups were present in all ten case studies. These groups initiate activities and represent the community"s voice in the public sphere. In the United Kingdom case studies, strong community voices and highly developed community networks were attributed to a "lack of faith" in government. In both countries, service providers recognize that especially highly organized community groups could be very helpful in "getting things organized'.

"We consider it important to have good relations with organizations within the community. If they are excited about our plans, that can sometimes lend more momentum ta our efforts than any kind of decision withim the local government. (Management Health Authority/GGD, Dic)

In general, having a limited understanding of the meaning of community development, projects seem to come up as a solution.

"We are mot far enough down the raad to convince people of the need for community development if they do nat come out of that [community development, MG] tradition. We can only get money if we can prove the effectiveness of what we are doing." (Professional

*I have struggled with the community participation documents; while we endorsed the principles we did 
not endorse any money for community participation (...) with regard to community development, 1 am rather speechlless about how to ga further than developing onother project:" (Management Health Authority department, $\mathrm{Hc}$ )

What appears is that people at top-management level of services are rather satisfied about these projects. They are satisfied because they feel that through these projects they can work on community questions. An important reason they feel compelled to confine community participation efforts to a project-only basis is that they do not know how to combine their mainstream statutory duties with the demands and questions generated by community development. They mentioned that they find it particularly difficult when community development ideas seem to compete directly with the time and other resources necessary to fulfil their statutory duties.

Expectations and support. Community workers, the managers of services, and politicians have different expectations of the projects. Community workers go directly into neighbourhoods and attempt to establish contacts and build relationships. They talk with people who live in specific areas about 'what bothers you and what might stimulate you to action'. Their work starts, thus, with community problems and ideas. The difficulty they have is going back to their services and their managers and trying to link the community questions and desires with statutory duties and prevailing work methods. The work of community workers is frustrating and difficult for they are tom between two different perspectives. The Health Authority/GGD, the organizations which employ most community workers, expect them to work on health promotion or preventive activities, though the community workers may want to start first with other 'non-health" projects (see box 6.1).

Community workers differ from politicians and management representatives in terms of the goals they seek to achieve. Community workers have democratization in mind and want people to develop the tools and skills to speak and act for themselves. Politicians and management representatives seem to have no explicit goals with regards to community development.

Same as the managers, politicians seem satisfied with seeing community projects take place. Their support is expressed through financial support on a project-by-project basis. Community development is not the explicit priority, and may not be a priority at all, as made apparent by the fact that there is not a permanent post on the municipal budget for a community development professional. In one case study, however, an example of an integrated approach to community development was found (see box 6.4).

\section{Claceow}

The positive equaluation of a community development project (see also the intraduction of chaplar five) aro the existing tradition in community wark, have been supportive for Glasgow Haalthy City in setting up o community development unitt. The sole remit of this unit is to make sure that (mainstream) fundig is provided for community unitiatives. The unit employs community development workers and trains local

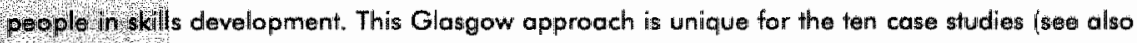
Mesemare (993).

Box 6. 4: Community development üntegrated.

To the majority of politicians and management representatives, having carried out a few community projects means 'having done community development'. Community development workers, on the other hand, try to make thein realize that community development work canno: take place with short-term funding and short-term projects. 
"My post within Healthy Cities is to moke them [locol government and managers of services, MG] realize that we newer get mainstream funding for community deveiopment wark." (Professional, Hal) "What wanted was local people to take part in and run the project and to deal with problems that come up along the way. It has taken us four years to make people comfortable enough to get up the courage and confidence to speak up about their own problems." (Community devellopment worker, Hib.) According to community workers, not only a limited understanding on the decisionmakers. part but also having an unrealistic time perspective inhibits community development:

Progmatism. It is not without reason that community workers often use, given the above explanation, a pragmatic way of reasoning:

"We do not always work in a cammunity development way, at least in the purest sense; somefimes there is money ovollable in three month' time. You then try to gef it rather than wait a long fime for longterm funding:" (Professional, Fbl)

Although community workers receive support for their work, the eventual impact at the policy level is poor. It leaves the workers of community projects with a great deal of frustration. Much of the results and learning from the projects is lost, because people do not tend to build upon or learn from the experiences of the project (see also Paulussen, 1994). Being supported by a Healthy Cities committee at least gives those involved in community projects the idea that they can influence policy-making. Like any other type of project, after all.

"community projects need the commitment of the main players in local politics." (Professional, Fa 1)

\subsubsection{Perceived contribution of Healthy Cities to community involvement}

The quotation at the begining of this section clearly describes the added value of Healthy Cities to community involvement. The perceived contribution of Healthy Cities to community involvement is that it ensures that at least explicit attention is paid to the role of community involvement. It fosters community projects and the provision of (project) financiall support (see table 6.1).

A few comments can be made in regards to the evaluation of community involvement. First of all, community workers in particular mention that 'there is a lack of understanding of what community development work means". It is argued that it is not so much, or not always, a lack of experience that causes a limited understanding. Maybe it is caused becanse previously uninvolved parties have a different understanding of the reasons for involving communities in work which concerns them. Perhaps it can be attributed to different ideas about the necessity for community involvement. It may also indicate a commumication gap. At any rate, it seems the different parties are not yet able to communicate about these differences in interpretation because they often do not realize they are talking about different things with the same words.

Secondly, it seems that the focus in community projects tends to be only or mainly on enabling the community to participate in activities or decision-making that affects their health. The other aspect of the 'wo-tiered approach" to community involvement is hardly stressed "namely, the opening-up of organizations to the idea of community involvement and making them comfortable with this concept. Furthermore, it is not yet clear whether and/or how far people want to be involved in decision-making that influences their health. Those who realize that they themselves can do something to reach a certain health status are most of the time not the people who have to worry about the provision of basic necessities for survival, or ewen for "keeping themselves afloat". And the question must eventually be addressed in regards to whether it is truly 'community involvement' if a few community representatives participate in a project? 
The Healthy Cities Movement for a city resulted in:

Different approaches with regard to community involvement, namely:

- community consultation

- community participation

- community development

- Community involvement al a project basis with (short-term) financial support

- Raising awareness for community involvement

What appears from the above evaluation is that particularly the community workers make an effort to convince the 'others' of the political and efficiency benefits of community work. As has been explained in the agenda building chapter, once again personal commitment, personal (communication) skills, and personal enthusiasm again appear to be the driving forces.

Perhaps the most important point, however, concerns the concept 'community' itself. The connotations of the word mean that it is very easily assumed that community projects are equivalent to geographical or target group projects. Not only the direct translation of this English word into other languages causes difficulties. It can also have various meanings in English or other languages. De Leeuw (1997) has expounded this very clearly in showing that community is not only bound to, for example, a geographic locality, race, religion, or profession. Even through television and Internet, "virtual' communities are formed. She has identified communities as "communication arrangements" and thereby identified an interesting link, especially for this research. Namely she made a link between community and policy-making.

\subsubsection{Organizational processes: intersectoral collaboration}

"Healthy Cities was not the primary reason the cooperation emerged,... but [without it, MG] I don't think we would be as far down the raad as we are now." (Management local authority, Id)

From the research findings, it appears that within a Healthy Cities context, meetings and projects are the two major ways in which intersectoral collaboration is operationalized. Here, intersectorality would be defined as meetings and projects with representatives of organizations, groups, or services in two or more sectors. These meetings may and often do take place in intersectoral committees newly established under the rubric of Healthy Cities (see Chapter Five). They can also take place in other forums where representatives of organizations and public and private service providers meet on a regular basis. Examples of such forums are city council committees or local government management-of- and directors-of-services meetings.

These projects and meetings often result in other projects and meetings, which may spin off still further into many diverse directions. The natural questions one would consider in this regard are such things as: where does such a process of "spinning off" lead? Does it, for example, result in broader networking, an increased sharing of beliefs and goals, or the more efficient development and implementation of policy? These questions, though not the specific domain of this thesis, are addressed as part of the discussion of the general question in Chapter Seven. For now we concern ourselves with the perceived contributions of Healthy Cities to intersectoral collaboration both at the operational and strategic levels: 
Provision of a network. Participation in a national Healthy Cities network, a Multi City Action Plan, or the international WHO Project gives a project access to people and information from other places, organizations, and countries. Participating in these networks certainly facilitates information collection as a whole, and can provide examples and experiences that can assist in solving concrete questions and problems in the local environment. In all case studies the Healthy City team members in particular, but also other participants, regularly received requests for information, advice, or consultancy. Experiences are shared by the participants of the network and efforts are made to extend the network. The network not only facilitates the exchange of resources, however; it also provides legitimacy and support for those groups and cities which participate. It demonstrates to the locality and sometimes even to the national government that local efforts are not an isolated phenomenon. In the United Kingdom case studies, for example, being part of an international network was felt as one way of getting around the national government's policy on Europe.

Promoting changes in structures. In Chapter Fowr it was shown that involvement in Healthy Cities stimulates the creation of new (political) committees, working groups, and intersectoral structures as well as a broader discussion of health and its determinants by existing committees:

In most case studies in the Netherlands it was felt that it would not be wise to establish a new and separate Healthy Cities steering committee. Instead it was recommended to consider the possibility of using existing intersectoral committees for this purpose. The Healihy Cities committees, it was thought, could be the steering groups of already existing projects or a simply a regular meeting of representatives of the major organizations and. associations in the city. One of the reasons for the hesitation to create yet another committee was that agendas of committees often get stuck on structural issues and along lines of accountability. Additionally, in the Netherlands, the GGD and local government, unlike in the United Kingdom, have a formal relationship in that the GGD often acts as a local government service. This may also explain the absence of a separate city-wide Healthy Cities steering committee in cities of the Netherlands (see also appendix 1).

In the United Kingdom case studies, Healthy Cities steering groups are to a large extent composed of representatives of the Health Authority services and local government services (see also at 'Promoting collaboration' (this section)). Nevertheless the majority of the indiwidual projects that are undertaken under a Healthy Cities label are implemented in both countries by intersectoral project groups.

Another important point with regard to changes in structures is that Healthy Cities ideas and principles have indeed become part of mainstream structures in some case study cities. This is reflected, for example, in the accountability of the employees of the project office and the responsibilities they hold with regards to key organizational structures within the municipal environment. Such integration was also made visible by the fact that some coordinators have recejved a permanent contract.

Promoting changes in resource distribution. Working on Healthy Cities has often meant that local government money becomes available to finance (demo) projects. In most case studies it took some time before separate Healthy Cities staff was hired; in the beginning, at least, most staff are employed on a temporary basis and work on Healthy Cities as part of another job. It was in only a minority of case studies that such staff was ultimately converted into a permanent and independent staff. Only in a few case studies (see Chapter Five table 5.2) was a permanent place created for a Healthy Cities coordinator within the local administrative system.

An example of an innovative way to simulate local projects is the establishment of a 
small grant fund to be used for the stimulation of local activities. This fund can provide community groups with a modest level of financial support with which to create and organize activities (see for example Small Grants Fund Report; Healthy Sheffield, 1993b).

Generally, interviewees were not aware that being involved in Healthy Cities most often means that only in the first few years do new money sources need to be identified and tapped for the activities of the city"s project. Such seed money is needed to finance demonstration projects, to provide education, and to stimulate organizational development. Furthermore, it is needed to set up a strategy and structure that can facilitate an integration of Healthy Cities into mainstream municipal business. Having achieved these results, additional possibilities for funding become available, leading to more opportunities, and the need for new priority setting with regards to programming and continuing fundraising. Additional finances can come through the ald channels. But they can also come through channels offered by the project's association with the international Healthy Cities Project. For example, some case studies were very creative in attracting European money for their projects. They made use of the fact that they belonged to an international network in order to attract such funding. Especially the personal efforts (entrepreneurship) and networks of those involved in the Healthy City core group resulted in the success of a multicity application for European Union resources.

Promoting changes in hiring new staff and formulating their tasks. Increased consciousness in regards to where and how health can be created and damaged is an important precondition to people's consideration of Healthy Cities as an overarching city-wide policy frame work. Although interviewees from all the case studies agree with this observation, it was noteworthy that some also suggested that the need for someone who had the sharing of the broader vision of health and its determinants as a formal responsibility. Such a post would not necessarily have to be newly established, it was thought; but the reallocation of existing resources to allow for at least one full-time person to work on Healthy Cities was felt as an important step, especially in light of the fact that health lacks an evident and high place on the organizational and political agenda.

In Dutch and British cities where such a post is still lacking, this wish may not be so far away. Such a coordinator post for Healthy Cities seems compatible with the recent changes in strategy of the Health Authorities and GGDs, which focus on the policy and advisory roles these organizations are capable of performing rather than (only) on direct provision of health services.

Promoting change in perception of the determinants of health.

"Healthy Cities has started to break down barriers, raise awareness within the city departments about their role in promoting health and around specific issues that needed interdepartmental attentiom." (Coordinator, Ho)

An additional advantage of Heallhy Cities when compared to other new "city-wide health initiatives was felt to be the broad attention it gives to where and how health is created. Healthy Cities, after all, calls for attention not only at an operational level, but also at the strategic-management and political levels. Different actors that are directly and indirectly involved in activities and processes in the urban context are asked to think about how their work or their organization relates to health. They also need to think about how different organizations and activities relate and influence each other (see for example box 6.5)

In other words., Healthy Cities stimulates a learning process in regards to health and especially in regards to its determinants. The learning process is facilitated simultaneously by health promotion professionals, (health) policy-makers from locall government, and Healthy City team members. All these people have formal responsibilities with regards to public health, and thus become directly involved. It is well that they do, for it seems un- 
likely that such leaming processes and the organizational development that takes place as a result would happen if such individuals did not take such an active approach in stimulating it.

\section{Glasgow}

Collaborative work on health issues has alwoys been gaing on "but collaborative work at the top was considered sos more difficult to establish. The writing of a city health plan toak about four years, but was Non of mulative in getting health on orgonizational agendas.

Tithe process marted off by a sell of four seminars which brought tiagether (senior) managers of organuations. The basic ided was to trickle down thought about "what is heolth?", "what do services do forthollhy

There was also homework involwed. The managers had to write an essay on thow do you see yourself, Your work, iond the implications on health?" Interviews took place with individuals as well.

Tha Itealthy Gities team drew in the end a draft document together based on all these descriptions.

60 me orgortizations aven odded strategic plans for the coming years. This draft was sent back thilg was What youllave said, do you agree?".

The process started in the arly 1990's and in 1995 the city thealth plan was endorsed by all partiners.

Box 6.5: Strategy to stimulate intersectoral collaboration.

An important limitation to support for health initiatives by organizations other than the Health Authority or GGD is that they have quite simply limited knowledge and insight with regards to how the activities that are undertaken in different policy sectors influence health. It is true that discussions and research on the interrelated nature of policy sectors have already taken place for quite a long time already, especially in research institutes, universities, and within the WHO, but these have not necessary trickled down (or around) to the people making everyday policy implementation decisions; nor, if they have trickled down, have they fallen on open ears, as traditional hierarchical organizational structures often inhibit true intersectorality. Health professionals involved in public health and health promotion, and those involved in Healthy Cities core groups, have a specific understanding of what is meant by health and the determinants of health; it must not be forgotten that the professional discussion is almost inevitably more developed than the common knowledge of those who are traditionally or normally not involved in health research and its controversies. This latter point may seem obvious, but it should not be taken as condescending. Health professionals spend a good deal of their time considering health and its determinants; persons in other fields devote their time to the development of other expertise, and it would be naive to think health is a "universal" professional priority.

Promoting collaboration. In three case studies in the United Kingdom, Healuhy Cities was reported as having stimulated collaborative work between and within the Health Authority departments and the local authority departments. Especially the collaboration between these two entities at the strategic level was unique.

"If is a unique situotion, all these people sitting together. There are direct links with the district council, regional council, and health board. Before [Healthy Cifies, MG] this would never have happened and had never happened.' (Politician, Fe(cc))

Illustrative to this quotation is the example that, in 1994, senior managers of influential organizations in Sheffield discussed and signed up for a so-called "Framework for Action". This framework was and is related to the most pressing public health issues in their city (see box 6.6 and Chapter Five). For some of these managers, early activities of the Framework represented the first time they ever met. By signing this document, they had become 
socially obligated to work on the promotion of the health of their city. Research has demonstrated that the involvement of this lewel is important to successful collaboration: "successful company relationships nearly always depend on the creation and maintenance of a comfortable personal relationship between the senior executives." (Moss Kanter, 1994) From the interviews appeared that cross-organizational committees, such as the meeting of these senior managers in Sheffied, could be appropriate forums for the initiation and perhaps coordination of Healthy Cities activities. At the same time, however, as already mentioned, most organizations and public policy sectors that operate in an urban context neither have a traditional nor formall duty or responsibility for public health. Therefore, representatives of a Healthy City team and the Health Authority/GGD, who have these statutory responsibilities, must play an active role in showing others their potential roles and responsibilities in addressing public health issues.

"It is my job to build collaborative links with those departments and to twist their orm, encourage them, plea with them." (Healthy City team member, Fal)

An active approach by health professionals is needed to assure that health aspects are incorporated into political and organizational decision-making. They can provide advice to relevant decision-makers both upon request or of their own initiative.

\section{Sheffield}

The fromevrork for Action is based on the analysis of a langle community consultation that took pllace in 1992 ( Dor city our health'). The framework is produced and printed as a loose-leaf system which ean be reod os o whole as well as in parts picking up on specific issues or 'specialist areas'. The objective of The framework for Action is "to set an agenda for multi-agency work to imprave people"s health and to Shope the condifions which howe on effect on health."

Foverty discrimination and environment hove been identified as key themes.

Tho cher executives of the arganizations involved decided on three pritorities for the first years based on the oressibilities of short term (visiblie) success. One of these priorities is work and health, for which the Shioffield ond Rotterhom Chamber of commerce are the leading agencies.

Box 6.6: Example of intersectoral collaboration.

Even within the core group of professionals who have responsibilities in regards to public health, experience with health promotion and health policy development can be quite varied. The Health Authority in the United Kingdom is very much inwolved in health care, community care, primary care, and to some extent disease prevention (Acheson. 1988). The GGDs in the Netherlands are very much oriented towards disease prevention and to a lesser extent towards health promotion. Due to their backgrounds and traditions, both organizations, though it holds for the Health Authority even more than the GGD, thave difficulties in taking up the role of policy adviser and health promotion initiator (Heijtkamp, 1996).

"The importance of working in alliances is generally accepted by the HA, but they have difficulties to come to terms with HPR/Preventive work because it is long-term and difficult to be sure about cause and effect. And to same extent it is a lack of faith." (Professional, N2)

It has to be mentioned, however, that although all Health Authorities/GGDs come from this background and find these difficulties, they have different ways of dealing with it, indicating that the problem is not an inherent one. All Health Authorities/GGDs in the case studies were under change or were considering the steps they had to undertake in order to receive a more prominent role in local (health) affairs and politics. Meijer (1994) 
and Joosen (1996) show that some groups are wery innovative in taking up new roles, but again others try to keep things as they were, limiting change to a minimum.

As alleady mentioned in Chapter Five, it is easy to confuse representation of individuals in activities or meetings with organizational involvement.

"I assumed that people came representing their organization. But thinking about it nown I do wander how much their organization knows about the existence of the group." (Professional, Jb3)

It was also mentioned that ultimately having these committed individuals, who represent different sectors, stimulates organizational collaboration. As

"the bottom line is with individuals. You have to have that enthusiasm, at least until it is incorporated into the organization's culture:" (Professional, Jb3)

"If you get individuals in companies interested in possibilities of change that is the way the campany eventually gets involved." (Manager, le)

Broadly spoken, however, Healthy Cities has had more influence on collaborative efforts between individuals in organizations than on collaboration between organizations themselves, which would be represented more formally. Generally, Healthy City ideas are not as yet explicitly stated in vision statements or strategic objectives of most involved organizations. "If [Health, MG] is not something that is consciously and systematically within each organization's [or deportment's, MG) thinking." (Management local authority, Gd)(an example of this is given in box 6.7)

\section{Groningen}

In 1993 the political decision had been taken to become part of the network of Healthy Cities in the Netherlands and a coordinator was appointed. Since then several attempts have been undertaken to stimulate intersectoral colliaboration to promots the health of the city.

A first oitempt was a consulitation with all municipal services concerning "what is your relation with health'. It appeared that senvices were not very keen to get involved in something "new' and they had difficulties In ilmagining what the consequences would be. The coordinator had not yet evident examples. The report of this consultation round received the status of an announcernent during the management teom meeting.

A second attempt was a consultation with all ather services and arganizations in the city cancerning the question what is your relation with health'. The result was that Healthy Citties could count on their support on poper, but nobody was able to give it a concrete interpretation.

A third atternpt was undertaken in 1994 with a so called community development approach. Problems ond ideas that came up through community development workers, including their working networks, were used in the efforts to operationalize Healthy Cities. This approcech is still continuing.

At the scme time a city council report on the physical and social structure of the city was developed. It was not realized that the plan actually fitted some basic Healthy Cities"s ideas.

Box 6.7: Attempts to stimulate intersectaral collaboration.

When rather high-level intersectoral discussion takes place, it has been interesting to find that not only is the strategy and practice of intersectoral collaboration in the interest of Healtiny Cities stimulated, but other collaborative efforts take shape which are, traditionally seen, unrelated to health, for example on economic development or city regenerations. Although this strategy was adopted because it was felt that it would more effectively stimulate true multi-sectorality than the setting up of yet another committee, it was questioned whether such an approach would ultimately doom itself to the same lack of specific concern with health which generated the concern in the first place. Difficulties were expected, given the fact that health is not part of the corporate objectives of most private, for-profit organizations. 
The Healthy Cities Movement for a city:

- Provides a (international) network

- Promotes changes in:

- local structures that are put into place to facilitate health promation

resource distribution

- staff tasks/hiring

- an understanding of determinants of health

- Pramotes collaboration

At the strategic level, larger and more important questions are at stake than at operational levels. This explains why there are many more examples of intersectoral projects than of strategic agreements for long-term, formal collaboration. Let alone that such collaboration would develop into policy. Nevertheless, intersectoral meetings at the strategic level and involvement of the political level do take place, and sometimes policy is the result.

\subsubsection{Perceived contribution of Healthy Cities to intersectoral collaboration} Intersectoral collaboration indeed takes place in case studies. The question, however, is how much can be attributed to involvement in Healthy Cities. Given the findings as provided in Chapters Four and Five, it can be questioned whether the content of the ideas embodied by Healthy Cities is reason enough for collaboration. For those organizations which share an interest in the health of their city, it is difficult to see how much of this interest can be attributed to being involved with Healthy Cities. Much of this collaboration, it might be asserted, would have happened anyway, without the presence of Healthy Cities, as a logical consequence of existing policy " developments, activities, and general trends. For example, the United Kingdom national government's policy stimulates collaboration ${ }^{6}$ at the local level. It also encourages competition between public and private serwice providers and through Compulsory Competitive Tendering $(\mathrm{CCT})^{7}$. This encouragement is not limited to non-health sectors; specifically with regard to public health, collaboration is stimulated (Funnel, Oldfield \& Speller, 1995). There is also a general tendency of local governments to reorganize themselves into less hierarchical and more flexible and conpetitive organizations (see for example Broekhwizen, 1992; Osborne \& Gaebler, 1993; Posner \& Rothstein, 1994; Stoové, 1992). These developments encourage organizations to collaborate and get inwolved in networks.

We distinguish here between intersectoral collaboration at operational and strategic levels. As noted, it is more common to find collaboration forms at the operational level than at strategic level. Still also at this level Healthy Cities delivers a specific contribution. Heallthy Cities provides (see table 6.2) an international network, outside contacts, examples, and ideas from other cities and countries. New intersectoral structures have been set up due to Healthy Cities. Healthy Cities also provides possibilities for attracting (European) money. It facilitates and stimulates thinking about where and how health is created. Through the Healthy Cities networks " examples are provided on what the contribution could be of the different policy sectors towards health promotion. This thinking was in the case studies a stimulus toward a reorientation of resource distribution (with regards to health) and the hiring of new staff. It is certain that without Healthy Cities, some people 
would never have met, and some key relationship, thus, never have begun. Furthermore, they would indeed not have been likely to have thought about how their work and ideas would relate to the health of the city.

\subsubsection{Political processes: political commitment}

"People within the local government are committed to what we [Healthy Cities feam, MG] are trying to achieve. We would not have been as successful as we have been if lacal government had not shown as much commitment as it did. If comes down to personalities." (Healthy City team member, Fall)

In Chapter Four (section 4.5) we have discussed the importance of political commitment to Healthy Cities projects. The conclusion reached in that chapter was that Healthy Cities indeed benefits to a great degree from political commitment, roughly to the extent it is present. However, the actual support given is more often symbolic than tangible. And in those cases where it is indeed tangible, it remains questionable how sustainable that support is. Support appears to often be the result of individual commitment by a local actor. Other times; support is the result of Healthy Cities being attached to subjects that are of high political priority.

"One of the problems we have had in the council is that [Healthy Cities, MG] has been focused very much around individual representatives of the departments and has relied upon their commitment.

These people move on, however." (Healthy City Team member, Ha) (see allso quatation in the beginning of this section and Chapter Four section 4.5).

The role played by individuals and the influence of individual commitment on the achievements of Healthy Cities is an important finding discussed in all the chapters of this thesis.

In sub-section 6.3.2 it has been shown that it is not at all self-evident that those who have no statutory duties with regards to public health take up a responsibility on for its protection or promotion.

"You invest your interests into the things you have most burning responsibility for. Health is long term with no direct results." (Politician, le)

This leaves those who have responsibilities for community care, disease prevention, or health promotion the task of taking up the active and stimulating rolle for efforts like Healthy Cities.

"If you are politically responsible for public health affairs, you need to be persionally active in making others interested. If will always be that way, despite rules and regulations, activities etcetera."

(Palitician, Ce)

It was observed that in the Netherlands, Healthy Cities very much embodies disease prevention and other activities, as these are performed by the GGD (see Chapter Five). An explanation for this finding may be the fact that local government in the Netherlands has a formal responsibility for disease prevention. In the United Kingdom, where local government has no explicit responsibility for disease prevention, Healthy Cities seems to be broader in its conceptualization. Under the Healthy Cities label in the United Kingdom, general issues such as poverty, democratization, and empowerment were more explicitly addressed than in the Netherlands.

Indeed, those with formal duties with regards to public health need to be alert with regards to what happens in the different policy sectors and organizations. There are in general no rules in sectors other than those related to health on the solicitation or provision of advice and comments on the potential effects of their initiatives and activities on the public's health. An additional difficulty with regards to prevention and health promotion is that these efforts are inherently based on preventing rather than curing, making it difficult to establish the harms associated with the status quo. Professionals in these fields are often 
bound by the necessity of having to describe what their efforts would presumably prevent from happening, rather than being ablle to show an immediate threat and need for action. "If there is something wrong with the housing or the greening something visible, the politicians are very much interested. But then it is really and visibly wrong. With regard to disease prevention and health promotion there is not yef something "wrong". So once in a while you need a little disaster to demonstrate that our service indeed is not a luxury." (Management Health Authority/GGD, Ac)

Examples of this can be found in the city planning arena. Discussion can take place from a health perspective when a city develops a new 'zoning plan". This discussion might address the location and number of green areas, play fields, housing density, or the possibilities for establishing a community health centre or a general practitioner"s practice. It is not self evident that all parties concerned will share the same thoughts about the elements in this plan. For example, high housing density will bring in more money on taxes, and thus is attractive to many parties, though it may not be to the benefit of a community"s health. Playing parks and green space need maintenance, and that costs money without generating any, making other more commercially viable alternatives rather tempting as substitutes.

It may not be a surprise that the position of public health seems to be weak within the public policy arena. This is due not only to the fact that differences exist with regards to the interpretation of the (formal) responsibilities of public health departments and to the practical consequences attached to them. It is also true that public health, compared with other public policy sectors, does not account for a large portion of the generation or dedication of the wealth in most municipal budgets. Thus, for a number of reasons it has low status within the municipal apparatus. This is apparent to even the casual observer; if public health would be an issue of widespread and regular concern, it would be a subject discussed at city council meetings. An analysis of the minutes of city council meetings, however, shows that collective prevention and public health issues hardly get past the status of announcements. If health issues are discussed in any depth, they are mostly discussed in the sessions of a committee responsible for health or health-related matters.

In our opinion, only local government's true acceptance of a broad definition of health would stimulate its deparments to reevaluate their policies and activities along healthrelated criteria.

\subsubsection{Perceived contribution of Healthy Cities to political commitment}

It is difficult for Healthy Cities to receive political support given the position of public health in local politics as discussed above. But Healthy Cities nonetheless has succeeded in achieving certain political support for health-related objectives. The question is, however, whether relatively greater support in this regard can be attributed to the presence of Healthy Cities. In other words, is it possible to determine what the specific contribution of Healthy Cities is towards increased political commitment for health activities?

Table 6.3 provides an overview of the major perceived contributions of Healthy Cities to political commitment for health at the local level. It seems that Healthy Cities plays an important role in increasing an understanding of what creates health. It is seen to have stimulated politicians to reflect on their roles with regards to the maintenance and creation of public health. Healthy Cities has generated attention for al "health agenda" by stimulating activities and providing evidence for the potential inherent in its own models of health promotion through demonstration projects.

"Healthy City people are pioneers. They seek to establish relationships between health ond other coun. cill responsibilities which the council hes never considered. In that way it influencies policy makimg ond the council's thinking." (Politician, Fe) 
Table 6.3: Healthy Cities and political Commitment.

The Heolthy Cifies Movement for a city:

- Stimulated changes in:

- the underatanding of healih determinonts.

- the local structures that are put in place to focilitate health promolion

- Increased commitment for health (activities), as health receives at least some attention in political discussions

This political commitment can be:

- tangible

symbolic

persondil

- city council widie

"We [Local authority, MG] make people ill. We have awful housing, we cannot provide them with jobs, we knack them down on the roads, we pollute them with toxins: exactly the things the Heolth Authority has no influence ower at oll." (Management local authority, Gd)

Interviewees mention that Healthy Cities has influenced the city council's thinking. But we question whether this change in thinking involved the entire council or some individual politicians. If it is the case that individual thinking of politicians and others is influenced by Healthy cities; it would be advantageous for health policy development if these individuals would be positioned at strategic (influential) places within organizations, such as at chief-executive level or as president of a city council committee. As mentioned in Chapter Four, such a position if not a prerequisite, but it will help them to reach, and possibly influence, a wider audience.

As was mentioned in Chapter Five, in some case studies it appears that Healthy Cities has been able to change city council administration. New city council committees and an intersectoral public health team have been created as a result of the efforts of various projects. Healthy Cities has even stimulated the development of a public health plan (see Chapter One). In other case studies. Healthy Cities was not perceived as mature or powerful enough to influence council structure and decision-making.

There are a number of criteria which seen to indicate whether Healthy Cities is perceived as powerful enough to influence decision-making and policy. From Chapter Four, it appears that the conceptualization of Healthy Cities is one important reason. Other reasons are the amount of time the city is involved in Healthy Cities, the experiences, the strategies, and the networks that are created and provided and the ways they are used. Furthermore, the understanding of how local politics works and how to play the political game are additional important factors that influence whether or not Healthy Cities is able to have a say in city council decision-making. Sornetimes the approach is too naive, due to limited knowledge of the organization and functioning of the local administrative system and local politics.

"Political costs and benefits is something wealth Authority/GGD, MG] are not very good of. We aften say "we wan't do that because that won't have any effect" even though politicians are saying "but we hove decided that it is important". Moybe we are too much driven by considering the real effects of our actions from the perspective of expert knowledge and not by glamour and media and the possibilities for constructing a political argument in our own interest." (Management Health Authority/GGD, Ac/a) This quotation clearly illustrates the differences in thinking and priorities between professionals and politicians. 
As importiont Healthy Cities successes are mentioned:

- Hacilitates meellings and activities that focus on health promotion.

- It speeds up processes such as collaboration, understanding where and how health is created, and dealing with local (health related) problems.

- Ht puis health on the political and sacial agendas and on some onganizational agendas and consequently it influenced decision-making processies.

- It establishes relationships between organizations and individuals representing different sectors.

- llegitimizes to undertake health promotion activities.

- It facilitates the efforts to attract (international) resources for collaborative (health related) projects.

- Ht gives a proof of evidence that the Health for All strategy and Ottawa Charter concepts can be put into prectice.

- It brings along skilled persons in areas that are central to health promotion.

\subsection{The additional benefit of Healthy Cities}

A question often posed to those who participate in Heallthy Cities is whether it makes a difference to them in terms of the performance of their duties to be part of such an initiative. In this research we have asked for the perceived relevance of the project. In other words, what is the perceived additional benefit of being a Healthy City? As explained before, we do not want to get entangled in proving cause and effect. At the same time, it is believed that the perceived relevance and value of Healthy Cities can be regarded as an indicator, if not proof, of the successes of a project (see also Maarse, 1995).

What is then the perceived additional benefit of Healthy Cities? In terms of content of activities that are undertaken locally, it was expressed that participation in a Healthy Cities network did not make a difference. Old activities seem simply to continue under a new label. Some new activities are initiated, though it is felt that most of these would probably have been started also with or without Healthy Cities as a logical consequence of previously existing policies and activities.

There are even a few interviewees who mentioned that Healthy Cities as such did not mean anything. It was only used as a label to summarize and package activities.

"Healthy Citties as such does not mean anything to me. It is a flag to make people enthusiastic which you need to undertake activities. The label can be Healthy Cities or something else." (Management Health Authority/GGD), Cc)

However, on the whole, Healthy Cities was perceived to thave added value to local efforts (see also table 6.4). The relevance of Healthy Cities is mostly defined in terms of facilitation. More precisely, involvement in Healthy Cities brings a meaningful framework to draw people together around health issues. It draws people together who otherwise never would have met, such as different chief executives of important organizations in a municipality. It also creates relations between the community and decision makers.

"Without Healthy Cities the Health Authority would still regard care as the one and only priority, and the Lacal Authorities would not go any further than their statutory functions. This means that little or no preventive work or health promotion work would be done. The beauty of Healthy Cities is that it brings many arganizations and small groups together, a thing that would not have happened without Healthy Cities." (Politician, $\mathrm{He}$ ) 
In most case studies there are offices and people, for example coordinators, whose sole mandate is to establish linkages between the several potential actors. These offices and people take on an engine role for Healthy Cities.

"I feel most people where wre work with understand what the problems are. But they wouldn't necessarily call that health." (Healthy City team member, Ga3)

Through the efforts of those who we have given the name of core participants (see Chapter Four), the process of leaming to understand where and how health is created and what can be done by each individual and organization to promote health in an urban context is accelerated. In that sense Healthy Cities functions as a sort of eye-opener, a key for innovation. "It has been an enabler that hos conwinced the porfies that things can work. It has been a key that opened the door to new thinking. You must as well as the motivators; people who can take an interest in [getting the job dane, MG]. I can give encourogement to them, but I cannot do their jab."

(Politician, Fo)

At the same time there are interviewees who disagree that a separate project office and separate Healthy Cities staff is needed to enlarge the attention for public health aspects. This finding was also illustrated in Chapter Five on domains. Because

"in the end the project office will think they are indispensiable because they will assume that without them lowing the line nothing will happen. Of course that would only be true because they had organized it in that way." (Management Health Authority/GGD, Ce)

All interviewees agree that health aspects are not inherently part of the criteria for judging activities and policies. Having Healthy Cities brings extra attention to health considerations. Furthermore, it brings along people who feel responsible, or have the formal responsibility due to their statutory tasks, for the health of their municipality and its inhabitants.

With regards to health policy development interviewees mention that it is difficult to mention the possible policy benefits Healthy Cities has made or can make.

"It is difficult to show the policy benefits of Health for All in the short-term. For example, how can yau measure the direct result of the time spent on inter-agency meetings?" (Seniar officer Local Authority, 14) Health policy development has not been explicitly a target in the ten case studies. It has been discussed in terms of a city health plan, plans of the director of public health, Health Authority plans, and health targets. But in most case studies it did not become apparent what such discussion really meant until the cities had participated already for a few years in the WHO Project or in the national network. In some case studies this means that Healthy Cities is not yet at a stage in which it might be reasonably expected to influence policy and decision making: instead it influences individual policy and decision-makers. In general the interviewees feel that the aspect of long-term policy development is lacking. At the same time all demonstration projects that are undertaken, all networking and negotiation that goes on, and all the efforts made by the core group of Healthy City participants, contribute to policy development. This point will be taken up again in Chapter Seven.

For one case study, participation in Healthy Cities was also helpful in freeing the city from its isolation. It brought new knowledge to the city. It brought to all case studies glamour and extro credit for health activities and it helped to attract resources.

Through involvement in Healthy City activities, participants learned to speak a common language. This was positively valued as it was generally assumed that "you can work with a completely different organization, with completely different beliefs, and bureaucratic processes. Well, you cannot." (Management Health Authority/GGD, Gc)

Overall, the interviewees in most case studies, in their own words, mention "probably we could have done without [Healthy Cities, MG], but we would not have come that for." (Politicion, Ae) 
"if we would not have been involved in Healthy Cities, we would have invented something like it." (Management local authority department, Dd/e)

Although interviewees agree that Healthy Cities makes some difference, they cannot say how much, as is illustrated by the following two quotations.

"I could not quantify how much of the change would be [due to Healthy Cities. MG], what percentage would be theirs and what percentage would be central policy change itself. There is, however, no doubt that if played a role." (Management Health Autharity/GGD, Gc)

"I don"t know how much Healthy Cities contributed. A lack of funding drove people together, it could be a result of governmental changes, it could be that using multi-facet submissions of funding for a geographical area encourages people to think about health gain and changes." (Coordinator, Ga) This leads to an overall conclusion that the major strength of Healthy Cities is facilitation and getting things in warious fields and on many aspects started. It was already mentioned in Chapter Four that the concept looses its power after some years. It may be the case that cities then decide to continue their activities and policy development under a new banner. but it may also lead to an end of Healthy Cities activities. We will come back to this conclusion in Chapter Seven.

\section{$\overline{6.5}$ How successfully are key concepts put into practice?}

Answering the question of whether the key concepts of Healthy Cities are successfully implemented in Project cities remains difficult. From the information presented in Chapter Three it appears that at the start of the Project these concepts were mainly used by WHO as ideological instruments. Generally speaking, these are central to WHO's constitution, programmes, and strategies, and it was assumed that they would have rhetorical strength on the ground. WHO put, at that time at least, more faith in the possibilities they saw for using these concepts to disseminate their vision than in the more time-consuming road of encouraging an academic foundation for the concepts. In this chapter, information has been presented which reveals that these key-concepts are indeed used in practice. In the opinions of the interviewees success has at times and even often hinged upon the broad appeal and mutual understanding they inspire. We have shown in Chapter Three that, during the years, academic attention for these (new) concepts has increased. What then can be concluded if we compare the findings in this chapter with those insights?

\subsubsection{Community involvement}

Table 6.5 compares our research findings, theory, and WHO's assumptions on community involvement.

In addition to the comparison provided in table 6.6 "a few remarks can be made when theory is compared with the research findings. If we break down our evaluation results along the lines of extent, phase, and number, as referred to by Van Asserria (1993), we see the following. We came across no examples of what has been called community control or community manipulation. In Healthy Cities efforts, community participation has meant by and large doing projects with the involwement of community representatives. These projects may be initiated by the community itself, with an active role for professionals where that is deemed necessary. It can also be that the project is initiated by professionals and that a community is asked to take an active role, what Evers (1989) referred to 
Table 6.5: Comparison between community inwolwement in theory and Healthy Cities practice.

\begin{tabular}{|c|c|c|c|}
\hline & $\begin{array}{l}\text { WhO Hedlthy Chles } \\
\text { profect }\end{array}$ & Theory & Resecarch \\
\hline What & $\begin{array}{l}\text { Participoticin of communthy } \\
\text { in decisionotiviking thet } \\
\text { ind wences its heolth. }\end{array}$ & 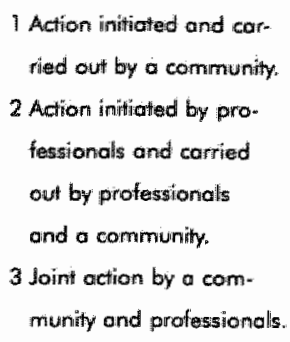 & $\begin{array}{l}\text { Consultation of the com- } \\
\text { munity on local government } \\
\text { ar argonizational palicy. } \\
\text { pllons, or activies. } \\
2 \text { Participation of a commu- } \\
\text { nity in health projectis. } \\
3 \text { Joint action by a commu- } \\
\text { nity and profiessiondis. }\end{array}$ \\
\hline Why & $\begin{array}{l}\text { - mpowerment; giving } \\
\text { people meons and silkills } \\
\text { llo decide for theminselwes } \\
\text { - democratiration }\end{array}$ & $\begin{array}{l}\text { - empowwerment } \\
\text { - to reach o predefined } \\
\text { herolth gool } \\
\text { - to lower costs }\end{array}$ & $\begin{array}{l}\text { empowerment } \\
\text { generel trend to failor work } \\
\text { to specific needs; so-called } \\
\text { neighbourhoad based } \\
\text { working }\end{array}$ \\
\hline When & - any time & $\begin{array}{l}\text { - any time } \\
\text { - health related matters }\end{array}$ & heolth projects \\
\hline How & - not speecified & - projects & $\begin{array}{l}\text { - projects } \\
\text { - citizen representation in } \\
\text { meetings }\end{array}$ \\
\hline
\end{tabular}

as professional projects. An active role means, for example, having responsibility for coordination, doing research, or organizing activities within the project. Most of the time, community is more involved in concrete projects than in, for example "general meetings such as those that take place in Healthy Cities city-wide steering groups. With regards to meetings and steering groups, it appeared that a whole community is often represented by only one or two people. Community is a fluid concept: it could mean, for example, a specific target group, or it could mean the people living in one geographic area. There was nonetheless much talk about participation of communities throughout the case studies. Given these results, we question the feasibillity of "the community approach" as championed within health promotion. There is a gap between theory and practice that needs to be bridged.

Community involvement in a project implies that a community is an important actor. In practice it concretely means involvernent of representatives of a community instead of the participation of an entire community. Besides the community, other parties are involved in putting together projects. These parties do not necessarily agree on the project, most often have different goals and different time perspectives, and may have difficulties in communicating with each other. Projects instead of. for example, a community development policy seems a satisfying solution for all parties. Politicians and managers are willing to commit themselves to a concrete, fixed-term project. But to express it rather boldly, they hesitate to regard community involvement as involving more than the consul- 
tation of communities to solicit their ideas, opinions, and wishes, Community development workers can show in these projects what can be achieved by working with a community and by enabling them to make their own decisions Communities themselves can get excited for the short period of time required to implement a given project. Moving beyond such projects, however, requires a reorientation of the ruling business. Instead of consulting people about their wishes, people would in principle be enabled to secure a measure of social and thus political power, and to help themselves on that basis. It goes too far to expound here the possibilities and consequences of such a reorientation. But a policy sociologist, Gilbert (1995) came up with the concept of the Enabling State in contrast with the proverbial Welfare State. Also Schuyt $(1997 \mathrm{a}, 1997 \mathrm{~b})$ elaborated on ideas of how to reorganize the current Welfare State according to the value orientations of empowerment and enablement. Healthy Cities can be used to enable people to be involved in decision-making that influences their health and opportunities for health. But it can also be used to stimulate and empower their involvement in decision-making. As mentioned above this last option would imply more fundamental changes than the first one.

The evaluation results also prowide another insight. In Chapter Three it was mentioned that health promotion research shows that a community approach unifies behavioral and social changes. Although the Bracht model (1990) is based on the idea of community ownership, the notion that behaviour change is needed and which specific behaviour changes should take place is left to the discerning eye and experience of the professional. In fact, this very much resembles a traditional health education approach. In Chapters One and Three we have shown that Healthy Cities and the Ottawa Charter are rooted in democratic ideals. That means that the community should have real ownership about what they see and define as 'good' (and healthy). What practice shows, however, is that Healchy Cities reflects a much more traditional top-down health education model than it does a radical reorganization of community organization and resources.

A limiting factor in the model developed by Bracht and Kingsbury (1990) is that it reasons very much from a health professional's perspective. No attention seems to be given to the political components of enabling communities or creating health within them. This makes the work of limited value for our purposes here; for it is not the initiation and implementation of community projects that causes the greatest difficulties. It is, rather, the use and the translation of the results of these projects into mainstream activities and policy that remains the most formidable barrier. Managers, even from the Health Authority/GGD as shown in the quotations and examples in sub-section 6.3.2, as well as financiers, for example, have great difficulty in seeing community involvement as a mainstream, everyday activity. They do see the advantages of community based work, embodied in such things as community needs assessments and program tailoring. These are seen to increase community satisfaction and the quality of the services and their efficiency. But they have great difficulty in picturing the actual participation of community in the performance of organizational or statutory duties. More attention should be provided to this obstacle if the target is to move from projects to policy. For example, more attention should be given to organizational development in terms of making organizations familiar with working on community involvement. Additionally, organizations can through training become more sensitive to how their work and policy influences the promotion of the health of the city and its citizens.

\subsubsection{Intersectoral collaboration}

Table 6.6 compares our research findings, theory, and WHO's assumptions on intersectoral collaboration. 
Table 6.6: Comparison between intersectorall collaboration in theory and Healthy Cities practice.

\begin{tabular}{|c|c|c|c|}
\hline & $\begin{array}{l}\text { Who Heallhy Citles } \\
\text { profect }\end{array}$ & Theory & Research \\
\hline What & 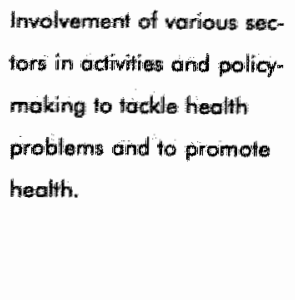 & $\begin{array}{l}\text { Colloborotion between ango- } \\
\text { nizations/organizotional } \\
\text { representatives from diffe- } \\
\text { rent sectors: Different levels } \\
\text { of tormalizotion possible. }\end{array}$ & 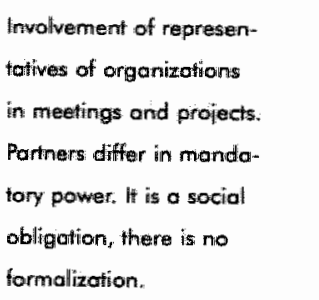 \\
\hline Why & $\begin{array}{l}\text { Health probliems transcend } \\
\text { organizational "sectoral, } \\
\text { andil national borcters. }\end{array}$ & $\begin{array}{l}\text { - pragmetic reasons } \\
\text { - benefit for oll pontners } \\
\text { involved }\end{array}$ & $\begin{array}{l}\text { - pragmatic reosions } \\
\text { - personel enthusicasm }\end{array}$ \\
\hline When & - ony time & - see above & $\begin{array}{l}\text { any time } \\
\text { - when there ore benefits } \\
\text { for the organization }\end{array}$ \\
\hline How & - not specified & $\begin{array}{l}\text { at operationol level: } \\
\text { projects } \\
\text { at manogement level: } \\
\text { retherics: }\end{array}$ & $\begin{array}{l}\text { - at operotional level: } \\
\text { comcrete projects } \\
\text { - at management levelt: } \\
\text { meetings } \\
\text { - initiated by the health sector } \\
\text { - individuals play a large role }\end{array}$ \\
\hline
\end{tabular}

Healthy Cities is in the case studies associated with the Health Authority/GGD. This is appropriate, as in all the case studies presented here, individuals of these organizations coinitiated Healthy Cities (see Chapter Four section 4.4. and Chapter Five section 5.5). Although individuals from other organizations are willing to take up the role of initiator or entrepreneur, it is not necessarily the case that the whole organization will follow (see Chapter Five sub-section 5.5.2). The organizations and their representatives that make up the Healthy Cities policy community can be subdivided at very least into a core group and a peripheral group (see Chapter Five sub-section 5.5.2). Also a distinction can be made between organizational and individual representatives. It must be mentioned that these representatives do not posses equal power. It is therefore necessary to investigate the meaning of involvement before jumping to conclusions about intersectoral collaboration.

Furthermore, two levels of intersectoral collaboration can be clearly distinguished in the case studies. One is at the operational level, as represented in the development and implementation of concrete projects. The other is at a (strategic) management level, through steering committees and meetings. That this collaboration is indeed intersectoral has been made visible in Chapter Five on domain construction. However, from sub-section 6.3 .2 it appears that often the aim of intersectoral collaboration is not the creation of a Healthy City. Instead, Healthy Cities is used as a means to stimulate or guide collaboration. For some cities. Healthy Cities arrived as a tool for intersectoral activities at just the right moment. The need to collaborate is enforced by pressures from national government, 
shrinking of finances, and by a restructuring of local government.

Our findings also correspond with those of Bisinga (1994), as most examples of collaboration in the case studies take place on a project-by-project basis. The city-wide Healthy Cities steering groups are examples of long-term collaborative efforts. Collaboration through such committees is informal and does not demand heavy commitments from the members; though it does sometimes require a financial contribution, the involved organizations hardly ever are required to give up any autonomy. The collaborative examples in the case studies can be found at the left side of table 3.3 (see Chapter Three section 3.4). They range from contacts to agreement. One could debate whether or not the organizations who signed and sponsored a city health plan, such as is the case in Sheffield, Glasgow, or Liverpool, came to a joint agreement or simply formed an alliance.

Nonetheless it remains in their eyes a social obligation to work toward the realization and development of the city health plan. The plan cannot be used to exert pressure to those who do not take their assignment serious. This may create problems when a powerful partner decides despite its 'social obligation' to limit development or expression of the plan out of self-interest.

Indeed, it appears that, as mentioned by Taket (1988), not all partmers in the collaborative process are equal. Based on our findings, however, we would express partial disagreement with her statement that the success of intersectoral efforts relies more on good rhetoric than on practical knowledge. We found that though this may indeed be true for most collaboration at the management level, many practical examples are provided in support of project development at the operationall level.

Our findings are also supportive of the argument made by springett (1995). Namely it is individuals, representing their organizations, who actually do the collaborating, rather than those organizations themselves through formal mechanisms. As demonstrated in Chapter Five, collaboration between individuals can be easily confused with collaboration between organizations. In fact, the meaning of a collaborative effort needs to be investigated before it is really known what kind of collaboration it represents.

What is apparent from the evaluation results is that the checklist for intersectoral collaw boration as referred to in Chapter Three (section 3.4), is mainly constructed from the perspective of those who support intersectoral collaboration. What is lacking on this list are the criteria which shadow the arguments provided by those who are not eager to get involved in a collaborative health project or strategy. We have provided through our evaluation insight into some of the reasons behind individuals' hesitation to get involved in collaborative initiatives. Their arguments include the premise that health is not traditionally part of their corporate or departmental objectives. Consequently they see no benefit to being involved because they cannot define or justify their role. Furthermore, it must not be forgotten that health professionals involved in public health and health promotion may have a clear understanding of what is meant by determinants of health, but the discussion they have with each orher on this issue is often more developed than is readily accessible to those who are traditionally or normally not involved in health-related research and its debates. WHO promotes intersectoral collaboration mainly out of a recognition that the origin of health problems is very multi-dimensional. The intersectoral collaboration which takes place on an issue based project may very likely result from a recognition of the complexity of the problem. But intersectoral collaboration at the management level can hardly be explained by a recognition of the complexity of pathogenesis. In section 6.3 .2 and section 4.4 (Chapter Four) it has been shown that other, more pragmatic reasons play a larger role (see also Chapter Five section 5.3 on priority setting between issues). 
Table 6.7: Comparison between political commitment in theory and Healthy Cities practice.

\begin{tabular}{|c|c|c|c|}
\hline & $\begin{array}{l}\text { Who Heallhy Chtes } \\
\text { Prolect }\end{array}$ & Theory & Research \\
\hline When & $\begin{array}{l}\text { Support by polificions for } \\
\text { health odiwities. }\end{array}$ & $\begin{array}{l}\text { Loical gowernment support } \\
\text { for actiwities and polibies. }\end{array}$ & $\begin{array}{l}\text { Support for Healthy Cities } \\
\text { (projectis). The noture of } \\
\text { commitment waties between } \\
\text { tangible and symbolic. The } \\
\text { level of commiltment varies } \\
\text { between city council-wide } \\
\text { and peirsonal. }\end{array}$ \\
\hline Why & "nol specified & $\begin{array}{l}\text { * to tackle problems } \\
\text { - to show that issues of } \\
\text { public concern receive } \\
\text { governmentol attention }\end{array}$ & $\begin{array}{l}\text { - progmatíc reasons } \\
\text { - personal interest } \\
\text { - local issues/'prablems } \\
\text { - content of Heolthy Cities }\end{array}$ \\
\hline When & - ony time & $\begin{array}{l}\text { - when pressing problems } \\
\text { - when promissed } \\
\text { - when the climate is ready }\end{array}$ & $\begin{array}{l}\text { - during ollection times } \\
\text { - when a pressing problem } \\
\text { - city promotion }\end{array}$ \\
\hline How & - not speciffied & $\begin{array}{l}\text { - madia } \\
\text { - pressure } \\
\text { - indiviual politicians } \\
\text { - making use of windows } \\
\text { of opportunity } \\
\text { - sacial entrepeneurs } \\
\text { - saftening up the system }\end{array}$ & $\begin{array}{l}\text { - making use of windows } \\
\text { of opportunity } \\
\text { - individual polliticians } \\
\text { - sociol entrepeneurs } \\
\text { - lectures, site wisits }\end{array}$ \\
\hline
\end{tabular}

\subsubsection{Political commitment}

Table 6.7 compares our research findings, theory, and WHO's assumptions on political commitment.

The findings on political conmitment are in accordance with the agenda building theories and WHO's expectations regarding the necessity of having political commitment for local health promotion efforts. Political commitment is indeed essential for Healthy Cities to be put in practice. "The interviewees also mention, perhaps not surprisingly, that achieving this commitment is difficult.

From Chapter Three (section 3.5) it appears that in general there is not much attention paid in health promotion research to the specification of the level and nature of political support. Based on our research findings, we can specify the level and nature of political support for Healthy Cities. The level of political support varies from the support of an individual politician and to that of a whole city council. The nature of support varies between tangible and symbolic. Different combinations of nature and levels of support were found in the case studies (see Chapter Four section 4.5, and this chapter sub-section 6.3.3).

Symbolic commitment means support for the project which does not put personal or public resources directly on the line. It can be a written city council declaration, which the 
councillors have unfortunately most often already forgotten the day after they have signed it. It can also mean an opening or closing speech delivered by a representative of the city council at a Healthy Cities meeting or conference. Tangible commitment means putting personal or public resources behind a project. This would include; for example, taking responsibility for defending Healthy Cities ideas in the political arena, or providing in-kind or financial resources to a project. At present, it is more common that concrete projects receive tangible support than that Healthy Cities as a framework for city-wide policy development is championed. We found furthermore, that although commitment may have been expressed city council-wide, it is individual politicians who support, defend, or promote Healthy Cities.

Demonstration projects often received city council wide tangible support. The recognition of the policy possibilities of Healthy Cities (see also Chapter Three and Chapter Seven) receives either individual politician or city council wide symbolic support.

Underlying the pattern of observations presented here is the fact that politicians do not think in the flexible time terms and systemic approach advocated by Healthy Cities. In subsection 6.3.3 it was shown that politicians commit themselves preferably to something tangible and concrete such as an issue-based demonstration project. These are preferred because they are perceived to provide visible results on a short-term basis. The long-term objectives of Healthy Cities in terms of policy development are neither fixed-term nor concrete. This concretization is something that is demanded by local government itself $f_{\text {w }}$ as well as other involved parties for the same or different reasons. Politicians who have political responsibili ties in regards to public health, such as those who are members of a public health city council committee, play a large role in defending, supporting, and promoting Healthy Cities in. the city council. It was mentioned by these individuals that having a few committed politicians is enough to raise the issue of Healthy Cities. Organisational and city council wide support is needed, however, if this support is meant to be tangible and long lasting. Therefore, it is necessary for those who promote the idea of Healthy Cities to have some knowledge about politics and how to play the political game. Health , from a political perspective, is not seen as a critical issue. Consequently, it is often not discussed in city council meetings apart from situations where health could conceivably be threatened. Unless issues are put on the agenda by a representative of the Health Authority/GGD or responsible politician. Therefore, if the target is to move politicians on health, concrete examples need to be provided. It was expressed by members of the Healthy Cities core group that due to such reasons as having no education in the field, they were not very clever in using political arguments. So addit tionally, health professionals need to learn about politics, because sometimes having a professional argument is enough to get movement, but sometimes it is not and other skills for persuasion must be brought to bear. Actors who are actively involved in health promotion and health education activities and policies - the way Healthy Cities is mostly used in the case studies- often have little knowledge of or training in policy and political science.

Yet, it appears that Healthy Cities as an instrument or framework for innovative ways to work on health promotion activities and policy is successful in stimulating political interest. It was mentioned that through the Healthy Cities projects and the cities' resulting involvement in a national and inter-national network, it became more widely recognized that health is influenced by virtually all local government sectors and the activities of organizations in a municipality. In general, however, politicians do not yet regard Healthy Cities as a framework for the creation of healthy public policy. They also do not regard it as a framework for integrating different public policies. They did not recognize Healthy Cities as such primarily because they had never realized that it was intended to be used in that way. Furthermore, if they sympathized with intersectoral policy development, they 
were generally already using other frameworks to establish sectoral integration and gear policies to one another.

In line with Cobb and Elder (1983) and Kingdon (1995), our evaluation results support the conclusion that having a few committed individual politicians is enough to at least temporarily raise general political attention for the issue. The challenge to those promoting Healthy Cities is to broaden this support to that of a larger audience and to make it less dependent on individuals. Healthy Cities advacates need to move towards the development of stronger and broader organizational support. In this chapter ideas have been presented regarding whether or not-and how-this eventually can be established.

\subsection{Conclusion}

That the three selected key-concepts, community involvement, intersectoral collaboration, and political commitment, are put into practice has been illnustrated in this chapter. Involvement in Healthy Cities gave the work on the critical concepts of given localities an extra push, extra attention, extra credit, and speeded up the processes of program implementation. But it cannot be denied that current trends, local governmental re-structuring and national government requests also stimulate to work on the three selected concepts. Exactily which key-concept receives priority depends on local circumstances, policies, and the ideas and skills of the people involved. According to the interviewees, it is possible to provide from each case study a success story with regards to these key-concepts. What success is and what it is not should be judged within this local context. For example, being able to start a large-scale ADS-campaign through Healthy Cities may be very innovative and successful in a city within the Republic of Slovakia. If Healthy Cities would be used to initiate such a campaign in Rotterdarm, in the Netherlands, it would not be evaluated as particularly innovative due to the history of health programming there, which includes such efforts. Two specific differences between the case studies in the Netherlands and the United Kingdom can be mentioned. It seems that in the United Kingdom case studies, more changes in city structures are made to facilitate the work on the three as well as other key-concepts than in the Netherlands. Examples of these changes are adaptions in the cily administration and the creation of city-wide steering groups. Also the leading case studies with regard to development of ideas for and action on the creation of a city-wide health policy or the creation of a city-wide policy with an eye for health aspects are located in the United Kingdom. Although we support the idea that it is local differences that can explain the differences between the case studies, this particular finding may be partly contributed to national differences. Namely the formall responsibilities of local government with regard to public health and the structure and functioning of the health system can be explanatory to this fuding. This idea will be further explored in Chapter Seven.

It appears from section 6.5 that there is not necessarily an interface between academic research results and theories and practice. In some case studies, having an experienced health promotion research institute and/or an active epidemiology department were advantageous. This was the case in for example Liverpool, Glasgow, Sheffield, and Rotterdam. It is, however, not a prerequisite. Take for example the Research for Healthy Cities Clearing House as referred to in Chapter Two (section 2.2), which is located at the University of Maastricht. Despite the presence of this institute, it took a long time before the city council and GGD of Maastricht showed any interest in Healthy Cities. Other factors also play a role, examples of which are provided in Chapter Four. 
The WHO could have made an effort to level out the differences in access and availability of research data for the WHO Project participants. They could have created a data-base on social processes likely to occur within the typical development process of Healthy Cities. Data collection and registration in all areas is a core activity of WHO. They see this as a politically neutral way to facilitate member states in developing strategies and activities. But they forget that registration causes changes and that consequendy data change as well (see for example De Bont, forthcoming). The WHO/EURO/HCPO provides a Healthy Cities data-base with practical case study examples. In this data-base, however, no connection is made between practice and theory. So we can only speculate whether it would have made a difference if cities were given the possibility of consulting a data-base with scientific and practical examples and evaluations in regards to central Healthy Cities concepts.

These very general key-concepts leave those who are working on them plenty of room for interpretation. The evaluation findings for all three concepts show that their meanings are quite fluid. It appears that it is easier to work on them at an operational level and through projects than at a strategic level and as a mainstream activity. In other words, the more practical the level, the easier it is to make the concepts reality. It must be mentioned, however, that political commitument remains the most abstract concept of these three. Intersectoral collaboration and community participation lend themselves to initiate issue based activities. But how can one establish a project based on political commitment? Political commitment can, nonetheless, be gained through these projects. This observation leads to the expectation that, for similar reasons, the concept of healthy public policy will be a difficult one to give concrete feet and hands. Like political commitment, it can be stimulated through other activities, however. Some of these activities and conditions have been detected in our research.

It also appears that the appearance of community participation and intersectoral collaboration shows a larger diversity than political commitment. Because political commitment is difficult to make concrete, there is not much variation in practice. This research has nevertheless made clear that a deeper analysis of political commitment is possible than simply the traditional statement that "it is important to have it.." That is, unfortunately, the argument that is normally provided by WHO/EURO, interviewees (see Chapter Four subsection 4.5.1), and health promotion researchers (see Chapter Three section 3.5). We have found that a distinction can be made along the lines of the nature of commitment. We distinguished tangible and symbolic commitment. Also a distinction can be made in terms of the level of commitment. We found city council wide and individual commitment.

It should be mentioned that health promotion and health education have a much longer familiarity and more experience with intersectoral collaboration and community participation than it does with political commitment. Pollitical commitment has a place within policy science and political science, fields which for a long time were virtually unknown by those working in public health. It may be that if intersectorality truly emerges in a significant way within health promotion, political and policy scientists will find a vocation within health promotion. In our opinion, this would be for the better. Health promotion is in great need of experience and knowledge in the policy sciences.

Other barriers that inhibited the work that was carried out on these key-concepts are mentioned in table 6.8 .

Interviewees in particular expressed their fears of projectism, non-institutionalization, and the presence merely of personal commitment in place of broader political support. This means that Healthy Cities is "doing some projects, [which is, MG] separate from ongoing policies and structures supported by enthusiastic individuals'. 


\section{Some Healthy Cities problems:}

- Mainstream (policies, organizations, actiwities) does not pick up the demo-project results; organizations do not own Healthy Cities.

- Healthy Citter has more influence on individual thinking than on organizational thinking/policy.

- Healthy Cities is not mature/powerful enough to influence policy-making.

- The ways Healy Cities is conceptualized and operationalized ("people talking nice to each other" - "an organization that runs projects') influence its possibilities.

- The stamp is on it, butt the drive is not behind.

- Polifical commitment is more often symbollic than tangible or it is lacking.

- There ing limifed insight how exactly public policy sectors influence health.

The fear expressed by Godlee (1995) that WHO overstresses their relationship with governments and neglects practitioners seems somewhat undeserved. As Healthy Cities practice shows that WHO (also) addresses practitioners. So far it are practitioners, and not government, who seem best capable to put these concepts into practice.

How do concepts look when they are put to work? The contribution of research like that reported upon in this thesis is that it shows that indeed different things occur under one and the same label. It makes therefore sense to ask the actors for their own subjective opinion in evaluating these activities. We have hopefully demonstrated clearly enough why it is only interesting to research whether or not something happens if at the same time the research also addresses the question why end how something happens. It has been shown in section 6.5 that there is still a gap between academic research and its use in Healthy Cities practice. Research of the Healthy Cities practice and evaluations by Healthy Cities practitioners is therefore valuable to researchers in refining and adapting their theories. 


\title{
Chapter \\ The meaning of Healthy Cities for policy development
}

\author{
Conclusions
}

\section{$\overline{7.1 \quad \text { Introduction }}$}

An important aim of Healthy Cities is to place or improve the position of health on the political and public agendas. In Chapters One, Two, and Three we have shown that this aim is justified on the basis of a number of identifiable assumptions and theories. In analysing the ten case studies, we have investigated the effects of involvement in Healthy Cities in terms of its role in making and improving the place for health on policy agendas. In Chapters Four, Five, and Six, we have shown what has happened in this regard, and have come up with some partial conclusions. But what is the overall conclusion? In other words, we might ask at this point what the meaning of Healthy Cities is for local (health) policy development. That is, what is the benefit of implementing the project at the local level from a policy perspective? Given the diversity which we have identified, it is a tricky task to draw an overall conclusion. Nevertheless, we will use this last chapter to expound upon the possibilities in that regard.

In theory. Healthy Cities is a very powerful concept because health is highly valued by the individual. There is generally a great deal of interest when there are issues at stake perceived as concerning threats to health (see Chapter Four for examples). Such concern demonstrates at least that health defined as the absence of serious pathology, a so-called "negative" concept of health "has mobilizing power. But from the empirical chapters it appears that it is more difficult to draw a similar conclusion about health as a "positive" concept.

It would be very legitimate to pose the question of whiether Healthy Cities indeed promotes the health of inhabitants of cities which adopt its strategies. Are such inhabitants healthier than those who are not living in a Healthy City? This is a question that is indeed very logical to ask, but which remains difficult to answer. First of all, like any other project based on health promotion ideas, it is expected that Healthy Cities will ultimately result in the realization of individual and community health gain. It is also expected that inequalities in health between individuals will decrease as a result of involvement in the project. Secondly, also the question of causality is at stake. When health is improved and damaged by a multitude of determinants, how would it be possible to assure that improvements in health status can be contributed to Healthy Cities activities and not to those of outside programs, economic growth, or any other concurrent change in the city? Thirdly, answering this question of whether Healthy Cities increases populational health status would require not only information about mortality and morbidity but also a discussion on relative changes in the quality of life of the population concemed. Furthermore, it would be necessary not only to have information at the population level, but also among. various sub-groups, especially with an eye toward disadvantaged populations "so that the question of greater equity could be considered. Fourthly, evaluating Healthy Cities only on the basis of traditional "health" indicators would be limited, as Healthy Cities aspires to improvement in areas beyond merely traditional measures of the absence of pathology: 
most notably, it aspires to improvement in community processes (see also Chapter Six, sub-section 6.2.2). Indeed, the question of measuring the overall impact of Healthy Cities efforts on populational health, though a tempting one, is as yet rather infeasible to answer concretely. It was partly for this reason that the research presented here limited itself to a more defined angle on Healthy Cities. Here, we have investigated the policy effects of Healthy Cities. So instead of using health criteria, we have used policy criteria to draw our overall conclusion.

In line with our original research question, theoretical assumptions, and Healthy City Project aims, we conclude with three observations which we regard as policy effect criteria of Healthy Cities. We discuss the policy effects of Healthy Cities in terms of: the type and level of policy development, the more specific consideration of the innovation Healthy Cities achieves in this regard, and, finally, whether Healthy Cities efforts leave a lasting impression in the communities within which they take place. It should be added, however, that every attempt at categorizing results does injustice to the tightly interwoven reality of practice. We therefore provide an overall, general finding on the policy effects of Healthy Cities. Nonetheless, it should be understood that the cities under study contributed to these generalizations through their combined strengths and weaknesses; thus, though we attempt to draw generalized conclusions, no single city and project embodied an ideal which the others failed to realize. Different combinations of success in terms of the three criteria are indeed possible, leading to different types of success for the cities and projects involved. Thus, for an individual case, though policy aspects of the process could be anam lyzed in the way presented here, the meaming of an evaluation should ultimately be interpreted based on the local situation itselff.

\section{$\overline{7.2 \quad \text { Type }}$ and level of policy development}

It seems that most individuals involved in Healthy Cities do not consciously realize that Heallhy Cities can have different meanings and play different roles from project to project, city to city. This is remarkable, if not only because such versatility was a key idea since the very start of the Programme (see Chapter One, sub-section 1.2.2). Nevertheless we analyzed these local differences at a more abstract level and found that there seem to be three policy functions of Healthy Cities resulting in three models. These models can be summarized by saying that, in different communities, Healthy Cities acts as the following:

1 The Health model. An inspiration source or framework for an innovative way to work on disease prevention and health promotion activities and policy.

2 The City madel. An inspiration source or framework for the integration of different municipal public policies and activities with the aim to promote health.

3 The Vision model. An inspiration source for the development of a city-wide future vision and integrated policy.

Inspiration source means, providing ideas how to move on and how to work in a certain area or an a certain subject. Framework means providing a structure, including some working mechanisms, to work in a certain area or an a certain subject.

In the first model, the policy function starts from a health problem or a disease. Healthy Cities is regarded as a useful and inspiring tool with which to work on health promotion and to implement disease prevention activities and policies. It is initiated by one sector, or by one organization, which is usually the Health Authority/GGD. Thereafter, an attempt is made to involve various sectors and communities. Furthermore, activities are mainly 
carried out on a project basis. Attempts are made to create and implement these projects based on local data, needs, and requests. During this entire process, efforts are made to catch the attention and to get the support of local government. In terms of the different meanings of health policy as indicated in Chapter Three section 3.6, this first option reflects very much the meaning of creating a health policy.

In the second model, Healthy Cities is used as a means to make people working in different sectors and at different levels realize that the decisions they make influence the activities of other organizations inside and outside their own sector. In this case, Healthy Cities makes decision-makers more aware of the idea that health can be damaged and created by decisions and actions in whatever sector. The promotion of individual health is thus realized not by directly targeting health problems at the individual or community level. Instead, health promotion takes place through policy-generated improvements of the environments where people live, work, and socialize. This option resembles very much the explanation in Chapter Three, section 3.6 , on creating beolthy public policy.

In the third model, the possible function of Healthy Cities in terms of policy development is rather abstract. Compared with the other two possible policy options, Healthy Cities is in this case not so much a means to stimulate, structure, or establish something. but rather a visionary goal in and of itself. In this case, policy-makers are inspired to think innovatively about the future developments in their city. It is based on the same roots as the second function of Healthy Cities described above. Namely, the basic idea is that decisions made at different levels in an organization influence the activities of other organizations within and outside the same sector. This implies, in essence, that traditional thinking along sectorial lines needs to be abandoned. We first identified this option from the first Healthy Cities booklet (WHO/EURO/HCPO, 1988a). We will label this policy process as creating a city-wide integrated policy.

In Chapter Two, section 2.7, we identified six focus points which we considered of relevance to analyze policy development processes in relation with Healthy Cities. We will now use these focus points as descriptors for the three models (see table 7.1). This list of six has been completed with some additional descriptors which we identified as relevant in the case studies.

What theoretical support can be given to those who want to use and research these Healthy Cities policy models? Supportive policy theories for all three models can be found in theories that fit with an interactive policy model (see Chapter Two, table 2.1).

Although the Health model can also be linked, or may even have a better fit, with more rational policy development approaches, such as the uni-centralized perspective. To be more specific the policy network approach can be used to research all three models, in terms of for example an analysis of the actors involved, their relationships, their strategies and goals, and the power they posses. The policy arena approach fits very much with the City model, were people from warious sectors negotiate about whether and how they should be involved in health activities. The policy stream model, fits with both the Vision model and the City model.

In terms of the three elements of the policy development process that we have researched the following can be mentioned on the three defined policy models.

Agenda building. The Agenda Building theory of Cobb and Elder (1983) can be used to analyze agenda building processes in both the Health model and City model. In particular when a rational approach toward policy development is used, or when the issues at stake are simple and uncomplicated the Agenda Building theory will appear to be useful in researching agenda building processes. The Policy Windows theory is very likely to be best capable of explaining the agenda status of issues in the Vision model and City model. That 
Table 7.1: Healthy Cities policy models and their descriptors.

\begin{tabular}{|c|c|c|c|}
\hline Modiall & $\begin{array}{l}\text { Model l: } \\
\text { Health model }\end{array}$ & $\begin{array}{l}\text { Model in: } \\
\text { City modsel }\end{array}$ & $\begin{array}{l}\text { Model wi: } \\
\text { Vision model }\end{array}$ \\
\hline Desicriptor & & & \\
\hline Aim & $\begin{array}{l}\text { The alm is fo promote } \\
\text { individuol and commumity } \\
\text { heolth ond to prewernt } \\
\text { diseoses. }\end{array}$ & $\begin{array}{l}\text { The aim is to put heolth on } \\
\text { the agendas of sectors } \\
\text { other than only the health } \\
\text { sectior. }\end{array}$ & $\begin{array}{l}\text { The oim is to promote the } \\
\text { heolth of the city as a } \\
\text { system. }\end{array}$ \\
\hline $\begin{array}{l}\text { Concepptualizerition of } \\
\text { Herelthy Cifiess }\end{array}$ & $\begin{array}{l}\text { An organization thot rurns } \\
\text { (health) projects; the } \\
\text { Health Authority/GGD. } \\
\text { Activities in the heolth } \\
\text { sector airmed at (individual } \\
\text { and public) health. }\end{array}$ & $\begin{array}{l}\text { Guidelines for infersectorid } \\
\text { colloborative wark. } \\
\text { A fromewronk for health } \\
\text { policy development. } \\
\text { Actiwities related to public } \\
\text { health. }\end{array}$ & $\begin{array}{l}\text { A tramework for city policy } \\
\text { development. } \\
\text { Guidelimes for intersectoral } \\
\text { calloboriatiwe work. } \\
\text { Activities not directly, or } \\
\text { not necessarily, related to } \\
\text { public theolth. }\end{array}$ \\
\hline Initiation & $\begin{array}{l}\text { Single sector initiated } \\
\text { (heolth sector). } \\
\text { The Healith Authority/GGD } \\
\text { (representutive) takes up o } \\
\text { mole as "socisl entreprenesu". }\end{array}$ & $\begin{array}{l}\text { Imitiated outside the heolith } \\
\text { sector (the heolth sector is } \\
\text { one of the partners). } \\
\text {. }\end{array}$ & Multi-sectoral ỉnitiotion. \\
\hline Support plalform & $\begin{array}{l}\text { Multi-sectoral involwement } \\
\text { and organizational commit- } \\
\text { ment for specific projectss. } \\
\text { In general individual come } \\
\text { mitment rather thom arganim } \\
\text { zattonal commitment. }\end{array}$ & $\begin{array}{l}\text { Multi-sectoral involvement, } \\
\text { ond both individual and } \\
\text { organizational commitment. }\end{array}$ & $\begin{array}{l}\text { Multi-sectorol involwement } \\
\text { and orgonizational } \\
\text { commitrent. }\end{array}$ \\
\hline Support styla & 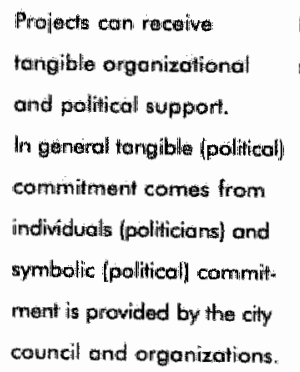 & $\begin{array}{l}\text { Both tongible and } \\
\text { symbolic commitment. }\end{array}$ & Tangible cormmitment. \\
\hline $\begin{array}{l}\text { Integration into } \\
\text { (axisting) structures }\end{array}$ & Mardly: project based. & $\begin{array}{l}\text { Organizational develop- } \\
\text { ment takes pllace; now } \\
\text { structures are put imto } \\
\text { place and/or old structu- } \\
\text { res ore adjusted. }\end{array}$ & $\begin{array}{l}\text { Supportive organizational } \\
\text { strumture, al operationol } \\
\text { and strategic level. } \\
\text { Vision is permanent part of } \\
\text { the political agendel. }\end{array}$ \\
\hline
\end{tabular}




\begin{tabular}{|c|c|c|c|}
\hline $\begin{array}{l}\text { Descriptor } \\
\text { V }\end{array}$ & $\begin{array}{l}\text { Model : } \\
\text { Health model }\end{array}$ & $\begin{array}{l}\text { Madel H: } \\
\text { Oifly model }\end{array}$ & $\begin{array}{l}\text { Atodel III: } \\
\text { Vision model }\end{array}$ \\
\hline $\begin{array}{l}\text { Integration of parndigm } \\
\text { I wistion development }\end{array}$ & $\begin{array}{l}\text { Projects are based on } \\
\text { issues of local interest. } \\
\text { Future wision development } \\
\text { hardly takes place, focus } \\
\text { remains an development } \\
\text { of short term strategies } \\
\text { and concrete activities. }\end{array}$ & $\begin{array}{l}\text { Vision dewelopmenit takes } \\
\text { place with regards to the } \\
\text { meaning of hewith in } \\
\text { different sectors. }\end{array}$ & $\begin{array}{l}\text { Future vision davelopment } \\
\text { tokes ploce on what o } \\
\text { heolthy city means. There: } \\
\text { is a balance between } \\
\text { future vision, strategies } \\
\text { and conere activities. }\end{array}$ \\
\hline $\begin{array}{l}\text { Evaluation of Healthy } \\
\text { Cities key-concepts }\end{array}$ & $\begin{array}{l}\text { Projects are used to } \\
\text { demonstrote (some) } \\
\text { Healthy Cities principles. }\end{array}$ & $\begin{array}{l}\text { Imtersectaral collaboration } \\
\text { and conmunity involves- } \\
\text { ment are put inta practice. } \\
\text { There is political } \\
\text { commitment. }\end{array}$ & $\begin{array}{l}\text { Intersectoral collaboration } \\
\text { and comminnity involvement } \\
\text { are put into practice. There } \\
\text { is political commitment. }\end{array}$ \\
\hline Time perspective & Short fermi. & Short term and long term. & Long term. \\
\hline Choices & $\begin{array}{l}\text { Progmatic: } \\
\text { non-fundamental. }\end{array}$ & $\begin{array}{l}\text { Progmaticic } \\
\text { small fundamental. }\end{array}$ & $\begin{array}{l}\text { Principal; } \\
\text { fundaimental. }\end{array}$ \\
\hline Changes & Minor. & Sonme. & $\begin{array}{l}\text { Mojor; fundamentiol. } \\
\text { Change and innovatiom } \\
\text { takes place when fulure } \\
\text { vision has been developed. }\end{array}$ \\
\hline
\end{tabular}

means in complex situations, with many actors, with their own ideas and strategies, the Policy Windows theory can be used to research agenda creation and agenda change.

Domain construction. In all three models actors from different sectors will be involved. The content of the activities in the Health model and City model relate to health promotion and disease prevention. It will be very likely that those actors with a tradition in public health and social service are involved in these activities. Other actors can be involved depending on their own interest and the arguments that are used to convince them to take part in such a health activity. In the Health model much can be still achieved if there is only individual commitment and involvement. But for both the Health and City model organizational and political commitment is needed for the creation and maintenance of a shared policy. In the Vision model organizational and political commitment and involvement at a high level is a prerequisite if policies and activities in the various sectors need to be geared to each other. This implies that the issues that are at stake in the Vision model are not directly or obviously related to public health, instead they are related to the health of the city as an organism. The theory of Laumann and Knoke (1987) can be used to analyze the domains in all three models in trying to understand what participation exactly means in a specific situation. In regards to structures can be mentioned that especially the 
Vision model cannot work when activities only take place at a short term project basis.

Key-concepts. Ideally seen in regards of community involvement (see Chapter Three, table 3,2) in all three models so called community development activities can take place. Though, given the experiences in the ten case studies, it is hard for community development activities to take place under the Health model. The so called 'community approach' is very likely to be supportive in the Health model and City model. We expect that so called community action is likely to be developed to a real extent in the Vision model. The way in which intersectoral collaboration is likely to be operationalized is in the form of networks or contacts (see Chapter three, tables 3.3 and 3.4) If, however, the objective is to achieve more long term or structural forms of collaboration, which is necessary in the Vision model and City model, but optional in the Health model, it is recommended to work in alliances. The implications for politicall commitment have already been addressed under 'domain construction'.

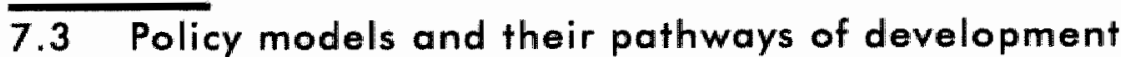

Choosing for one of the policy models as indicated above sets a path for Healthy Cities in a municipality. In figure 7.1 an attempt is made to illustrate patterns that we distinguish based on the three policy functions for Healthy Cities we have described. On the basis of the findings and conclusions as provided in Chapters Four, Five, and Six, it is also possible to concretize these patterns to specific situations, though such specifity would lay beyond the scope of this thesis. It must be mentioned that Healthy Cities can also be used for many other (pragmatic) reasons (see for example Chapter Four section 4.4) which may not necessarily result into one of the policy approaches as defined in figure 7.1.

We will explain the meaning of figure 7.1. A municipality gets involved in Healthy Cities because it is seen as a means of starting or enhancing efforts toward health in the city. There is at that very moment an ideal environment to begin focusing on health or on the development of the city's ability to address health from a multi-sectoral perspective (start). If initiators are interested in enhancing health directly, it is not unlikely that individual or community health promotion and disease prevention programmes are developed. However, as mentioned, it is also possible to focus on other aspects of community development in the name of Healthy Ciries. Namely, attention can be given to what the different sectors and organizations in the city can contribute to decrease a certain health problem or threat to health and to promote individual and community health.

A start from a perspective other than a strict "health perspective" implies that Healthy" Cities results in organizations from different sectors being made aware of the fact that their decision-making and activities influence public health. The other approach, an integrated policy approach, is based on the acknowledgement that consequences of decision-making go beyond organizational and sectorial borders. An awareness needs to be developed of such inter-organizational or -sectorial interaction in terms of the importance of a developed vision on the meaning of Healthy City in a specific locality for ultimately effecting change in the quality and disparity of resident health. Ultimately it is believed that having a city with sound systems will promote the health and wellbeing of its inhabitants.

The combined data from the case studies causes us to doubt that an evident "choice" is made for using Healthy Cities in one of the three indicated ways. Direct observation reveals that instead the function Healthy Cities taken on within a given community is steered by the circumstances. This leads one to the question of which municipal criteria would be 


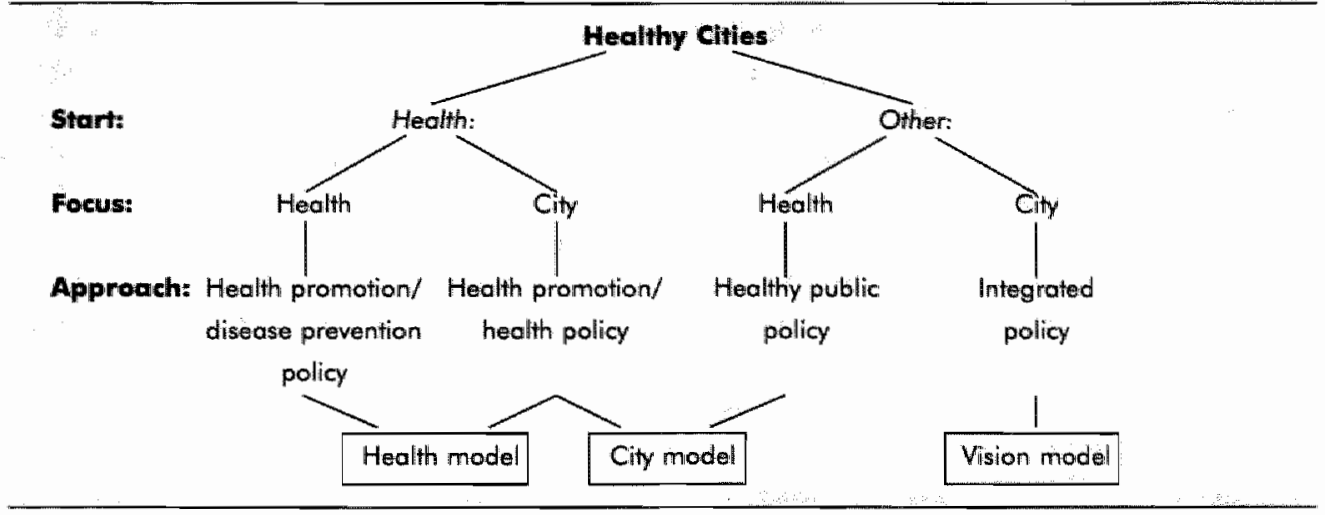

Figure 7. 1: Policy development patterns for Healthy Cities.

most important in predicting the type of Healthy Cities which emerges in any given community. According to our findings, the most important aspects that influence the use of a certain policy model are:

- the initial reasons for involvement. From Chapter Four (section 4.4) it appears that reasons for getting involved can be as various as local health problems. But also pragmatic reasons were mentioned, such as personall preferences or the possibilities offered through involvement in an international network.

- the actors who have been active in getting the city involved in the Project, including their professional responsibilities and duties. For example, if these actors are employed by the Health Authority/GGD it should not be seen as remarkable that Healthy Cities starts off as 'doing health projects' and is perceived as 'something from the Health Authority/GGD'. Furthermore, not just initially important figures, but also actors involved in the demonstration projects influence the direction Healthy Cities takes.

- the examples which are provided to those interested in Healthy Cities. The first activities in a "new' Healthy City will be in line with the examples that are available and provided in its environment. Therefore it can, for instance, start with a smoking cessation campaign based on Healthy Cities key concepts but also fit comfortably within an existing safety policy.

A last remark related to the discussion of the three policy models of Heallhy Cities is the comparison of the case studies at a national level. Our empirical chapters support our assumption that it is not so much national characteristics but local circumstances and characteristics (see Chapter Two) which are important in explaining variety in locall policy development. Nonetheless, there are some differences which seem best explained by pointing at influences unique to the United Kingdom and the Netherlands at the national level. Perhaps most important among those influences for our discussion here are the very different policy approaches in the two countries with respect to health promotion at the locall level.

The first policy model for Healthy Cities (Health model) can be found in both the Netherlands and the United Kingdom case studies. The content of the activities undertaken within this model, however, differs between the countries. From Chapter Five (section 5.3) it appears that in the United Kingdom case studies, to a larger extent than in the Netherlands, general issues such as economics (poverty), (poor) housing, liveability, inequalities, and community development receive attention from a Healthy Cilties perspective. Lifestyle and care activities, in contrast, are undertaken under a Healthy Cities label in both countries. It cannot be concluded that poverty issues, housing, or unemployment receive 
no attention in the Netherlands. In the Netherlands, these issues are simply not targeted through Healthy Cities. They are part of other programmes, such as the so-called "social: reriewal" programme or other types of urban redevelopment. And it is open to question whether in this present situation these activities and policies are discussed in terms of their future health consequences.

In the United Kingdom case studies only, the second policy model for Healthy Cities (City model) is starting to appear. We could not, however, find evidence of the third policy model for Healthy Cities in the ten case studies. It does not mean that such vision creation does not take place. But as yet, on the whole, in these ten case studies Healthy Cities has mot been used for long term city-wide policy dewelopment.

Two reasons for the existence of differences at the national level are legal responsibilities and examples that are provided to the Healthy Cities projects. First of all, local government in the Netherlands has a legal responsibility to work on disease prevention at the community level. Therefore, when they get involved in Healthy Cities, they almost automatically regard it as a framework or instrument for accomplishing this legal duty. Local government in the United Kingdom does not have this as their explicit responsibility.

Secondly, the examples that are available to new Healthy Cities initiatives by municipalities that are already involved in Healthy Cities in the Netherlands are (innovative) health promotion and disease prevention projects. Furthermore, through the project Healthy Public Policy, which is carried out by the Association of Dutch Municipalities (VNG). Healthy Cities is promoted as an inmovative method and means with inspiring concepts to work on disease prevention and health promotion activities and policy at a locill level. From Chapter Three it appears that this project, however, can best be described as the stimulation of a health policy rather than healthy public policy. In the United Kingdom we could not identify a project with similar aims, though this in itself shows how differing the available examples for action can be along national lines.

\subsection{Innovation}

In general Healthy Cities is hardly seen as an available framework for the eventual creation of Healthy Public Policy. This is not to say that it cannot be effective in this regards, however. None of the case studies started Healthy Cities based on the City model, but in three case studies a change was visible from health policy towards healthy public policy as the project matured. Healthy Cities is not used at all as a framework for integrating different public policies based on a city wide future vision. Politicians, for example, did not recognize Healthy Cities in such a way, because they had never realized that it could be used in that way. Furthermore, if they were indeed sympathetic towards intersectoral policy development, they were already using other frameworks to establish integration and to link policies to one another. For example, in the Netherlands the Large Cities policy [Grote Steden beleid, MG] or Rotterdam's Social Renewal, and in the United Kingdom a City Regeneration Alliance were mentioned as playing a comparable role to what was hoped for Healthy Cities. It must be mentioned, however, that unlike these more specific frameworks, Healthy Cities offers something unique: namely, despite its name, Healthy Cities offers a framework for all municipalities regardless of their size.

At first sight, therefore, one might conclude that what happens in Healthy Cities is not particularly innovative. In the case studies, Healthy Cities began in the interest of better public health, disease prevention, and health promotion activities. Healchy Cities as a tool 
or framework for working on health promotion actiwities and policy has been successful in gaining political and organizational interest. At the same time, it was mentioned that through the Healthy Cities projects and the inwolvement in a (inter)national network, it was more and more apparent that health is influenced by the different local government sectors and activities of organizations in a municipality.

We can explain why we detected mainly the Health model in the case studies. An important reason is that the people who are actively involved with Healthy Cities are representatives from the public health sector. Additionally, it is the policy model where the required change is least radical. In all case studies, some level of first order change was detected. In other words, we found minor adjustments in a city that do not change the core of its organizational structure or power structure. In the three case studies which changed their focus from health to the achievement of a health through structural alignment toward health, the cities concerned are working towards second order change, which means radical change involving a paradigmatic shift (Bartunek \& Moch, 1987; Levy \& Merry, 1985).

Furthermore, the Health model is the most easy to concretize into activities. The Healthy Cities policy process based on this model can start off with pragmatic thinking, creativity, persistence, and entrepreneurial skills. Working with projects are helpful in extending the scale and scope of activities. For example, they can play a role in creating political support and organizational support by finding health dimensions in issues that are already on their agendas ("hitch-hiking" see Chapter Four section 4.6 and sub-section 4.7.2). Through projects it is possible to show at short term notice concrete and visible results. From the empirical chapters, it appears that such results are needed to sustain momentum and political commitment. There is a danger, however, that the learning of projects is lost if there is no idea to what long term goal their cumulative results should contribute. This is the fear for so called "projectism". It is recommended in this respect to eventivally develop a long term vision and goal for health promotion policy.

The other two policy models we have identified are more difficult to concretize and demonstrate. This finding can be used to explain why the concrete results gained in the firsti policy model are used or even needed to start off discussions about the meaning of Heallthy Cities in terms of the other policy models which we identified. Interestingly, in the three cities that are using the City model to develop health policy, the evolution of their Healthy Cities efforts from a focus on health to a focus on healthy structures were an evaluation of the first five year involvement in the WHO Project (Liverpool); a responise to the results of a major community research which had been carried out (Sheffield), and the strong input of individualls involved, their personal skills, and their positions in the city networks (Glasgow). The direct reasons for using another policy model differ among these three case studies. But they all had a (political) climate that was ready for such a change (see Chapter Four sub-section 4.7.2), there were some years experience with Healthy Cities, they had the right people with entrepreneurial skills and people from various organizations showed (personal) interest.

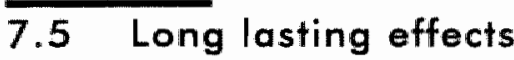

Regardless of the policy approach, basic changes in day-to-day operations are needed. As projects play an important role, we have to ask whether projects can be an exigine for change. Projects do not automatically result in policy nor is that often even the intention. A project is a fixed-term, one-time enterprise to test or generate knowledge and/or 
working mechanisms. What it can do, however, is facilitate policy-making processes. Not the practical outcome of one concrete project, but a cumulative process of consequences of a series of projects, seems to influence decision-making. For this reason, other factors than the theoretical effectiveness of a particular project are likely to play decisive roles. Such factors are vision, the personallities involved, commitment, political skills, the political agenda and ways and levels of communication. It appears that projects influenced attitudes and beliefs and facilitated the creation of 'supportive environments' for Healthy Cities. Additionally, they give Healthy Cities visibility, hands and feet, and can help put issues on the political agenda, or improve their status on that agenda.

Although much can be learned by cities participating in Healthy Cities from the demonstration projects of other cities, it must be realized that success stories cannot be simply replicated, assuming a first success is a guarantee for a second. Much depends on receptive contexts for change and on the people's own understanding, interpretation, and ideas. Pettigrew et al. have stressed that though conditioning of the local context, in terms of local perceptions and practices, is possible, it is also potentially transitory. "Receptive contexts for change can be constructed through processes of cumulative development but such processes are reversible, either by the removal of key individuals or ill considered or precipitous action." (Pettigrew et al. 1992 p. 276) And we have shown that currently Healthy Cities is very dependent on key individuals, the skills of a local coordinator, the support of a key politician or person in a key position of power within the local bureaucracy. Also, all projects seem to a certain extent vulnerable to temporary attention due to successful attachment of Healthy Cities to issues that are part of the immediate political agenda and/or important individuals. This attention fades away, however, as soon as the issue and/or person it is attached to are no longer priority (see Chapter Four).

We regard all cities which have been or still are involved in Healthy Cities as policy pioneers. Some of them will continue with Healthy Cities activities and policy devellopment even when the WHO Project has come to an end. Others will need a new powerful label in order to feel inspired enough to move further. Because the major strength of using the Healthy Cities label is initiating local health policy development and influencing people's thinking and acting accordingly. After some years this concept looses its power, and a new powerful label is needed to continue the activities that have been started under Healthy Cities. Still other cities will come to the conclusion that the value of Healthy Cities was not to be found in the possibilities it provided for the development of policy. It may be possible that these will get involved in another promising initiative for the same reasons they got inwolved in Healthy Cities.

We expect that only a few cities will ultimately use Healthy Cities in moving towards policy development that goes beyond the Health model, if only because of the fact that a requirement to develop intersectoral policy combined with the decentralization policy of national government puts pressures on locall govermment to act in a direction for which Healthy Cities provides an ideal model. These cities have to do more with less or the same resources. Creating a Healthy Public Policy or an integrated policy is initially a time-consuming process because it involves building up a new infrastructure supportive to heall th promotion and a critical mass of persons with a consciousness of the vision involved. Therefore it may be dependent on outside stimuli to provide a strong enough incentive to make the necessary investment worthwhile. Unfortunately, though the multi-facetedness of systemic health problems implies that many people get involved in tackling them, each individual or party generally favours one aspect of the process or goal. It is seldom that people are able to integrate or favour many aspects or that they have an overall vision. Consequently these aspects are treated as separate parts, which precludes, very understandable, a holistic and integrated policy (see also Schuyt, 1997b). 


\subsection{Innovations in a fuzzy domain}

Many would say that Healthy Cities is a modern idea, because of its strive for the reduction of inequalities in health and democratization which are core elements of modernity. Both politics and science have a prominent place in establishing this goal, two elements who have been described by Lyotard $((1984)$ in Davies \& Kelly, 1993 p. 165) as central to modernity. Kelly, Davies, and Bruce (1993), however, mention in that respect in terms of research Healthy Cities can best be explained as a modern problem. Meaning that when Healthy Cities stays within the conventional scientific research, it will not succeed in its mission and will be just one of the many attempts to work on delivery of health care. So what these authors suggest, and we agree with them on that aspect, is that if Healthy Cities is meant to achieve fundamental changes it needs supportive research based on ideas of post-modernity. Research questions are not obvious but are 'matters of cispute' (Kelly, Davies \& Bruce, 1993 p. 161) and are dependent on local values and practices. Valuable examples in this respect regarding policy research are provided by Abma (1996) and Guba and Lincoln (1989) (see also Chapter Six, section 6.2). Such research is incompatible with discipline-led (imperialized) science. The various disciplines which according to a social health model (see Chapter One, sub-section 1.5.1) can contribute towards an increased insight into the origins of health should instead be integrated. This means that in that respect often a seemingly rather eclectic choice of supporting theories are needed to conduct and support Healthy Cities research. In terms of the policy models that we have defined and described also in terms of supportive theories in section 7.2 "especially the Vision model and to a lesser extent also the City model would be in tune with such post-modern research approach.

Our own research is in fact an example of a modern research approach, we did a discipline-led, policy science, research. But at the same time our research method does not fit: exactly within the boundaries of modern research, because we did not use just one supportive theory. Instead we used (see Chapter Two) a variety of supportive theories to analyze, interpret, and discuss our research findings. Our research was also heavily steered by local influences and practices. And having done the research, we still find that we have used a very appropriate research framework. Indeed it did not provide on forehand very clear directions for the researcher. The direction was further developed while undertaking the research. But using an other, more directive and narrow research framework would not have provided so much insight as we have gained now. Moreover, we truly believe that policy is developed and re-developed in activities and because of interaction between people. The implication thereof is that these practices and people need to have an important voice in our scientific research and development or refinement of supportive theories.

Another comment we can make regarding our research method is on the research question. Research which is heavily influenced by practice needs to start of with a more general research question than we used. The research started with the following research question: 'In what way hus the WHO Healthy Cities Project, its ideas and principles contributed to the development of local health policy?' It appeared that this question is a much more complex question than it seems. Not only Healthy Cities but also health policy has different meanings. This implies that we have in one question two unstable variables. Furthermore, the Healthy Cities Project is based on many assumptions and concepts and there is also variety as to how these are dealt with in practice. Additionally, although standard elements of a Healthy Cities domain were indicated (see Chapter Five section 5.6), the specific boundaries in a municipality are being formed in situ, while activities are undertaken. Furthermore, there are many reasons for getting involved in Heallhy Cities (see Chapter Four section 4.4) and 
a similar variety is shown in the evaluation of working with Healthy Cities key-concepts in practice (Chapter Six, sections 6.3, 6.4, and 6.5). All these factors influence the concrete policy implications for Healthy Cities at local level. Still, in every empirical chapter we drew conclusions on the three policy aspects we investigated. And at a more abstract level we came, based on the conclusions of the empirical chapters, to the insight that there are possible functions for Healthy Cities in terms of policy development. Therefore the original research question could best be rephrased as 'What ore the (health) policy implications of Healthy Cities?'. The answers to this questions are provided in sections $7.2,7.3,7.4$, and 7.5 .

The way we used our research method and analyzed the case studies contributed to what Milio described (see Chapter Three, sub-section 3.6.3) to the development of a methodology and understanding in what Healthy Cities can contribute to health policy development: The research results show what Healthy Cities offers in ten case studies. They also reveal that regarding policy development Healthy Cities has various opportunities. This last finding may not be very innovative. Still we claim, first of all, that many involved in Healthy Cities do not realize that there is so to say a certain choice opportunity in using Healthy Cities for policy development. It is recognized and it has been demonstrated throughout the thesis that local and national environments dictate the role Healthy Cities can play. But exactly this finding also explains why it may be that people are hindered to reflect on possible other roles which can be played by Healthy Cities with regard to policy development. Secondly, we also question whether it is realized that although participants talk a similar language and work on similar principles in practice they do and point at different things. These differences within and between municipalities were demonstrated by researching the ten case studies.

WHO initially left open how Healthy Cities should be used in municipalities (WHO/EURO/HCPO, 1988a). But at the same time WHO steers cities through the Project requirements and filters the examples provided to cities. This is a dilemma. WHO receives from cities requests for information and examples. And yet at the same time the provided examples push the cities into a certain direction (see section 7.3), which reduces their autonomy and perhaps their creativity as well.

Milio (1990) mentioned that the power of Healthy Cities is (1) the provision of a grounded vision, (2) a policy laboratory, and (3) a political resource. Based on our research findings we have a few comments to make.

1. Healthy Cities can provide a grounded vision if it moves beyond projects. Projects are used to demonstrate how Healthy Cities can work and what can be achieved. However, the danger is not unlikely for Healthy Cities 'to suffer from projectism" (see also Chapter Five). To limit or avoid projectism:

- projects must be used as examples to test or demonstrate Healthy Cities principles;

project must be used to construct policy; or,

- working at a project basis must be a policy in itself.

If, however, projects are merely evidence of the absence of policy, there is a legitimate reason to fear that Healthy Cities will never move further than "putting some projects together'.

2. Is Healthy Cities a policy laboratory? Healthy Cities is indeed a laboratory for various health (related) projects . Successes of Healthy Cities projects result in projects, agenda building, and small changes in political, organizational and social fields. In 1989 de Leeuw concluded on the implementation possibilities of a policy based on ideas of a healthy public policy in the Netherlands, that this was partly feasible in the long run, but that there were few stimuli to really concretise the intentions (De Leeuw, 1989b). It is our conviction that even now some eight years later, the policy development that takes place is 
still far away from a healthy public policy. From this concluding Chapter (see previous sections) it appears that health policy development, and the way Healthy Cities is used to facilitate this process, is more limited than what is possible. Healthy Cities is mostly used to develop (new) disease prevention and health promotion activities and policies. So the resources of this policy laboratory are (yet) not used or discovered in practice. What is needed? We have indicated in our research several elements of which a very crucial element is: having social entrepreneurs or policy advocates who know how to relate projects to policy, who know how to manage and facilitate social change processes and network analysis.

3. It was observed in our research, and also recognized by Milio, that projects do not give long lasting benefits to a city. The major strength of Healthy Cities is that it can set things into motion. This is also a political resource, it can move health (temporarily) up on the political agenda (see Chapter Four). Healthy Cities has proven its political strength if, for example, a national policy supportive to Healthy Cities is developed. And in both countries Healthy Cities is supported by national governments by being mentioned in national government documents or by being supported as a project. At the same time real commitment is only proven if it is still available at times that the results of projects need time to mature, a process of social change is set into motion, and when visible results are no longer evident at short term notice.

Municipalities involved in Healthy Cities demonstrate that they are pioneers indeed and that others can learn from them. They search for and demonstrate possibilities for the renewal and overhauling of existing policy and for the creation of innovative policies supportive to health. But the policy possibilities of Healthy Cities have only been explored to a limited extent. The implications of Healthy Cities are to the largest extent demonstrated by action for disease prevention and on-the-ground health promotion action; in other words, Healthy Cities initiatives in the cases under study here remained primarily within the domain of what has been identified as the Health model. An attempt has been made to explain why this happens in this chapter. Incremental changes take place. But to prevent one incremental change from opposing or undoing the other, it is necessary that the actors involved, or at least local government, develop, share, and support an agreed upon vision. This vision can facilitate and guide the policy process and fixes the course for the subsequent development of Healthy Cities in the municipality. For Healthy Cities this is important because of the instability of its policy community, the change in and use of strategies and the consequences of working at a project basis. These instabilities do not matter as long as it is clear where the combined effort of the different strategies, activities and people is heading towards. Fundamental change processes, such as Healthy Cities is capable of bringing about, need time, vision, energy, and committed people at community, political, and organizational level. Though it cannot yet be concluded that Healthy Cities is a highly effective means for achieving healthy public policy, the process has perhaps just begun. And, to conclude with a quotation of Senge (1995): "You must not pull out a radish from the earth to see whether it grows." (p. 29). 


\section{Summary}

\section{Innovations in a Fuzzy Domain}

Healthy Cities and (Hiealfti) Policy Development

in the Netherlands and the United Kingdom

This thesis contains a research on the meaning, the perceived value, of Healthy Cities for local (health) policy development processes according to those involved in these processes. When we mention Healthy Cities, we mean all activities and initiatives which have been set in motion by the WHO Healthy Cities Project and those which are based on a similar ideology and principles.

\section{Healthy Cities and health policy in an urban setting}

In Chapter One the origins and ideas of the WHO Healthy Cities Project are presented. It provides the background to the inquiry. Healthy Cities is explained in terms of its stated ideas, requirements, purposes, and policy approach. A Healthy City is not a city with a certain health status. Instead it is a city that is committed to the goal of health for its citizens and is willing to work continuously toward that goal. The WHO Healthy Cities Project started in 1987 with a first eleven cities. In 1997, the WHO Project consists of 36 project cities located in 23 countries. Besides the official WHO Project cities which have organized themselves in an international network, also national Healthy Cities networks exist. This inquiry involves ten cities, participating in the WHO Healthy Cities project and/or in the national Healthy Cities networks of the Netherlands and the United Kingdom.

Healthy Cities was regarded by WHO as a way to implement local Health for All, an important WHO policy direction, efforts. The major aim of Health for All is to reduce health inequalities between people. With all its concepts and ideas Healthy Cities is meant to offer cities and their governments new and inspiring methods to work on Health for All and on health promotion at the local level. An important aim of the WHO Project and of national networks is to put health high on the political agenda and to develop local health policy. In this chapter appears that health policy is used to label different activities. We distinguish two approaches to health policy development. One approach begins from a health perspective. Central to this approach is the belief that health problems can only be addressed if contributions are made from different policy sectors. This approach is also known as intersectoral policy-making or facet-policy. A second approach starts from a sectoral perspective. Central to this second approach is that each policy sector should judge its actions, plans, and policies not only, for example, on economic aspects, but also on possible health consequences. This policy approach has come to be known as a Healthy Public Policy approach. Whether and how Healthy Cities works towards such intersectoral and/or healthy public policy development is a central question posed by the research presented here.

\section{Research Framework}

Chapter Two contains the research framework. First the research is located within the scope of academic research conducted thusfar in regards to Healthy Cities. What appeared is that Healthy Ciries policy research, or even local health policy research, is a field which has hardly been explored. Healthy Cities research covers many different forms of urban-related, health promotion-based research. Nonetheless, research explicitly aimed at local health policy development in Healthy Cities is scarce. The research framework was highly inspired by the assumptions and principles of health promotion and Healthy Cities on the one 
hand and literature reviews on policy science and the above mentioned research on the other hand. As our aim is to analyze and understand how local health policy is developed in Healthy Cities, we not only need to understand Healthy Cities, its principles and underlying assumptions. We also need a policy analysis approach which could be expected to be an enlightening tool in looking at processes of local health policy development. We found this in a pluri-centralized perspective policy approach. This approach sees policy-making as an interactive process of negotiation. The varying actors, all with unique goals and, more importantly, distinct value-systems, are linked together through a network of activities, decisions. (past) experiences, and motivations. This interpretative process, based primarily in dialogue at the local level, results in local differences in the process of outcomes of policy development. Chapters Four, Five and Six demonstrate quite clearly what this means.

The present research is a qualitative, multiple, explorative case study with descriptive and analytical, and some evaluative, components. This research has an intermational comparative component, as it involves cities from two different countries. This investigation supports the exchange of information in regards to the similar problem of deweloping Healthy Cities efforts and the institutionalization of those efforts in local health policy development. But is was hypothesized that it was no so much the national characteristics but local circumstances and practices which are important in predicting whether and how a local health policy will be developed.

The sample of ten cities has been selected by virtue of the cities" performance and visibility as Healthy Cities and the amount of time that the cities had dedicated to the initiative. Being involved in Healthy Cities, either in a national network and/or in the WHO Project, was seen as an indicator for willingness and efforts to develop health policy. Data have been derived from three information sources, namely key-informant interviews, participation and site visits, and secondary information sources.

\section{Rhetoricall strength and scientific evidence}

The Healthy Cities Project was developed on the basis of a number of key-concepts. Some of these concepts were quite new when the WHO Healthy Cities Project began, or were at least new in the way they were applied to the health sector. It was thus difficult for many people to grapple with how one could best work or implement them. Chapter Three contains an analysis of scientific research findings on some concepts central to the Healthy Cities Project. Attention is given to community involvement, intersectoral collaboration, political commitment, and healthy public policy. For those not familiar with bealth promotion rhetoric it provides more insight into the specific scientific meanings of given terms and their context. But what appears also is that in the years insight, knowledge, and experience has grown, as has the consideration of their scientific foundations. Writing this chapter gave us the opportunity for creative reflection on the research findings presented.

\section{Why Act?}

Reasons for cities to become involved in Healthy Cities and how this eventually establishes its position on the political agenda is subject of Chopter Four. The place and priority of an issue on the political agenda is an important factor in the policy-making process.

Theoretical support for this chapter comes from two agenda building theories which focus on the process side of agenda bulding. We use the Agenda Building theory, which is based on the question how to overcome barriers that prohibit an idea from becoming the subject of political debate and subsequent policy-making. This theory contains three madels. In the inside-initiative model it is not the general public but policy-makers within 
a governmental bureaucracy who put an issue on the institutional agenda. The mobilization model starts with policy proposals that are developed within government. In the outside-initiative model public attention and recognition through media are regarded as prerequisites for an issue to achieve agenda status. The other theory is the Policy Windows theory, which is based on the question why it is that certain issues and solutions receive politicall attertion and others not. Three so-called streams are distinguished which influence the agenda setting process in federal government: politics, problems and policies. Issues can reach, or increase in, decision agenda status by coupling these three processes. So for an issue to receive decision (specific, high priority) agenda status it has to be recognized as a problem, opportunity or threat, there has to be a solution available, and the political climate has to be ready for a change. In all other situations the issue will not receive agenda status or a it can reach, general, low priority, governmental agenda status.

In terms of both these theories it can be concluded that the political agenda status of Healthy Cities is low: If Healthy Cities is part of the decision agenda, it is because of personall efforts and/or due to successful hitch-hiking. Hitch-hiking means in this case attaching Heallhy Cities to powerful persons and/or to issues that are already part, or very likely to become part, of the political agenda. Reasons for getting inwolved in Healthy Cities in the first place can often be explained by personal, pragmatic, policy and structure reasons. Healthy Cities conceptualization (how it looks like), political support, experience and knowledge of health policy development, personal and organizational commitment to the Project's ideas and goals and the way this is visualized, and the perceived relevance of the Project are important determinants in the Healthy Cities agenda building process. (Re) conceptualization through a process of softening up (Policy Windows theory) or issue manipulation and issues expansion (Agenda Building theory) is at the core of Healthy Cities agenda building practice. This means that even if localities are comparable, it is likely that the way Healthy Cities is put into practice, is defined, operationalized, and organized will show differences. Variation in the mixture of these elements causes differences in appearance and agenda status of Healthy Cities. Therefore, although the Agenda Building Theory mobilization model will suit particular agenda building processes in some of the cities, overall the Policy Windows theory has a better fit with the agenda building practice as obserwed in this study

\section{The Fuzzy Domain}

In Chopter Five an effort has been made to show the domain compositions, in other words, to describe what activities take place within which structures, and who is involved. The importance of having this insight is that in policy development and evaluation, it is critical to have a broad overview of activities, structures, and involved or otherwise relevant actors. The WHO has requirements for the narure of activities a project city must carry out. It appears that the activities that are undertaken in the case studies are generally aimed to fulfil these requirements. The domain based on activities in both countries covers all public policy sectors except for city planning, general affairs, and public affairs. The content of the activities in all ten case studies centres very much around public health (lifestyle) and social welfare issues and to a lesser extent around traffic (public transport) and public safety.

WHO also formulated requirements in regards to structure and organization of Healthy Cities (projects) as a whole. The two ways to organize Healthy Cities that we identified are: establishing new structures and using existing structures. Moreover Healthy Cities as part of both new and existing support structures can operate either separate from or integrated within other local structures. There is a tendency of Healthy Cities to move from mere project status toward greater integration with existing policy structures. At the same 
time this process appears to be difficult, long term, and is hindered by several barriers. An analysis of the identified structures and activities resulted in the identification of the Healthy Cities actors. We distinguished core and peripheral actors. These actors most of the times represent organizations but they are unequal in the amount of formal (decision. making) authority the posses. This last finding has consequences for policy-making and decision-making processes. The policy process is not only influenced by that aspect, but also by the fact that they can take up different roles within the policy-making process. Creating domains based on activities, structures, and actors results in different compositions. But there are some elements that can be identified as standard to whatever Healthy Cities domain in whatever case study in whatever country. But at the same time; these standard elements are so general that they are not very informative. Case study domains contain some of the standard elements, but the specific domain composition, the core and peripheral actors and the roles they play, changes over time and may even differ between activities. It is therefore only possible to show Healthy City domains and to compare them by freezing them at a particular moment in time. The boundaries of the domain are not fixed. Health policy research, therefore, cannot start with a definition of the Healthy Cities domain which sets the boundaries of such a domain beforehand. What exactly constitutes this domain in any given city must be constructed based on an interpretation of (and participation in) the available structures, the activities, the involvement and ideas of actors. The findings and conclusions of this chapter nonetheless do provide some guidance and points of attention for domain construction.

\section{Pathways of Development}

In Chapters One and Three some of the major Healthy Cities concepts have been explained in theory. Chapter Six addresses their evaluation. How have these key-concepts of Healthy Cities been put into the local practice in any of all of the cities under study, and why have these concepts been more successfully implemented in one particular urban environment than in another? The definition of 'success' was mainly left to the interviewees. We have used a process evaluation, the pathways of development which are used when working on (intermediate) output, and to a lesser extent the evaluation results focus also on intermediate output itself. We do not address the question of whether or not goals are achieved. We are also not interested in finding out whether or not certain activities that happen in Healthy Cities are so called "proxies" for future health outcomes. We leave that discussion for another forum. We instead try to provide insight into what happened (process and output) and how this is evaluated from the participant's point of view. Anything mentioned on the relation between the evaluated key-concepts and Healthy Cities represents the perceived contribution and the perceived benefit as mentioned by those involved in Healthy Cities. This is the critical factor, it is argued here. For it is this perceived vallue that has a large influence over whether a project or policy is going to succeed.

In Chapter Three we listed the main Healthy Cities key-concepts which are all used and/or known in the case studies. We divided these concepts into three process categories which represent the types of activities which take place in Healthy Cities: social processes, organizational processes, and political processes. In each process one key-concept is highlighted. Concretely, it means that the evaluation results of community involvement (social), intersectoral collaboration (organizational), and political commitment (political) are presented.

In the case studies, three main approaches were used under the banner of community involvement: community consultation, community participation, and community development. Interviewees mentioned as reasons for community participation in activities and 
planning, and for working with community approaches: to increase "client" satisfaction, to increase efficiency (the fit between (community) service demand and service provision), and to reach those groups which easily slip through the sieve of the traditional health service web. The major form of work on community participation as it appears from the case studies is community (development) projects with (short-term) financial support. The reasons for choosing projects and how these are valued may be explained from four perspectives: experience, expectations, support, and pragmatism. The largest contribution of Healthy Cities is that it raises awareness for community inwolvement. Compared with theory, community involvement in Healthy Cities reflects a mich more traditional topdown health education model than it does a radical reorganization of community organization and resources. Several reasons are given to explain this finding.

From the research findings, it appears that within a Healthy Cities context, meetings and projects are the two major ways in which intersectoral collaboration is operationalized. Here, intersectorality would be defined as meetings and projects with representatives of organizations, groups, or services in two or more sectors. The perceived contributions of Healthy Cities to intersectoral collaboration both at the operational and strategic levels are: it provides a network, it promotes changes in structures, it promotes changes in resource distribution, it promotes changes in hiring new staff and formulating their tasks, it promotes change in understanding determinants of health, and it promotes collaboration. Much collaboration, it might be asserted, would have happened anyway, without the presence of Healthy Cities, as a logical consequence of existing policy, developments, activities, and general trends. But it is certain that without Healthy Cities, some people would. never have met, and some key-relationship, thus, never have begun. Furthermore, they would indeed not have been likely to have thought about how their work and ideas would relate to the health of the city. With regard to intersectoral collaboration theories two observations were made. First of all, collaboration between in individuals, representing organizations, can easily be confused with collaboration between organizations. In fact, the meaning of a collaboration effort needs to be investigated before it is really known what kind of collaboration it represents. Secondly, it appeared that the checklists for intersectoral collaboration lack the criteria which shadow the arguments provided by those who are not eager to get involved in a collaborative health project or strategy. What they show is that the discussion health professionals have with each other is often not readily accessible to those who are traditionally or normally not involved in health-related research and its debates. Provision of attention to this aspect and to the primary goals and interests of groups and organization is needed to attract the attention and interest of these new partners in local health policy development.

Healthy Cities benefits to a great degree from political commitment, when it is present. However, the actual support given is more often symbolic than tangible. And in those cases where it is indeed tangible, it remains questionable how sustainable that support is. Support appears often to be the result of individual commitment by a local actor. It may not be a surprise that the position of public health seems to be weak within the public policy arena. This is due not only to the fact that differences exist with regards to the interpretation of the (formal) responsibilities of public health departments and to the practical consequences attached to them. It is also true that public health, compared with other public policy sectors, does not account for a large portion of the generation or dedication of the wealth in most municipal budgets. Healthy Cities nonetheless has succeeded in achieving certain political support for health related objectives. Healthy Cities played an important role in increasing an understanding of what creates health. It is seen to have stimulated politicians to reflect on their roles with regards to the maintenance and creation 
of public health. Healthy Cities has generated attention for a 'health agenda' by stimulating activities and providing evidence for the potential inherent in its own models of health promotion through demonstration projects. In some case studies it has stimulated changes in the local structures that are put in place to facilitate health promotion. There are a number of criteria which seem to indicate whether Healthy Cities is perceived as powerful enough to influence decision-making and policy. For example, the understanding of how local politics works an how to play the pollitical game are important factors that influence whether or not Healthy Cities is able to have a say in city council decision-making. Our research has made clear that a deeper analysis of political commitment is possible than simply the traditional statement that 'it is important to have it'. We have found that a distinction can be made along the lines of the nature of commitment. And also a distinction can be made in terms of the level of commitment.

As important Healthy Cities (perceived) successes are mentioned: the facilitation of meetings and activities that focus on health promotion, it speeded up processes, it has put health on the political and social agendas, it stimulated establishment of relationships between organizations, it legitimizes health promotion activities, it facilitates the efforts to attract resources for collaborative projects, it brings along skilled persons, it gives proof of evidence that the Health for All strategy can be put into practice. A major strength of Healthy Cities is that this concept can set people and things into motion. The power of the concept may however decrease during the years. Interviewees expressed their fears of projectism ('doing projects'), non-institutionallization, and the presence merely of personal commitment in place of broader political support.

\section{The meaning of Healthy Cities for policy development}

And finally in Chapter Seven an effort is made to draw based no these partial conclusions an overall conclusion with regard to our research question. We conclude with three observations which we regard the policy effect criteria of Healthy Cities: the type and level of policy development, the more specific consideration of innovation Healthy Cities achieves in this regard, and, finally, whether Healthy Cities efforts leave a lasting impression in the communities within which they take place. It should be understood, however, that no single city and project embodied an ideal which the others failed to realize.

We identified three policy models for Healthy Cities. In the Health model Healthy Cities is used as a framework and inspiration source for an innovative way to work on disease prevention and health promotion activities and policy. In the City model Healthy Cities is used as a framework and inspiration source to integrate health on the agendas of different (public) policy sectors and organizations. In the Vision model Healthy Cities is used as an inspiration source to develop a city-wide future vision and integrated policy for the city. It views the city as an organism, and through Healthy Cities a vision development takes place that assures that the different sub-systerms that interact are both "healthy" in themselves as well as in relation to each other. These policy models have their own paths of development and descriptors. They all can be supported with theories that are linked with an interactive way of policy development. The case studies illustrate that policy is being created, but the case studies differ in how consciously there is tried to guide this development towards a developed vision. So there is variation in the role that is played by Healthy Cities in this respect. Only the Health model can also be supported by more rationally based theories. The reason that the Health model and City model are used in practice and the Vision model not, can be explained by the degree of change that is required, the actors that are involved, the initial reasons for involvement, and the examples that are provided to cities. 
In general terms of research and theoretical support, we conclude that when Heallthy Cities moves away from direct health activities, so when it is used according to the City model and Vision model, it also moves away from traditional research and fits closer with postmodern research ideas.

Municipalities involved in Healthy Cities demonstrate that they are pioneers indeed and that others can learn from them. But the policy possibilities of Healthy Cities have only been explored to a limited extent. The implications of Healthy Cities are to the largest extent demonstrated by action for disease prevention and on-the-ground health promotion action. More fundamental change processes, such as Healthy Cities is capable of bringing about, need time, vision, energy, and committed people at community, political, and organizational level. These processes have perhaps just begun. And therefor, to conclude with a quotation of Senge (1995): "You must not pull out a radish from the earth to see whether it grows." (p.29). 


\title{
Samenvatting
}

\author{
Innovations in a Fuzzy Domain \\ Healthy Cities and (Health) Palicy Development \\ in the Netherlands and the United Kingdom
}

Dit proefschrift doet verslag van een onderzoek naar de betekenis, de gepercipieerde waarde, die betrokkenen toekenmen aan Healthy Cities voor de ontwikkeling van lokaal (gezondheids) beleid. In dit proefschrift is "Healthy Cities" alle activiteiten en initiatieven geinitieerd door het Healthy Cities Project van de Wereld Gezond-heidsorganisatie (WHO) en/of gestoeld op dezelfde ideologieën en principes.

\section{Healthy Cities and health policy in an urban setting}

In Hoofdstuk Een wordt uitgelegd waar het Healthy Cities idee zijn oorsprong in vindt en wat precies de achterliggende ideeën, doelstellingen, beleidsopvatting en verplichtingen zijn. Het is niet zo dat een Healthy City voldoet aan een bepaalde gezondheidsstandaard. Een Healthy City is een stad die werkt aan gezondheidsbevordering van haar inwoners. Het WHO Project startte in 1987 met elf steden. In 1997 is dit aantal uitgegroeid tot 36 project steden verspreid over 23 landen. Naast het officiele WHO project zijn er ook nog nationale netwerken van Healthy Cities. Het onderzoek is uitgevoerd in tien steden die deelnemen in het WHO Healthy Cities Project en/of in de nationale Healthy Cities netwerken in Nederland en het Verenigd Koninkrijk.

Healthy Cities wordt door de WHO gezien als een manier om haar Health for All strategie op een vernieuwende manier op het lokale niveau te concretiseren en implementeren. Health for All is de beleidsstrategie van de WHO waarin zij streeft naar vermindering van gezondheidsverschillen. Een van de doelstellingen van het Project is dan ook om gezondheid hoog op de politieke en sociale agenda"s te plaatsen en een lokaal gezondheidsbeleid te ontwikkelen. Maar wat is lokaal gezondheidsbeleid? Daar lopen de meningen over uiteen. Dit proefschrift onderscheidt twee benaderingen. De eerste benadering start vanuit een gezondheidsperspectief. Een belangrijk kenmerk van deze benadering is dat de oplossing van gezondheidsproblemen geschiedt door bijdragen vanuit verschillende sectoren. Deze benadering noemt men ook wel facet-beleid. De tweede benadering start vanuit een sectorperspectief. Een belangrijk kenmerk van deze benadering is dat alle beleidssectoren hun beleid en beslissingen beoordelen op consequenties woor (volks)gezondheid. Deze benadering wordt een healthy public policy [gezond openbaar beleid, MG] genoemd. De vraag is welke bijdrage Healthy Cities levert aan dergelijke (facet en/of gezond openbaar) beleidsontwikkeling.

\section{Research Framework}

Hoofdstuk Twee bevat het onderzoeksraamwerk. Het geeft een overzicht van onderzoek dat met betrekking tot Healthy Cities plaats vindt. Het blijkt echter dat er nog veel te ontdekken valt. Met name beleidsonderzoek op dit onderwerp windt nauwelijks plaats. Op basis van het getraceerde onderzoek, de veronderstellingen die aan Healthy Cities ten grondslag liggen, en beleidstheorieën, werd een raamwerk geconstrueerd om het onderzoek in banen te leiden. Het gekozen analyse-instrument is gevonden in de zogenaamde interactieve beleidsbenadering. Deze beleidsbenadering ziet beleidsontwikkeling als een proces van interactie en onderhandeling tussen meerdere actoren, met verschillende ideeèn, strategieèn, ervaringen, etcetera. Dit uitgangspunt verklaart tevens het feit dat lokale verschillen ontstaan in beleidsontwikkeling. Het onderzoek kan omschneven worden als reen meervou- 
dige-exploratieve-case-study met beschrijvende, analytische en evaluatieve componenten. Het onderzoek heeft ook een international vergelijkende component. Echter de stelling is dat alhoewel nationale karakteristieken de rol van Healthy Cities beïnvloeden, het de lokale karakteristieken zijn die uiteindelijk tekenen voor de totstandkoming van beleid.

De tien steden zijn geselecteerd op basis van hun zichtbaarheid, activiteiten en ervaring als Healthy City. Data zijn afkomstig van sleutelfigureninterviews " participatie in activiteiten, bezoeken op lokatie; en secundaire informatiebronnen (zoals rapporten en notulen).

\section{Rhotorical strength and scientific evidence}

Healthy Cities is omgeven van een heleboel sleutelbegrippen die een centrale rol spelen. In Hoofdstuk Drie worden een aantal van die sleutelbegrippen nader uitgelegd en wordt gekeken wat er bekend is in termen van wetenschappelijk onderzoek. De begrippen 'community involvement", "intersectoral collaboration", "political commitment" en "healthy public policy', passeren de revue. Het schrijven van dit hoofdstuk biedt de mogelijkheid om de bevindingen uit Hoofdstuk Zes, waarin direct betrokkenen bij Healthy Cities dezelfde begrippen evalueren, te koppelen aan de bevindingen uit wetenschappelijk onderzoek en theorieën.

\section{Why Act?}

In Hoofdstuk Vier is de hoofdvraag "waarom zou je deelnemen aan Healthy Cities?". En betekent deelname an Healthy Cities ook dat dit onderwerp een plek veroverd op de politieke agenda? Immers de plek en de prioriteit die een onderwerp heeft op de politieke agenda speelt een belangrijke rol bij beleidsontwikkeling. Twee verschillende agendabouw theorieën worden gebruikt om de casussen op dit aspect te analyseren, de Agendabouw theorie en de Policy Windows theorie. De eerste theorie richt zich op beantwoording van de vraag hoe barrières genomen kunnen worden die belemmerend werken bij het verkrijgen van politieke aandacht voor een 'goed idee'. De tweede theorie richt zich op beantwoording van de vraag waarom sommige onderwerpen en oplossingen politieke aandacht krijgen en waarom dus de politieke agenda verandert. Om deze vraag te beantwoorden wordt beleidsworming gevisualiseerd als drie stromen: beleid en ideeën, politiek en problemen. Bij een koppeling van deze drie stromen wordt een 'vuilnisvat' oftewel arena gecreëerd waarin de actoren uit deze drie stromen met elkaar zullen onderhandelen.

De redenen voor interesse en deelname aam Healthy Cities is divers, bijwoorbeeld persoonlijke redenen, pragmatische redenen of actuele beleidsontwikkelingen. Voor wat betreft de agendastatus van Healthy Cities kan op basis van beide theorieën worden geconcludeerd dat deze laag is. Met name de Policy Windows theorie verklaart het proces van agendabouw in Healthy Cities tot in detail. Persoonlijke betrokkenheid en het meeliften met onderwerpen die hoge politieke prioriteit hebben, kunnen (tijdelijk) de agendastatus van Healthy Cities verhogen. Belangrijke factoren die een rol spelen in dit verhaal zijn: operationalisatie, politieke betrokkenheid, kennis en ervaring op het terrein van volksgezondheidsbeleid, en individuele en organisationele betrokkenheid. Via allerleil wegen tracht een kleine groep, en zogenaamde social entrepreneurs in het bijzonder, mensen en organisaties 'warm' te maken voor Healthy Cities. Dat proces wordt 'softening up the system" genoemd.

\section{The Fuzry Domain}

Een constructie van het beleidsdomein is onderwerp van Hoofdstuk Vijf. Op drie manieren, een analyse van deelnemers, activiteiten en structuren wordt een poging ondernomen om dit domein zichtbaar en inzichtelijk te maken. Wanneer naar activiteiten wordt gekeken, 
dekt het domein alle belleidsterreinen behalve stadsplanining, algemene zaken en openbare zaken. Activiteiten liggen met name op het terrein van openbare volksgezondheid en individueel gedrag en sociale- en welzijnszaken en in geringere mate ook op het gebied van verkeer (veiligheid en vervoer). Het verankeren van Healthy Cities gebeurde via nieuwe structuren of integratie in bestaande structuren. De tendens is om te starten met (demonstratie) projecten los van het bestaande, om vervolgens aan de hand van de aldus verkregen resultaten een grotere plek te claimen voor dergelijke initiatieven. Het projectmatig werken kan echter ook de institutionalisatie van Healthy Cities bemoeilijken, zodat Healthy Cities niet verder zal komen dan "een organisatie die aardige projecten doet". Dus de vraag hoe vam projecten naar beleid en/of hoe projecten een rol te laten spelen in beleid is een belangrijke vraag die deelnemers zich (zouden moeten) stellen.

De actoren zijn ingedeeld in een kerngroep en een perifere groep. Alle actoren vertew genwoordigen meestentijds organisaties, maar bij samenwerking blijkt vaak dat de machisverdeling en de status van deze vertegenwoordigers niet gelijk is. Sommige mensen nemen deel op persoonlijke titel (de organisatie weet van niks) terwijl anderen deelnemen met een mandaat van de organisatie. Met name in beslissingsprocessen levert dit problemen op. Ook voor analyse van samenwerkingsverbanden is dit een punt van aandacht, wat is de betekenis van participatie van een bepaalde organisatie?

Deze domeinconstructie heeft duidelijk gemaakt dat het domein "fuzzy" is, het is moeilijk om er grip op krijgen. Het is alleen zichtbaar te maken door de situatie op een bepaald moment als het ware te bevriezen. Echter, het hoofdstuk geeft wel een aantal kern-elementen van zo'n domein en geeft handvatten voor domeinanalyse en -vaststelling.

\section{Pathways of Development}

In Hoofdstuk Zes geven deelnemers aan lokale beleidsontwikkeling en Healthy Cities hun mening over een aantal centrale begrippen. Hoe worden deze begrippen in praktijk gebruikt en wat is de gepercipieerde waarde in het beleidsproces? Deze evaluatie is een proces-evaluatie. Het laat de wegen zien die worden bewandelt bij het werken aan intermediaire output en in zekere zin levert de evaluatie ook informatie over deze intermediair output zelf. Het behalen van de door de WHO gestelde doelen en het behalen (of niet) vam een bepaalde gezondheidsstatus zijn geen onderdeel van deze evaluatie.

Alle Healthy Cities sleutelbegrippen zijn in drie categorieën verdeeld: sociale processien, organisationale processen, en politieke processen. Uit iedere categorie is een begrip voor: evaluatie geselecteerd: betrokkenheid van de bevolking, intersectorale samenwerking en politieke betrokkenheid.

Met betrekking tot betrokkenheid van de bevolking bij Healthy Cities (activiteiten) werden de volgende drie vormen getraceerd. consultatie, deelname en ontwikkeling van persoonlijk vaardigheden. De vorm waarin participatie gestalte krijgt is projecten. Het werken op projectbasis kan ondermeer worden verklaard door de ervaringen dje men heeft met betrekking tot samenwerking tussen professionals en bijvoorbeeld mensen uit een bepaalde wijk maar ook door de verwachtingen die zowel bij de bevolking als bij de overheid en organisaties leven ten aanzien valn bottom-up ontwikkelen van activiteiten. In elk geval sllagt Healthy Cities erin om bottom-up ontwikkeling van beleid en activiteiten te stimuleren. Al moet worden geconstateerd dat er geen sprake is van een radicale reorganisatie in de zin dat de stem van de bevolking daadwerkelijk de richting bepaald. In praktijk overheerst (nog steeds) de top-down benadering.

Intersectorale samenwerking betekent binnen Healthy Cities vergaderingen, bijeenkomsten en projecten. Er kan niet worden gezegd dat deze samenwerking niet plaats zou vinden als een gemeente niet betrokken zou zijn bij Healthy Cities. Wat well opvalt is dat 
zonder Healthy Cities een antal organisaties en mensen elkar nooit hadden ontmoet en derhalve zouden sommige vormen van samenwerking niet hebben bestaan. Deze samenwerkingsvormen stimuleerden op hun beurt ook weer dat organisaties gingen nadenken over hoe hun werkzaamheden en beslissingen relateerden aan gezondheid. En dus ook welke rol ze zouden kunnen spelen ten aanzien van gezondheidsbevorderende activiteiten binnen hun gemeente. Een belangrijke bevinding was dat samenwerking op individueel niveau erg gemakkelijk verward wordt met interorganisationele samenwerking. Echter, een nadere analyse van samenwerkingsvormen is noodzakelijk allworens een uitspraak te doen over de betekenis van de samenwerkingsrelaties. Daarnaast vallt op dat veel checklists voor intersectorale samenwerking met name uitgaan van de voorstanders van samenwerking. Zulke Lijsten zouden aan kracht winnen wanneer ze ook argumenten en criteria bevatten. vanuit het perspectief van de organisaties die geen heil zien in samenwerking. In elk geval lijken degenen die een traditie hebben in de gezondheidssector te vergeten dat hun ideeen en discussies zeer moeilijk toegankelijk zijn woor degenen die deze traditie niet hebben.

Healthy Cities krijgt politieke ondersteuning, maar deze ondersteuning is in grote mate afhankelijk van individuen en de wijze waarop Healthy Cities is geoperationaliseerd. De positie van volksgezondheid in de politieke arena is zwak. Dit heeft te maken met traditie maar ook met het feit dat in deze sector geen spectaculaire bedragen omgaan. Maar ook hier bleek het geval dat dankzij Healthy Cities ook op het politiek vlak lessen zijn geleerd over de mogelijke rollen die een gemeentelijke overheid kan spelen ten aanzien van bevordering wan de volksgezondheid. Met name dat gezondheidsbevordering kan plaatsvinden vanuit meerdere lokale overheidssectoren was voor vele politici een eye-opener. Het bleek dat mensen die inhoudelijk betrokken zijn bij Healthy Cities weinig begrip hebben van het lokalle politieke systeem en het zogenaamde politieke spel. Het zijn meestentijds geen onderdelen geweest van hun (wetenschappelijke) opleiding. Het verdient derhalve aanbeveling om tijdens bijvoorbeeld een opleiding tot gezondheidsvoorlichter ook aandacht te schenken aan beleidswetenschap of bestuurskunde.

Met betrekking tot onderzoek op het terrein van gezondheidsbeleid en gezondheidsbevordering wordt ten aanzien van politieke ondersteuning zelden een verdergaande conclusie gedaan dan te constateren dat het belangrijk is. De bijdrage van dit onderzoek is dat het een onderscheid aanbrengt zowel in de aard als in de mate van ondersteuning.

Wat als meest belangrijke bijdrage van. Healthy Cities wordt ervaren is: de facilitering van bijeenkomsten en activiteiten ten aanzien van gezondheidsbevordering, het versnellen van processen, het onder de aandacht brengen van wat de beleidsconsequenties zijn van een positiewe benadering van gezondheid, het brengt mensen met zich mee met bepaalde capaciteiten en kwaliteiten en het vergemakkelijkt de aanvraag van financiële middelen voor internationale projecten. Met andere woorden Healthy Cities is uicermate geschikt als middel om het maken wan gezondheidsbeleid en gezondheidsbevonderende activiteiten in gang te zetten. Het kan dit proces als het ware een krachtige zet te geven. Deze kracht en inspirerende werking wordt echter minder gedurende de jaren.

\section{The meaning of Healthy Cities for policy development}

In Hoofdstuk Zeven tenslotte wordt getracht een conclusie te trekken met betrekking tot de hoofdvraag van het onderzoek: wat is de betekenis van Healthy Cities voor de ontwikkeling var lokaal (gezondheids) beleid? De conclusie is onderverdeeld in drie aspecten die worden beschouwd als beleidseffectcriteria: soort en mate van beleidsontwilkkeling, de mate van vernieuwing, en de beklijving. Maar er wordt ook opgemerkt dat geen enkele gemeente noch project ideaal-typen zijn. Hoe dan ook zijn drie beleidsmodellen opgesteld voor de beleidsrol van Healthy Cities gebaseerd op de bevindingen uit ons onderzoek. In 
het Gezondheidmodel is Healthy Cities een ramwerk en inspiratiebron om op een vermieuwende manier te werken aan ziekteprewentie en gezondheidsbevorderende activiteiten en -beleid. In het Stadmodel is Healthy Cities een raamwerk en inspiratiebron om gezondheid te integreren op de agenda"s van verschillende beleidsterreinen en organisaties. In het Visiemodel is Healthy Cities een inspiratiebron voor de ontwikkeling van een toekomistvisie over de stad als geheel en de gevolgen voor beleidsontwikkeling. De stad wordt in dit model beschouwd als een organisme met diverse systemen en organen. Om deze systemen en organen in optimale conditie te houden is het nodig dat ze zowel op zichzelf als in relatie tot elkaar 'gezond' zijn. Ieder beleidsmodel heeft een eigen ontwikkelingstraject en karakteristieken.

Alle case studies laten door hun activiteiten zien dat beleidsontwikkeling plaatsvindt, maar ze laten ook zien dat deze ontwikkeling niet gebeurd op basis van een bewust gekozen beleidsmodel en bijbehorende visie. De rol die Healthy Cities speelt varieert derhalve. Dat met name het Gezondheidmodel wordt gebruikt wordt verklaard door: het feit dat dit slechts geringe (niet fundamentele) veranderingen vraagt ten opzichte van de status quo, de betrokken actoren, de redenen om te starten met Healthy Cities, en de voorbeelden die gemeenten aangereikt krijgen (van bijwoorbeeld andere gemeenten). Ten aanzien van onderzoek en theoretische ondersteuning wan beleidsontwikkeling is de conclusie dat des te verder Healthy Cities afstaat van traditionele gezondheidsactiviteiten, dus in het Stadmodel en met name het Visiemodel, het ook steeds verder van traditioneel (modern) onderzoek komt te staan en er dus meer te verwachten valt van postmoderne onderzoeksideeën.

Dus alhoewel Healthy Cities innovatief en grensverleggend bezig zijn waar het gaat om gezondheidsbevorderende projecten, kan een zelfde conclusie nog niet getrokken worden wanneer het gaat om beleidsontwikkeling. De meer fundamentele veranderingen die Healthy Cities zou kunnen bewerkstelligen vragen om tijd, visie, energie, en mensen die zich daarvoor sterk maken op politiek, organisatie alswel op een algemeen maatschappelijk vlak. Zulke veranderingsprocessen zijn wellicht net begonnen en men moet wiet nu al, om met een uitspraak van Senge (1995) te eindigen: het worteltje uit de grond willen trekken om te zien of thet groeit. (p.29) 


\section{Notes}

\section{Notes Chapter One}

1 For instance, from 3 to 14 June 1996 the second Hibitat conference in istanbul rook place. Habitat II was a World Conference called by the United Nations General Assembly. The focus of this conference the management of urbanization and the improvement of living conditions. Intemational bodies and govemnent represeritatiwes discussed the investurnerts and consequent action that need to take place. Efforts are currently being made to develop nteriational policy guidelines that should ster nations in this matter (WHO, 1996).

Habitat on Human settlements took place in Vancouver in 1976. The aim of that conference was to mitigate the effects of rapid urbanization.

2 comments on the assimptions on which the Projeck is based and its underlying sources in relevance to this investigation will be presented in chapter two where the research design is described.

3 It is WHO's policy to work in so-called mandatory periods of five years.

4 At the same time however, the WHO has a list with requirements for cities to participate in the WHO Healthy Cities Project (see table 1.3). The list of requirements which cities have to meet for the second fiveyear period of the Project (1993-1998) is even longer and more cetalled than the list of requirements for the frit five years (see WHO/Euro/HCPO (1988). Healthy Cities papers 1, 2, and 3. Copenhagen: FADL; Tsouros, A. (ed.) (1991). WHO Healthy Cities Project. A project becomes a movement. Review of progress 1987-1990. Copenhagen: FADL

5 This Ministry was re-mamed Ministry of Health, Welfare and Sports in August 1994.

6. Social renewal wax introduced in the Netherlands around 1990 in order to strengthen the relation and communicarion between government and the public at large, particularly with regard to social policy development: The most important areas of work are work and education, the liwing environment, and the renewal of care and welfare activities (Tweede Kamer der Staten Generabl. Note Svciale Vemietwing: opdracht handreiking. 1989-1990, nr.4,7 Maart 1990 21455). Major characteristics are: starting with the needs of the population. intersectoral collaboration "community participation, tailored projects and tailored policies. Healthy Cities is axplicitly refierred to as an exarnple of a municipal action oriented programme for collective prevention and face policy dewelopment.

7 the main reason for changing the name of the network was that it was felt that the word "city' did not cover all Ficaldh for All accivities that were undertaken in the United Kimgdom at the local level.

8 The same goes for disease determinants. For example, it is know from research what factors infuence coronary heart diseases. Revearchers have no doubts that there will be more factors that infuence these diseases than they currently know. It is not possible however to predict the percentage by which a factor, or combination of factors, causes a disease. For example, phenylketonuria can be explained for $100 \%$ by genetical factors, but also for $100 \%$ by environmental factors or lifestyles (see for example Maas \& Habbema, 1987).

9 In 1948 the WHO's constimtion has been accepted by the conference of the United Nations (articles 55 and 57 of the "United Natians Charter"). The WHO is gowerned by a World Health Assembly, composed of representatives of member states. Although treatment of diseases and fighting infectious diseases remain important areas of attention to WHO, primary health care and healh promotion are very much stimulated by the organization (see als well Pannemborg, 1978). 
10 Data from the World Bank and the Organisation of Economic Cooperation and Developinent (of industrialized countries) (OECD) show that there is only a linear relation between Gross National Product and individual health starus in wery poor countries (World Bank, 1993).

11 Health education is primarily aimed at a change of (individual) behaviour and targeted often at risk groups. Behaviour is however only one of the determinants of health according to the Blum health model, and therefore only one of the elements of health promotion. Examples of a traditional health education policy intervention would be influencing cigaretce consumption parterns by a mass snedia campaign or a target group based education on health effects of smoking. Examples of a health promotion policy intervention would be increasing taxes on cigarette sales. and stimulating non-smoking policies.

12 For example, Amsterdam 1891 (the public health service and public health care service (1889) were unified into one service in 1923), the Hague 1912, Utrecht 1914, Rotterdam 1919, Tilburg 1920.

\section{Notes Chapter Two}

1 Medline is an automated bibliographic retrieval system in the field of public health, health care, and medicine.

2 Originally, policy theory aims to reconstruct the assumptions that are maintained by those who are involved in policy development and implementation (Hoogerwerf, 1989; Ringeling. 1985). In this concrete siruation in means to reconstruct the assumptions of those, the WHO and her consultants, who have "created" the Heal thy Cities idea. A different policy theory could be developed based on assumptions of those who are working with (implementing) Healthy Cities.

For policy theories on Healthy Cities see also Milewa \& de Leeuw (1996), who instead of "policy theory' use "policy ontology". For discussions about the use and mis-use of this concept, see also Scholter, H. (1993), Het concept beleidistheorie in onderzoek: afbakening en kwaliteit. In Heffen van, O., Twist van, M. (redi.) Beleid en Wetenschap. Alphen aan de $\mathbb{R}$ ijn: Tjeenk willink.

3 The WHO CC RHC at the University of Maastricht has initiated a research to investigate what health means and how it is defined and constructed by the general public. This research is currently undertaken and will last until August 2000.

4. In the Netherlands the local government finds in the Collective Prevention Act (1991) a formal responsibility for health policy development. This act has been evaluated twice since its inplementation (see KPMG, 1993; see Inspectie woor Volksgezondheid, 1995). Conclusion of both evaluations is that the majority of local governments do not know how to move about with this responsibility. A committee chaired by professor Lemstrat gave advice to the Minister of Health, Sports and Welfare in 1996 how to facilitate locall health policy development (Commissie Versterking Collectieve Preventie, 1996).

5 Currently the public sector both in the United Kingdom and Netherlands shows a direction of flexibilisation of working conditions and structures. Organizational ideas and management theories from the private sector are entering the local government sector.

6 Even if it would be considered an implementation study, we would argue that although for theoretical and analytical reasons separation of implementation and development may be useful. policy is often developed while implemented (see also Lipsky, 1980). The formal document in which the policy is written down reflects (social) developments. The implementation of this document is also a process in which the plan is 
interpreted and adjusted in the light of different other developments, and impressions and persomal values of those actors involwed (sce for examples: Guba, E., Lincoln, Y. (1989). Fourth Gaturation Ewaldation. Newbury Park SAGE and Schwandt T. (1994) Constructivist, Interpretivist Approaches to Hunan Inquiry. In Denzin, N. Lincoln. Y. (edis.). Handbook of Qudhtative Resedrch. Thousand Oaks: SAGE.

7 De Leeuw (1989b) show how the actors in the health care field can influence if and how health pollicy will be developed. De Leenw concluded that the majonity of the actors decided that health policy, as under discusssion in this research, was not their priority.

8 Berg (1997) addrestes in his research on rationalizing medical decision-making the differences and difficulties of interpreting genexal rules in specific contexts.

9 These authors see policy making as a process of defining and treating ill-structured issues and problems. Most tools that are available in social science were originally develloped to study well-strucnured problems and issitues IIl-structured issues and problens are "messy", "they ore complex mixtures of highty interdeperdent important problens that by definition cananot be formulated, let alane solved, independently of one another" (Mitroff \& Emshoff, 1979 p. 1).

10 The researcher has been involved in the WHO Healthy Cities Project since 1990, when performing a Masters thesis on national networks; she has been employed as a project officer for the coordination centre of the mational network of Healthy Cities in the Netherlands, has attended conference and business meetings and delivered lectures. She is also a member of the WHO collaborating centre for Research on Healthy Cities, in Maastricht.

11 In the United Kingdom the general selection resulted in 16 cities as being "active" and participating for sorne years in the project. The national coordinator and a member of the management committee of the UKHFAN were asked independently from each other, withovt knowing the result of the general selection, to name cities that were visible and active in the UKHFAN. A match between these three lists resulted in eight cities. consisting of three project WHO project cities and five national network cieles. Two of these cities took no interest in participation in this research.

12 A major aim of the WHO Healthy Cities Project is to move health high upon the political agenda. It was assumed that those who have formal responsibility for health policy development are the persons who have to push the issue on the agenda. Making them interested in Healthy Cities is also important because these people play (at present) an important role in formal decision naking and resource distribution.

13 Besides formal interviews also informal discussions have contributed to a better understanding of the issues situation, etcetera.

14Four people are mentioned twice in this list of interviewed people as they represented two posiltions. In the Netherlands, unlike the United Kingdom, coordinationship was part of the coordinators regular employment as a health promotion officer (1), director of GGD (1), head of (local government or GGD) deparment (2).

15. It was decided not to use questionmaires to avoid ethnocentric bias as the researcher was more acquainted with the Dutch situation than with the situation in the United Kingdom. (see also Hofstede (1995) in Korsten, A., Bertarand, A. Jong de, P.. Soeters, J. (red.). International wergellijkend onderzack. Den Haag: VUGA. Interviews were expected to provide more in-depth information and it gave the researcher the possibility to ask for clarification when necessary. 
16. Mirroff and Turoff basically see five differen inquiry systerns: Leibniam (truth is analytical; use theoretical models). Lockean (truth is experimental; use empirical models), Kantian (truth is synergetic , use a mix of theory and empiry). Hegehan (truth is conflicnal; use two contradictory plans). Singerian (uruth is pragimatic; look for multidisciplinary aspects). For example, in a research situation this implies that a Kantian approach will test two different plans and look for differences. A Singerian approach will teflect on what takes place and will seek for the "hidden assumptions".

17 sere previous mote $(16)$.

\section{Notes Chapter Four}

1 Their ideas seem inspired by the Systems Theory (see also Katz \& Kabn, 1966: Keuning, 1973: Thompson. 1967). Systems. Theory draws attention to the relation between the organization and their enviromment. Organilzations operate in an envinomment, have relations with this environment and therefore "exchange" exists between the orgazization and its environment. They influence each other. Organizations monitor their envinonment in seanch for possible, potential, visible and latent opportunities or threats.

2 De Leeuw investigated the feasibility of Nota 2000 (A Dutch health policy document). Feasibility as described by de Leeuw (1989 p. 72) is "the perception by warious publics of whether or not Dutch health policy (Noto 2000) will be operational and implemented in the foresecable future through concrete bealth objectives/targets, allocation of resources and capacities to that end".

3 See Kopprenjan (1993) for the application of the stream model as one of the main inspiration sources for developing an arena model for analysing policy making processes at the Duth Deparment of Interior affairs.

4 Kingdon's study focuses on two policy terrains (Health and Transport) of the federal government in the United States of America. His aim is to find out why it is that some issues do receive attention and others do not. He uses a case-study approach and has interwiews with (key) decision-makers and policy-makers to collect his data.

5Kingdon mentions that even in 'hard" science like mathematics and natural science, theories come up to study complexity and Ruidity (like for example patterns of smoke).

Kingdon refers in his book to the work on anticipation and adaption to the (changing) environment, following the principles of evolution (see also Waldrop, 1992). He compares the development in the policy stream with the process of natural selection in the evolutionary model (Kingdon, 1995, p. 226 and further). These developments can occur at a regular basis but can also go by a sudden change. a "punctuated equili. brium":

6 Kingdon considers governments to be 'organized anarchies' where order and disorder are both present (Mucciaroni, 1991 p. 460).

7. The research setting (case studies) that Kingdon used to develop and test his theory were all United States federal government settings, originally transport and health and in the new edition of his work he included the Reagan Budget of 1981 and the Tax Reform Act of 1986.

8. This is comparable to what Cobb and Elder mention about trigger devices (see sub-section 4.3.1). 
9 Health and hawing an interest in health is disconnected from being a patient or not.

10 In Kingdon's regearch in only $26 \%$ of the interviews and in 4 of the 23 case studies the mass media was mentioned for having influence on the governumental agenda. Whereas interest groups were mentioned in $84 \%$ and academics in $66 \%$ of the interviews.

I1 Mulki City Action Plans (MCAPs) are collaborative strategies between cities on a specific topic. Examples are for example AIDS, Local Agenda 21, Sports and Active Living or Elderly.

12 In city twinniag 'old' WHO Froject cities link with "new" WHO Project cicies, especially cities in east and' central Europe, in order to provide them with assistance and help.

13 His work was primarily directed towards diffusion of techmical inmovations that are adapted or rejected by individials or organizations. He does not mention governments as such.

An example that his basic reasoning can be used as well as a source of inspiration to study innovation processes in other fields is prowided by van Assema (1993). She used this theory in her research on Community projects in health promotion. Another example is provided by Ruiter (1995) who applied this theory on the WHO 'Health Promoting Schools project' in Bulgaria.

14. Most activities are funded on a project basis. But projects do exist for a fixed period of time. When a project is about to finish, it is more likely that funding for a totally new project will be achieved or that the project can continue for another few years than that the results of the project will be used to transfer the project into mainstream business.

\section{Notes Chapter Five}

1 This national governmental money came to an end. At present local governments can make bids for so called. Single Regeneration money.

2. The Greater Glasgow Health Board operates comparable to a Health Authority.

3 This research was conducted in the United States of Amserica.

4. They refer to March and Olsen"s (1976) theory on 'Ambiguities in choice' and Olson"s (1965) theory on "The logic of collective action'.

5 They focus in their study on the role of corporate actors on State policy-making in two donnains: Health and Energy. In our research their gemeral ideas are used, but our focus is not specifically on corporate actors and their influence on policy-malking. The stage the cities were at during the reseanch, individuals were more involved and influential than orgamizations.

6 They used media coverage, lobby circuit, the suggestions of experts , and participation in meetings of the Congress and Senate as sources for defining the actors and their importance.

7 Until 1996 Eindhowen was the coordinating city for this MCAP. In 1996 the decision was made to withdraw from this MCAP. Since then the remaining cities have sought a new coordinator and not much activities have been undertaken. Ideas have come up to re-name the MCAP in Active Living (instead of Sports and Active Living) and to broaden its objectiwes into 'A Healthy Ciry is an Active City'. 
8. A re-organization that is caking place in the local govemment in Amelo in 1997 will probably result in an entire local gowermment Healthy Cities department.

9 The draft was launched for the public in the summer of 1995. Comments could be made. A reviscd nersion was formally accepted as the Liverpool Cly Health Plan in January 1996. This document was signed by senior representatiwes of key-organizations in dhe city. Since then efforts are made to implennemt the plam.

10This requirement is part of the United Kingdom mational govermment Health of the Nation white paper.

11 The concept "social renewal' has been used origimally by the city govermment of Rotterdam to work on reduction of social and welfare probiems in the city. The national govemment has in fact borrowed this word from them to work on reduction of inequalities in cities. National government wrote a policy document "Social Renewal: tasks and guidelimes (1990). The government wants the cities/municipalities to work on three key areas: a reduction of long term unemployment; promotion of the liveability of the city; and, promotion of the quality of care. The whole operation did not bring much extra money along, the idea was to achicwe social renewal by redirecting existing money and by a change in working mechanisms and struktures. We can see many comparisons between social renewal and Fealthy Cities. Both ate very broad concepts, aimed at chamging ways of working and aimed at a reduction of inequalities. When social renewal activities take place under the umbrella of Healthy Cities or the other way around, one open-ended concept is exchanged with an other open-ended concept. But if cities hawe to work on social renewal, it makes senwe for Healthy City entrepreneurs to plea for the Healuly Cities Project. The chances that local govermment is willing to listen and to work on it are not unlikely as it has been demonstrated in Rotterdam. Almelo and Findhoven.

12A Community Health Council is an adwisory body to the local authority and Health Authority with regard to heallin matters.

1.3* AHO collaborating centre is an institution designatted by the Director-General to form part of an internatianal collaborative network carrying wut activities in support of the Organization's programme at all levels." (Vuori \& Tirado "1991). It is not necessarily an entire institution, but also a department, or laboratory, or a group can be designated as a centre.

14 Gusfield distinguishes political and causial responsibility. According to him, having the causal responsibility for a problem means that the person actually caused the harm. Having political responsibility, means being inwolved in controlling the situation and/or solving a problem.

\section{Notes Chapter Six}

1 According to Bressers (1993) three issues ane important to evaluation: (1) the choice of the subject of the ewaluation study. (2) the obstervation of this subject, and (3) the criteria against which to judge this sibject. These issues can be used to divide evaluation research into categories. For example "the subject of the cvaluation can be sub-divided according to policy flield, the time (ex-post or ex-ante), the content, the processes and effects, and into summatiwe or formative (making up the baiance or explanatory). Criteria can also be used to divide evaluation research. Examples of such evaluations are goal attaininent, effect research, or efficiency research. An ofter used distinction is between a qualitative and quantitative way of datia collection.

2 Data were collected in 1993 and 1994 . Analysis of the findings took place in 1994 and 1995

3. REBUS, Rotterdam Epidemiological Neighbourbood Characteristics System [Rotterdams Epidemiologisch Buurtkenmerken Systeem, MG], is a computerized geographical based information system for the Rotterdam 
area. It mainly targetsi health related aspects. GLOBE is a joint research project between the Erasmus University in Rotterdain and the GGD in Eindhowen. It services a sirnilar goal as REBUS.

4 See Chapter Fiwe, note 11 .

5 In only one case siudy (Newcascle) an example of a health parnership at senior level was available that was not specifically based on Healthy Cities or Healch for All. The idea came originally from the Healthy Anthority. It was proposed that the partnership should involve the Health Authority, local authority, community health council, the voluntary sector, and people inwolved in health service provision. The Fealthy City coordinator was expected to act as a representative of the community.

The aim of this partnership is to come up with strategies for the city and to make sure that each organization can play a part in their development and implementation. The partnership does not deal with individuals and practical issues. Instead it is aimed at strategies and longterm objectives. The partnership is accountable to the Heal the Authority and city council.

6From a comparative study it appeared that the United Kingdom central government is behind other goveraments in the Eturopean region with regard to collaborative efforts. This may be an explanation of the involvement and stimulation of the national government in getting local governments to collaborate. (See Batley, R., Staker, G. (eds.) (1991). Local gowernment in Europe. Houndsmill: MacMillan.)

7 Since 1979 National government has introduced competition to locall authority service provision. This has been formalized through Compulsory Competitive Tendering (CTT) in 1980. To the mational government's opinion the local authorities made not enough efforts to increase their efficiency through competition. CTT requires for a defined group of services that are traditionally supplied through local government the need to tender with external organizations for a contract. (see Channdy, D., Uttley, M. (1993). The Economics of Compulsory Comperitive Tendering. Issues, Evidence and the Case of Municipall Refuse Collection. Public policy 8. Adninistrotion, 8 (2). pp. 25 41.) 


\section{References}

Abbema, E. (1995). The common grounds and collisions of two trendy movements; Sustainable Development and Healith Pramotion (paper). Maostricht: University of Maastricht.

Abma, T. (1991). Drie kernproblemen van beleidsevaluatie doordacht wanuit de naturalistische benadering.

Beleid en Mootschappii, 8 (5), pp. 222-237.

Abma, T. (1993) Voorbii de technocratische oriëntatie in beleidsevaluatie. Beleid \& Maotschappii, 10 (5), pp. 244-254.

Abma, T. (1996). Responsief exalueren. Discoursen ${ }_{n}$ controwersen en allionties in het Postmaderne. (Phd Thesis, Erasumus University Rotterdam). Delft: Eburon.

Acheson, D. (1988). Public Health in England. The reportt of the committee of inquiry into the future development of the public health function and commumity medicine. London: HIMSO.

Allison, G. (1971). The essence of Decision: Explaining the Cuban Missile Crisis. Boston: Little, Brown and Company.

Antonovski, A. (1984). The sense of coherence as a determinant of health. Advances, (1), pp. 37-50.

Antonowski, A. (1987). Unrovelling the Mystery of Health: How People Manage Stress and Stay Well. San Francisco: Jossey Bass.

Arnstein, S. (1969). A ladder of citizen participation. Journol of the American Institute for Planners, july, pp. 216-224. Ashton, J. (1991). The Healthy Cities Project: a challenge for health education. Healthy Education Quarterly, 18 (1). pp. $39-48$.

Ashton, 1. (1992). Healthy Cities. Milton Keynes: Open University press.

Ashton, J., Grey, P., Barnard, K. (1986). Healthy cities - WHO's New Public Health initiative. Health Promotion, 1 (3), pp. 319-324.

Ashton \., Seymour, H. (1988). The New Public Health: the Liverpool experience. Milton Keynes: the Open University.

Assema, P: (1993). The development, implementation and evaluation of a community health project. (Phd Thesis, University of Maastricht) Maastricht: Universitaire Pers Maastricht.

Bachrach, P, Baratz, M. (1970). Power and Poverty; Theory and Practice. Oxford: Oxford University press. Boiley, S. (1993). Public Choice Theory and the Reform of Local Government in Britain: From Government to Governance. Public Policy and Administration, 8 (2), pp. 7-24.

Bartunek, J., Moch, M. (1987). First-Order, Second-Order, and Third-Order Change and Organization Development linterventions: A Cognitive Approach. The Journal of Applied Behavioral Sciences, 23 (4), pp. 483-500:

Barnett, P. Howden-Chapman, P., Smith, A. (1995). Unemployment, work and health: opportunities for healthy public palicy. New Zealand Medical Journal, 108 (998), pp. 138-140.

Boum, F. (1993). Healthy Cities and change: social movement or bureaucrotic tool Health Promotion International, 8 (2), pp. $31-40$.

Baum, F. (1994). Is targeting health compatible with health development? Paper presented at the VII international Conference of the World Federation of Public Health Associations, Bali, Indonesia.

Baum, F., Sanders, D. (1995). Can Health Promotion and Primary Health Care achieve Health for All without a return to their more radical agenda? Health Promotion International, 10 (2), pp. 149-160.

Belleman, S. (1994). Gemeentelijke overheid en lokaal gezondheidsbeleid. In Garretsen, H., Haess de, W., Schrijver, M. (red.). Lokaal gezandheidsbeleid. Reeks gezondheidsbeleid - deel 7. Houten: Bohn Staflew Van Loghum.

Berg, M. (1995). Rationalizing medical decision-making. (Phd Thesis, University of Maastricht). New York: MIT press.

Bernstein, E., Wallerstein, N., Braithwaite, R., Gutierrez, L, Labonte, R., Zimmerman, M. (1994). Empowerment Forum: A Dialogue between Guest Editorial Board Members. Health Education Quarterly, 27 (3), Pp. 28 1-

294. 
Blennerhosset, S., Forromt, W., Janes, J. 11989). Support For Communizy Health Projects in the United Kingdom: A role fior the National Health Service. Heath Promotion, 4(3), pp. 199-206.

Bloom, G. (1985). Two models for change in the health services in Zimbabwe. International Joumal of Health Siervices, 75 (3), pp. $451-468$.

Bont de, A. (forthcoming). Ziekten, cyfers en internationad beleid. De WHO als een tramsnationale organisatie. (Phd Theisis. University of Moostricht),

Boogaard, wan den J. (1994). Rumtelike ordening, wolkshuiswesting en gezondheid. In Gorretsen, $H_{2}$, Haes de, W., Schripver, M. (red.). Lokaal gezondheidsbeleid. Reeks gezondheidsbeleïd - deel 7. Houten: Bohn Stafleu Van Loghum.

Booguard, J., Groat, B. (red,) 1995). Gezondheid en Leefomgeving. Gezonde Steden reeks 5. Assen: wain Gorcum.

Bracht, N. (ed.)(1990). Health Promotion af the Community Level. Newbury Park: SAGE.

Bracht, N., Kingsbury, L. (1990). Community organizetion principles in health promotion: A Five-Stage Model. In Brachi, N. (ed. 1990) Health Promofion at the Community Level. Newbury Park: SAGE.

Bracht, $N_{,}$, Gleoson, J. (1990). Stratagies and Structures for Citizen participation. In Bracht, N. (ed.) (1990) Health Promotion at the Community Level. Newbury Park: SAGE.

Braithwaite, R., Bianchi, C., Toylar, S. (1994). Ethnographic Approach to Community Organization and Health Empowerment. Health Education Quarterly, 21 (3), pp. 407-416.

Bressers, J. (1993). Belleidsevaluatie en beleidseffecten. In Hoogerwerf, J. (red.). Overheidsbeleid. (vilfde druk) Alphen oan den Rijn: Samsom H.D. Tieenk Willink,

Bresseirs, J., Hoogerwerf, A. (red.) (1995). Beleidsevaluatie (derde druk). Alphen aan de Rijn: Somsom H.D. Tjeenk Wililink.

Broekhuizen, A. (1992). Tilburg bereikt de grenzen von verzakelijking. Binnenlands Bestuwr Management, 8 (7), pp. 17. 19 .

Brown, E. (1991). Community action for health promotion: a strategy to empower indiwiduals and communities. International Journal of Health Sevices, 21 (3), pp. 441.456.

Bruinsma, G., Zwonenburg, M. (eds.)(1992). Methodologie voor Bestuurskundigen. Muiderberg: Coutinho. Blum, H. (1974). Plomning for Health. New York: Human Sciences press.

Bulow-Hube, S. Morisky, D. (1987). The innovation-decision model and workplace health promotion programis. Health Education Research, 2 (11), pp. 15-25.

Burch, M. Wood, B. (1989). Public Policy in Britain. (2nd edition) Oxford: Basil Blackwell.

Castlemilk Partmership (1994). It is coming together. Castlemilk partnership strategy report. Scotland: HMSO.

Cortwright, P (1989). The Self Help Allance - an experiment with 18 self help support projects in different parts of Englarid. Health Promotion, 4 (3), pp. 207-214.

Charltan, $B$, White, M. (1995). Living on the margin: a salutogenic model for sociomeconomic differentials in health. Public Heallth, 109 (4), Pp. 227-234.

Cabb R. Elder C. (1983). Participation in American Politics: The Dynamics of Agenda-building. Baltimore: John Hopkins University press.

Coher, $M_{1}$, March, $\rfloor_{1}$, Olsen, ل. (1972). A garbage can model of organizational choice. Administrative Science Quartarly, $17(1)$, pp. $1-25$.

Cohen, D. (1994). Health Promotion and costueffectiveness. Health Promothon Intermationol, 9 (4), pp. 281-287.

Commissie Versterking Collectieve Preventie (1996). Gemeentelijk Gezondheidsbeleid Beter op zijn placts. Advies van de commissie Versterking Collectieve Preventie fcommissie Lemstra). Zoetermeer: Ministerie Volksgezondheid. Walzijn en Sport.

Considine, M. (1995). Public policy, a critical approach. London: MacMillan.

Cook, T, Reichard, C. (eds.) (1979). Qualitotive and Quantitative methods in evaluation rasearch. Bieverly Hills: SAGE. 
Costongs, C., Springett, J. (1997). Towards a framework for the evaluation of urban health reloted policies. Subrritted to Evaluation.

Crumbly, A. (1992). A management Review of the Liverpool Heathy Cities Project. (an intternal document). Liverpool: Liverpool City Council.

Csepeli, G. (1989). New alternatives of community bullding un Hungary. Health Promotion, 4 (3), pp. 247.254.

Curtice, L., McQueen, D. (1990). The WHO Healthy Cities Project an anatysis of progress. Edimburgh/Copenhagen: RUHBC, WHO/EURO.

Curtis, S., Taket, A. (1996). Health \& Societies. Changing Perspectivers. London: Arnold.

Dahl, R. (1961). Who governs? Democracy and power in an American cily. Now Haven: University press.

Dam ten. J. (1997). Gezonde stadgezichten. Een studie naar gezondheidsverschillen wen stedelijk gezondheidsbe:leid. Amsterdam: Thesis publishers.

Dam ten, J., De Leeuw, E. (red.)(1993). Gezonde Steden en onderzoek. Reikwijdte, methoden, toepassingen. Gezonde steden reeks 3. Assen: van Gorcum.

Davies, K., Kelly, M. (eds.) (1992). Healthy Cities. Research \& Practice. London: Routledge:

Delaney, F. (1994). Muddling through the middle ground: theoretical concerns in intersectoral collaboration and health promotion. Health Promotion International, 9 (3), pp. 217.225.

Derksien, W., Korsten, A. (red.)(1989). Lokaal bestuur in Nederland. Alphen aan den Rijin: Samsom HD Tjeenk Willink.

Dolan-Mullen, P., Evans, D., Forster, J., Gottlieb, N., Krouter, M., Moon, R., O'Rourke, T., Strecher, V. (1995). Settings as an Important Dimension in Health Education/Promotion Policy, Pragrams, and Research. Health Education Quarterly, 22 (3), pp. 329-345.

Draper, R., Curtice, L., Hooper, J., Goumans, M. (1993). WHO Healthy Cities Project: Review of the first five years. (1987-1992). Copenhagen: WHO/EURO.

Dror, Y. [1968). Public Policymaking re-exomined. Scranton: Chandler publishing company.

Drucker, P (1991). The discipline of innowation. In Henrey, J., Walker, D. (eds.). Managing innovation. Londion: Sage.

Dubos, R. (1959). Mirage of health. Niew Yark: Horper \& Row,

Dubos, R. (1962). Torch of Life. New York: Tridient Press, Simon \& Schuster.

Duhl, L. (1963). The Urban Condition: People and Policy in the Metropolis. New York: Simon \& Schuster.

Duhl, L, (1995). The Sacial Entrepreneurship of Change. New York: Pace University Press.

Edelman, M. (1988). Constructing the Political Spectacle. Chicago: University of Chicago press.

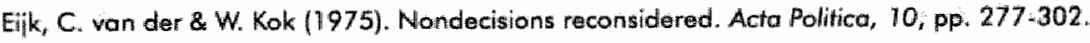

Eisenga. M. (1994). Characteristics and implementation of intersectoral oction: theorias af collaboration and networking tested. RHC Monograph Series nr. 5. Maastricht:WHO/CC/RHC.

Elcack, H. (1982). Local gowernment: politicians, professionals and the public authorities. London: Methuen.

Evans, R., Barer, M. Marmor, T. (eds.) (1995). Why are some people healthy and athers not?: the daterminarts of health of populations. Berlin: Walter de Gruyter.

Evers, A. (1989). Promoting health-localizing support strucutures for community health projects. Health Promotion, 4 (3), pp. $183.18 \mathrm{~B}$.

Evers, A., Farrant, W., Trajan, A. (eds.) (1990). Healthy Public Palicy at the Local Level. Frankfurt am Maim: Campus Verlag.

Farrant, W. (1991 la). "Addressing the contradictions" health promation and community health action in the United Kingdom." International Journal of Health Services, $21(3)$, pp. 423-439.

Farrant, W. (1991 b). Building Healthy Public Policy: The Healthy Communities Movement as an Entry Point. A review of Recent Literature. Vancouver: Social Planning and Resource Council of British Columbia. 
Feuersteim, M, 11980). Rural health problems in developing counfries: the need for a comprehensive community approach. Readings in Health, Development and Community Participation, special series nt. 3, pp. 31-41.

Flynn, E, Roy, D., Rider, M. (1994). Empowering Communities: Action Research through Healthy Cities. Health Education Quarterly, 21 (3), pp. 395-405.

Fortin, JP, Groleau, G., ONelll, M., Lemieux, V., Cardinal, L., Racine, P. 11992]. Québec's healthy communities projects. The ingredients of success. Health Promotion, 31 (2). pp. 6i-10.

Fortmann, S., Flora, J., Winkleby, M., Sehooler, C., Taylor, C., Fanquahar, J. (1995). Community Intiervention Trials: Reflectionis on the Stanfond Five-City Project Experience. Americon Journal of Epidemiology, 146 (6), Pp. 576.586.

Francke, A., Richardson, R. (1994). Evaluqtie onderzoek. Konsen woor een kwalitotieve benadering. Bussum: Coutinho.

Franken, M. 1993). The European Network of Health Promoting Schools in Romania. (Masters thesis Health Education) Maastricht: University of Maastricht.

Funnell, R., Oldfield, K., Spellar, V. (1995). Towards Healthier Alliances. Londorv: Health Education Authority/Wessex Instifute of Public Health.

Garcici, P, McCarthy, M. (1996). Measuring Health. A step in the development of city health profiles. Copemhagen: WHO/EURO.

Garretser, H., Raot, H. (1989). Gezondheid in de vier grote siteden. Den Haag: Wetenschappelijke Raad voor het Regeringsbeleid, SDU vitgeveril.

Garratsen, H., Haes de, W, Schrïver, M. (red.)(199.4). Lakaal gezondheidsbeleid. Reeks gezondheidsbeleid - deel 7. Houten: Bohn, Staflew, van Loghum.

Gemeente Tilburg/GGD Midden-Brabont (1991). Then intenties voor een gezond beleid.

Gezonde Stad Rotterdam (1 994). From project to policy. Or: The art of motorcycle maintenanice. 4th interim report. Rotterdam: Municipal Health Service for Rotterdam area.

Gilbert, N. (1995). Welfore Justice: restoring social equity. Newy Hoven: Yale University Press.

Glasgow City Council (1993). Glasgow city council: how it works. Glasgow. Public relations department Glasgow city council.

Glasgow Cily Housing (1993). Single homelessness and mental health issues in Glosgow. A research study commissioned by Glasgow District Council City Housing, undentaken by the Richmond Fellowship and Glasgow Council for Single Homeless.

Glasgow Healthy City project (1992). Glasgow Healthy City project 4 years on. The Health of the city, a shared cancern. Glasgow: Hill and Hay.

Godlee, F. (1995). "WHO in Europe: does it have a role?" British Medical Journal, 310 (11), pp. 389-393.

Gooskens, J. Komaliinslijper, N., Veen, C. (1997\%. Een Gezonde Stad,..zo doe je datl Den Haag: VNG vitgeverii.

Goumans, M. (1993). What about healthy metworks? An analysis of structure and arganization of national thea thy cities networks in Europe. RHC Monograph Series nr. 3. Macistricht: WHO CC RHC.

Goumans, M. (1994). Gezandheidsbeleid, bestaat dat? Tijdschrift voor Gezondheidsbevordering, 15 (4), Pp. 175-183.

Goumans, M. (1995). Putting concepts into the Halth policy practice. In Bruce, N., Springett, J., Hotchkis., J., Scott-Samuel, A. (eds.). Research and Change in Urban Community Health. Aldershot: Avebury.

Goumans, M., Kruifff, A., Wevers, H. (1993). Vif wethouders c.s. over hun lokale gezondheidsbeleid. Thidschriff voor Gezondheid en Politiek, 11 (4), pp. 12-15.

Goumans, M., Springett, J. (1997). From projects to policy: "Healthy Cities" as a mechanisim for policy change for health" Health Promotion International, 12 (4), (in piress).

Graci, van de H., Hoppe, R. (1992). Beleid en Politiek. Een inleiding tot de beleidswetenschap en de bestuurs « kunde. Bussum: Coutinho. 
Green, L., Raeburn, J. (1990). Comtemporary Developments in Hedith promotion: definitions and challenges. In Bracht, N. (ed.). Health Promotion at the Community Level. Newbury Park: SAGE.

Greene, 1. (199.4). Qualitative programme evaluation. Practice and promises. In Denzin, N., Lincoln, Y. (eds.). Handboak Qualitotive Reseorch: Thousand Oaks: SAGE:

Greenwood, J."Wilson, D. (1984). Public Administration in Britain. London. George Allen \& Unwin.

Gubo, Ex, Lincoln, Y. 11981$)$. Effective evoluation. San Francisco: Jossey Elass.

Guba, E., Lincoln, Y. \1989\%. Fourth generation Evaluation. Newbury Park: SAGE.

Gumning-Schepers, L. (1992). Beleidsepidemiologie, what's in o name? Tijdschrift voor Sociale Geneeskunde, 70 (1), pp. 68.71 .

Gusfield, J. (1981). The Culture of Public Problems: Drinking-Driving and the symbollic order. Chicago: the University of Chicago Press.

Hommersley, M., Atkinson, P. (1991). Etnogrophy: principles in proctice. London: Routledge. Hampton, W. (1987). Local Government and Urban Poltics. London: Langman.

Hancock, T. (19900). From "Public Health in the 1980's" to "Healthy Toranto 2000": The Evolution of Healthy Public Policy in Toranta. In Evers, A., Farrant, W., Trojan, A. (eds.) (1990). Healthy Public Policy ot the Local Level. Frankfurt am Main: Campus Verlag.

Hencock. T. (1990b). Developing Healthy Public Policies at the Local Level. In Evers, A., Farrant, W., Trojan, A

(eds.) (1990). Healthy Public Policy at the Local Level. Franlkfurt om Main: Campus Verlag.

Hancack, T. (1992). The Healthy City from concept to application. In Davies, K, Kelly, M. (eds.). Healthy Cities. Research \& Practice. Londor: Routledge.

Hanks, P. (ed) (1989). Collins Dictionary of the English language (2nd edition). London: Callins.

Healthy Cities support team Sheffield (1993a). Community development and Health. The way forward in Sheffield. Sheffield: Healthy Cities support team.

Healthy Cities support team Sheffield (1993b). Healthy Sheffield small grants fund report. Sheffield: Healthy Sheffield suppont team:

Heallthy Sheffield 2000 (1991). Our city - Our health. Ideas for improving health in Sheffield. Sheffield: Healthy Cities planning team.

Heallthy Sheffield [1994). "Our city - Our health' Framewark for Action Healthy Sheffield. Sheffield: E.S.S. Heffen van, O., Twist van, M. (red.)(1993). Beleid en Wetenschap. Alphen aan de Rijn: Tjeenk Willink. Heiitkamp, P. (1996). Global Health Promoling Partnerships in WHO's Organizational perspective: A participatory Research on ten successful cases of WHO's Heath Promoting Portnerships and their Organizational Preconditions. (Mosters thesis in Health Policy and Administration.) Moastricht: University of Macstricht.

Hofstede, G. (1995). Principes wan interniationaal-vergelinkend onderzoelk. In Korsten, A., Bertrand, A, Jong de, P., Soeters, J. (red) (1995). Internationad vergelijkend onderzaek. Den Hocig: VUGA.

Hogwood, B., Gunn, L. (1984). Policy analysis for the real world. Oxford: Oxford Umiversity press.

Hoogerwerf, A: (1989). Owerheidsbeleid. (wierde druk) Alphen aan de Rinn: Samsom.

Houwaart, E. (1991). De Hygiënisten. Artsen, staat \& volksgezand heid in Nederland, 1840.1890. Groningen: Historische Uitgeverij.

Howlett, M. (1994). Policy paradigms and policy change: lessons from the Otd and New Canadian Policies Towards Aboriginal People. Policy Studies Journal, 22 (4)], pp: 631-649.

Hufen, J., Ringeling, A. (1990). Beleidsnetwerken. Overheids-, semi-owerheids-en particuliere organisalties in wisselwerking. Den Haag: VUGA.

Hunkeler, E., Dovis, E., MeNeil, B., Powell, J., Polen, M. (1990). Richimond quits smoking. A minority Community Fights for health. In Brocht, N. (ed.). Health Promotion at the Community Level. Newbury Park: SAGE.

Idenburg, $\mathbb{P},(1992)$. Wat is sociale vermieuwing? Beleidswetenschap, 6 (1), pp. 31. 14.

Hich, 1. (1976). Limits to medicine. Medical Nemesis: The Expropration of Healih. Landon: Marion Boycars. 
Inspectie woor de Volksgezondheid (1995). Gemeentelijke betrokkenheid bij collectieve prewentie. Rijswilk: Minsterie wen WWS.

Jacobs, J. (1961). The death and life of great American cities. New York: Random House.

Jerkings-Smith, H., Sobotier, P. (1994). Exaluating the Advocacy Coalition Framewark. The Journal of Public Policy, $18(3)$, p. $181-191$.

Janabhai, $C$., Coovadia, H., Abdaol-Karim, 5. (1986). Socia-medical indicators for health in South African.

International Journal of Health Services, $16(1), \mathrm{pp} .163-176$.

Joosen, 1. (1996). De GGD in antwikkeling... If Innovatie in beleid, organisatie en taken van GGD*en. (Masters

thesis in Healuh Policy ard Adminstration;) Modstricht: University Maastricht.

Juffermons, P (1982). Stoot en Gezondheidszorg in Nederland. Nïmegen: SUN.

Kaditk; di (1995). The European Network of Health Promoting Schools. A research to the functionung of the Suppont Centres. (Mosters thesis Health policy and administration). Maastricht: University of Maastricht. Katz, D., Kathn, R. (1966). The Social Psychology of Organizations. New York: Wiley \& Sons.

Kelly, M., Davies, K., Chartton, B. (1992). A modern problem or a post-madern solution? In Davies, J., Kelly, M. (eds.). Healthy Cities, Resiearch \& Practice. London: Routledge.

Kenis, P, Schneider, V. (1991). Policy newworks and policy analysis: scrutinizing a new analytical toolbox. In Marin, B., Mayntz, R. (eds.) (1991). Palicy Networks. Empirical Evidence and Thearetical Cansiderations. Frankfuit: Campus/Westview:

Kennedy. A. (1994). Practising Heath for All" in a Glasgow housing Scheme. The Drumchapel Healthy Cities Project 1990-1992. Glosgow: Drumchapel Community Health Project.

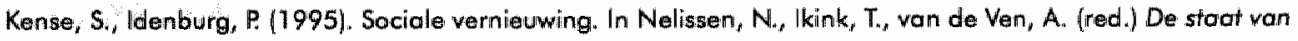
vernieuwing. Leiden: Stenfert Kroese.

Kerkhoff, A: (1994). Honderd jaor gemeentelijke geneeskundige en gezondheidsdiensten. Bussum: Coutinho. Kerkhoff, A. (1995). Overheid en gemeentelijke gezondheidszorg in deze eeuw. Een terreinverkenning. In Rigter,

R. (red), Owertheid en gezondheidszorg in de twintigste eeuw. Een verslag van het symposium ter gellegentheid van het viffentwintjarig bestaan van de stichting Historica Medicinae op 7 Mei 1993. Ratterdam: Erasmus Publishing.

Keuning, D. (1973). Algemene systeemtheorie, Systeembenadering en Organisatietheorie. Leiden: Stenfert Kroese.

Kiekbusch, 1. (1986). Health promotion: a global perspective. Canadian Journal of Public Health, 77, pp. $321-326$. Kickbusch; 1. (1989\%). Good planets are hard to find. WHO Healthy Cities Papers nr. 5. Copenhagen: FADL. Kickbustch 1. (19896). Haalthy Cities: a working project and a growing movement. Health Promotion, 2 (4), pp. $77-82$

Kickbusch, 1. (1989 ). Approaches to an ecological model for public health. Health Promotion, 4 (4), pp. $265-268$. Kickbusch, 1. (1995). Health Promotion: the way forward. Health Promotion International, 10 (1), pp. 1-3. Kingedon, J. (1984; 1995). Agendas, Alternatives and Public Policies. New Mork: Harper Collins callege pubilishers. Klin, E. (1992). Policy communities, subsystems and netwrorks. An examination and reformulation of some concepts for analyzing complex policy processes. Resecirch Programme: "Policy and Governonce in Camplex Nehworks" Working paper nr. 4. Rotterdam/Leiden: valkgroepen Bestuurskurnde Erasmus Universiteit Rottordam/Rijksuniversiteit Leiden.

Klijn, E. (1994). Policy Networks: an overwiew. Theoretical Background and Main characteristics of the Policy Network Approach. Research Programme: 'Policy and Governance in Complex Networks' Working paper nr. 11. Rotterdam/Leiden: vakgroepen Bestuurskunde Erasmus Universiteit Ratteridam/Rijksuniversiteit Leiden.

Kilin, E., Teisman, G. (1992). Beleidsnetwerken: anolyse en management. Een theoretische beschouwing ower analyse en management van beleildsprocessen in complexe beleidsstelsels. Research Programme: 'Policy and Governance in Complex Networks' Working paper nr. 2. Rotterdam/Leiden: wakgroepen Bestuurskunde Erasmus Universiteit Rotterdam/Rïksiuniversiteit Leiden. 
Komter, A. (1983). De onmacht van het getal. Kennis er Methode, 7 (3), pp, 202-226.

Koppenjan, J. 1993). Monagement van de beleidsworming. Den Haag: VUGA.

Koppenjan, J., Ringeling, A., Veld ter, R. (red.) (1987). Beleidsworming in Nederlond; aen vargelikkende studie naor de totstandkoming von wetten. Dien Haag: VUGA.

Korsten, A., Bertrond, A., Jong de, P., Soeters, J. (red.)(1995). Internationacl vergelijkend onderzoek. Den Haag: WGA.

KPMG Klynveld Management Consultants/Nederlionds linstituut voor Praeventieve Gezondheidszorg TNO 1993). De werking van de Wet Collectieve preventie volksgezondheid.

Kuypers, P, Lans, van der J. (1994). Verzorgingsstaat-nieuwe-stijl wraag om modern paternalisme. Nolkskront, Forum, 26-02-1994, pp. 18.

Labontê, R. (1989). Pesticides and healthy public policy. Canadian Joumal of Public Health, $80(6), \mathrm{pp}, 469$. Labonté, R. (1994). Health Promotion and Empowerment: Reflections on Professionall Practice. Health Education Quarterly; 27 (2), pp. 253-268.

Laumann, E., Knoke, D. (1987). The Organizational State. Wisconsin: University of Wisconsin Press.

Leeder, S. (1995). The Contribution of Epidemiology to the Definition of Health Goals and Targets for Australio. International Joumal of Epidemiology, 24 (3), pp. S109-112.

Leeuw de, E. (1989 a). The Sane Rewolution. Maastricht: van Gorcum.

Leeuw de, E. (1989b). Health Palicy: Maastricht: Sawannah/Datawyse.

Leeuw de, E. (1993). Health pollicy, epidemiology and power: the interiest web. Health Promation international, 8 (1). pp. 49-53.

Leeuw de, E. (1997). Beyond community action: communication arrangements and policy metworks. Im Poland, B., Green, L., Rootman, 1. (eds.). Seftings for health promotion. Newbury Park: SAGE.

Leeuw, de E., Breemer ter Stege, C. Jong de, G. (red.) (1990). Research for Healthy Cities. Proceedings of an international conference 21-23 June 19.89, the Hague the Netherlandis. Leiden: Netherlands Society of Public Health and Science.

Leeww de, E., Goumans, M. (1993). Current Research and Evaluation on Healthy Cities programines. A Focus on Community Research Priarities and the Producers and Users of this Research. Paper presented at the International Healthy Cities and Communities Conference, San Francisco.

Leeuw, de E., O'Neill, M., Gaumans, M., Bruilin, de F. (eds.)(1993). Healthy Cities Research Agenda. Praceedings of an Expert Panel. RHC Monogiraph Series nr. 2. Maastricht: WHO CC RHC.

Leeuw, F. (1989). Beleidstheorieën: veronderstellingen achter beleid. In Hoogenwerf, A. Overheidsbeleid (vierdie druk). Alphen aan de Rin: Samsom.

Lehning, P, Simonis, J. (red.) (1987). Handboek beleidswetenschap. Meppel: Boom.

Laüienaar, M., Niemöller, B. (1988). Intenview: barrieres voor carrieres: vrouwen in hét openbaar bestuur. In Derksen, W. Korsten, A., Biertrand, A. (red.). De praktijk van onderzoek. Problemem bil anderzoek van polim tiek, bestuur en beleid. Groningen: Wolters-Noordhof.

Levin, L., MeMahon, L., Ziglio, E. (eds.)(1993). Econamic Change, social Welfare and health in Europe. WHO Regional Publlication. European Series nr. 43. Copenhagen: WHO/EURO.

Levin, L., Zighio, E. (1996). Health promotion as an investment strategy: considerations on theory and practice. Health Promotion International, 11 (1),pp. 33-40.

Levy, A., Merny, U. (1986). Organizational transformation. Praeger publishers.

Liedekerken, P., Jonkers, R., Haes de, W., Kok, G., Salan, J. 11990). Effectiveness of Health Education. Utrecht: Landelijk Centrum voor GVO.

limbeek van, J., Alem wan, V., Rengellink, H. (1992). Epidemiologie en beleid. Tijdschriff woor Sociale Geneeskunde, $70(1)$, pp. 63-67.

Lipman, M. (1992). Veranderen voor anderen. Een tussentijese evaluatie van de implementatie van het Gezande Stad beleid binnen de GGD Rotterdam e.0.. Rotterclom: GGD. 
Lipsky, M. (1980). Street-fevel bureacracy: Dilemmas of the individual in public senvices. New York: Russel Sage Foundation.

Liverpool District Health A:uthority (1994). Annual report director of Public Health (1993-1994). Liverpoot: LDHA. Liverpool Healthy Cily (1995). Draft Cify Health Plan for Liverpool. Liverpool: Liverpool Healthy City.

Logghe, (19. (1996). Integratie: het beste gezondheidsbeleid? RHC Monograph Series nr. 13. Macstricht: WHO CC RHC.

Lugo, N. [1996). Empowerment Education: A Cose Study of the Resource Sisters/Companeros Program. Health Education Quarterly, 23 (3), pp. 281-289.

Mararse, J. (1990). Overheid en wolksgezondheid. In Moorse, J., Mur-Veeman, I. (red.). Beleid en Beheer in de Gezondheidsziorg. Assen/Maustricht: van Gorcum.

Maarse; 1: (1995). De verklaring van de effectiviteit van een beleid. In Bressers, 1, Hoogerwert, A. (red.).

Beleidsevaluatie. (derde druk). Alphen oan den Rijn: Samsom H.D. Tjeentk Willink.

Maas, van der P., Habbema, J. (1987). Madellontwikkeling en informatie: twee voonwaarden woor gezondheidsbeleid. In Dekker, E, Wijberg. B. (red.). Gezondheidsbeleid over de grenzien van gezondheidszorg. Reeks gezondheidsbeleid, deell 1. Alphen aan de Rijn: Somsom Stafleu.

Mackembach, J. (1994). Ongezonde Verschillen: over sociale strotificatie en gezondheid in Nederland. Assen: van Gorcum.

Mahler, H. (1981). The meaning of "Health for all by the year 2000". World Health Forum, 2 (1), pp. 5-22.

March; J., Olsen, J. (1976). Ambiguity and Choice In Organizations. Bergen: Universtitets-forlaget.

Marin, B., Mayntz, R. (eds.) (1991\%. Policy Netwarks. Empirical Evidence and Theoretical Considerations.

Fronkfurt: Campus/Westview.

Maso, 1. (1989). Kwolitatief onderzoek. Moppel: Boom.

Mason, R., Mitroff, 1. (1984). Challenging strotegic planning assumptions: theary, cases and techniques. Kansos. McDermott, W. (1977). Evaluating the physician and his technology. Daedalus, 106 (136).

MeKeown, T. (1976). The role of Medicine. Dream, mirage or nemesis. London: Nuffield Provincial Haspital Trust.

MetKinlay, J. (1992). Health promotion through healthy public policy: the contribution of complementary research methods. Canadion Journal of Public Health, 83 (2), suppl. 1, pp. 11-19.

Mckinlay, J. (1993). The promotion of health through planned sociopolitical change: challenges for research and policy. Sacial Science and Medicine, 36 (2), pp. $109-117$.

Mcleroy, Ka, Bibeav, D., Steckler, A., Glanz, KK. (1988). An Ecological Perspective on Health Promotian Programs. Health Education Quarterly, 15 (4), pp. 351-377.

MeNamara, R. (1993). Community Development Strategy. Glasgow: Glasgow Healthy City Commumity Support Unit. Mega, V. (1996). The Wellbeing of Cities and Citizens in Europe. In Price, C., Tsouros, A. (eds.). Our Cities, Our

Future: Policies and Action Plons for Heolth and Sustainable Development. Copenhagen: WHO/EURO, Ayuntamiento da Madirid, OECD, EFlLWC.

Meijer, A. (1994). De GGD in zinin omgewing. In Garretsen, H., Hoes de "W., Schiniver, M. (red.). Lokaal

Gezondheidsbeleid. Reeks gezondheidsbeleid - deel 7. Houten: Bohn, Stafleu Von Loghum.

Milburn, M. (1991). Persuasion and Politics. The Social Psychology of Public Opinion. Pacific Grove: Brooks/Cole publishing company.

Milio, N. (1986). Promoting Health through public policy. Ottawa: Canadian Public Health Association.

Milio, N. (1988). Strategies for health-promating policy: a study of four national case studies. Health Promotion, 3 (3), pp. $307-311$.

Milio, N. (19900). Towards healthy public pollicy in food and nutrition. Public Health, 104 (1), pp. 451-54

Milio, N. (1990b). Healthy Cities, the new public healith and supportive research. Health Promation International, 5 (4), pp. $291-297$.

Millo, N. (1991). Making healthy public policy; developing the science by learning the art: an ecological framework for policy studies. In Badura, B., Kickbusch, I. (eds.). Health promotion research. WHO Regional Publications European Series nr. 37. Copenhagen: WHO/EURO. 
Milewa, $T_{0}$, Leew de, E. (1996). Reasons and protest in the new urban public health movement an observation on the sociological analysis of political discourse in the "healthy city". Britisch Jouninol of Sociology. 47 (4), pp. $657-670$.

Mitroff, ${ }^{\prime}$., Turoff, M. (1973). The whys bethind the hows. IEEE Spectrum, March, pp. 62.71.

Mitroff, J., Emshoff, J. (1979). On Strategic Assumption-making: a diallectical Approach to policy and planning. Academy of Manogement Review, $4(1)$, pp. $1: 12$.

Moss Kanter, R. (1994). Collaborative Adwantage: The Ant of Alliances. Harvard Business Review, 72 (4), pp. 96 108

Mucciaroni, G. (1992). The Garbage Can Model \& the study of Policy Making: A critique. Polity, 24 (3), pp. 459. 482.

Mullen, P., Evans, D., Forster J., Gottlieb, N., Kreuter, M., Moon, R., O'Rourke, T., Strecher, V. (11995). Settings as: an Important Dimension in Health Education/Promotion Policy, Programs, and Research. Health Education Quarterly, 22 (3), pp. 329-345. (Theme issue on 'Creating Capacity: A Ressearch Agenda for Public Health Education.")

Navarro, V. (1986). Crisis, Heatth and Medicine: A social critique. New York: Tavistock Publications.

Nijhuis, H. (1994). Voonwaorden voor vernieuwing van Public Health. Een wetenschaps- en maatschoppintheore*isch perspectief. Rijswijk: Elmar.

Ookley, P. (1989). Cammunity involvement in health development. An examination of the critical issues. Geneva: $\mathrm{WHO}$

Oers van, 1. (1993). A geographic information system for local health policy. Assen: van Gorcum.

O'Connor, B. (1995). The Wictorian Declaration a unifying force. Canadian Journal for Cardiology, $11(11)$, sup. plement A pp. 12A-13A.

O'Neill, M. (1989). Community health projects in Quebec: can they participale significantly to promote the health of the populations in the years to come? Health Promation, 4 (3), pp. 189-198.

O'Neill, M., Pederson, A. (1992). Building a methods bridge between public policy analysis and healthy public palicy. Canadion Jourmal of Public Health, 83 (2). suppl. 1 pp. 25-310.

Olson, M. (1965). The Lagic of Callective Action: Public Goads and the Theory of Groups. Cambridge: Harvard University Press.

Osborne, D., Gaebler, T. (1993). Reinventing Government. How the entrepreneurial spirit is transfarming the public sector. New York: Plume.

Palumba, D. (ed.) (1987). The politics of evaluation. Newbury Park: SAGE.

Pannerborg, C. (1978). A new international health order. An inquiry into the international Relations of World Health and Medical Care. Albliasserdam: Davids Decor.

Parsons, T. (1979). Definitians of health and illness in the light of American values and social structures. In Jaco, E.

(ed.) Patients, Physicians; and Illness. A saurceboak in Behaviaral Science and Health: New York: The Free Press.

Patton, M. 1978). Utilization focused evaluation. Beverly Hills: SAGE.

Patton, M. (1990). Qualitative evaluation and research methods (2nd edition). Newbury Park: SAGE.

Paulussen, T. (1994). Adoption and implementation of AIDS education in Dutch secandary schools. Utrecht"

National Centtre for Health Education: \& Promotion.

Pearson, A. (1991). Managing innovation: an uncertainty reduction process. In Henrey, J., Wolker, D. (eads.). Managing innovation. Landon: SAGE.

Pederson, A., O'Neill, M., Roatman, l. (eds.)(1994). Health Promation in Canada. Prowincial, netional \& internationcl perspectives. Toronto: W.B. Saunders.

Pettigrew, A., Ferilie, A. McKee, L. (1992). Shaping Strategic Change. London: SAGE.

Pinder, L. (1988). From A new perspective to the Framework: a case study on the development of health promotion policy in Canada. Health Promotion, 3 (2), pp. 205-212. 
Polond, (19960). Knowledge development and evoluation in, of and for Healthy Community imitiatives. Part 1 : guiding principles: Heath Promotion International, 11 (3), pp. 237-247.

Poland, B. (1996b). Knowledge development and evaluation in of and for Healthy Community initiatives. Part II: potential content foci. Health Promotion International, 11 (4), pp. 341 -349.

Posner, B., Rothitein, L. 1994\. Reinventing the Business of Gowernment: An Interview with Change Catalyst Diavid Osborne. Honord Business Rewiew, 72 (3), pp. 133-143.

Price, $C_{1}$, Tsouros, A. (1996). Our Cittes - Our Future: Policies and Action Plans for Health and Sustainable Development. Copenhagen: WHO/EURO, Ayuntamiento de Madrid, OECD, EFILWC.

Querido, A. (1965). Eien statstaezicht op volksgezondheid. Den Haag: SDU.

Radaelli, C. (1995). The rolle of knowledge in the policy process. Journat af European Public Policy, 2 (2), pp. 159-183.

Reineveld, M. (1995). The measurement of Local Public Health. (Phd thesis, Uniwersity of Amsiterdam). Wageningen: Ponsen \& Loaijen.

Robertson, A, Minkler, M. (1994). New Health Promation Movernent: A Criticall Examination. Health Education Quarterly, 27 (3), pp. 295-312.

Rifkin, S. [1980). Community participation in health: a planner's approach. Reodings in Health, Development and Community Participation, special series (3), pp. 1-7.

Robertson, A., Minkler, M. (1994). Now Health Promotion Movement: A Critical Examination. Health Education Quarterly, $21(3)$, pp. 295-312.

Rogers, E. [1983] Diffusion of Innovations [third Edition]. New York: the Free Press.

Ruiter, R. (1995). The European network of health promoting schools in Bulgario: development of school level. (Master thesis Health education) Maostricht: University of Maostricht.

Saan, H. (1990). A checkligt to assist the planning of intersectaral action. In Taket, A. (ed.) (1990). Making Partners. Intersectoral action for health. The Hague/Copenhagen: WHO/EURO, Ministry of Welfare, Health and Cultural affairs.

Saan, H., Ellenkamp, J., Boogcard, wan den J. (red.)(1994). Intersectorale actie. Vaor grensbewoners is smakkelen normaal. Gezonde steden reeks nr. 4. Assen: van Gorcum.

Sabatier, P. (1987). Knowledge, Policy-oriented Learning, and Policy Change. And advocacy Coalition Framework. Knowledge, Diffusion, Utilization, 8 (4), pp. 649-692.

Schwartz, H. Jacobs, J. (1979). Qualitative Sociology, a methad to the madness. Niew York: The free press.

Sehwartz, R., Goodman, R., Steckler, A. (1995). Theme Issue: "Policy Advocacy Interventions for Health Promotion and Education". Health Education Quarterly, 22 (4), pp. 421-527.

Schuyt, K. (1997a). Do samenlaving is gean oude stoel die zomaar vit elkaar valt. Volkskrant, Forum, $18-01-1997, \mathrm{pp} .18$.

Schuyt, K. (1997b). Sociaal beleid moet mensen waoral stimulerem zichzelf te helpen. Volkskront, Forum, 22-02-1997, pp. 18

Scotp-Samuel, A. (1989). The WHO strategy and community nuttrition in the United Kingdom. Nutrition and Heolth, 6 (3), pp. 129-133.

Senge, $\mathrm{P}$. [1995). Uitsluitend willen overleven is ongezond. Intermediair, 31 (42), Pp. 25-29.

Secretary of State for Health (1990). The Nationol Health Service and Community Care Act. London: HMSO. Secretary of State for Health (1992). The health of the nation: a strategy for health in England. London: HMSO Siler-Wells, G. (1987). An implementation model for health system reform. Saciol Science and Medicine, 24 (10\%, pp. 821.832 .

Silwerman, D. (1993). Qualitative data. London: Sage.

Simon, H. [1957]. Admimistrative behaviour: a study of decision-making pracesses in administrative organization. New York: MacMillan. 
Snithies, 1., Adams, L. (eds.) (1990). Community porticipotion in health promotion. London: Health Education Authority.

Springett, J. (1995). Intersectoral collaboration: Theary ond Practice. Liverpool: Institute for Hedth, Liverpool John Moores Uniwersity.

Staatsalmanak (1996). Stootsalmonak voor het Koninkrijk der Nederlanden (1995-1996). Den Hoag: SDU.

Stake, R. (ed.) (1975). Evaluating the Arts in Education: A responsive approoch. Columbus (Ohio)! C.E. Meritll.

Stake; R. (1994). Case studies. In Denzin, N., Lincoln, Y. (eds.). Handbook of Qualitative Research: Thousand Ooks: SAGE.

Steweson, H., Burke, M. (1991). Bureaucratic logic in new social movement clothing the limits of health promo tion research. Health Promotion International, 6 (4), pp. 281-289.

Stone, D. (1989). Causal Stories and the Formation of Policy Aglendas. Political Science Quarterly, 104. (2), pp. $281-300$.

Stoové, E. (1992). Contractmenagement en zelfbeheer. De europese gerneente, 28, pp. 23-28.

Strauss, A, Corbin, J. (1990). Basics of qualitative research. Newbury Park: SAGE.

Sullivan, T. (1991). Strategic planning for health. How to stay on top of the game. Health Promotion, simmer, pp. $2-13$.

Svaboda, B. (1989). Community health projects in Austria. Health Promotion, 4 (3), pp. 255.259*

Swaan de, A. (1993). Zorg en de Staat. Welzijn, ondenwijs en gezondheidszorg in Eupropa en de Verenigde Stałen in de nieuwe tijd. Amsterdam: Uitgeveri Bert Balkker.

Swaan de, A. (1995). "De sociologische studie wan de transnationale samenleving.". Het Amsterdams sacialagisch tijischrift, 22 (1), pp. 16-35.

Swamborn, P. (1987). Methoden wan saciaal wetenschappelijk onderzaek. Meppel: Boom.

Taiket, A. (ed.)(1990). Making Partners. Intersectoral action for health. The Hague/Copenhagen: WHO/EURO, Ministry of Welfare, Health and Cultural affairs.

Tatenhove, van 1, Leroy, P. (1995). Beleidsnetwerken: Een kritisch analyse. Beleidswetenschop, 9 (3), pp. 128. 145 .

Teilsman, G. (1992). Complexe besluituorming. Een pluricentrisch perspektief op besluitvorming over ruimtelïke investeringen. Den Hoog: VUGA.

Thampson, J. (1967). Organizations in Action. New York: MeGraw-Hill.

Thompson, B., Kinne, S. (1990), Social change theory. Applications to Community health. In Bracht, N. (ed.) Health Promotion of the Community Level. Newbury Park: SAGE.

Townsend, Pr, Dovidson, N., Whisiehead, M. (eds.) (1990). Inequalities in Health. The Block report - The Health Divide. London: Penguim Sacial Sciences.

Trojan, A. (1990). Supporting self-help groups and community organizations: from ressarch to pollicy and practice. In Evers, A., Farrant, W. Trajan A. (eds.). Healthy Public Policy at the Local Level. Frankfurt am Main: Compus Verlag/Westriew Press.

Tsouros, A. (ed.) (1991). The WHO Healthy Cities Project: o project that becomes a mowement. Review of progress 1987-1990. Copenhagen: FADL.

Tsouros, A. (1995). The WHO Healthy Cilties Projecti: state of the art and future plans. Health Promotion International, $10(2)$, pp. 133-141.

Tweede Kamer (1982). Wet Woorzieningen Gezondheidszorg. Tweede Kamer, vergoderiaar 1982-1983, 17720.

Tweede Kamer (1986). Over de ontwikkeling van gezondheidsbeleid: feiten, beschouwingen en beleidswoornemens (Noto 2000). Tweede Kamer, zitting 1985-1986, 19500, nrs. 1-2 (28 April 1986)

Tweede Kamer (1990). Wet Collectieve Preventie Volksgezondheid. Tweede kamer, vergaderjaar 1988.1989 , 20977.

Tweedle Kamer (1991). Gezondheid met Beleid. Gezondheidsbeleid 1992. Tweede Kamer, verguderjeror 19911. 1992,22459, nr. 2.

Tweede Kamer (1993). Wet Voorzieningen Gehandicapten. Tweede Komer, vergaderjoar 1993.1994, 22815 
Tweede Komer (1995). Gezond en Wel. Volksgezandheidsbeleid 1995-1998. Tweede Kamer, vergoderjuar 1994 - 1995,24126 , nrs. 1.2 .

UPCHS (1996). An Urbenizing World: Glabal Report on Human Settlements. Oxford: Oxford Uniwersity Press.

Vellheer, W. (1994). Kantelend besfuur. (Sociale en Culturele Studies - 20). Rjiswilk: Sociaall cultureel planburo. Veirkruisen, W., Wis, B. (1995). Gemeente en gemeentewet. de herziene druk. Stadts-en bestuursirechit 6 . Nijumegen: Ars aequi Libri.

Villalbi, 1., Costa, J, Oller, N. (1989), Community initiotives against AlDS in Barcelona. Health Promotion, 4 (3), p. $225-230$

Waldrop, M. (1992). Complexity: The Emerging Science at the Edge of Order and Chaos. New York: Simon and Schuster.

Wallerstein, N., Bernstein, E. (1994). Introduction to community empowerment, participatory education, and health. Health Educiotion Quarterly, 21 (2), pp. 141-1.48.

Water von de, H, van Hertien, L. (11996). Bull's Eye or Achilles" Heel. WHO's European Health for All Targets Evaluated in the Netherlands. Leiden: TNO Prevention and Health.

Watt, A. (1986). Community Health Ediucation: A time for Coution? In Rodmell, S., Watt, A. (eds.). The politics of Health Education. Ralising the issues. London: Routledge.

Webster, P. Price, C. (eds.)(1996). Heathy Cities Indicators. Analysis of data from across Europe. Copenhagen: WHO/EURO/HPCO, South East Institute of Public Health.

Werna, E. Harpham. T. [1995). The evaluation of Healthy City Projects in Develaping Countries. Habitat Internationol, $19(4)$, pp. 629-641.

Werno, E., Harphom, T. (1996). The Implementation of the Healthy Cities Project in Developing Countries. Lessans from Chittagong. Habitat International, 20 (2), pp. 221-228.

Whelan, A., Mohrr, R., Short, 5. (1992). Waving or Drowning. Evaluation of Heallhy Cities in Australlio (notional secretatiat). Final report Australian Community Health Association.

WHO (1947). Preamble to the Constitution of the World Health Organizotion. Geneva: WHO.

WHO (1977a). Hoalth for All by the Year 2000. World Health Assembly. Geneva: WHO.

WHO (1977b). Cammunity invalvement in primary health care: a study of the process of community motivation and continued porticipation. Report for the 1977 UNICEF-WHO Joint Committee on health policy (JC21/UNICEF WHO/77.2 Rer 2). Geneva: WHO.

WHO (1991). City networks for health. Technical discussions on strategies for health for all in the face of rapid urbanizalion. Geneva: WHO.

WHO (1995). WHO Healthy Cities: A programme framework. A review of the operation and future development of the WHO Healthy Cities programme. (WHO/EOS/95.11) Genewa: World Health Organization.

WHO (1996). Creating Healthy Cities in the 21st Century. Background on health in human settlements.

Background paper to the United Nations conference on Human settiements. (W/HO/EOS/96.9) Habitat II, Istambul, Turkey 3-14 June. Geneva: WHO.

WHO, Health \& Welfare Camada, Canadian Public Health Assaciation (1986). Ottawa Charter for Health

Promotion. An Internotional Conference on Health Promotion - The Move Towards A New Public Health, Now. 17.21 , Ottowa.

WHO, UNICEF (1977). Community involwement in Primary Health Care: A study of the process of community motivation and continued participation. Report for the 1977 UNNICEF.WHO Joint cammittee on thealth policy. Geneva: WHO.

WHO/EURO (1985). Targets for Health for All. Copenhagen: WHO/EURO.

WHO/EURO (1988). The Adelaide recommendations, Healthy Public Policy. Copenhogien/Adellaide: WHO/Euro and Department of Community Health Services, Australian Commonwealth. 
WHO/EURO (1989). Europeon Charter on Environment and Health. First European Conference on Environment and Health. Copenhagen: WHO/EURO.

WHO/EURO (1991) Rewised targets for Health for All. Copenhagen: WHO/EURO.

WHO/EURO (1992). Ploying for time... Creating supportive enviranments for Health. Repon from the 3d International Canference on Health Promotion. Sundsvall, Sweden June 9.15 1991. Sundsvalli United Nations Environment Programme, WHO, Nordic Cauncil of Ministers.

WHO/EURO (1993). European Netwrork of Health Promoting Schools Resource Manual. Coperihagen: WHO/EURO.

WHO/EURO [1994). The WHO Health Promoting Hospitals Project. Copenhagen: WHO/EURO.

WHO/EURO (1995). Securing Investment in Health. Report of a Demonstration Project in the Provinces of Bolzano and Trento. Copenhagen: WHO/EURO, Yalle Schaol of Public Health, and Office for Public Managementt.

WHO/EURO [1996]. Inwestment for health in Slowenia. Report of a Team from WHO Regional Office for Europe and the European Committee for Health Promotion Development. Copenhagen: WHO/EURO.

WHO/EURO/HCPO (1988a). Promoting Health in the Urban Context. WHO Healthy Cities papers no. 1.

Copenhagen: FADL.

WHO/EURO/HCPO (1988b). A Guide to Assessing Healthy Cities. WHO Healthy Cities papers no: 2.

Copenhagen: FADL.

WHO/EURO/HCPO (1988c). Five-Yeor Planning Framewark. WHO Healthy Cities Papers no. 3. Copenhagen: FADL.

WHO/EURO/HCPO (1992). Twenty steps for developing o Healthy Cities project. Copenhagen: WHO/EURO. WHO/EURO/HCPO (1993). City Action for Health. Review of the first phase of the Healthy Cities project.

Copenhagen: WHO/EURO.

WHO/EURO/HPCO (1994a). National Healthy Cities Networks in Europe. (2nd edition). Copenhagen: WHO/EURO.

WHO/EURO/HPCO (1994b). Action for health in cities. Copenhagen: WHO/EURO, University of Edinburgh. WHO/EURO/HCPO (1994c). City Health Plans and City Health Planning. (IICP HCIT $9401 \mathrm{MT} 06 / 7$ ) Copenhagen: WHO/EURO.

WHO/EURO/HCPO (1995a). City Health Plons. Current stalus in WHO Healthy Cities Project Network.

Response to questionnaire to Healthy City projects. (ICP HCIT 9401 MT 06/9) Copenhagen: WHO/EURO. WHO/EURO/HPCO (1995b). Health and sustainable development: Implications for cities in the second phase of the WHO Healthy Cities Project. Background paper to the Business Meeting of the Healthy Cities Project, Madrid 20-21 March 1995. Copenhagen: WHO/EURO.

Warldbank (1993). World Development Repart 1993. Investing in health. Washington: World Bank. World Resources Institute (1996). World Resources 1996-97. New York: Oxford University press.

Yin, R. (1990). Case study research. Design and methods. (revised edition) Newbury Park: SAGE.

Zaal, K., Ooijendiikk, W. (1993). Gezonde Steden Beleid Almelo. Leiden: NIPG/TNO.

Zee van der, H. (1983). Tussen vraag en aanbod. Beginselen van sociaal-wetenschappelijk onderzoek. Meppel: Boom.

Ziglio, E. (1986). "Uncertainty" in health promotion: Nutrition policy in two countries. Health Promotion, I (3), pp. $257-268$.

Zwaan van der, A. (1979). Interorganisationele samenwerking in de gezandheidszorg. Tijdschrift woor Sociale Geneeskunde, 57 (5), pp. 151-159. 


\section{Appendices}

\section{Appendix 1: Local Public Administration}

"Each lacal authority needs to be studied as a political system in its own right."

(Stanyer in Hampton $(1987)$ )

\section{United Kingdom}

\subsection{Thie structure}

Until the effectuation of the Local Government Act of 1972 the local administrative structure in the United Kingdom consisted of county borough councils, rural councils, and district councils: The county borough council was responsible for the provision of all locall services in large cities and towns. In smaller areas, service provision was divided between the county council, the municipal borough, the rural district, and urban district council. Some rural districts were divided into parishes, with parish councils. This all resulted in a two or three tier structure of government. The London Government Act of 1963 replaced the county council in this specific area with the Greater London Council. The most important reason for this administrative reorganisation was that due to the migration from the city of London to the sub-urbs the old administrative structure was no longer adequate.

In 1966 the national government installed two committees who had to investigate the local government structure in England and Scotland. The Conservative government was, however, not satisfied with the suggested recormmendations for England (58 unitary multi purpose authorities, excluding three areas where a two tier system was suggested by the Recliffe-Maud committee). The recommendations of the Scotland committee (the Wheatley committee) fitted far better with central government's proposals.

This resulted in 1972 in a Local Government Act for Britain. In this act a three tier government structure was introduced. The first tier consists of six metropolitan county councils, 47 non-metropolitan county councils and the Greater London Council. In the second tier 333 non-metropolitan districts replaced the mumicipal boroughs, urban and rural district councils. Besides the non-metropolitan districts, an additional 36 metropolitan district council and 32 London Borough councils and the city council of London are part of the second tier. Finally, 11.000 parishes (England) and communities (Wales), of which 8000 have councils, compose the third tier. In Scotland a Local Government (Scotland) Act was adopted in 1973. Comparable to England also here the major reform was a reduction in the amount of councils and authorities. Scotland had with the 1973 Act nine regional councils, 53 district councils, 1350 community councils and three island authorities.

With the reorganisation of government because of these Acts local authorities lost there responsibility for some services, such as water supply and sewage disposal. The tasks and responsibilities that are under local govermment responsibility are nowadays: housing (rentals), environmental services, personal social services, police, fire, school education, public transport (except for British Railways), roads (except for highways), refuse collection, leisure and recreation and city planning (Bailey, 1993).

\subsection{Finances}

Local government income is derived from different sources, such as: locall rates (local property taxation), central government grants, and charges for services, for example, toll, fare, interest, fees, etcetera. Local government can also receive so called 'capital grants' from 
central government or can take loans in order to finance long term capital expenditures. like land or buildings. In order to have additional income, local government can as well sell a part of their land properties. Most local government money ( $85 \%$ ) comes from central government. Central government cam put a limit on what local government can spent. Within these limits local governments have a certain amount of discretion about the extent to which that money is spend on housing, or education, or social services. So there is discretion but within very tight limits. With regard to joint funding of health and community care programmes in a city most local authorities form a Joint Consultative Committee (JCC) with a Health authority and some other actors. Both the Health authority and local authority put finances in the committee's budget.

\subsection{Administrative structure and political structure}

A city administration consists of several departments or services. A Chief-Executive is responsible for the city administration. In recent years city administrations show a change towards a corporate organization structure.

The city council is chaired by the Mayor, who is elected annually by the full Council following the yearly local elections in May. Having a yearly election implies that only part of the city council members change seats. This "partly renewal' has to guarantee a continuity of processes in the city council. Councillors participate on a voluntary basis and every year $1 / 3$ of the council is under election. The majority of the council business is delegated to committees and the day-to-day management is delegated to paid officers of the anthority.

The departments receive their work through activities of either the city council or the various committees and sub-committees. The Chief-Executive, city councillors, and officers from the various departments, take place in a policy and resource committee. It is within this committee that resources are divided between the departments and that decisions on policy development and policy integration are made. The other (sub)committees are chaired by councillors, but contain furthermore members from different parties and officers.

Officers, a group with a specialist knowledge, are said to form about $20 \%$ of all local authority employees, civil servants form another 50\% and the third category (30\%) of employees consist of teachers, firemen, and police. The local authority officers are most likely to be involved in policy development and public administration management roles (Greenwood \& Willson, 1984). Chief officers spent much time in liaising with other departments or with groups and organization in the locality in order to formulate the most appropriate corporate strategy.

\subsection{Party politics}

The most important political parties in local government are Conservatives, Labour, and Liberal democrats. Besides these three some local parties may exist:

The Conservative party and Labour party, the largest parties att local level, have a principal difference in government style. "The' Conservative perspective on government is that government exists to make sure that the system can function in itself and provides only assistance to those who are by no means able to take care for themselves. The provision of services must take place from a 'value for money' point of view. 'The' Labour perspective on the other hand is that government services should be available for all who want to make use of it. This means that rates and taxes may raise if this is of benefit for the provision of services for those who need them.

How the local politics exactly operate may however differ from locality to locality. Local circumstances and personalities and ideas of the councillors and officers may have more influence on the political process than the several basic party political ideas (see also Elcock, 1982). 
Until 1948 local government had a large role in public health and in the administration of health care. With the start of the National Health Service (NHS) in 1948, regional hospital boards; hospital management committees and executive councils for general practitioners took over local government tasks of strategic planning and resource allocation. County and Country borough councils remained responsible for district nurses and ambulant services. Furthermore, local government had also to appoint a Health Committee and a Medical Officer of Health to oversee the service provision.

The reorganization of the NHS in 1974 resulted for local government again in the loss of responsibilities for health care to local and regional bodies that are financed and appointed by a central government sector. Local government, however, retained its responsibility for the personal social services. Social workers are employed by the local authority. After the 1974 re-organization the NHS had four levels of management and four types of administering and controlling bodies: central government department of health, Regional Health authorities, Area Health authorities which were divided in Family Practitioner committees and District Management teams. In 1982 the Area Health authorities and District Management tearns were unified into local Health authorities.

Local authority is represented with a maximum of four persons in the governing body of a Health authority. Local authority is also represented in the Community Health Council which is a body of community representatives and councillors. Community Health Councils have no executive or managerial functions but are responsible for investigating complaints about local health service provision, considering proposals for the closure or change of use of NHS institution, and checking on the quality of local service provisions. Local authority and district Health authority together with voluntary organizations form Joint Consultative Committees. The concrete from of these committees varies, because the boundaries of a local authority may differ from the Health authority boundaries. Joint Care Planning Teams coordinate the NHS and local authority services that are available for the patient groups on which they are focusing, for example elderly or the mentally ill.

During the years many other changes took place within the NHS. The most recent changes are a result of the National Health Service and Community Care Act (1990) which introduced a separation of purchasers from providers and introduced a market mechanisms in the NHS.

\subsection{The cities}

Glasgow. Glasgow is divided in 66 wards, with each ward retuming one councillor for the ciry council. The city council consist by May 1994 of 54 Labour councillors, five Conservative councillors, two Scottish Nationalist councillors, two Independent councillors, two Scottish Militant Labour councillors and one Liberal Democrat councillor. Labour forms the admiaistration, what means that committees are chaired by Labour members and have Labour majorities.

"The Councills policies are based on the monifesto produced by the City Labour Party before the 1992 elections. Its strategic objectives are to increase the number of jobs in the city, to tackle urban deprivation and envirommental problems, and to halt the loss of population and encouroge more people to live in the city." (Glasgow City councl, 1993 p. 4)

The sub-committees of the Policy and Resource committee are directly related with Healthy Cities. The sub-committee on the city environment and health came into existence because of Healthy Cities. It was recognized by the city council that they do not control all the resources necessary to create a healthy environment in Glasgow, nor that they have exclusive responsibility for these issues. Therefore, the sub-committee recognises the importance of working in partnership with all other agencies active within Glasgow, and 
develops and supports joint action through demonstration projects. Furthermore, the Healthy Cities itself is also regarded as a kind of sub-committee under the responsibility of the Policy and Resource committee.

Not only the district authority but allso a regional authority plays an important role in Glasgow. This authority has responsibilities, for example, for social work, education. police, fire-brigade, road and transport service, water service, and sewage disposal. The strategic management group of the regional authority coordinates the regional activities and seeks cooperation between departments. The regional authority holds a health issues group. This groups exists because of the recognition that most of the authority services have health implications, for example the police force's help is needed to create safe neighbourhoods. Furthermore, the police is also involved in tackling alcohol and drugs problems.

The Healthy Cities project provided an opportunity for the two authorities to get together on many issues, for example, social problems that stem from housing problems or traffic and (air) pollution.

Liverpool. The political composition of the city council was after the 1994 May elections 44 Labour and 44 Liberal-Democrats, two Conserwatives, two Liberals, five Liverpool Labour and two Militant Labour members. The Labour party made up the administration and they chaired the committees. It was basically a Labour administration and a city council with no clear majority.

The city administration has eight departments: housing, consumer services, development and environmental services, a resource directorate (which deals with finances, land and architecture services the city council provides), a leisure service including tourism, the arts, eduction and social service, personnel and administration, the operational services and the central policy unit. The Healthy Cities project is part of the central policy unit. The directors, including the assistant Chief-Executive and the Chief-Executive, form the management team for the council. The assistant Chief-Executive functions as the secretary to this management team. Furthermore, he is also responsible for running various programmes and projects.

The two committees that are responsible for health are the Social Service committee and the Environmental and Consumer Protection Cormmittee. Both of these committees have representatives on the board of the Health authority. Although there are many political differences between the several committees and parties, in general they agree on the importance of health protection, health promotion, and envirommental issues.

Newcastle. The city council had by June 199478 members: 60 Labour, 12 LiberalDemocrats, and five Conservatives. Each city council member represents a ward of the city. One ward can have more representatives of more than one party. The administrative structure of the departments was about to change in 1994 into a flat structure with sections that are responsible for the provision of certain services.

At the time of data collection for the research (1994-1995) Healthy City Newcastle was not yet far enough developed to influence policy decisions of the city council. The project was noticed by politicians, officers, and policy makers and its value and possibilities were under consideration.

Sheffield. In June 1994 the Sheffield city council was composed of 56 Labour councillors, 22 Liberal-Democrats, eight Conservatives and one Independent Democrat. The Healthy Sheffield initiative comes under responsibility of the Environmental Heallth and Standards programme committee.

Due to reasons of poverty and a decline in economics and employment, health has been always on the political agenda. Although there is a general interest in health, the Healthy 
Cities ideas as such are most supported by the department of Housing, the Family and Community Services Programme committee and the Environmental Health and Standards Programme committee.

Winchester. The political make-up of the Winchester city council (55 seats) was by June 1994: 28 Liberal Democrats; six Labour; two Independent Conservatives; 17 Conservatives; and two Independents. The Liberal Democrats had an overall majority of one.

Two city council committees are of direct influence for the work of the HFA coordinator, although the other committees have as well their linkages with her activities. The Policy and Finance committee has to advice the council on its overall strategy and priorities, bearing in mind the broad social and other needs of the district; review the effectiveness of all the Council's work; and allocate and review the resources necessary to meet the Council's responsibilities. The Environmental Health Committee ranges from long standing "traditional" local government tasks, such as pest control, refuse collection, food safety and hygiene checks in shops and restaurants, provision of public toilets and adequate sewerage, and licensing of hackney carriages and places of entertainment. In 1995 issues like pollution control, health education, control of dogs, recycling initiatives and the WHO Health for All idea (and thus Winchester Healthy City) have been added as new tasks to this committee.

\section{The Netherlands}

\subsection{The structure}

The effectuation of the Municipal Law of 1851 took place in a period in which legal foundations for a renewed administrative structure of the Netherlands were concretized (The Constitution (1848), the Election Law (1850), the Provincial Law (1950), Law on Dutch Citizenship (1950)). In Thorbeckes eyes, under who's responsibility the above mentioned Laws were created, local government should invite citizens to actively participate in governmental affairs. This was expected to also stimulate citizen participation in, and their commitment to, provincial and national governmental affairs. It seems that these ideas fitted very much with the democratic thoughts of the Healthy Cities project that came into existence some 135 years later.

The Netherlands has a so-called three tier government, besides the national government, twelve provincial governments and about 572 municipal governments exist. These municipalities vary in amount of inhabitants from approxirnately 724195 (Amsterdam) to 981 (Schiermonnikoog) (Staatsalmanak, 1996).

During the last 100 years the social position of the government has changed from a night-watcher state to a welfare state with more government interference. Government policy can be subdivided into:

1 An allocation function of collective and semi collective goods and serwices.

2 A stabilization function in employment, economic growth, macro economical purposes, administration and control of conjunctural movements by a well balanced income and spending policy.

3 A distribution function, implying an equal distribution of goads and resources by means of subsidy, taxes, and allowance.

Local government in the Netherlands used to operate rather autonomously from the central government. Central government has, however, centralised the responsibility for distribution and stabilization policy, resulting in more 'co-government' tasks for the local government. Local government was given an increased responsibility for tasks related with the community welfare affairs. Local government has no own policy with regard to the 
stabilization function. Also for the distribution function central government has the prime responsibility and local government has a co-government task. Most municipal tasks relate to the allocation function and partly to distribution.

\subsection{Finances}

The finanices of the local government come for the largest part through the central government by means of:

- general allowances. A yearly budget based on specific standards.

- specific allowances. The amount of money and the spending policy are defined by central government.

Additionally, local government has their own income, less than $15 \%$ of the total municipal budget, through local taxes and income from property and business (see also Verkuisen \& Vis, $1995 \mathrm{p} .278$ ). In $198770 \%$ of the municipal budget consisted of specific allowances. The finances for public health are within the municipal fund as general allowances and specific allowances for specific tasks. Before the Act on Collective Prevention came into existence (1989), local government received a specific allowance to finance a municipal public health service.

\subsection{Administrative structure and political structure}

Traditionally the municipal secretariat and the municipal secretary are responsible for policy and advice to the city council and for the organization of the municipal administration. The municipal secretary functions as a 'chief-executive' for the services and departments and is the linking-pin between the political and the administrative side of the municipal organization. During the years several other organizational structures were developed due to changes in the environment of the municipal organization and the main believes of 'what good government constitutes'. Furthermore the size and problems of the municipality are also decisive in selecting a particular model for the municipal adninistrative organization. Examples of organizational models are a sector model, functional model, staff model, and a concern model (see also Derksen \& Korsten, 1989). The role of the municipal secretariat is in these models less prominent as in the traditional model. Services or departments receive delegated responsibilities for policy development and budget maintenance. In a concern model services even operate as if they are separate organizations. such as is the case, for example, in Tilburg.

Coordination and adjustment between services or departments takes place either through the municipal secretariat and/or through management team meetings between heads of departments and directors of serwices.

The city council is chaired by the Mayor. The Mayor is appointed at recommendation by the central government. Local elections take place every four years in March. City councillors represent local and national political parties. Councillors are elected according to the rules of equal representation [evenredige vertegenwoordiging, MG]. Council business is delegated to (sub-) committees and the day-to-day work is delegated to departments.

The city council consists of nine to 45 councillors. So-called 'Aldermen', which are elected from the city council, and the Mayor form the dajly governing body of the municipality. Each Alderman has specific areas under his or her responsibility. The daily governing body governs often by the rules of "collegial government". That means that the whole body is responsible for decisions taken by an individual member.

\subsection{Party politics}

National and local political parties are involved in local government politics. Particularly 
the local parties, as they are attached to one particular municipality, can cause 'unexpected. differences with national politics. On average six political parties are involved in local elections. In municipalities over 100.000 inhabitants the amount of political parties is more likely to be about twelve. Derksen and Korsten (1989) mention that local elections offer a varied programme in parties and candidates with differences between municipalities. It is, therefore, difficult to use local election results as a proxy for national elections. It is even difficult to compare the ellection results between the municipalities.

The major parties in (national) politics in the Netherlands are the Liberal Democrats (VVD), the Christian Democrats (CDA), the Labour Party (PvdA), the Democrats (D'66) and Green Left Party (Groen links).

\subsection{Public health}

With the effectuation of the Municipal Law of 1851 the local gowernment received an explicit task with regard to supervision of public health service. Local government, however, did not take up this task very seriously, mainly due to political disagreement with regard to govermmental tasks in society. This had as a consequence that the hygienic situation caused some epidemics (cholera "typhus, and smallpox).

In 1865 the Law on State Supervision of Public health affairs became effective, but this Act could not impose the local governments to undertake action in this field. Public hygienic efforts were undertaken in the beginning of this century. It was only after 1918 that the local government started in some cities to offer health care from a social perspective. So-called municipal medical services came into existence (for example 1891 in Amsterdam, 1920 in Tilburg; and 1926 in Eindhoven). These services offered primarily sociall medical care and took care of public hygiene. During the years these tasks have changed towards collective preventive activities.

In 1980 a discussion started how to divide the tasks with regard to health care and public health between the three layers of government. According to the Law on Health Care Provision (WVG) the local government was given responsibility for primary health care facilities and planaing of establishment of individual professionals in primary care such as dentists and physicians. Also somcalled collective preventive tasks, such as youth health and prevention of infectious diseases delivered by a mumicipal public health service is part of local government responsibility in public health. The discussion about the implementation of the WVG stimulated the development of Municipal health services (GGD) in the cities that had not yet developed tasks in this field. Consequently it resulted in a duplication of the amount of services in ten years, 30 in the ninety seventies and 63 in the early ninety eighties.

The WVG, however, never came into existence. This created a problem, because herewith the legal basis for the GGDs felt apart. In 1989 the Act on Collective Prevention (WCPV) bridged this gap. Through this law local govermment has to promote continuity and coherence in collective prevention and has to adjust collective preventive activities to curative care activities. Local government has: to collect epidemiological data; to guard the health dimension in decision-making on the living environment; to promote hygiene and psycho hygiene; and, to contribute to prevention programmes, such as health education. The GGD is also responsible for collective preventive measurements with regard to disease prevention and collective prevention of health risks for youngsters. With regard to receiving a place for public health on the agenda, this act states (art. 5 sub 2) that before taking decisions which may have important consequences for collective prevention, the city council, Mayor, and councillors are requested to consult the GGD for advice.

It is local government who has political responsibility for public health, they have to 
balance consequences of decision-making on public health against other consequences. The GGD has a professional responsibility for public health.

Besides having responsibilities for disease prevention according to the WCPV, local govermment also has responsibilities in other fields. Local government has responsibilities with regard to health protection by working on envirommental health, the living environment, garbage collection, clean water and sanitation. Iocal government can work on health promotion through social cultural activities, education, sports, police and behaviour and lifestyles campaigns and activities. Local government's responsibilities with regard to health care are primarily related with the quality assurance, availability and distribution of care facilities.

\subsection{The cities}

Almelo. Almelo is located in the middle-east of the Netherlands. It has a central function in an area named North-Twente. An area were approximately 200.000 people live. The city is an old industrial centre where after world war II several industrial sectors came together. mainly from steel industry, electronic industry, food industry and furniture. The city counts 65291 inhabitants on a square root of 38.76 kilometres(*). It is the 42 largest municipality in the Netherlands.

The city council has 33 seats, which were divided in 1996 between: nine Christian Democrats (CDA), nine Labour (PvdA), four Democrats (D66), four Liberal Democrats (VVD), one Green Left party, and six seats were divided between four other parties.

Eindhoven. Eindhoven is located in the south of the Netherlands. It is an industrial city, with electronic industry as an important element. Eindhoven counts 197353 inhabitants living on a square root of 88,67 kilometres $(*)$. It is the fifth city of the Netherlands.

The city council has 39 seats, which were divided in 1996 between: eight Christian Democrats (CDA), six Democrats (D66), six Labour (PvdA), five Elderly party (AOV), five Liberal Democrats (VVD), 3 Green Left party (Groen Links), and six seats were divided between five other parties.

Groningen. Groningen is located in the north-east of the Netherlands. It counts 169661 inhabitants on a square root of 79.8 kilometres(*). It is the sixth largest city in the Netherlands.

The city council has 39 seats, which are divided in 1996 between: 10 Labour (PvdA), seven Democrats (D66), six Green Left party (Groen Links), six Liberal Democrats (VVD), four Christian Democrats (CDA), three Socialist Party (SP), and three seats divided between two parties.

Rotterdam. Rotterdam is located in the south-west of the Netherlands. Having a large sea-harbour has had a major impact on the city. Rotterdam counts 592080 inhabitants, living on a square root of 99.9 kilometres $(*)$. It is the second largest city in the Netherlands.

The city council has 45 seats, which are divided in 1996 between: 12 Labour (PvdA), seven Democrats (D66), six Christian Democrats (CDA), six Liberal Democrats (VVD), five Centrum Democrats (CD), three Green Left party (Groen Links), and six seats divided between five parties.

Tilburg. Tilburg is located in the south of the Netherlands. Since the 17 th century the city has been very famous because of its wool industry. Nowadays modern industry has taken over and changes in the city and city infrastructure were made to change from a wool industry city to a compact modern industry city. Tilburg counts 164280 inhabitants living on a square root of 79.3 kilometres(*) and is the seventh largest city in the Netherlands. 
The city council has 39 seats, which are divided in 1996 between: 10 Christian Democrats (CDA), six Labour (PvidA), five Democrats (D66), four Liberal Democrats (VVD), four Green Left party (Groen links), and ten divided between other parties.

(* = Staatsalmanak (1996i))

\subsection{Statistical information}

This section contains some statistical information on social-economical indicators and health indicators in the two countries under study.

Table 1.5: A comparison of health indicators between the United Kingdom and the Netherlands.

\begin{tabular}{lll} 
& United Kingdam & The Netherlands \\
Population & 57 million & 15.1 million \\
Gross Domestic Product (GDP) & 814 bilion ECUs & 232 billion ECUs \\
Health expenditure & $6.6 \%$ of GDP & $8.3 \%$ of GDP \\
Birth rote & 13.8 per thousand & 13.2 per thousand \\
Death rate & 11.2 per thousand & 8.6 per thousand \\
Leciding causes of death: & & \\
Cardio Vascular diseases & $49 \%$ & $44 \%$ \\
Cancer & $36 \%$ & $41 \%$ \\
Respiratory diseases & $8 \%$ & $5 \%$ \\
Accidents & $4 \%$ & $6 \%$ \\
Diabetes Mellitus & $1 \%$ & $2 \%$ \\
Other & $2 \%$ & $2 \%$ \\
Source: Andersen Consulting and Burson Morsteller (1993). The Future of European Hecith Care. \\
Life expectancy at birth: & & \\
boys & $73.6 \%$ & $74.3 \%$ \\
girls & $79.0 \%$ & $80.3 \%$ \\
\hline
\end{tabular}

Source: Eurostat (1995). Een statistisehe Blik op Europo 1983-1993. Statistisch jaarboek 1995. 
Table 1.6: A comparison of employment rates between the United Kingdom and the Netherlands on socialeconomic indicators.

\begin{tabular}{|c|c|c|}
\hline & United Kingdom & The Netherlonds \\
\hline Area & $244111 \mathrm{~km}^{2}$ & $41028 \mathrm{~km}^{2}$ \\
\hline Density & 237 habitants $/ \mathrm{km}^{2}$ & 298 habitants $/ \mathrm{km}^{2}$ \\
\hline \multicolumn{3}{|c|}{ Male working population } \\
\hline (15.64 years $)$ & $84.2 \%$ & $79.3 \%$ \\
\hline \multicolumn{3}{|c|}{ Female working population } \\
\hline (15.64 years $)$ & $65.9 \%$ & $56.0 \%$ \\
\hline \multicolumn{3}{|l|}{ Employment: } \\
\hline industry & $31.2 \%$ & $25.5 \%$ \\
\hline services & $66.5 \%$ & $70.1 \%$ \\
\hline agriculture & $2.3 \%$ & $4.4 \%$ \\
\hline
\end{tabular}

Source: Eurostat (1994). Regio's. Statistisch Jaarboek 1994.

Table 1.7: A comparison of unemployment rates between the United Kingdom and the Netherlands.

United Kingdom The Netherlands

$\begin{array}{lrl}\text { Unemployment rate: } & & \\ \text { men (all ages) } & 12.5 \% & 5.4 \% \\ \text { men (25-49 years) } & 10.3 \% & 4.4 \% \\ \text { men (50-6.4 years) } & 11.9 \% & 3.8 \% \\ \text { women } & 7.6 \% & 7.7 \% \\ \text { women (25-49 years) } & 6.6 \% & 7.5 \% \\ \text { women (50-64 years) } & 5.4 \% & 5.4 \%\end{array}$

Saurce: Eurostat (1995). Een statistische Blik op Europu 1983-1993. Statistisch jaorbook 1995.

Table 1.8: A comparison of housethold composition between the United Kingdom and the Netherlands.

United Kingdom The Netherlands

Households (\% of total population):

one family household

no children

with children

one parent household

men alane
$70 \%$

$11 \%$

$13.2 \%$

$0.5 \%$

$3.3 \%$
$62 \%$

$9.1 \%$

$13.7 \%$

$0.6 \%$

$1.9 \%$

Source: Eurostat (1995). Een stotistische Btik op Eumopo 7983-1993. Stotistisch jaarboiek 1995. 


\section{Appendix 2: Item List for interviews (english version).}

Local government: polificion + civil serwant

Heolth authority: head of department member of staff involved with health policy dewelopment

Other:" coordinatar + staff of Healthy Cities Project or Health for All initiative

\section{Introduction}

My name is Marleen Goumans and I am working as research associate at the University of Limburg, school of health sciences.

First of all I want to thank you for you kind co-operation within this research. I think that the participation of you city in this research is of great value. And the time you have made available to participate in this interview is highly appreciated.

The purpose of the research is to find out what local health policy means in practice, what factors influence the development of this policy and if/how the participation within HC and/or HFA does make any difference.

Your city has committed itself to the HFA strategy and you are a member of the UKHFAN. I consider this HFA strategy and the HC project as innovative. I am interested to find out what influence these concepts and ideas have on the development of your local health polïcy $(\ldots . . .$.

\section{General information:}

\section{(...)}

\section{Health policy}

1 locall health policy: health promotion, disease protection, disease prevention and sick care? (all)

2 Can you give a definition of health policy? Is health an issue in you local policy? Can you give an illustration? Is it increasing/decreasing? Where does it come from? Is there any relation with papers (f.e. working for patients or the health of the nations) of the national government. Does it have a legislative basis? (dll)

3. What does "policy-freedom" mean to you? How much freedom has a local authority (health authority) regarding the formulation of health policy? (all)

4What is your formal task in the health (policy) field? (all)

5 What are the organisations/actors that are inwolved in implementing health policy in your city? (ask for an organogram of the organization + additional information like finances, year report, other) (all)

6 What is the importance of local data? What do you do with local data? (all)

7 What is your opinion on community participation in health policy development? When should a community participate? (all) 
8 Intersectoral development of policy, is that something worthwhile and achievable? Can you give any examples of this type of policy in your city? When should intersectoral development of policy be executed? Is health an issue in other sectors? (all)

9 In what ways is politics involved in health policy? When is politics involved in health policy? Any relations with policy and/or national laws? (all; HA; loc. gov.)

10 Relation between local authorities and health authorities with regard to health related matters? (HA; loc. gow.)

11 What are the information channels you use when you have to develop and/or judge a certain policy initiative? (all)

12 What are the factors that influence your decision when you have to develop and/or judge a certain policy initiative?

(show picture). What factors influence policy development? (see picture) (all)

13 How are local services financed? Where does the money come from? How is the money distributed within the organization? How are the local services judged for their activities? (loc. gow.)

1. What do you consider as your tasks in the health field? Is health an issue in other sectors? If so, can you give an illustration? (all)

15 Can you give a top five of the major health (related) problems in your city? (all)

16 In what amount do you consider a city health plan to be a useful tool? Do you have such a plan? If yes, what happened since the plan has been written and/or the city council approved the plan? if no, are you planning to develop such a plan? (oll)

17 What is the extend to which projects influence policy decision making that has an impact on health? (??)

Has the HCP contributed to the development of a real HPP? If yes, please give an explanation and examples. If not, why not? (all)

How much would have happened anyway and to what extent has HCP become an enabling factor? (all)

18 What are the ruling parties in your city government? (loc. gow.)

What is the government style?

How can local authorities co-ordinate activities of its own departments and outside organisations and initiatives? Are you familiar with inter-corporate policy planning?

19 Is the status of the local authorities influenced by the structure of the regions? (loc. gov.)

20 What is the income of local government? Where does it come from? (loc. gov.)

What is the income of health authorities? Where does it come from? (HA)

Does financial dependence lead automatically to a demonstrable effect on policy choice? 
21 Local authorities have no legal tasks regarding health care, but what about public health and/or health promotion? (loc gow.)

What is the role of council members and civil servants regarding health policy development and health (related) issues? (loc. gov.)

What are the formal responsibilities of the health committee? (loc. gow.)

What are the responsibilities of the health committee regarding health related matters and development of health policy? (loc. gow.)

In how many (local) authorities are you participating? (loc. gov.)

22 What is the influence of party politics on (health) policy? (loc. gow.)

Is party politics based on pas success or future considerations? (loc. gov.)

What is the influence of CTT (Compulsory Competitive Tendering) on the development of health policy? (loc. gow." HA)

23 What is the legal task of the health authority with regarding public health and/or health promotion? (HA)

What alliances were established between the HA and local government and other organizations in the city with regard to this task? (HA; loc. gov)

Has your local health authority central policy units? (HA)

\section{Healthy Cities and HFA}

1 Who takes (is) formall responsible for health policy and who for HC?

2 What is the influence of HFA in the UK health system (national and local)? How, can you give examples?

3 What has been the motivation/reason for your city to participate within the UKHFAN and/or the WHO/HCP?

4 Which people and organizations are important in this city concerning HC projects? And concerning Health policy? Can you list five leaders (individuals/organizations)?

5 What sectors are involved in HFA/HC initiatives? Who is supportive to HFA/HC? How do they make that visible? How do you finance $\mathrm{HC}$ ?

6 What is the organizational structure of $\mathrm{HC}$ in your city? How is HC linked with existing organizations/services and initiatives in the city?

7 What is the strategy you use to implement HC? Are politicians involved? If yes, how? If no, why not? Does HC have a formal basis? How is it financed? What is the budget? What are the main activities?

8 What contributions does your organization (health authority, local authority, other) make to HC?

9 Can you give me an example of what you consider to be typically "HC-like"?

10 Do you have projects that are related to $\mathrm{HC} / \mathrm{HFA}$ ? What is the influence of these projects on the overall city health policy? 
11 Are there any evident changes in the (local) health sector and/or health policy since you are involved in UKHFAN and/or WHO/HCP?

12 What is the long term perspective on local health policy with regard to HC/HFA?

13 What is the importance for the development of local health policy to be part of UKHFAN?

\section{Priority-setting:}

1 Expected effects

2 Media (local)

3 Media (national)

4 Issue

5 Setting

6 Political costs/benefits

Financial costs/benefits

Governmental costs/benefits

7 Content

8 Political pressure

9 Municipal workplan

10 National developments

11 Existing policy

12. Law and Acts

13 Community

14 Pressure groups

15 Other 


\section{Appendix 3: Healthy City domain composition based on activities, structures, and actors, case study and country specific.}

\section{Healthy City domains: country specific and case study specific}

Figures $5.2 \mathrm{a}, 5.2 \mathrm{~b}, 5.4 \mathrm{a}, 5.4 \mathrm{~b}, 5.6 \mathrm{a}, 5.6 \mathrm{~b}, 5.6 \mathrm{~b}, 5.7 \mathrm{a}$, and $5.7 \mathrm{~b}$ are case study specific domains based on activities and actors. Figures $5.2 \mathrm{c}, 5.4 \mathrm{c}$, and $5.6 \mathrm{c}$ are country specific domains. They are constructed based on the case study specific domains. Figures 5.2 show domain composition by activities. Figures 5.4 show domain composition by actors divided in public policy sectors. Figures 5.6 show domain composition by actors divided in organizationall types.

Figure 5.2a: Healthy City domain based on activities (the Netherlands case studies).

Major issues Almelo

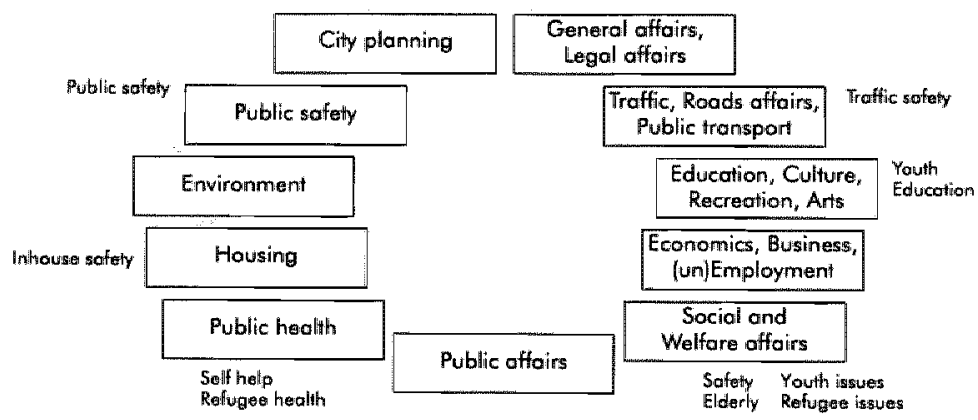

Major issues Einclhoven

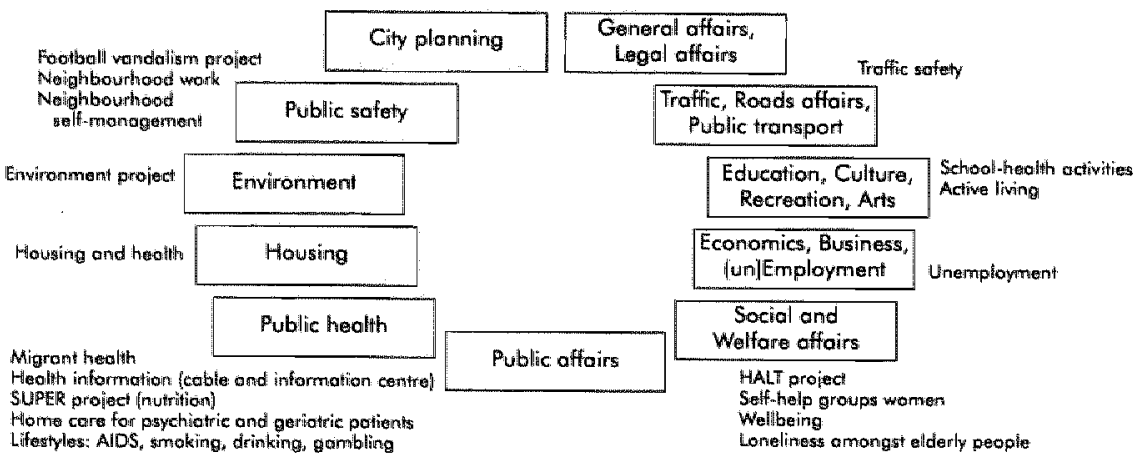


Figure 5.2a: Continued.

\section{Major issues Groningen}

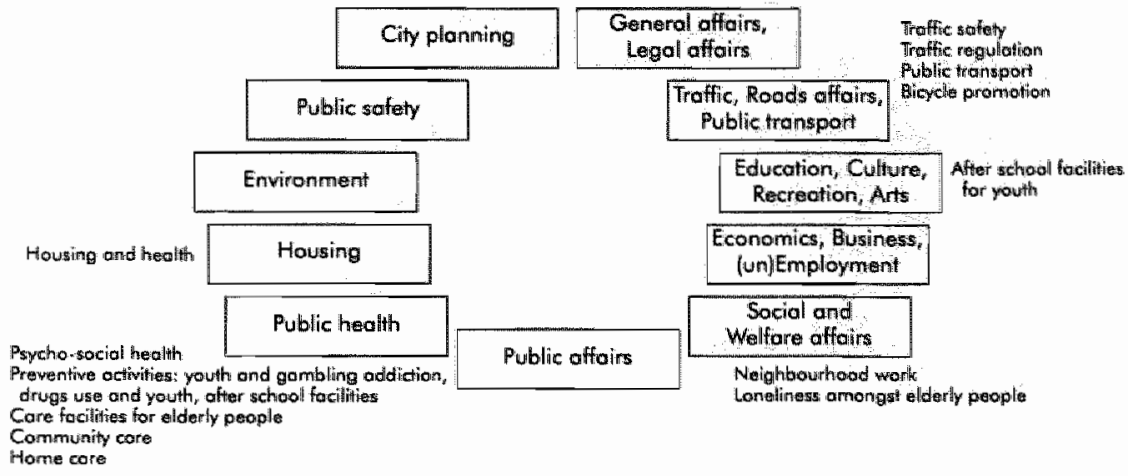

\section{Majar issues Rotterdam}

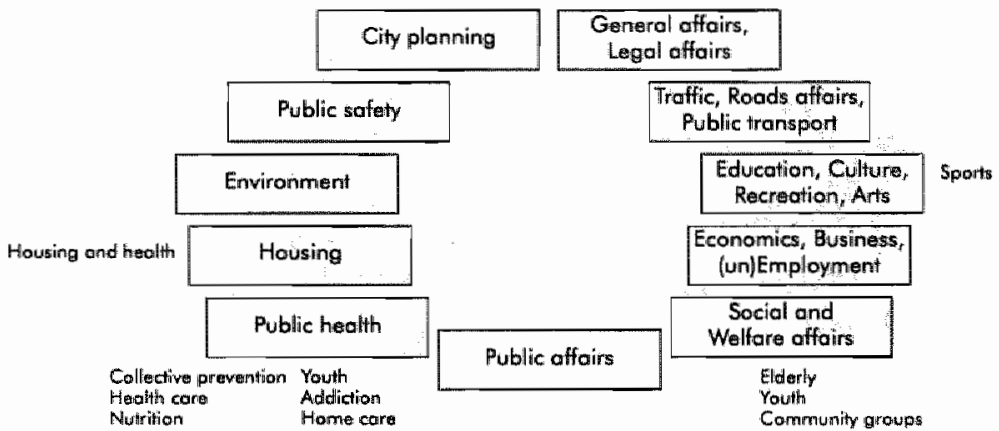

Major issues Tilburg

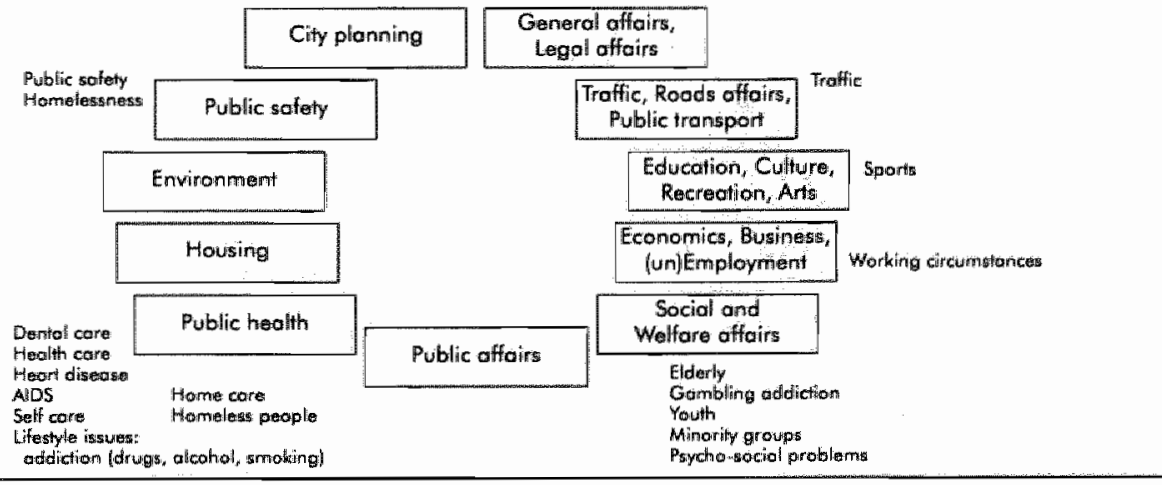


Major isisues Glasgow

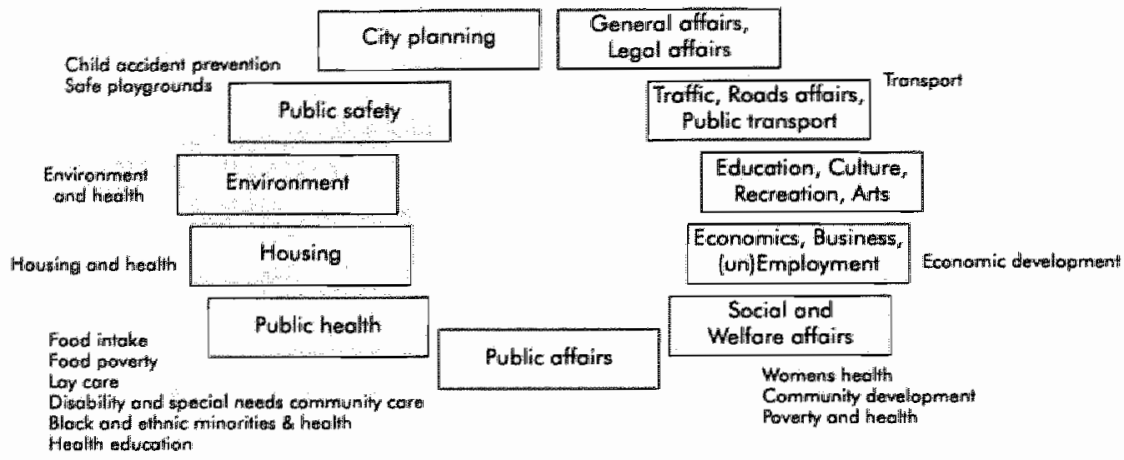

Majar issues Liverpool

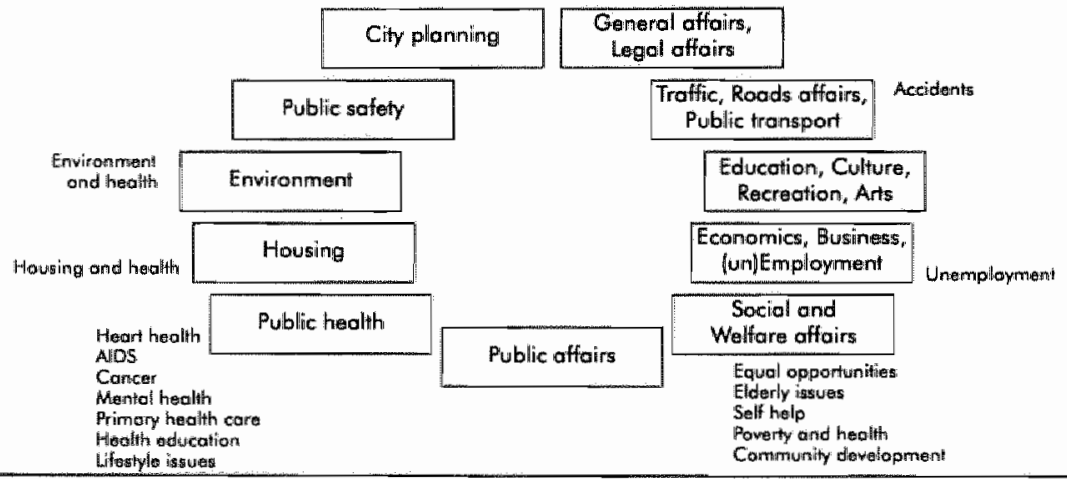

Major íssues Newcastle

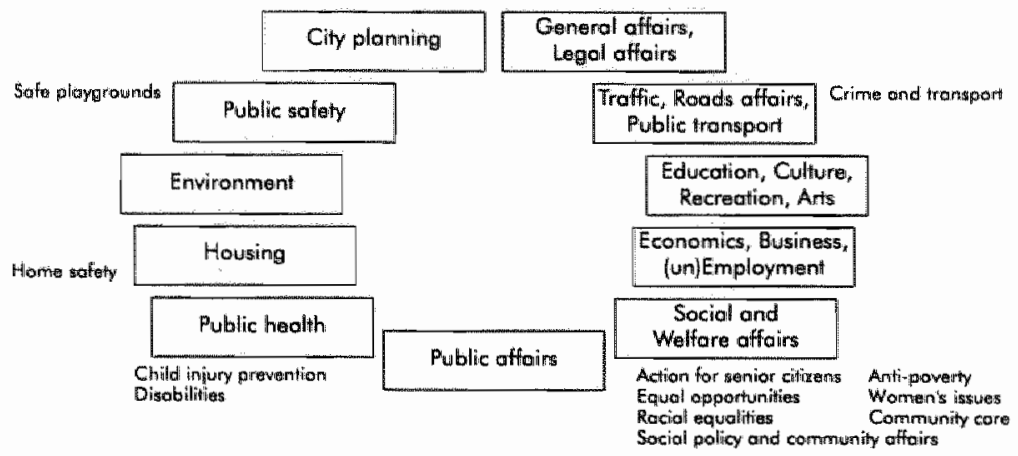


Figure 5.2b: Continued.

\section{Major issues Sheffield}

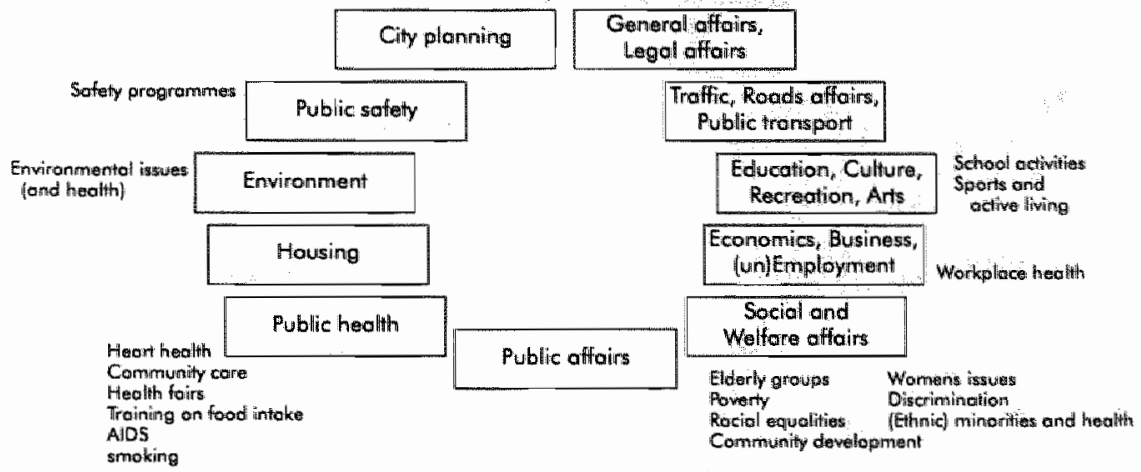

Major issues Winchester

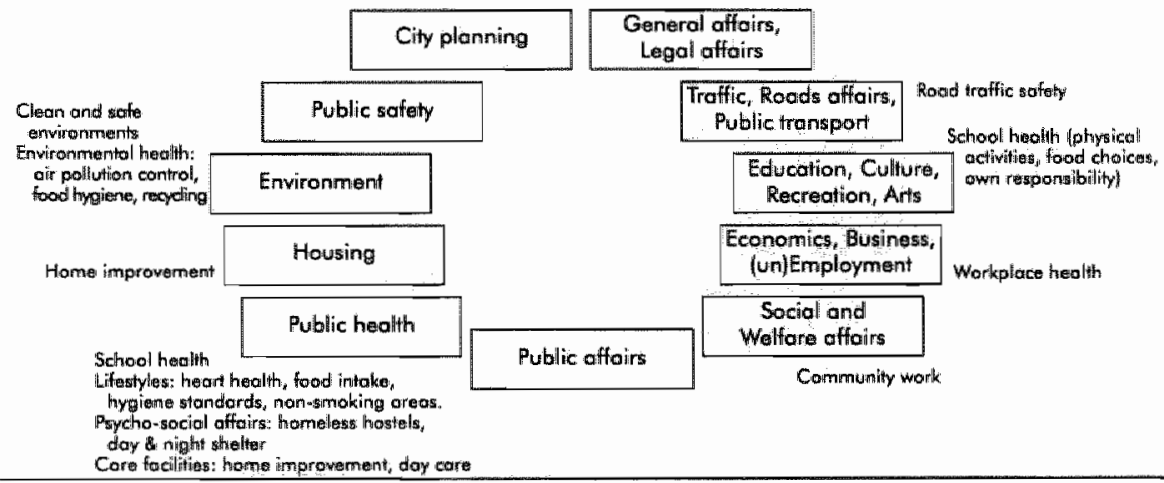


Figure: $5.2 \mathrm{c}$. Healthy City domain based on activities (the Netherlands and the United Kingdom).

Heolthy City activities (the Netherlands)

City plemning

General affairs,

Legal affoirs

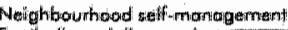

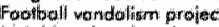

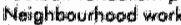

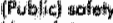

Public sollety

Hormelassiness: Traffic, Roods affairs
Public transpont

Troffic \{regulation, Eofezy)

Thas transpon

Bicycle promotian

Envirormmerr! propect Environment

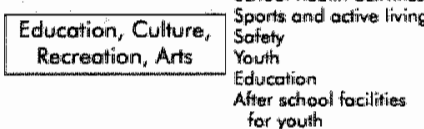

Hais ive and heoflis

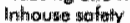

Economics, Business

fun Employment Unemployment

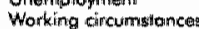

Siglf corto

Sinfth tivip

Deatall core

Drental core

itoert ditweos Homeles p-ople

Refugerealith SUPER proinect (nutrition)

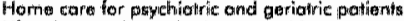

Lif mathyles: smoking, drinking, gambling

Hoalth information (cable ond intormation centrot

Public affoirs
Soriall and Welfore offoirs

HALT project Relwgee issues

Whalbeing Sociol prevemtion

Psychlo-isociel problems Youth

Minority groups Solety

Community growps Neighbourhood work

Seif help groups wornen

Corm focilities for elderly people

(Lonalin amongwi) elderly people

Healthy Clity activities (United Kingdom)

\section{City planning}

Chilld accelldent provention Solet playground

Publitic soffety

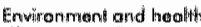

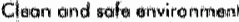

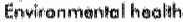

ealer polliwion comtrol

food thyolitin,

Environment

reegritivi

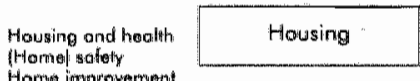

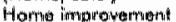

\begin{tabular}{|c|c|}
\hline 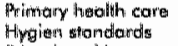 & Public heolth \\
\hline 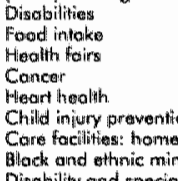 & $\begin{array}{l}\text { Loy carle } \\
\text { food poverty } \\
\text { Heolth educotion } \\
\text { AlDS }\end{array}$ \\
\hline
\end{tabular}

Public affoirs
Transpedre terime: Traffic, Roods affairs, Aood tratife sotety Public transpart

\section{eneral offairs,}

Legal affoirs

Disubjility and tpeciol needs comsmumity core

\begin{tabular}{|c|c|}
\hline & Sethool \\
\hline $\begin{array}{c}\text { Education, Cuthure, } \\
\text { Recreation, Ants }\end{array}$ & octivities, foud chesticos, \\
\hline
\end{tabular}

\begin{tabular}{|c|c|}
\hline $\begin{array}{c}\text { Ecchomics; Business, } \\
\text { (unjijEmploymernt }\end{array}$ & 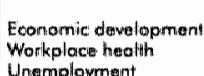 \\
\hline
\end{tabular}

Social and

Weltore affoirs

Solt helo

Action for stenior citizens Equell oppontumillies

Racioll enualities Women's hed lith

Community care: Powerty and healsh

(ethric) minotities and healtin

Sacioll policy and community affairs

Community development work 
Figure 5.4a: Healthy City domain based on actors (1) (the Netherlands case studies).

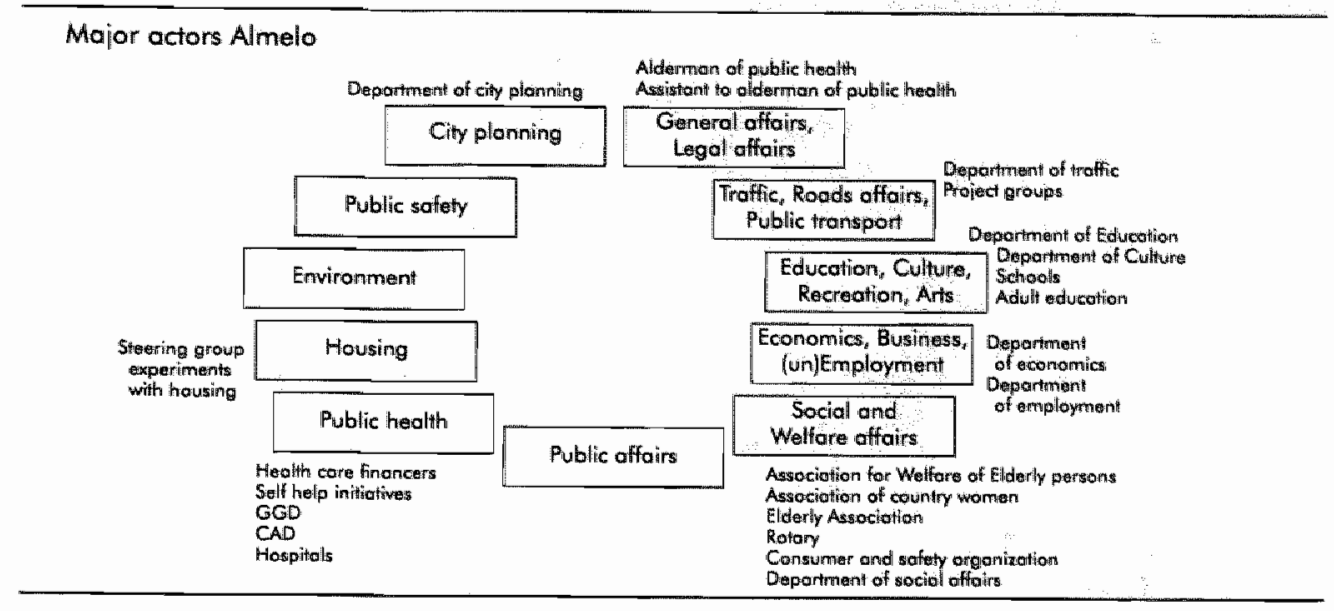

\section{Major actors Eindhoven}

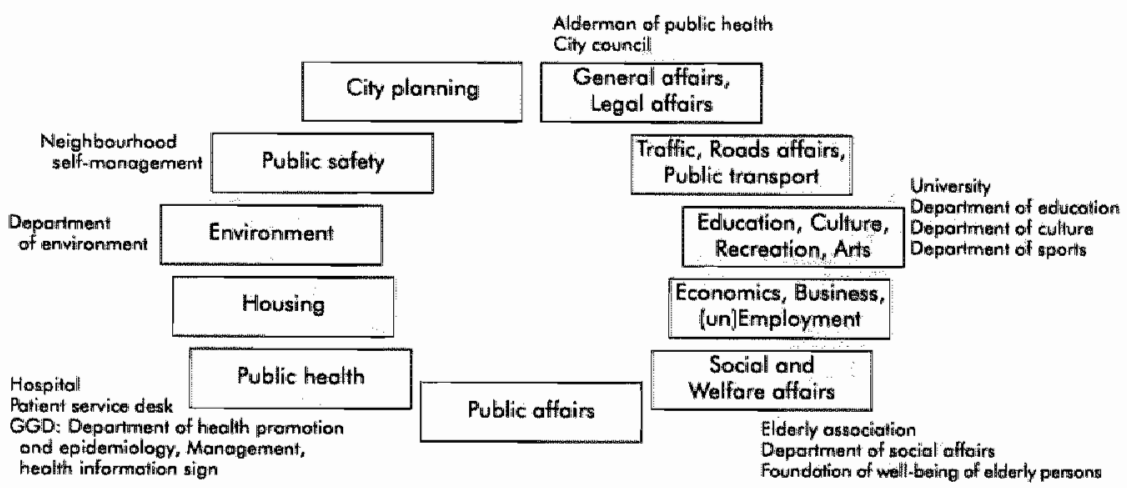

\section{Major actors Gromingen}

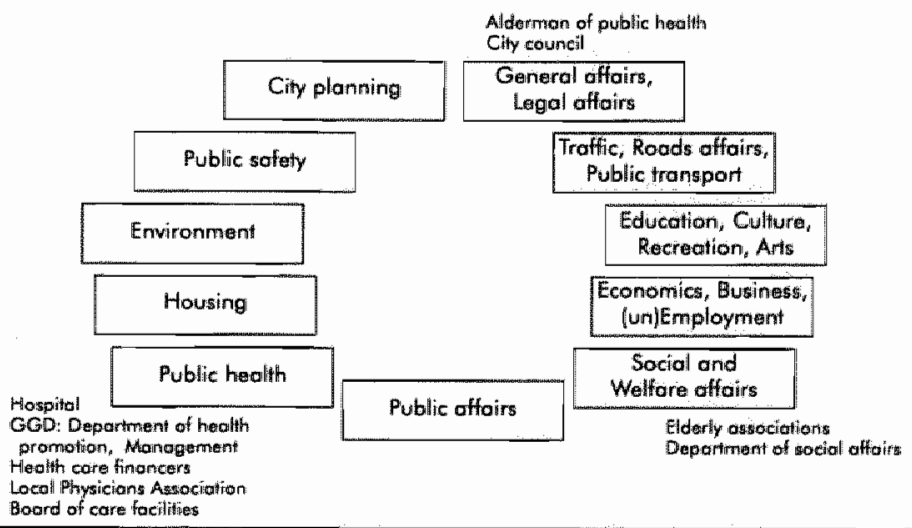


Figure 5.4a: Continued.

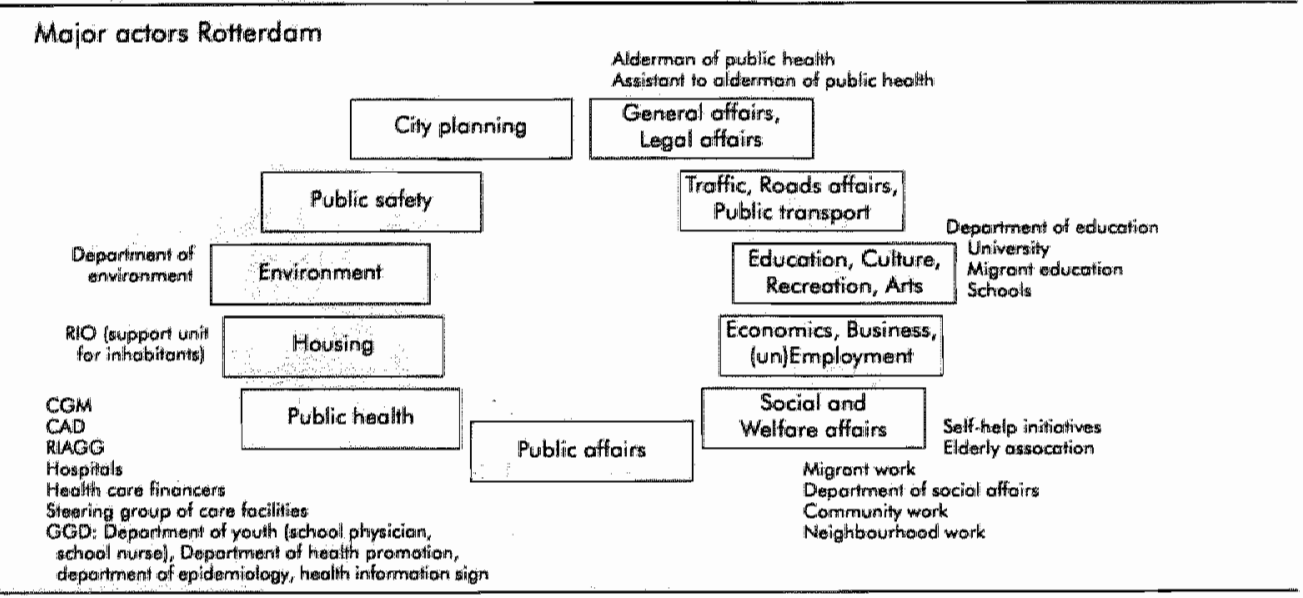

\section{Major actors Tilburg}

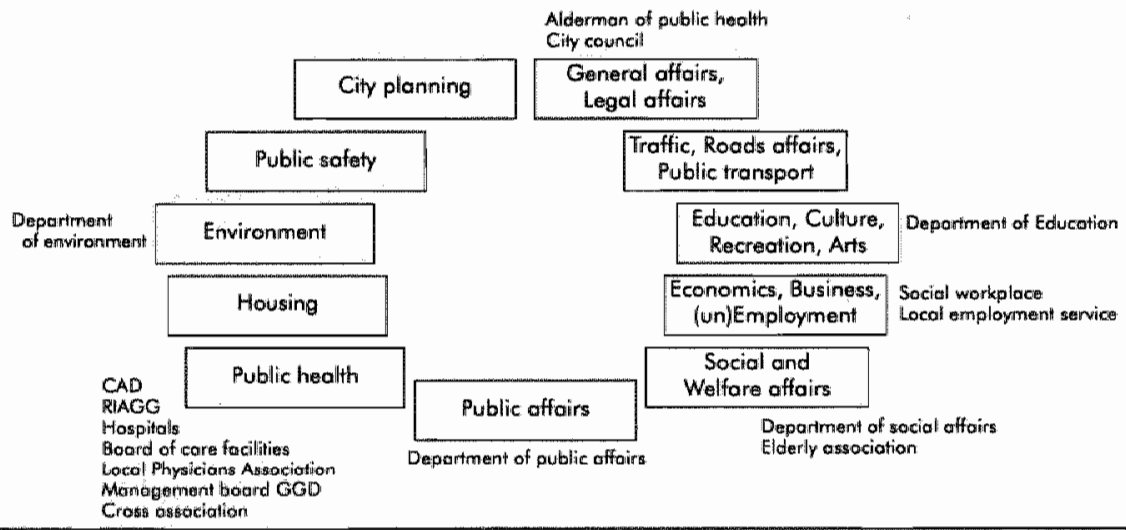


Figure 5.4b: Healthy City domain based on actors (1)(the United Kingdom case studies).

\section{Major actors Glosgow}

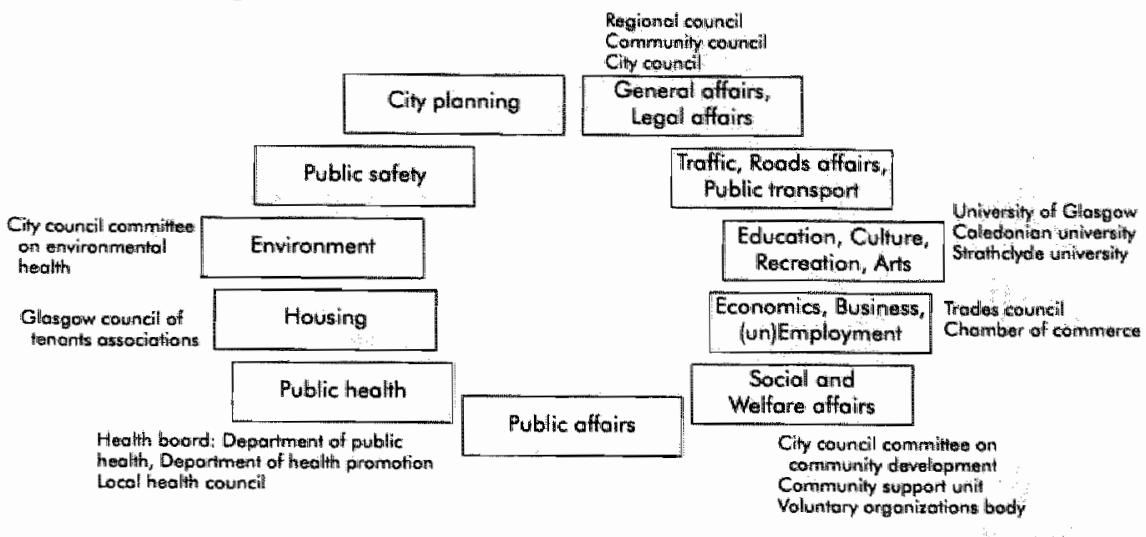

\section{Major octors Liverpool}

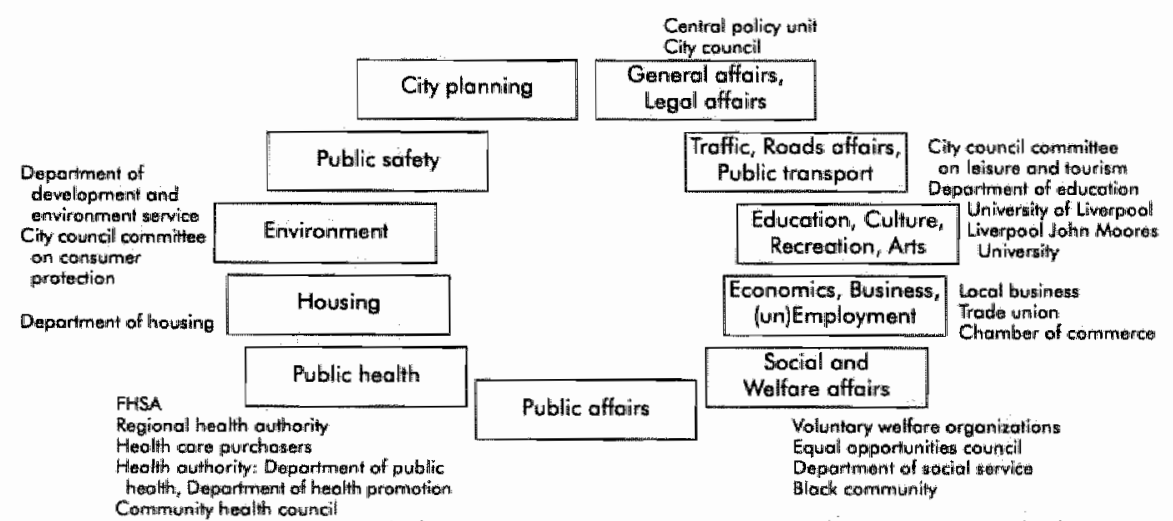

Major actors Newcastle

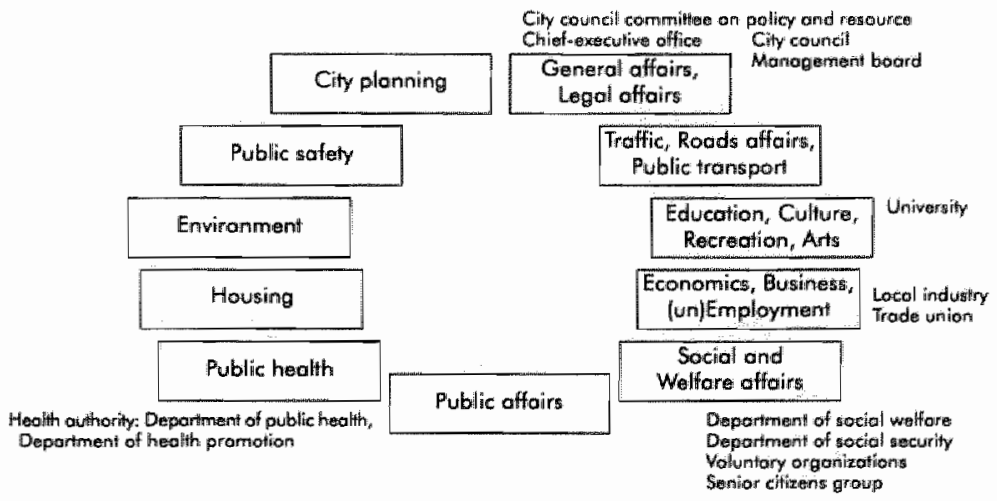


Figure 5.4b: Continued.

Major actors Sheffield

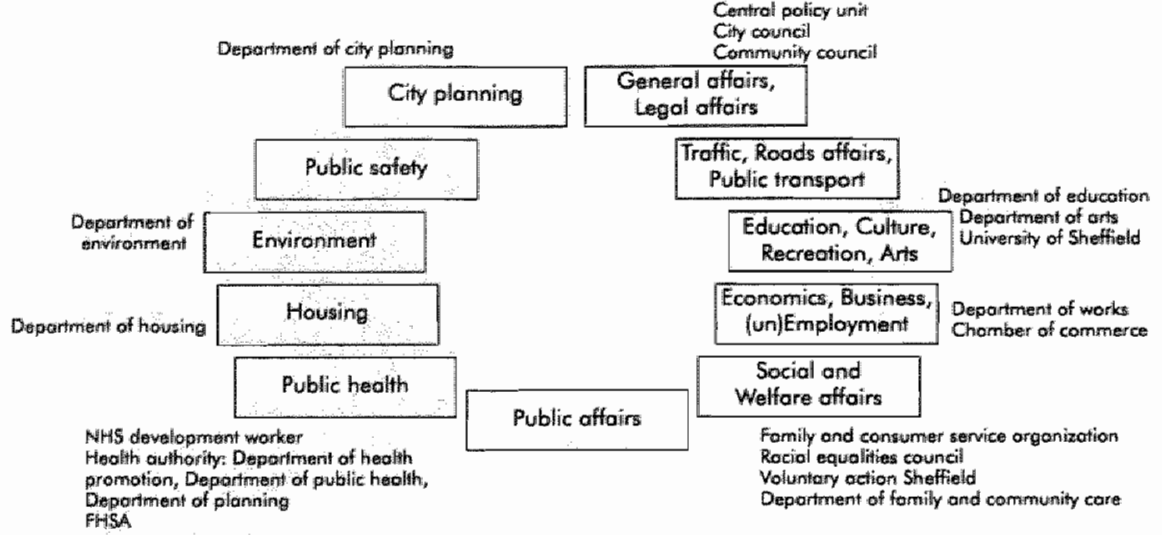

\section{Major actors Winchester}

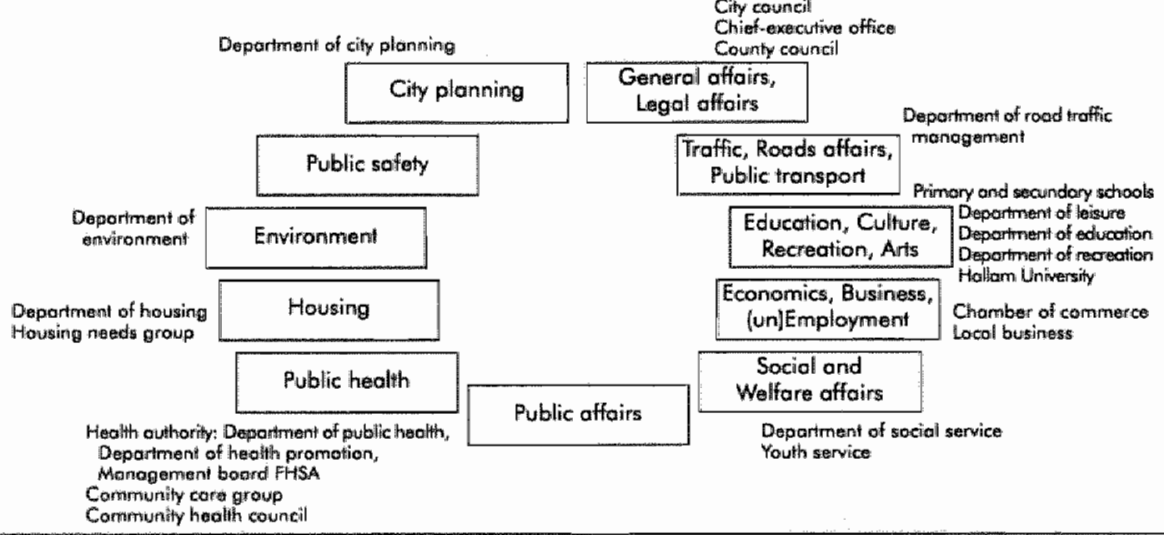


Figure 5.4c: Healthy City domain based on actors (I)(the Netherlands and the United Kingdom).

Healthy City Actors (the Netherlands)

Deporitment of eity ploniring

City planning
Aldiermiton of poiblete the the

\begin{tabular}{|c|c|}
\hline $\begin{array}{l}\text { Genverol affairs, } \\
\text { Legol effairs }\end{array}$ & $\begin{array}{l}\text { Assistonyt to aldermon of public frealth } \\
\text { City council }\end{array}$ \\
\hline
\end{tabular}

Nieighthourhood: solf-morragiement

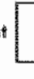

Public safety

Depointment of enviromment

\section{Environment}

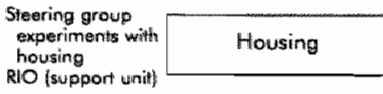

$\left.\begin{array}{c}\text { Traffic, Raods affairs, } \\ \text { Public transport }\end{array}\right] \begin{gathered}\text { Deportment of traffic } \\ \text { propoct groups }\end{gathered}$

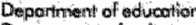

Education Culture Department of culture

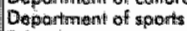

Sechools

Untistair thity

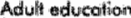

Mignent ediucation

Eicanamics, Bussinessiy

(un) Employment Soxid

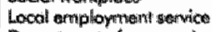

Deptartiruery of eccomomics

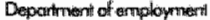

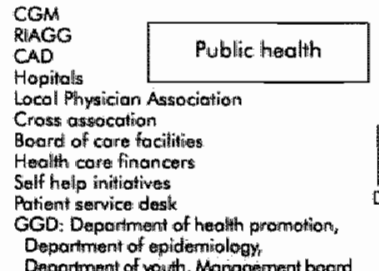

Public offoirs

Sociol and

Welfare affairs

Associalian for wollare for eleforly personi

Association of cowrity women

Elderly asisociuthon

Motary

Consurver and safebry argantzotion

Deportment of social alfoirs

Sell help onnitiotitues

Comminily work

Naightbourhioad wark
Healthy City Actors (United Kingdom)

Departmenis of city planming

City plonning

Public safely

Cilly council commithe on consumer protectham

Deppartment of dewelopment and environnent service

Cily councl commintere

on enwireinmenta!

healith

Depoment of envitron ment

City courncil commitie on environment and houlth

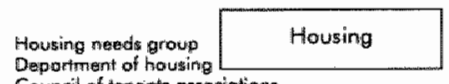

Council of temonts cossiociations

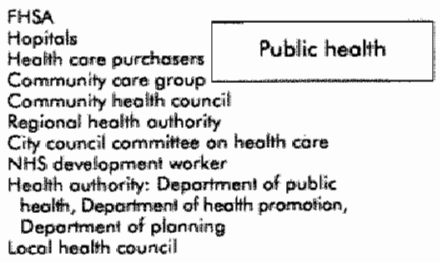

Chiet-executive office Regional coune

\begin{tabular}{|c|c|}
\hline $\begin{array}{l}\text { Gemeral affoirs, } \\
\text { Lagal affairs }\end{array}$ & $\begin{array}{l}\text { Community coutincil } \\
\text { Montagement board } \\
\text { City council }\end{array}$ \\
\hline
\end{tabular}

Traffic, Rouds offoirs,
Pulbluc transport
Pulblice tramsport

\begin{tabular}{|c|c|}
\hline & \multirow{3}{*}{ 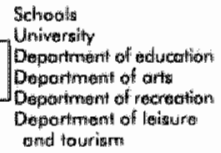 } \\
\hline $\begin{array}{l}\text { Education, Culture, } \\
\text { Recreation, Arts }\end{array}$ & \\
\hline & \\
\hline $\begin{array}{l}\text { Economics, Business, } \\
\text { (uni) Employment }\end{array}$ & \multirow{2}{*}{ 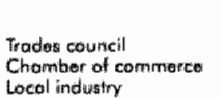 } \\
\hline & \\
\hline
\end{tabular}

Public affoirs
Sociol and

Weltare offoirs

Wellitore organizations Community supporl wint

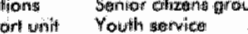

Equal opportunitities cound black comminity

Dieporimazit of socital wertore

Digpariment af sociol securitity

Drepartmamt of flamily and community conto

Cionsumer semviec organizetion

Voluntary angarizations body

Voluntor we lfore arganizetion:s

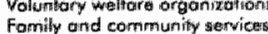

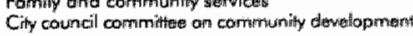


Figure 5,6i: Healthy City domoin based an actors (II)(The Netherlands case studies).

\section{Major octors Almelo}

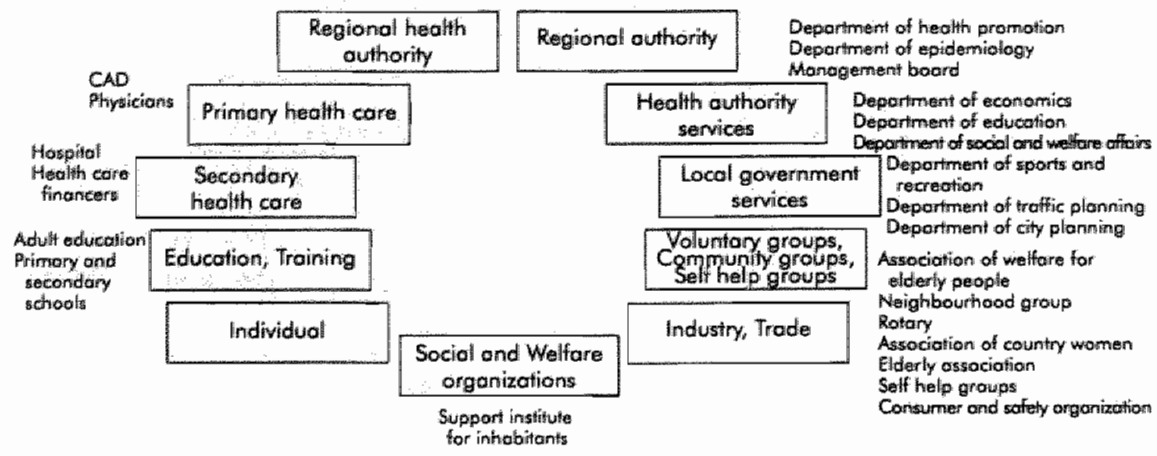

Majar actors Eindhowen

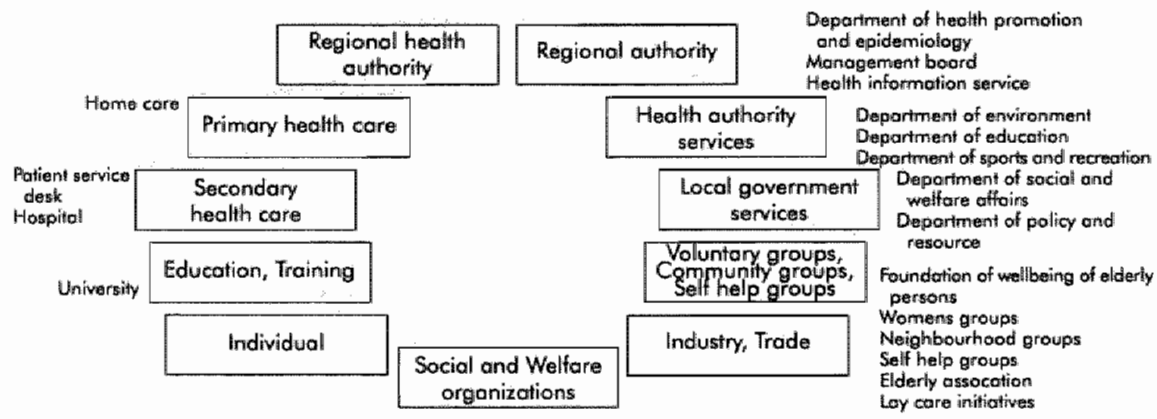

Majalr actolrs Groningen

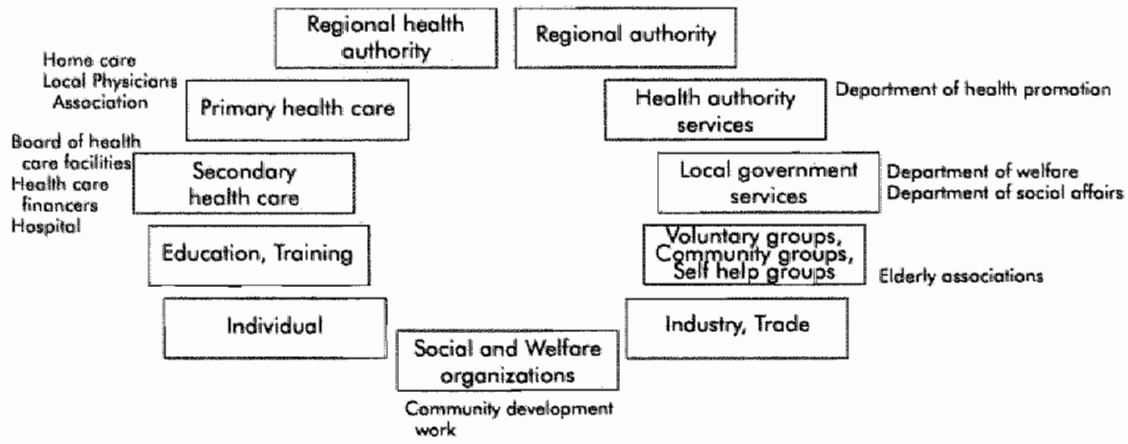


Figure 5.6a: Continued.

\section{Major actors Rotferdam}

Home care

CGM thealth care and

cornmtunity gervicel

श日, $G G$ CAD

tocel Physicians Assuciation

Volutitary home corre

Childiren consultation desk

Hospitud

Board of core foctitive

Healith care finoncers

\begin{tabular}{|c|}
\hline $\begin{array}{c}\text { Secondan } \\
\text { healiht core }\end{array}$ \\
\hline Education, Tra ining \\
\hline
\end{tabular}

FAO (reduction of

inequoluties)

Uniwersity

Primary ond

secondary schools

Individial

Communuily porticiponts

\section{Regiond hallth} outhority

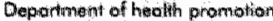

Depardment of exidem alongy

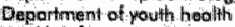

Health informalian stign

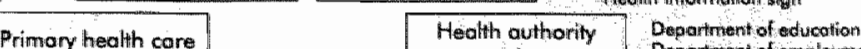

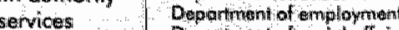

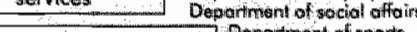

Locil government Depathent cal sports
servicess and rotatidien

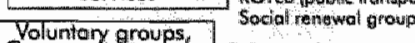

Community groups Sell helo group

Industry, Trade ormenimotion

Neighibawirheod groups

Community support centre

Yolunion centires

NOIO

Self help grougs

Elderly assoogition argamizations

Consumer ond sctioti

ARBO (working eircumsthantes)

Migrient associotions

orgohisiztion

\section{Major actors Tilburg}

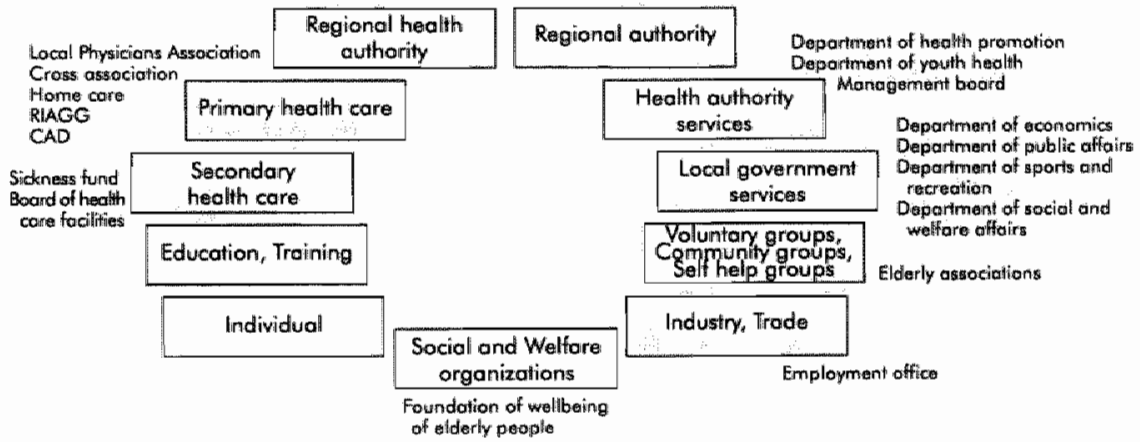


Figure 5.6b: Healthy City damain based on actors (III)(The United Kingdom case studies).

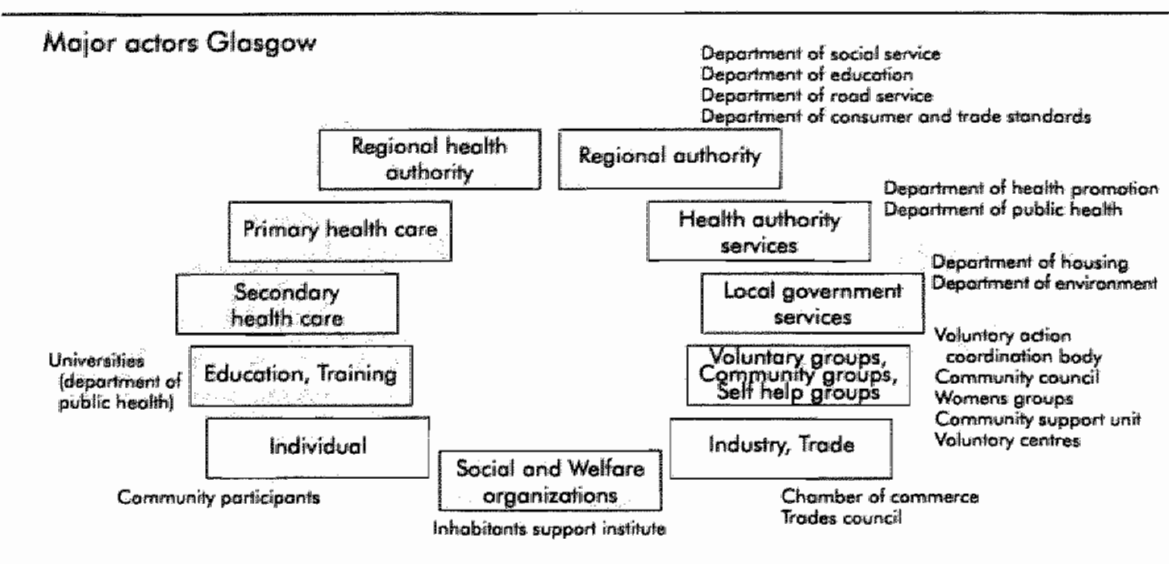

\section{Major actors Liverpool}

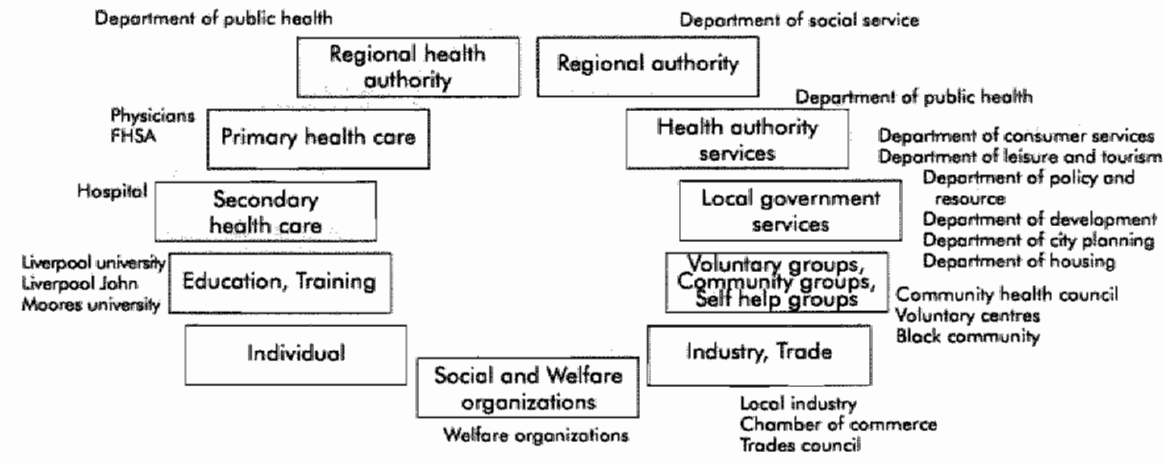

\section{Major actors Newcastle}

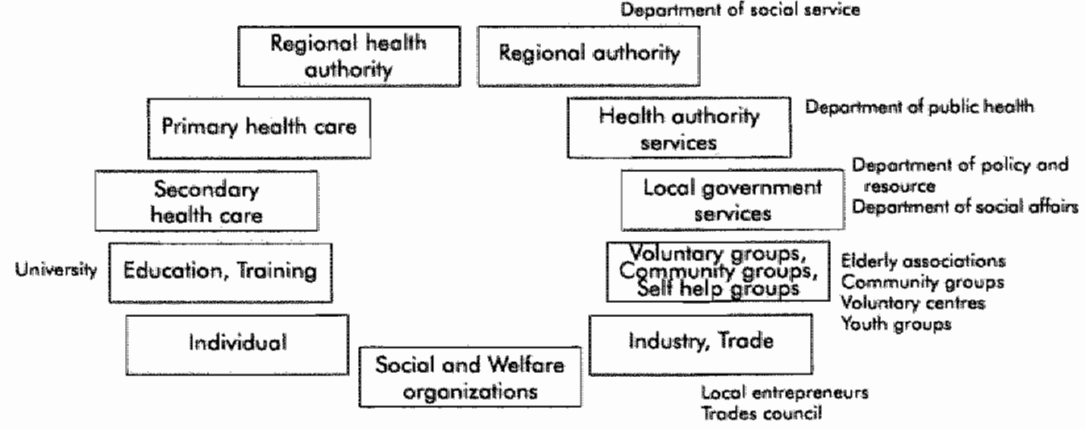


Figure 5.6b: Continued.

\section{Mojor actors Sheffield}

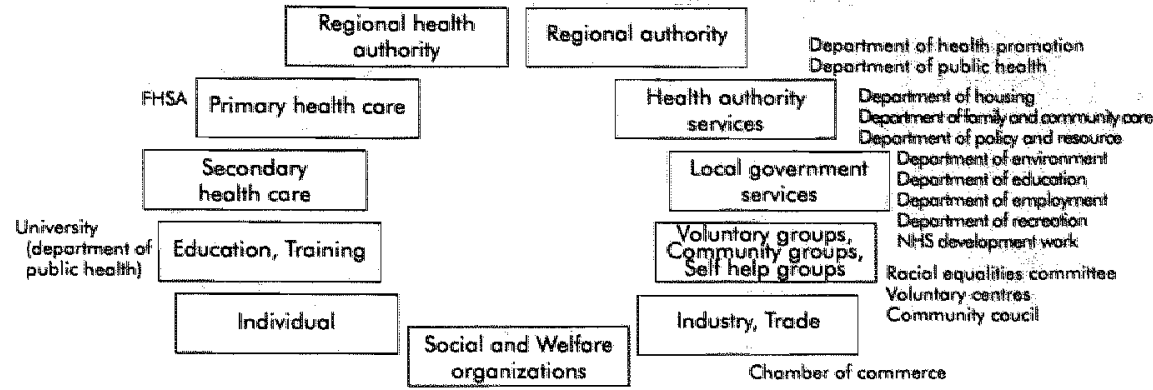

Major actors. Winchester

Department: of social service

County coumcil

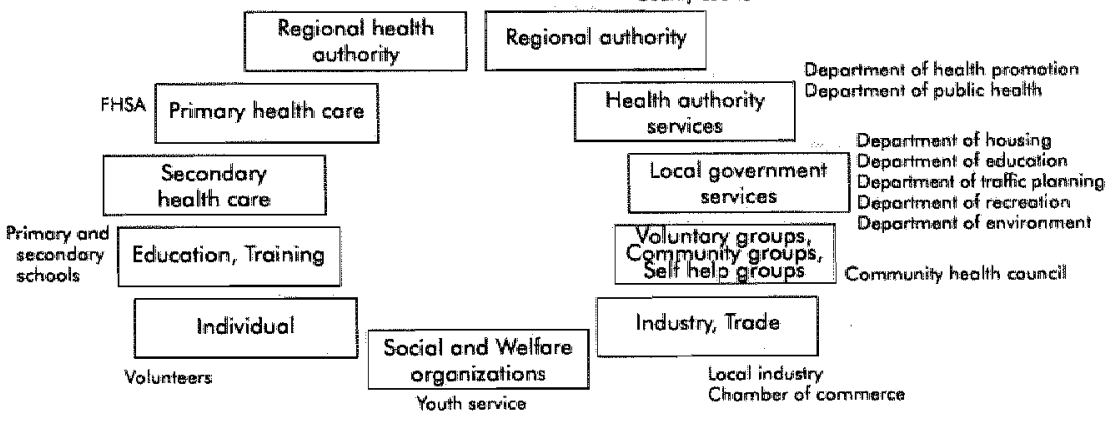


Figure 5.6c: Healthy City domain based on actars (II)(The Neflherlands and the United Kingdom).

Hew ithy City Actors (the Netherlands)

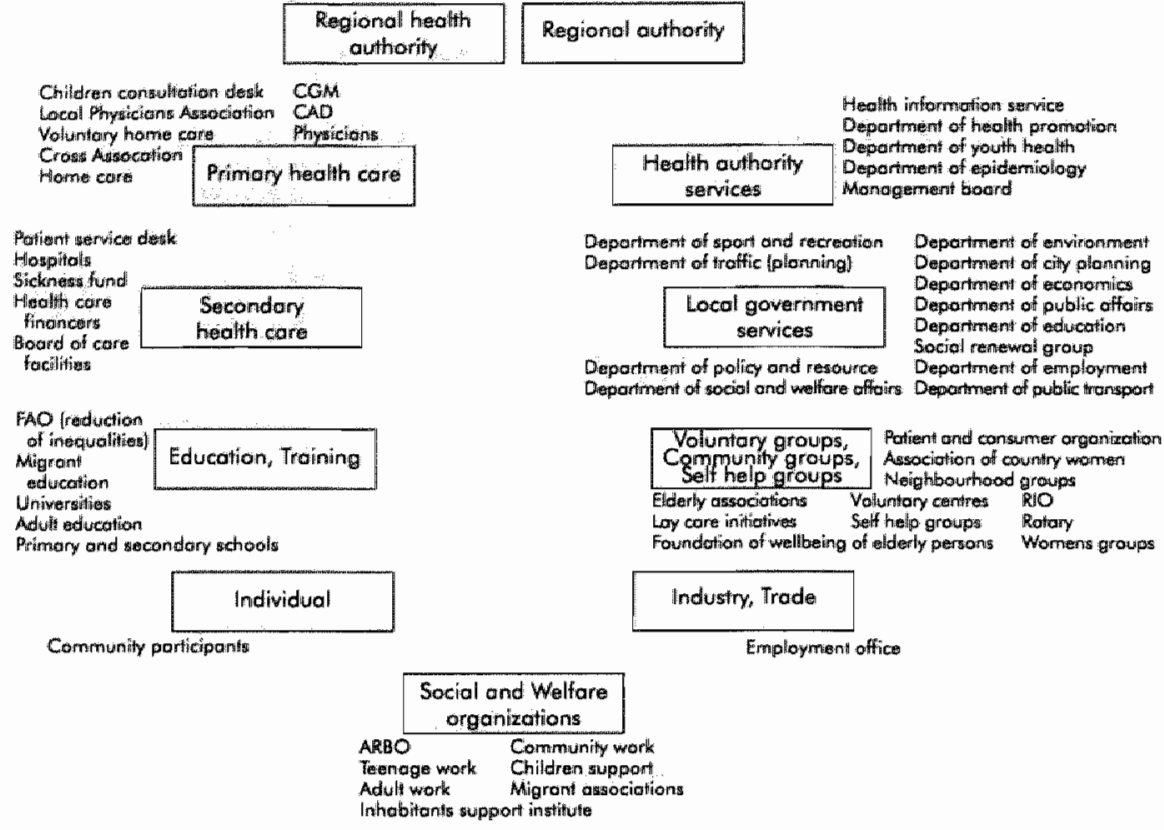

Healthy City Actors (United Kingdom)

Department of public health

Regional heilth authority

Department of sociol senvice:

Regional authority Department of edication

Depautment of consumer ond trode standards Coumty council

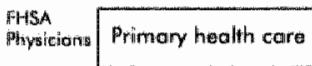

Hospilais Secondary hoolth cere
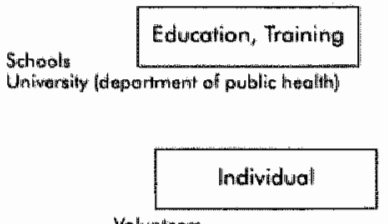

Sociol and Walfare orgonizationsi

Inhabitonis support institute Wellore orgonizations

\begin{tabular}{|c|c|}
\hline $\begin{array}{l}\text { Hedth outhority } \\
\text { services }\end{array}$ & 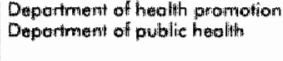 \\
\hline
\end{tabular}

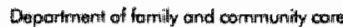

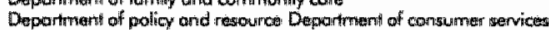

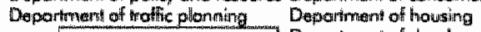

Local government Deporiment of dewelopprnent

ocal government Deppormment of education services Doporment of recrection

Deporment of envitontmant Deportment of employmtarth

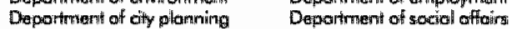

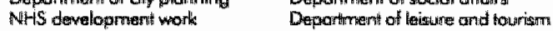

Voluntory giroups,
Commumity groups,
Self helpgroups

Youth grawp: Woliuntion centres Eldarly possuciotions Black comatnunity Wiomens giroups Racial oqualities Comminnity counteils commithe 


\section{About the Author}

Marleen Goumans was born 19 december 1967 in a wery small village named Geysteren. She grew up in this place and after her highschool period at 'Jerusalem' in Venray, she went in 1986 to Maastricht to study Health Sciences. She received her masters degree on Health Policy and Administration in june 1991. The start of her research for her Masters degree in 1990 has been her introduction to Healthy Cities. Since then she has been involved in many ways in the (inter)national Healthy Cities movement. From may 1991 until january 1992 she was employed by the municipal health service of Eindhoven as a project officer for the national network of healthy Cities in the Netherlands. In december 1991 she started her $\mathrm{PhD}$ research at the University of Maastricht, Faculty of Health Sciences, department of health ethics and philosophy. Since april 1997 she is employed by the Association of Dutch Municipalities to advice and assist the national Healthy Cities network cities and to carry out the project "Healthy Public Policy'. 



\title{
Behorende bij het proefschrift
}

\section{Innovations in a Fuzzy Domain}

\author{
Healthy Cities and (Health) Policy Development \\ in the Netherlands and the United Kingdom.
}

Marleen Goumans

Maastricht, 23 januari 1998

1 Health is not a mobilizing concept. (dit proefschrit)

2 Intersectoral collaboration is in Healthy Cities more interpersonal than interorganizational. (dit proefschrift)

3 Een succesvolle actie begint vaak met een onbezonnenheid.

4 Beleidswetenschap en bestuurskunde zïn essentiële bestanddelen van een GVO curriculum. (dit proefschrift)

$5 \mathrm{Om}$ inzicht te krijgen in de verschillende Healthy Cities beleidspraktiiken is een interlakale vergelijking zinvoller dan een internationale vergelijking. (dit proefschrift)

6 Dat het niet gebruikelijk is voor top-instituten om milioenen guldens te betalen voor een tussentijdse transfer van gecontracteerde top-aio's is een pregnant bewijs van het feit dat de commercie in deze tak van sport nog niet heeft toegeslagen.

7 Het vitvoeren van een goed idee is als het opvoeden van een kind. Het moet eerst in beschermde kring worden gekoesterd en gevoed totdat het krachtig genoeg is om de confrontatie aan te gaan met het grote publiek.

8 Evenals zeilers willen beleidsmakers een bepaald doel bereiken. Beleidsmakers kunnen daarbii veel van zeilers leren. De schipper stippelt de koers vit, maar de weersomstandigheden en kwaliteit van de boot bepalen de uiteindelijke route.

9 Het is geen toeval dat in de term decentralisatie de woorden cent en tralie zitten.

10 Voor Schiphol geldt: meer vluchten kan niet meer. 